\title{
The Ontario Anti-Bullying Framework and its potential impact on Indigenous Students in Northern Ontario
}

by

Robyn Alexandria O'Loughlin

A thesis submitted to the Faculty of Graduate and Postdoctoral Affairs in partial fulfillment of the requirements for the degree of

Doctor of Philosophy

in

Legal Studies

Carleton University

Ottawa, Ontario

C 2021, Robyn Alexandria O’Loughlin 


\begin{abstract}
Critical reflection of the term 'bullying' and the behaviours that define the term are rarely criticized in mainstream society. In 2012, the Ontario anti-bullying framework came into effect under the Education Act. The underlying message of the framework is that bullying behaviour is not tolerated, thus the buy-in message for all Ontarians is that all students are protected in school. This is not always the case for Indigenous students. My research and dissertation explore how northern educators understand the Ontario antibullying framework policies and how the framework impacts colonial relationships. The sample in this study consists of 12 educators (10 teachers, 1 vice-principal and 1 principal) working in northern Ontario. Semi-structured interviews were conducted, and data were analyzed through a multi-grounded theoretical approach. The participants shared their personal background, their understanding of Indigenous history and politics, and their understanding of the anti-bullying framework.

Many themes emerged from examination of the data. The theme of minimizing serious behaviour as simply 'bullying' is of particular importance. This study found that the term 'bullying' may be used by teachers or administrators to minimize instances or severity of violence, harassment and racism (against Indigenous and non-Indigenous youth). Furthermore, even though participants appreciated Indigenous history and culture, they did not apply that knowledge in their approach to bullying but instead relied on the mainstream definition of bullying. The cumulative impact suggests a new theoretical insight — reliance on the mainstream discourse of bullying may reproduce settler colonial foundations of the education system.
\end{abstract}




\section{Dedication}

I dedicate my dissertation to my grandparents, Ann and Joseph Stupendick, and Gerard and Mary O'Loughlin. They raised my parents to be empathetic, who raised me to be empathetic. I aim to live in your footsteps and teach Jasper, Aspyn and Raine to also be empathetic. We are all human beings.

\section{Acknowledgements}

It has taken me some time to complete this research for various different reasons, however, throughout it all, my supervisor Dr. Vincent Kazmierski has been extremely supportive and understanding. Not only am I thankful for the endless hours of time that Dr. Kazmierski provided, but I am thankful that he supported and understood my personal circumstances. Dr. Kazmierski truly cares about student learning and success. Thank you for being patient and for challenging my thoughts. It was a pleasure working with you.

To my committee members, Dr. Dale Spencer and Dr. Diana Majury, thank you for providing your thoughts and expert suggestions. I appreciate the time that you have taken to help guide my research. Dr. Spencer, it was also a pleasure working with you at the Journal. Dr. Julie Garlen and Dr. Rosemary Nagy, thank you for providing your thoughtful constructive feedback on this research. You both have pushed my critical thought. Thank you for contributing to my work.

I would also like to thank the two Directors of Education who took a whim and accepted my research proposal based on simple 'cold' e-mailing. If it were not for their critical evaluation of existing laws and policies, I am not sure that this research would have moved forward. Thank you to the Indigenous Education Authority for agreeing to 
also participate in my work. Thank you to the twelve participants for sharing their knowledge and professional experiences. Also, thank you to the Indigenous researcher who I consulted. Collectively, the contributions to my dissertation and the wider scope of this topic are greatly appreciated.

Next, I would like to acknowledge Dr. Melanie Adrian in the Department of Law and Legal Studies at Carleton University. Thank you for hiring me as the English Editorial Assistant for the Canadian Journal of Law and Society/ La Review Canadienne Droit et Société (July 2013 - September 2019). My experiences with the Journal will never be forgotten. Through this position, I met wonderful legal studies scholars who, through discussions, my critical thought has expanded. This opportunity does not come often, and I am very thankful that I had the opportunity to be part of academic publishing during my doctoral studies.

Thank you to various other professors who advocated on my behalf when I encountered difficult times, particularly Prof. Brettel Dawson. I enjoyed working with you over the years.

As I continue moving down the list of people who have impacted my research, next on the list are professors from Lakehead University in Thunder Bay. Dr. Lori Chambers, thank you for continuing to inspire me and challenge my thinking. I am grateful for your continued support, mentorship, and friendship. Dr. Lynn Martin, thank you for recognizing the value in my work. It is through our discussions that a Health Sciences Masters course, Indigenous Youth and Bullying from a Mental Health Perspective, was developed. To my master's students who I have had since the inauguration of the course, your own learning inspired my learning — it is through 
critical reflection and discussion that we understand larger systems at play and their impact on Indigenous people.

Dr. Vicki Kristman, thank you for hiring me as a Research Associate through the EPID@Work (Enhancing the Prevention of Injury and Disability @ Work) Research Institute at Lakehead University. Over the years, I have grown as a researcher and writer because of the experiences I have had with you; grant writing, paper writing, and conducting research on workplace mental health. It is through working on various research projects with you that I was introduced to the wonderful people at Nokiiwin Tribal Council, who have also impacted this research and my analysis. Audrey Gilbeau, Jeff Robert, Conway Lesperance, Tiffany Rogowski, Dr. Brian Dunn, Gwen Andrews and Corey Anderson, specifically, thank you for taking the time to guide and clarify any questions I have had about Indigenous politics. I am so thankful for our working relationship and friendships.

Now I would like to acknowledge all of the people in my family who have been involved in this journey. To my children, Jasper, Aspyn and Raine - you have been patient with me as I worked on this research for many years. At times, the three of you were little supervisors, telling me at your bed time, 'goodnight mommy, go work now' so that I could work in the evenings. As I complete this research during the COVID-19 pandemic, Jasper works alongside me completing her homework, reminding me to focus if she thought I got off-track. To Adam, thank you for supporting this writing journey and for travelling with me during data collection. This road has not been easy, but this chapter in my life is closing. After 13 years of university, I am looking forward to the next chapters in my life. 
To my parents Linda and Jerry O’Loughlin, words cannot express how thankful I am for the endless hours of childcare so I could be alone with my thoughts. Thanks Dad, for travelling with me to complete interviews in isolated locations. Thanks Mom, for listening to drafts of my work. To my grandmother Ann — I miss you dearly and am sad that you are not here to see me complete this project. Your experiences in the Fort William Sanatorium have impacted this project. I know you are proud of me.

To my friends - you know who you all are — it has taken a long time, but I finally made it to completion. You have been there for me during times of stress and times of happiness. Many of you helped me work through my thoughts, provided your suggestions and offered words of encouragement. Specifically, to my friend Sara Maskiewicz, thank you for the endless hours of discussion on Zoom. It is through our very thoughtful and critical discussions that I was able to strengthen my argument around this important and rarely verbalized topic. I am also very grateful for friends who have provided additional support through babysitting and dinners for the kids and I.

Thank you to everyone who has inspired my academic career and offered support. I understand that I am a prime example of a woman who starts their career and does not stop when children are born. I am so grateful for all of the support that I received during my studies and know that I meet the criteria of 'academic motherhood'.

Lastly, my trip to the Canadian Human Rights Museum in Winnipeg, Manitoba in September 2019, brought further inspiration as I worked through this research. The following quotes offered words of wisdom,

"The point is to be a part of something larger than yourself, and wholeheartedly embrace and engage in our incredible world." - Michelle Bachelet, President of Chile 
"Where, after all, do universal human rights begin? In small places, close to home — so close and so small that they cannot be seen on any maps of the world." - Eleanor Roosevelt, First Chairperson of the United Nations Commission on Human Rights

"Like every other human institutional endeavor, justice is an ongoing process. It is never done, never fully achieved. Each decade, each year, each month, indeed each day, brings new challenges.” - Beverley McLachlin, Chief Justice of Canada

I hope this research is impactful for those who read it. Miigwetch! 


\section{Table of Contents}

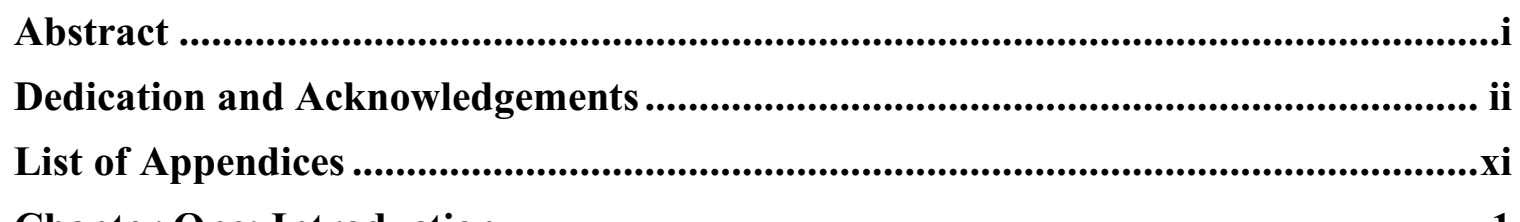

Chapter One: Introduction ..............................................................................1

Contemporary Policy - Truth and Reconciliation Commission Calls to Action ......... 1

The Challenges in Northern Ontario............................................................... 4

Indigenous People in Thunder Bay, Ontario and the Seven Youth Inquest ..............5

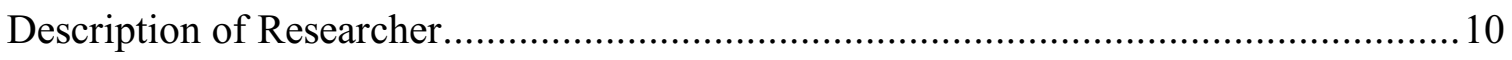

Remaining Chapters of my Dissertation.............................................................. 13

Chapter Two: The Legislative Context for this Study ............................................16

Section I: Indigenous Students and Ontario's Education Act ...................................... 16

Provincial and Federal Jurisdiction ............................................................. 16

Funding Differences Between Provincial and Federal Schools .............................. 17

School Boards - Ontario First Nation, Métis and Inuit Education Policy Framework

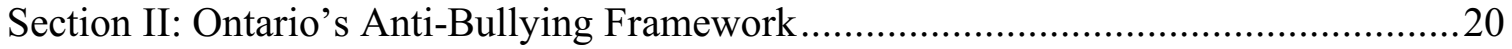

Creation and Implementation of Ontario's Anti-Bullying Framework ....................20

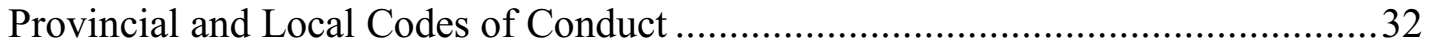

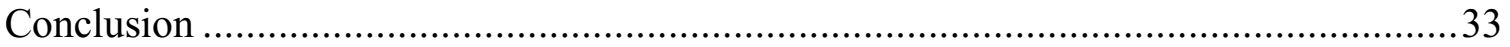

Chapter Three: Settler Colonialism and Its Impact on the Education of Indigenous

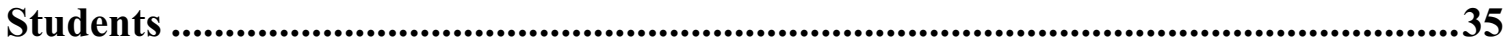

Broader Challenges of Equitable Access to Education for Canadian Indigenous Peoples35

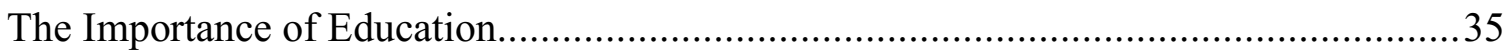

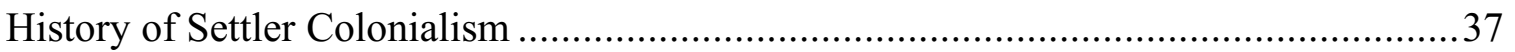

The Impact of the Reserve System ................................................................. 42

The Impact of Residential Schools .................................................................46

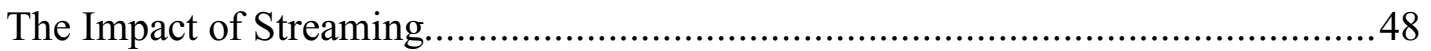

The Impact of Curriculum.............................................................................. 50

The Impact of Discriminatory Policies and Practices........................................52

A Critical Framework for Understanding the Potential Impacts of Colonialism on the

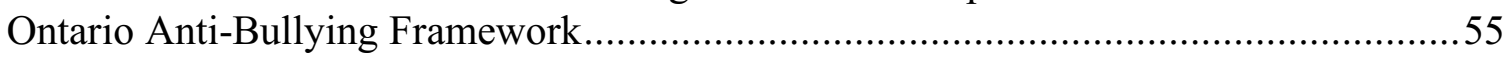

Criminalization of Indigenous Youth and Education ..............................................56

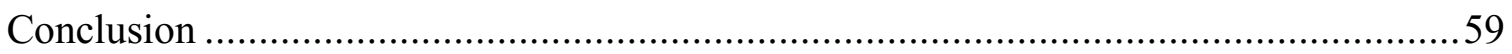


Chapter Four: A Review of the Bullying Literature and Theoretical Framework of Bullying as a Label that Obfuscates Racism, Violence and Harassment ................61

Origins of Bullying as a Phenomenon.......................................................... 61

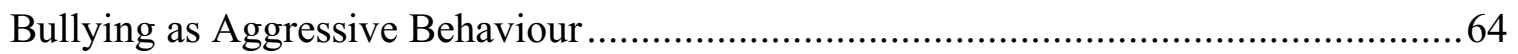

Bullying as the Result of Individual Psychological Factors ........................................68

Bullying as Gendered Behaviour .......................................................................... 71

2SLGBTQIA Perspectives on Bullying in Schools ..................................................... 74

Bullying as Influenced by Socioeconomic and Cultural Factors..................................76

Bullying as Influenced by Educational Environments and Teachers...........................77

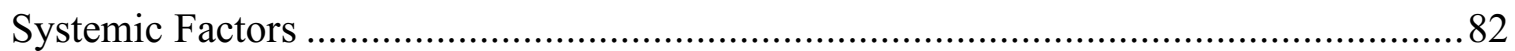

Anti-Bullying Frameworks and the Identification/Construction of Bullies and Victims.. 84

Recognizing Social Construction within the Policy-making Process ............................ 88

Concluding Discussion on the Bullying Phenomenon ......................................... 90

Chapter Five: Methodology and Methods.................................................................93

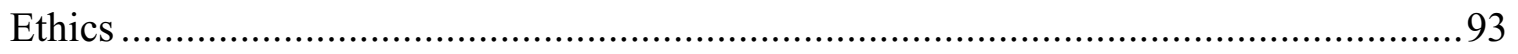

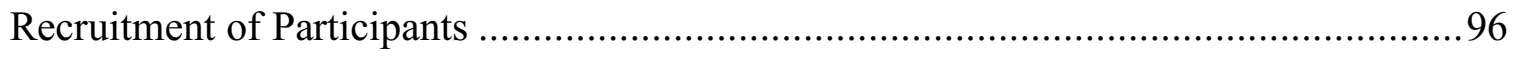

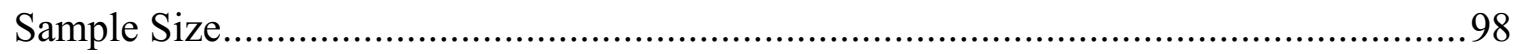

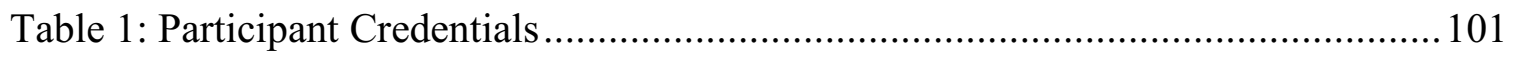

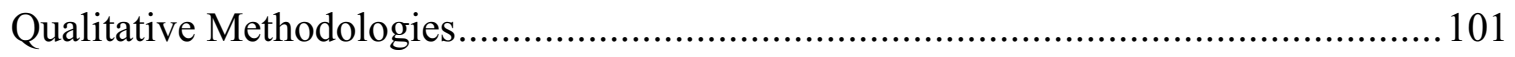

Multi-grounded Theoretical Approach ..................................................... 102

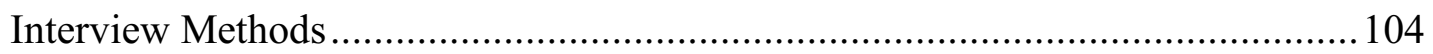

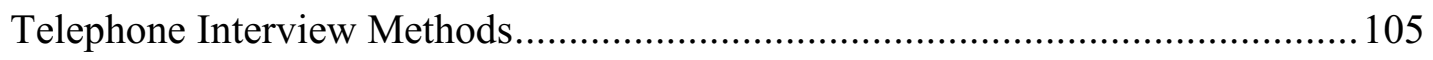

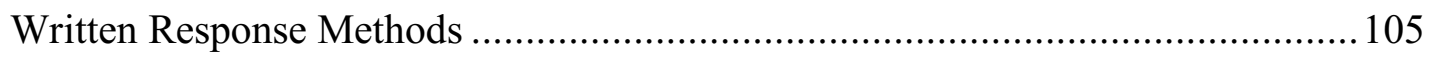

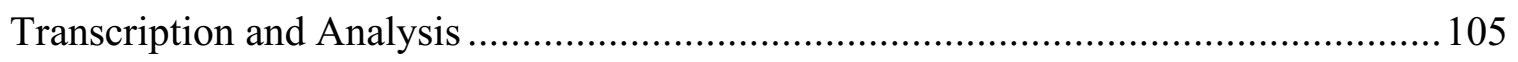

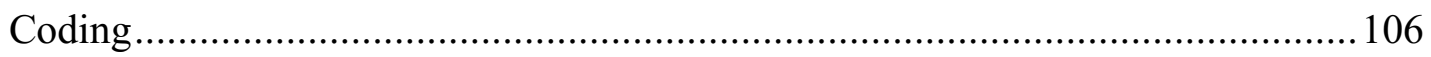

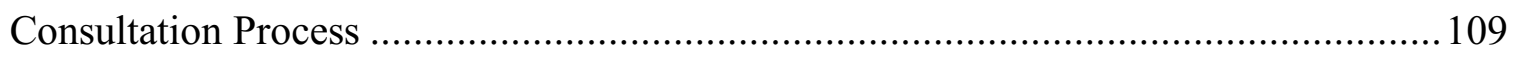

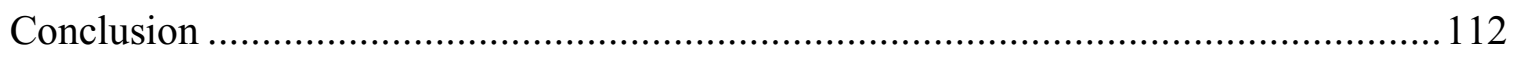

Chapter Six: Context: Colonial Educators and Indigenous Students .....................113

Current Qualifications for Becoming a Teacher ............................................... 114

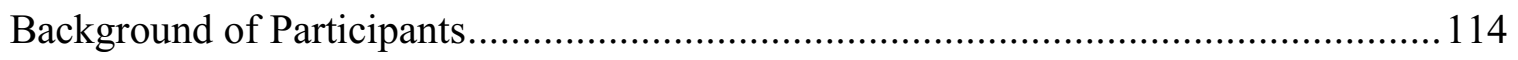

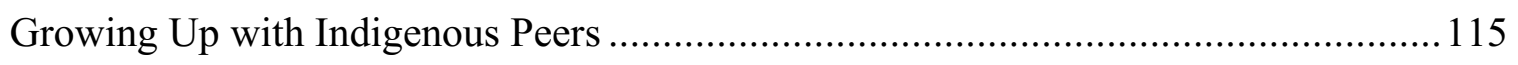

Community Demographics and Comments........................................................... 118

Growing up in Southern Ontario ......................................................... 120

Political Understanding of Indigenous History and Residential Schools ..................... 122

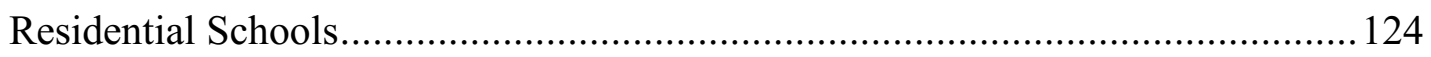


Life Experiences and Indigenous Ways of Knowing..... .129

Reconciliation and TRC's Calls to Action 134

"We're trying" - TRC Influenced Changes, Student/Community Responses and Teacher Comfort Level

Moving Off-Reserve for High School - Impacts on Indigenous Youth 145

Conclusion

\section{Chapter Seven: Awareness and Implementation of the Ontario Anti-Bullying}

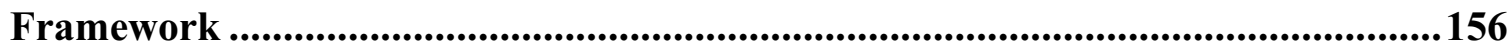

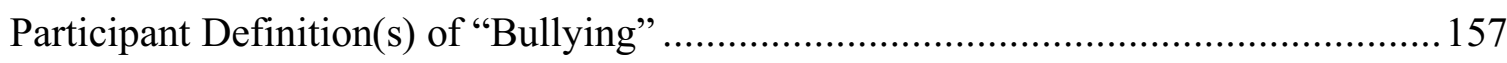

Training Concerning the Ontario Anti-Bullying Framework: 'Conditions of Employment'

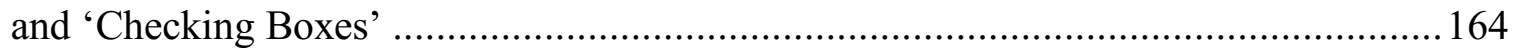

Implementation of the Ontario Anti-Bullying Framework in Schools.......................... 166

Ignoring the Framework - Teachers Using Their Own Discretion........................ 171

Incidents Labelled as Bullying Behaviour Involving Indigenous Students................... 177

Participant Suggestions to Potentially Improve Anti-Bullying Measures...................... 188

Recognize and Deal with 'Bullying Behaviour' ............................................... 189

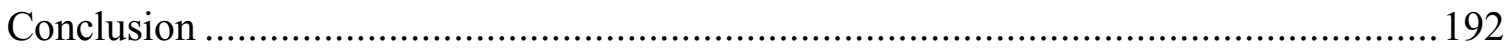

Chapter Eight: Discussion: Educator Appreciation of Indigenous Culture ........... 194

Geographic Differences between Educators and the Engagement with Indigenous Culture

The Danger of the Failure to Recognize the Impact of Settler Colonialism on the

Education System..... 203

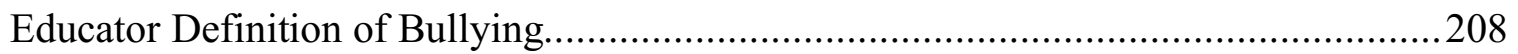

Mislabelling of Harassment and Violent Behaviour as Bullying ................................214

Sexual Harassment and Assault ..................................................................... 214

Targeted Harassment and Physical Violence .................................................2. 215

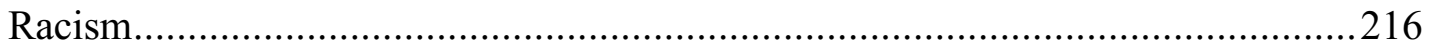

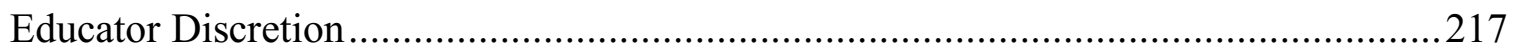

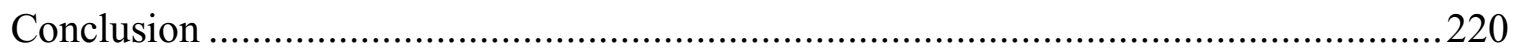

Chapter Nine: The Process of Self-Reflexivity ........................................................222

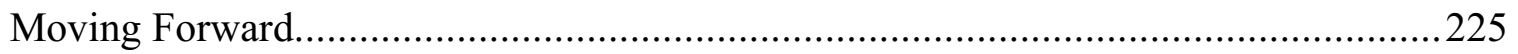

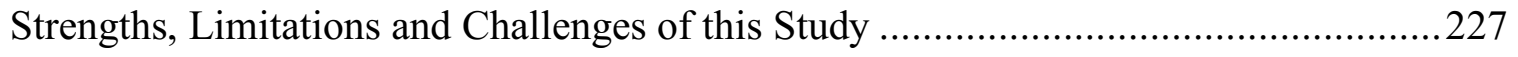

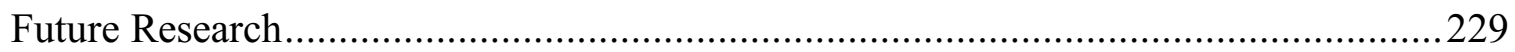

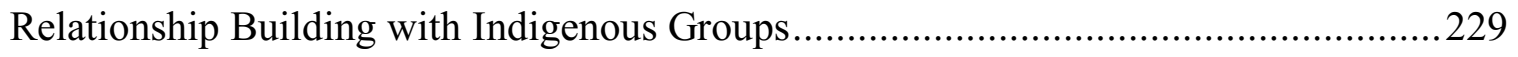

Concluding Thoughts: Ontario's Anti-Bullying Framework and the TRC ..................230

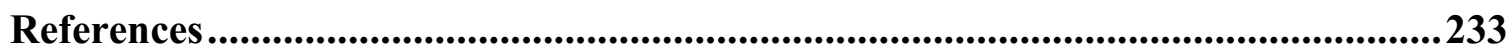


Appendix A: Carleton University Research Ethics Board-A Clearance Certificate

Appendix B: Letters to potential participants (two separate letters) ........................269

Appendix C: Consent Forms (two separate forms)......................................................273

Appendix D: Draft Interview Guide......................................................................2279 


\section{List of Appendices}

Appendix A: Carleton University Research Ethics Board-A Clearance Certificate, dated January 26, 2018

Appendix B: Letter to potential participants introducing them to the study (there is one for Public/Catholic school boards and one for Indigenous schools)

Appendix C: Consent Forms (there is one for Public/Catholic school boards and one for Indigenous schools)

Appendix D: Draft Interview Guide 


\section{The Ontario Anti-Bullying Framework and Its Potential Impact on Indigenous Students in Northern Ontario}

\section{Chapter One: Introduction}

\section{Contemporary Policy - Truth and Reconciliation Commission Calls to Action}

The Truth and Reconciliation Commission of Canada (hereinafter referred to as the TRC) is part of the Indian Residential Schools Settlement Agreement, whose mandate was "to inform all Canadians about what happened in Indian Residential Schools" (TRC, n.d.). The TRC is the result of out-of-court settlement that resolved 15,000 civil lawsuits, 5,000 alternative dispute resolution cases and 11 class actions (Nagy, 2014). The TRC provided a national voice for Indigenous ${ }^{1}$ people: they suffered from and continue to navigate the impacts of colonization (TRC, 2015). The TRC documented the experiences of survivors, families, communities and anyone else impacted by the residential school legacy. The TRC was active from 2008 to 2015. In June 2015, their final report and calls to action were released, and in December 2015, the Commission was deactivated (TRC, n.d.).

The TRC's final report released 94 calls to action for Canadians to integrate into everyday life and social practices. The explicit purpose of these calls to action is for the betterment of Canadian society, as a whole, by integrating Indigenous culture into society and for non-Indigenous people to learn, understand and ultimately incorporate Indigenous culture into daily life. The focus of the calls was on Legacy (child welfare; education; language and culture; health and justice) and Reconciliation (Canadian government and the United Nations; Royal Proclamation and Covenant of Reconciliation; Settlement

\footnotetext{
${ }^{1}$ I use the term Indigenous to encompass any person who considers themselves to be First Nation, Métis or Inuit.
} 
Agreement Parties and the United Nations; Equity for Aboriginal People in the Legal System; National Council for Reconciliation; Professional Development Training for Public Servants; Church Apologies and Reconciliation; Education for Reconciliation; Youth Programs; Museums and Archives; Missing Children and Burial Information; National Centre for Truth and Reconciliation Commemoration; Media and Reconciliation; Sports and Reconciliation; Business and Reconciliation; and Newcomers to Canada) (TRC, 2015).

The TRC has recommended a balance between Indigenous education and the Western educational system (Doige, 2003; TRC, 2015). Under 'Legacy', the 7 calls to action address the education and employment gap Indigenous youth face in comparison to non-Indigenous Canadians. Under 'Education for Reconciliation', the 4 calls to action recommend amending Westernized curriculum to incorporate curriculum around residential schools, treaties, Indigenous history and contemporary contributions to Canada, and funding.

The calls to action invite us to consider the broader impact of colonialism on the Ontario education system and the more particular impact of specific policies and practices, such as Ontario's anti-bullying framework, on Indigenous students. As yet, there is no academic research or literature published on the potential impact of Ontario's anti-bullying framework on Indigenous students. These are issues that the province of Ontario must now address.

My dissertation research responds to the TRC's calls to action by addressing part of the legacy of settler colonialism on the education of Indigenous youth. My work examines how teachers understand and implement Ontario's anti-bullying framework and 
how this understanding potentially impacts their process of teaching Indigenous students within the context of the TRC and colonial legacy, specifically how teachers support their pupils in completing secondary education. In this way, this dissertation has the potential to address the calls to action under both the Legacy and the Education for Reconciliation headings, while also contributing to the scholarly literature on Indigenous education in contemporary Canadian society.

My dissertation analyzes the Ontario anti-bullying framework through a critical understanding of the concept of bullying and the historical implementation of antibullying and 'safe schools' initiatives. By closely examining existing anti-bullying literature, laws and policies, a critical discussion is opened about the links between antibullying initiatives and racism in the education system and the prevalence of contemporary colonialism in education. More specifically, it is possible to question whether the anti-bullying framework implemented in Ontario's education system negatively impacts Indigenous youth who attend high school off-reserve and whether colonialism is reinforced through this framework, including through educator perceptions and actions. I ask: How do teachers understand and implement Ontario's anti-bullying framework? How are their approaches influenced by their backgrounds and experiences? Do they perceive differences in the implementation of the anti-bullying framework to Indigenous and non-Indigenous youth?

To answer my research questions, I interviewed teachers who are employed in northern Ontario from two provincially-funded school boards and one Indigenous education authority. I wanted to gain an understanding of educator perspectives on the Ontario anti-bullying framework, how educators define bullying, and how they have been 
trained, understand and implement the framework. Foreman (2015) argues that "bullying discourses have gained so much power in educational contexts and in public consciousness that it has become practically impossible to understand in-school violence outside the binary logic of protection (i.e. victims of bullying) and vilification (i.e. pathologising 'the bully')" (p. 157). Are colonial relationships perpetuated in schools despite (or because of) the anti-bullying framework that is purported to protect all students in Ontario schools from bullying behaviour?

\section{The Challenges in Northern Ontario}

The calls to action of Canada's TRC are particularly important in northern Ontario, where there is a large Indigenous population. Northern Ontario is home to 99 reserves, where the Canadian government placed many Indigenous people away from White people during the Western invasion and settlement in what is now Canada (Backhouse, 1999; Mawani, 2009; Monchalin, 2016). Most of the reserve bands are Treaty signatories. In northern Ontario, treaties signed in consultation with the Canadian government include: Robinson-Huron Treaty (signed 1850), Robinson-Superior Treaty (signed 1850), Treaty 3 (signed 1873), Treaty 5 (signed 1875) and Treaty 9 (signed 1905) (Ministry of Indigenous Affairs, 2017). ${ }^{2}$

In northern Ontario (up to and including Sudbury and Sault Saint Marie, Ontario), there are 68 high schools (66 of those are part of the Public and Catholic education systems). ${ }^{3}$ The following school boards in northern Ontario house high schools:

\footnotetext{
${ }^{2}$ Treaties are "constitutionally recognized agreements between the Crown and Indigenous peoples" (Hall, 2011, para. 1). Treaties describe the exchanges that took place between Indigenous people and the Canadian state "to share some of their interests in their ancestral lands in return for various payments and promises" (Hall, 2011, para. 1). Treaties helped form the relationship between Indigenous groups and the Crown. However, the Crown did not keep its word and the Canadian government is involved in multimillion dollar land settlement claims (CIRNAC, 2019).

${ }^{3}$ This number excludes the French-only school boards in northern Ontario.
} 
1. Sudbury Catholic District School Board (4 high schools);

2. Northeastern Catholic District School Board (2 high schools);

3. Kenora Catholic District School Board (1 high school);

4. Huron-Superior Catholic District School Board (3 high schools);

5. District School Board Ontario North East (11 high schools);

6. Rainy River District School Board (3 high schools);

7. Superior-Greenstone District School Board (5 high schools);

8. Lakehead Public District School Board (5 high schools);

9. Keewatin-Patricia District School Board (6 high schools);

10. Thunder Bay Catholic District School Board (3 high schools);

11. Rainbow District School Board (11 high schools); and

12. Algoma District School Board (12 high schools).

There are also two Indigenous-only high schools, part of the Northern Nishnawbe Education Council (NNEC): Dennis Franklin Cromarty High School in Thunder Bay, Ontario, and Pelican Falls High School outside of Sioux Lookout, Ontario. These are the secondary schools that Indigenous youth from the north have the option of attending. For those Indigenous youth attending high school as part of the NNEC, many families choose to send their children to Pelican Falls High School to ensure they are in a safer environment, given Thunder Bay's history of Indigenous youth who have perished while attending high school away from home (CBC, 2017).

\section{Indigenous People in Thunder Bay, Ontario and the Seven Youth Inquest}

According to Statistics Canada, Thunder Bay, Ontario, Canada is the Census Metropolitan Area that is home to the highest proportion of Indigenous residents who live 
off-reserve in Canada (StatsCan, 2019; Ministry of Indigenous Affairs, 2019).

Approximately 13\% of the census metropolitan area of Thunder Bay's population (total population of 2019 census is approximately 121,000) identify as Indigenous (StatsCan, 2019; Ministry of Indigenous Affairs, 2019). To attend high school (grades 9-12), many Indigenous youth do not have the option of staying in their home communities as stated above (Eden, 2016).

Although Indigenous students on a reserve do have the option of attending high school 'at-a-distance', this is only possible if there is access to a computer and consistent, reliable internet (Eden, 2016). More commonly, their options include: a) to stop attending school or b) leave their home communities to attend school and live with extended family or with boarding families (TVO Current Affairs, 2017). Many Indigenous youth who live in the north find it extremely difficult to leave their home communities to attend an Indigenous-only or provincially-funded high school where they may not know anyone or have the same supports as their home.

The concept of bullying in schools became a topic of important conversation in Ontario's Legislature in 2011, when the government introduced amendments to the Education Act to specifically address the issue of bullying. When Ontario's anti-bullying legislation was debated in 2011, I reflected on how Indigenous people in my home community of Thunder Bay (and elsewhere in northern Ontario) would potentially be impacted, specifically those Indigenous students who move to Thunder Bay to attend high school. ${ }^{4}$ Part of the reason I reflected on this was due to the fatalities in Thunder Bay

\footnotetext{
${ }^{4}$ Thunder Bay, Ontario is home to Dennis Franklin Cromarty High School, which is part of the Northern Nishawbe Education Council (NNEC) (NNEC, 2014). Indigenous youth who are part of NNEC's communities have the option to attend high school in Thunder Bay, Ontario or Sioux Lookout, Ontario (Pelican Falls High School). The reason the students either attend in Thunder Bay or in Sioux Lookout is
} 
involving seven Indigenous students attending Dennis Franklin Cromarty High School:

Jethro Anderson (d. 2000), Curran Strang (d. 2005), Paul Panacheese (d. 2006), Robyn

Harper (d. 2007), Reggie Bushie (d. 2007), Kyle Morrisseau (d. 2009) and Jordan

Wabasse (d. 2011). The fatalities of Indigenous high-school aged youth in Thunder Bay have continued and remain a valid concern for families who are considering options for higher education for their children. The students listed died while attending Dennis Franklin Cromarty High School; however, there have been other Indigenous youth who have died, such as Josiah Begg and Tammy Keeash, both passing away in 2017, while visiting the city. Rather than address this problem with the first fatality, it took 10 years and additional lives (those who died attending Dennis Franklin Cromarty) for an inquest into these deaths to be opened. ${ }^{5}$

The 7 Youth Inquest into the circumstances and causes of death of the students from Dennis Franklin Cromarty began on October 5, 2015 and ended on June 28, 2016. With over 200 witnesses and family members providing testimony, this inquest was the most far-reaching attempt in the history of the Province of Ontario, to explain multiple factors linking to systemic issues that relate to the deaths of Indigenous youths ${ }^{6}$ (Findlay,

\footnotetext{
because there is no high school on their reserve. Thus, if they want to further educate themselves up to Grade 12, they must leave their home communities (CBC, 2017).

${ }^{5}$ The inquest was originally only for Reggie Bushie, however, "his inquest was stalled in 2008, due to concerns regarding the lack of First Nations representation on jury rolls. NAN legally pursued this issue to the Court of Appeal, and politically advocated for solutions with the Ontario government" (Falconers, 2019, para. 2). Justice Frank Iacobucci was appointed to "review the issue of First Nations representation on jury rolls" (para. 2). Iacobucci J. developed, in consultation with an Implementation Committee, Debwewin, a way to allow First Nations community members to volunteer for Coroner Inquest juries; "Ontario passed a regulation to allow First Nations people living on reserve to volunteer, and the Volunteer Jury Initiative began" (para. 3). See Coroner's Act, R.S.O. 1990, c. C.37 O. Reg. 266/14: On-Reserve Representation, Juries at Coroners' Inquests, Territorial Districts of Kenora and Thunder Bay.

${ }^{6}$ For further information about the 7 Youth Inquest from an Anishinaabe Canadian journalist's perspective, please see Talaga, T. (2017). Seven fallen feathers: Racism, death, and hard truths in a northern city. House of Anansi.
} 
2016). On June 28, 2016, Dr. David Eden, the Coroner in the investigation, presented his findings and cited the following as causes of death for the seven youth: drowning, drowning with ethanol intoxication, and unknown causes. In the same report, Dr. Eden published 145 recommendations to multiple organizations including the Government of Canada; the Government of Ontario; Nishnawbe Aski Nation; Northern Nishnawbe Education Council; Keewatinook Okimakanak; and Mattawa Learning Centre (Eden, 2015). His recommendations touched on topics of reconciliation; education; living conditions and health issues on reserve; transition plans for students attending school offreserve; missing persons protocols; and creating partnerships in the community as factors that needed to be addressed in order to prevent further deaths.

Dr. Eden's report, however, did not address links between his recommendations and how the sum of the topics he touched on create systemic issues which Indigenous people must navigate. Rather, it only discussed the causes of death mentioned above. I believe that these students encountered larger systemic factors, such as racism, harassment and violence, coupled with the fact that they were outside their home communities, separated from familial support.

Stemming from these results, a review of the Thunder Bay Police Services Board was conducted (Sinclair, 2018). The 2018 Office of the Independent Police Review Director Report acknowledged racism and ignorance of systemic issues in Thunder Bay Police Service investigations. Since Thunder Bay is the 'hub of the north' in Ontario, it is likely that the Thunder Bay Police Services Board has influenced other areas of northern Ontario by setting standards of how Indigenous people are treated by police. Many police officers in Thunder Bay have ignored ongoing issues Indigenous people face; Ryan 
McMahon, a podcaster in Thunder Bay declared, "Thunder Bay Police stopped seeing Indigenous peoples as humans" (CBC Radio, 2018, para. 32). McMahon's statement is well-founded as there have been multiple fatalities involving Indigenous people that were not thoroughly investigated because of racist stereotypes (Sinclair, 2018). Thus, this review was necessary and timely; it is imperative to view the impact of systemic racism by police on a wider scale.

In October 2019, the Office of the Independent Police Review Director, Thunder Bay Police Service, Nishnawbe Aski Nation and others declared they will re-open four of the cases from the inquest, those of Jethro Anderson; Curran Strang; Kyle Morriseau; and Jordan Wabasse under the leadership of Ken Leppert, a retired detective superintendent with the Ontario Provincial Police (Diaczuk, 2019). ${ }^{7}$ The goal of this investigation is to re-evaluate investigation notes, outcomes and causes of death to determine if there is new evidence or if they can pinpoint systemic problems such as racism, violence or stereotypes which may have been significant factors in the deaths (Diaczuk, 2019). The results of the review are not yet available; in an April 20, 2021 news release, the public was informed that the OIPRD reinvestigation reports are expected in June 2021 (Diaczuk, 2021).

The legacy of the lost Indigenous lives speaks to the issue of bullying in Ontario schools. Indigenous youth navigate multiple factors that they may be targeted for in school, such as not being able to read or write. Rather than consider where the behaviours stem from, the Indigenous youth may be harassed or face racism due to issues that are beyond their control (issues with education on-reserve is discussed later in chapter three).

\footnotetext{
${ }^{7}$ There are other cases that will be re-opened as well, but are not included in the scope of this project.
} 
Indigenous youth navigate systemic issues and may face negative behaviour for their inability to 'catch up' to youth who have been educated off-reserve. The systemic issues faced while trying to obtain an education put Indigenous youth at risk of facing negative behaviour in school. Additionally, because of stereotypes, Indigenous youth may also be blamed for the negative behaviour they face.

\section{Description of Researcher}

As part of my dissertation, it is important to acknowledge my social location. I identify as a woman and am a settler Canadian from Thunder Bay, Ontario. Growing up in Thunder Bay, I witnessed racism against Indigenous people; I witnessed violence against Indigenous people; and I witnessed harassment against Indigenous people. As a child, I did not understand what Indigenous people had endured. Growing up, I had questions like: why did the larger community disregard their existence? Why were they viewed as problems? My parents did not have the answers to these questions, either. My father emigrated from Ireland to Canada in the 1970s, working in the bush as a mechanic. After that, he was employed by a company on the Fort William First Nation Reserve in Thunder Bay, Ontario. My mother worked as a laboratory technologist. My maternal grandmother, however, knew what happened to Indigenous people, but she rarely spoke about it. She had witnessed racism in Thunder Bay and during her own forced institutionalization and involuntary medical experimentation at the Fort William Sanatorium where Indigenous people were also being tested upon; she wanted to leave her experiences behind. After hearing my grandmother's story, I became interested in Indigenous politics and, ultimately, motivated to engage in further research concerning the barriers faced by Indigenous people. I understand I am writing from a point of 
privilege and am putting myself forward for Indigenous people to trust me and to trust the analysis I provide in this dissertation.

I wrote this dissertation in an attempt to address some of the broader social problems that are inflicted upon Indigenous people. Indigenous youth are not granted the same access to education as non-Indigenous people. Acknowledging that Indigenous youth must face existing systemic issues and addressing how these issues intersect with current policy and social realities in their quest for education is an important feature of this work.

This research, specifically my analysis and discussion, have been influenced by the working relationship I have with the Nokiiwin Tribal Council in Thunder Bay, Ontario. I have been involved in many research projects with Dr. Vicki Kristman (Lakehead University - EPID@Work Research Institute (Enhancing the Prevention of Injury and Disability @ Work Research Institute)), who introduced me to the Nokiiwin Tribal Council in August 2018. Working with Dr. Kristman, I have honed my research skills. I have also learned many life lessons from employees at Nokiiwin, and community members from Animbiigoo Zaagi'igan Anishinaabek (Lake Nipigon Ojibway), Biinjitiwaabik Zaaging Anishinaabek (Rocky Bay First Nation), Bingwi Neyaashi Anishinaabek (Sandpoint First Nation), Fort William First Nation and Netmizaaggamig Nishnaabeg (Pic Mobert First Nation). Although the EPID@Work Research Institute and the Nokiiwin Tribal Council are not involved in this research study, my experiences with both organizations impacted how I analyzed the research data, I owe a great deal to the members of the Nokiiwin communities - I have learned about building trust, respect, Indigenous culture, the medicine wheel, what life is like on reserve, the issues many 
Indigenous populations face as a result of government funding, lateral violence, the lack of emergency services available and education delivery on-reserve.

I know that I am considered a trustworthy ally to members of the Nokiiwin Tribal Council; as Boudreau Morris (2017) refers to this type of relationship, “'decolonizing solidarity' as a basis for settler and other peoples to work in solidarity with Indigenous peoples in the context of settler colonialism" (p. 457). I am a settler, working in solidarity with the Nokiiwin Tribal Council, to decolonize historical views of Indigenous people. Although the focus of my dissertation is on the Ontario education system, without a direct tie to an Indigenous organization involved in this research, I aim to speak with Indigenous people and other scholars (Fortier, 2017). The research I do with EPID@Work and the Nokiiwin Tribal Council focuses on workplaces. The relationship that has developed is one that grew out of respect, trust and solidarity; I know that I am considered an ally to the Nokiiwin Tribal Council - I have been invited into community, have attended community gatherings, have sat around the sacred fire, and as a researcher, I have asked questions to Nokiiwin members about labour force participation, and bullying and lateral violence in the workplace. Audrey Gilbeau, the Executive Director of the Nokiiwin Tribal Council, Dr. Kristman and I also published work on the importance of including Indigenous workers in workplace mental health (O'Loughlin, Kristman \& Gilbeau, 2021). Cumulatively, my experiences and life lessons learned impacted how I analyzed my research. Similar to scholars Korteweg and Root (2016), listening and learning from Nokiiwin members helped me "engage in an affective learning process attuned to difficult knowledge that improved our $[\ldots]$ responsibilities to be more 
accountable for ethical relationality with Indigenous peoples" (p. 180). I hope that my research 'speaks with Indigenous people' (Fortier, 2017).

\section{Remaining Chapters of my Dissertation}

The remaining chapters of my dissertation are organized to give context to my research, reveal teacher data that answer my research questions and to provide context for future research. Chapter two contains a discussion of the legislative context for this dissertation, which is split into two sections. The first section focuses on the labyrinth of legislation and political issues Indigenous youth and their parents navigate to access education, between federal and provincial jurisdictions. The second section discusses the history and implementation of the anti-bullying framework under the Ontario Education Act.

Chapter three discusses the historical context of colonialism, the impact of residential schools and the effects of these on accessibility of equitable education for Indigenous youth. Chapter four provides a review of the literature on the bullying phenomenon and outlines the history of the development of the concept of 'bullying' starting from Dan Olweus' work in Norway. Much of the literature focuses on individual causes of bullying, rather than recognizing that the behaviour is influenced by larger systemic issues. In the literature review, I also introduce scholars who are more critical of the term bullying, such as Walton (2005a, 2005b, 2005c, 2011), McGregor (2008) and Winton and Tuters (2015). These scholars argue that an understanding of bullying requires in-depth recognition and analysis of underlying issues, such as racism, harassment, and violence; this argument contributes to the framework of analysis in my dissertation. 
Chapter five provides a discussion of the methodologies and methods I used for my research. I employed a qualitative approach and multi-grounded methodologies while conducting in-person interviews, telephone interviews and written responses as data collection methods for my research. In consultation with an Indigenous researcher, ${ }^{8} \mathrm{I}$ adopted some aspects of Albert Marshall's Two-Eyed Seeing approach during data analysis, acknowledging the importance of recognizing positive aspects of both Western and Indigenous perspectives. In this chapter, I also reflect on how working with the Nokiiwin Tribal Council in Thunder Bay impacted this research.

The resultant data from my research is discussed in chapters six and seven. Chapter six presents the broader context for understanding the approaches adopted by my participants when faced with incidents of bullying. It considers a variety of background data on my research participants, such as their childhood experiences of growing up with or without Indigenous peers. The chapter also presents the data from my research participants specifically concerning the TRC; how they understand the TRC's calls to action, and whether or not they believe these have been implemented in their school's curricula. In chapter seven, I discuss the responses of my research participants concerning their understanding of the bullying phenomenon, their understanding of the Ontario antibullying framework, and how the anti-bullying policies were implemented in their schools. This includes a discussion on exercises of discretion, as some teachers reported that they did not always follow all of the steps required under the anti-bullying framework.

\footnotetext{
${ }^{8}$ The Indigenous researcher does not wish to be named in this research. Further details about the consultation process are in chapter five.
} 
Chapter eight then provides a discussion of my findings and how these findings fit within, and expand the scope of, the broader academic literature. Themes discussed will include: histories of formative years with or without Indigenous peers; differences among participants growing up in southern/northern Ontario; participant engagement with Indigenous history and culture; participant definitions of bullying; participant understanding of the Ontario anti-bullying framework; and use of teacher discretion in responding to bullying incidents. Finally, chapter nine concludes this dissertation by providing an overview of this study, how the Ontario anti-bullying framework connects to the TRC, its strengths, limitations and challenges of conducting this research, as well as offering areas of future research that may stem from this work. 


\section{Chapter Two: The Legislative Context for this Study}

This chapter provides the legislative context for my dissertation. In the first section, I discuss the legislative framework for Indigenous education in Ontario, including differences between federal and provincial jurisdiction. The second section includes a discussion about the creation and implementation of the Ontario anti-bullying framework, including the 2012 amendments to Ontario's Education Act that introduced the current anti-bullying framework in the province's education system.

\section{Section I: Indigenous Students and Ontario's Education Act}

\section{Provincial and Federal Jurisdiction}

Promoting educational equity for Indigenous people is complicated by the fact that they are stuck in "educational purgatory" (Wilson, 2007). Indigenous education is "bound and restricted by political fighting that leaves it underfunded, unregulated and unsupported" (Wilson, 2007, p. 248). In part, this is due to a jurisdictional overlap in Canada, leading to service and accountability gaps. Indigenous students' education is controlled under the Indian Act, while education services for all other students are regulated under provincial laws, such as the Ontario Education Act. The idea of ensuring equitable treatment for Indigenous youth in school based on a strategy of school safety, in addition to the compliance to the anti-bullying framework, is complicated by the fact that provincial education laws establish and regulate these protocols in school (i.e. board prevention and intervention plans), whereas federal education legislation does not (ISC, 2018a). While Indigenous-led education institutions must have their curricula inspected and approved by the Ontario Ministry of Education, they do not follow provincial 
education laws. These institutions may develop internal policies; however, these internal policies are not always publicly available. ${ }^{9}$

\section{Funding Differences Between Provincial and Federal Schools}

Ontario recently adopted a new framework for funding Indigenous education. Since September 1, 2019, the Ontario Ministry of Education has been implementing a 'reciprocal education approach,' where Indigenous students who live on reserve may attend schools that are part of a school board or the students who are eligible to attend schools in a school board "may attend [Indigenous]-operated or federally-operated schools, subject to the school's admission policies" (OME, 2019c, para. 3). The funding for federally operated or band-operated schools is not equivalent to the funding for provincial schools (Drummond \& Rosenbluth, 2013). Federally funded schools received "20 to 50 per cent lower than provincial education funding” (Drummond \& Rosenbluth, 2013, p. 3).

The choice of where Indigenous youth attend high school depends on parents and family accepting the school the student will attend, band funding and the distance the school is away from home (ISC, 2018a). Families who send their children to high school off-reserve need to apply for enrollment, regardless of which system they want to be part of (ISC, 2018a). In Ontario, there are tripartite education agreements between Indigenous bands, the Ontario Ministry of Education and Indigenous Services Canada establishing that students fall under provincial legislation when they attend a provincial Public or Catholic school off reserve (ISC, 2018b). These agreements are created acknowledging that an Indigenous student will attend an off-reserve secondary school that is regulated by

\footnotetext{
${ }^{9}$ At the time of writing this chapter, the policies were not posted online, and e-mailed requests were not responded to.
} 
Ontario's Education Act. The student's band will pay the provincial school a tuition fee. To be eligible, the student must live on a reserve as defined under the Indian Act (Canada) (Plan for Care and Opportunity Act (Budget Measures), 2018 S.O. 2018, c.8 Bill 31; Education Act, 2019). Under the Education Act, an Indigenous student should be afforded the same quality education as non-Indigenous students. At a minimum, Indigenous students who attend Public or Catholic schools under the Education Act are eligible to receive the same services as other students who are not regulated by the Indian Act. They may receive further services if their home "entity" (i.e. the band of which the student is a member) enters into an agreement with the school board to pay for the additional services.

\section{School Boards - Ontario First Nation, Métis and Inuit Education Policy Framework}

Many Indigenous leaders have advocated that Indigenous youth should have access to the same resources as students enrolled in Public and Catholic education boards while maintaining cultural differences and languages (Battiste, 2013; Friedland \& Napoleon, 2015; Wilson, 2007). To provide a potential answer to this, the Ontario government created the Ontario First Nation, Métis, and Inuit Education Policy Framework (OME, 2007). In 2007, the Ontario Ministry of Education, identified [Indigenous] education as one of its key priorities, with a focus on meeting two primary challenges by 2016 - to improve achievement among First Nations, Métis and Inuit students and to close the gap between [Indigenous] and non-[Indigenous] students in the areas of literacy and numeracy, retention of students in school, graduation rates, and advancement to postsecondary studies. (p. 
This framework has been implemented in the public and Catholic school boards, "to improve the academic achievement of the estimated 50,312 [Indigenous] students who attend provincially funded elementary and secondary schools in Ontario" (OME, 2007, p. 5). The overriding barriers to reaching the Ontario Ministry of Education's goals were a lack of awareness and understanding among teachers and schools of Indigenous learning styles, cultures, histories and perspectives (OME, 2007).

In policy, the Ontario Ministry of Education now mandates inclusion of First Nation, Métis and Inuit culture in the education curriculum. For example, rather than offering only traditional English courses studying European and British authors such as Shakespeare, there are courses that focus on Indigenous-Canadian authors (Brean, 2017; People for Education, 2017). There are also courses which focus on land-based education, an alternative learning classroom (Scully, 2012). Although there have been Ontario First Nation, Métis, and Inuit Education Policy Framework reports published in 2009, 2013 and 2018 crediting the Ontario Ministry of Education with its efforts in understanding Indigenous culture and how it can be incorporated into the education system, there is still not a full recognition that Indigenous communities may adopt a different educational framework from the Western perspective.

One of the most important factors in ensuring Indigenous students' equitable access to education within this context of complex jurisdictional issues, historical discrimination, socio-economic and geographic barriers is the requirement to keep Indigenous students safe while they are attending school. This leads to the consideration of Ontario's anti-bullying framework, which will be outlined below. 


\section{Section II: Ontario's Anti-Bullying Framework}

\section{Creation and Implementation of Ontario's Anti-Bullying Framework}

Ontario's anti-bullying framework is part of a larger legislative strategy to curb the problem of violence in schools. The first stage in the creation of the modern legal framework to combat violence in Ontario schools was the introduction of then Premier Harris' Conservative Government's Safe Schools Act, 2000, An act to increase respect and responsibility, to set standards for safe learning and safe teaching in schools and to amend the Teaching Profession Act (hereinafter referred to as the Safe Schools Act, 2000), which governed the behaviour of all persons in school (301(1)). The Safe Schools Act, 2000 amended the Ontario Education Act such that 'mandatory suspension of a pupil' became a consequence for certain negative behaviours (s. 3, Safe Schools Act, 2000). The newly introduced section 306(1) of the Education Act stated that:

It is mandatory that a pupil be suspended from his or her school and from engaging in all school-related activities if the pupil commits any of the following infractions while he or she is at school or is engaged in a school-related activity:

1. Uttering a threat to inflict serious bodily harm on another person.

2. Possessing alcohol or illegal drugs.

3. Being under the influence of alcohol.

4. Swearing at a teacher or at another person in a position of authority.

5. Committing an act of vandalism that causes extensive damage to school property at the pupil's school or to property located on the premises of the pupil's school.

6. Engaging in another activity that, under a policy of the board, is one for which a suspension is mandatory. (Safe Schools Act, 2000) 
There was a general clause that provided school principals with the ability to determine the length of a suspension. Section 306(9), dealing with 'Factors Affecting Duration of Suspension' stated, 'the principal shall consider the pupil's history and such other factors as may be prescribed by regulation and the principal may consider such other matters as he or she considers appropriate" (Safe Schools Act, 2000). The language introduced to the Education Act through the Safe Schools Act, 2000, allowed school principals the authority, in consultation with other educational personnel, to decide whether standard suspensions and expulsions were necessary in the circumstances. As such, the Safe Schools Act, 2000, provided school boards with power to allow their principals to impose disciplinary actions in school (Safe Schools Act, 2000; Bhattacharjee, 2003). Any pupil, parent, guardian of pupils and others who may be present in schools under the jurisdiction of the respective school board was required to be aware of this policy (Safe Schools Act, 2000, s.301.(3)).

Under the Dalton McGuinty Government, the Ontario Education Act was further amended by the Accepting Schools Act, an Act to amend the Education Act with respect to bullying and others matters, on September 1, 2012 (hereinafter referred to as the Accepting Schools Act). This legislation further amended the Education Act, by, among other measures, adding bullying to the list of issues that provide suspension as a disciplinary response. The legislation was developed with the guidance and advice provided by the Promoting Relationships and Eliminating Violence Network 
$(\text { PrevNET })^{10}$ and the Accepting Schools Expert Panel. ${ }^{11}$ Part of the reasoning for the

amendment to include negative behaviour defined as bullying in the disciplinary

framework of the Act stemmed from the publicized suicides of two Ontario youths: 15

year old Jamie Hubley and 11 year old Mitchell Wilson (Howlett, 2011), both of whom

were mentioned in the Ontario Legislature when the anti-bullying legislation was

debated. ${ }^{12}$ The addition of the label 'bullying' to the legislation was not critically

evaluated and not considered problematic. The debates indicate that the term "bullying

behaviour" was accepted as if there was a generalized understanding of what bullying

meant and the type(s) of behaviour(s) associated with the term. However, I argue that the

\footnotetext{
${ }^{10}$ PrevNET is led by Scientific Director Dr. Wendy Craig of Queen's University. There is a multitude of Canadian research scientists, graduate students and other academics involved in the institute (PrevNET, 2019).

${ }^{11}$ The development of the Accepting Schools Expert Panel was discussed in the following Ontario Legislature debates: Broten, L.C. (Hon.). (2011, Dec. 1). "Anti-Bullying Initiatives." Ontario. Ontario Legislature. Hansard, $40^{\text {th }}$ Parliament, $1^{\text {st }}$ session; Broten, L.C. (Hon.). (2011, Dec. 7). "Accepting Schools Act, 2011." Ontario. Ontario Legislature. Hansard, $40^{\text {th }}$ Parliament, $1^{\text {st }}$ session; Broten, L.C. (Hon.). (2012, March 26). “Accepting Schools Act, 2012." Ontario. Ontario Legislature. Hansard, 40 $0^{\text {th }}$ Parliament, $1^{\text {st }}$ session; MacCharles, T. (2012, April 4). "Accepting Schools Act, 2012." Ontario. Ontario Legislature. Hansard, $40^{\text {th }}$ Parliament, $1^{\text {st }}$ session; Broten, L.C. (Hon.). (2012, May 16). "Anti-Bullying Initiatives." Ontario. Ontario Legislature. Hansard, $40^{\text {th }}$ Parliament, $1^{\text {st }}$ session; and Broten, L.C. (Hon.). (2012, June 4). “Accepting Schools Act, 2012." Ontario. Ontario Legislature. Hansard, $40^{\text {th }}$ Parliament, ${ }^{\text {st }}$ session. The Accepting Schools Expert Panel Co-Chairs were introduced to the Legislature during the following Ontario Legislature debate: Broten, L.C. (Hon.). (2012, June 14). "Anti-Bullying Initiatives.” Ontario. Ontario Legislature. Hansard, $40^{\text {th }}$ Parliament, ${ }^{\text {st }}$ session. The Accepting Schools Expert Panel was established in June 2012. It had 22 members during its existence who were from various forms of employment, such as teachers, researchers, medical professionals, superintendents and social workers. The expert panel met quarterly for 4 years (to June 2016). Their mandate was "to inspire the culture change needed to support safe and accepting schools initiatives; advise the Ministry of Education on evidence-informed resources and practices that support building and sustaining a positive school climate in all Ontario schools; and advise on the best ways to share this knowledge" (Ferguson \& Gordon, 2016, p.4).

${ }^{12}$ Mitchell Wilson was discussed in the following Ontario Legislature debates: Dickson, J. (2012, Feb. 28).

"Anti-Bullying Campaigns." Ontario. Ontario Legislature. Hansard, 40 $0^{\text {th }}$ Parliament, $1^{\text {st }}$ session.; MacLeod, L. (2012, Mar. 26). “Accepting Schools Act, 2012.” Ontario. Ontario Legislature. Hansard, 40 ${ }^{\text {th }}$ Parliament, $1^{\text {st }}$ session; McKenna, J. (2012, April 25). “Accepting Schools Act, 2012.” Ontario. Ontario Legislature. Hansard, $40^{\text {th }}$ Parliament, ${ }^{\text {st }}$ session. Jamie Hubley was mentioned in the following Ontario Legislature debates: MacLeod, L. (2011, Nov. 23). "Jamie Hubley." Ontario. Ontario Legislature. Hansard, $40^{\text {th }}$ Parliament, $1^{\text {st }}$ session; MacLaren, J. (2011, Dec. 7). "Mental Health Services." Ontario. Ontario Legislature. Hansard, 40 ${ }^{\text {th }}$ Parliament, $1^{\text {st }}$ session; MacLeod, L. (2012, March 26). "Accepting Schools Act, 2012." Ontario. Ontario Legislature. Hansard, $40^{\text {th }}$ Parliament, $1^{\text {st }}$ session; Tobin, S. (2012, Apr. 17).

“Accepting Schools Act, 2012." Ontario. Ontario Legislature. Hansard, 40 ${ }^{\text {th }}$ Parliament, $1^{\text {st }}$ session. Jamie Hubley is also mentioned in Ontario Legislature debates up to April 10, 2019 (see MacLeod, L. (2019, Apr. 10). “Anti-Bullying Initiatives." Ontario. Ontario Legislature. Hansard, $42^{\text {nd }}$ Parliament, $1^{\text {st }}$ session).
} 
term bullying obfuscates behaviour such as discrimination (including racism), violence and harassment. Hubley and Wilson experienced these behaviours, yet they were labelled as bullying.

Jamie Hubley was the only openly gay student in the high schools he attended (Howlett, 2011). He was also a figure skater. Other teenagers had harassed Hubley constantly since Grade 7. It was reported that "teens tried to stuff batteries down his throat on the school bus because he was a figure skater" (Burke, 2011, para. 3). Hubley left a suicide note on his online blog, "I don't want my parents to think this is their fault, either. I love my mom and dad. It's just too hard. I don't want to wait three more years, this hurts too much" (Burke, 2011, para. 10). The actions the boys took against Hubley were viewed as bullying, not harassment or physical assault.

Mitchell Wilson was diagnosed with muscular dystrophy at age 9 (Howlett, 2011). In November 2010, he was mugged by an older boy in his school. He was 10 years old. The child who physically assaulted Wilson was arrested, charged with assault and removed from their school (Nurwisah, 2011). The harassment, however, did not end; older boys who were friends with the guilty child followed Wilson home daily, taunting him and blaming him for their friend's fate (Nurwisah, 2011). Wilson feared for his life, anxiety was present, and his muscle strength deteriorated. On September 6, 2011, Mitchell Wilson was found with a plastic bag tied around his head (Nurwisah, 2011). The acts of harassment by the older boys appeared to go unnoticed by authorities; Premier McGuinty stated that the Ontario government was 'stepping it up';

We [the Ontario government] are determined to take the next step to ensure that in our schools we send a very clear, strong and direct message: we will not tolerate 
bullying of any kind, at any time, for any reason. (The Canadian Press, 2011, para. 11)

Premier McGuinty hoped the anti-bullying framework would prevent further tragedies and make schools safer for all youth (The Canadian Press, 2011).

The Accepting Schools Act (Bill 13) received royal assent on June 19, 2012, coming into effect on September 1, 2012 (Legislative Assembly of Ontario, 2012). The Accepting Schools Act amended Ontario's Education Act with respect to bullying and other matters. It also amended section 1(1) of the Education Act to include a definition of bullying. The definition of 'bullying' introduced through the legislation is broad and ambiguous. The Accepting Schools Act defined bullying as,

aggressive and typically repeated behaviour by a pupil where,

(a) the behaviour is intended by the pupil to have the effect of, or the pupil ought to know that the behaviour would be likely to have the effect of,

i. causing harm, fear or distress to another individual, including physical, psychological, social or academic harm, harm to the individual's reputation or harm to the individual's property, or

ii. creating a negative environment at a school for another individual, and

(b) the behaviour occurs in a context where there is a real or perceived power imbalance between the pupil and the individual based on factors such as size, strength, age, intelligence, peer group power, economic status, social status, religion, ethnic origin, sexual orientation, family circumstances, gender, gender 
identity, gender expression, race, disability or the receipt of special education; ("intimidation"). (Education Act, 2019, 1[1.1])

Since this Act was implemented, schools have had the authority to discipline students for behaviour labelled as bullying. The personnel who provide the evidence to discipline students are educators, who bring issues to the school principal, who then informs parents and, if warranted, the police.

Cyber-bullying is also part of the anti-bullying framework, defined as bullying via social media websites, text messages, and other online media where bullies can intensify their negative actions in front of a globalized audience (s.1.0.0.2, Accepting Schools Act, 2012). Both behaviours recognized as bullying and cyber-bullying affect a student's ability to learn in school (Cassidy et al., 2009). The installation of the anti-bullying framework also means that activities defined under the bullying umbrella which happen outside of school time or off school property, but impact the larger student body, can be brought to the attention of the principal. The principal must then decide what the best approach is to handle the issue(s) brought forward.

When the Accepting Schools Act was debated, it was noted that parents and students "have a responsibility to work together [...] to make sure that our children are celebrated for their differences and not bullied because of them" (Legislative Assembly of Ontario, 2011, para. 6). It was also stated that parents and students must feel comfortable in knowing that the school environment is free from harassment, violence, intolerance and intimidation (Legislative Assembly of Ontario, 2011). The broad scope of behaviour included in the legislative definition of bullying provided education officials with greater authority to deal with these types of behaviours, potentially preventing 
negative behaviour. At first glance, the amendments introduced through the Accepting Schools Act, 2012, appear to be beneficial with respect to safety at school. However, there is concern that the framework allows educators, particularly teachers, a great deal of discretion in determining when to treat behaviour as "bullying" in order to trigger the protocols under the framework. These concerns will be discussed in the next chapter.

The Accepting Schools Act imposed a requirement on school boards to implement bullying prevention and intervention plans (Education Act, 2012, s.303.3(1)). The content of the plan is to "address any matter specified in the policies or guidelines made under clause 301(7.1)(i)" (s. 303(2)). Section 301(7.1) states,

The Minister shall establish policies and guidelines with respect to bullying prevention and intervention in schools, which must include policies and guidelines respecting,

(a) training for all teachers and other staff;

(b) resources to support pupils who have been bullied;

(c) strategies to support pupils who witness incidents of bullying;

(d) resources to support pupils who have engaged in bullying;

(e) procedures that allow pupils to report incidents of bullying safely and in a way that minimizes the possibility of reprisal;

(f) procedures that allow parents and guardians and other persons to report incidents of bullying;

(g) the use of disciplinary measures within the framework described in clause (6) (a) in response to bullying; 
(h) procedures for responding appropriately and in a timely manner to bullying;

(i) matters to be addressed in bullying prevention and intervention plans established by boards under section 303.3. 2012, c. 5, s. 10 (4).

Using the Accepting Schools Act amendments as a starting point to reflect on behaviour classified as bullying, the Ontario Ministry of Education published, Working Draft: Safe and Accepting Schools Model Bullying Prevention and Intervention Plan (OME, 2013a). The document outlines what is required to meet Ontario Ministry of Education anti-bullying standards. Each board under the Ontario Ministry of Education must consult and seek input from students, teachers, other staff, parents, guardians and anyone who has a vested interest in the wellbeing of the school climate and culture. There is a difference to be noted in the climate and culture of the school. School culture refers not just to the student body, policies or mission statements, it necessarily includes and reflects the way that teachers and other educational personnel interact and work together, and how they cooperate with each other with respect to their own values, beliefs and assumptions (Hoy, 1990; Kutsyurba et al., 2015). It also refers to the behaviours that contribute to the social and psychological environment of the school. By contrast, school climate refers to perceptions of the school environment; this includes patterns of students', parents' and school personnel's reported experiences of school life, which reflect norms, goals, values, interpersonal relationships, teaching and learning practices and organizational structures (Kutsyurba et al., 2015). Based on the amendments to the 
Education Act under the Accepting Schools Act, school climate surveys are to be completed 'on a regular basis'. ${ }^{13}$

A school board's bullying prevention and intervention plan is to be reviewed regularly by the school community, in consultation with school climate survey results. In recognition of a strong legislative and policy framework, the draft working plan ${ }^{14}$ lists several steps for bringing systemic change, such as,

The Education Act, as amended by the Accepting Schools Act, 2012, sets out the following requirements:

- Review policies, procedures and guidelines and include the school community in this process in order to build upon and sustain a positive school climate.

- Review guidelines and procedures or develop new ones to address discrimination and harassment as they may apply to students, staff, parents and community members.

\footnotetext{
${ }^{13}$ Copies of the policies and procedures can be found on the Ontario Ministry of Education website: Ontario's equity and inclusive education strategy can be found here: http://www.edu.gov.on.ca/eng/policyfunding/Equity.pdf; Ontario Ministry of Education's Promoting a positive school climate: A resource for schools, can be found here: http://www.edu.gov.on.ca/eng/parents/introdoceng.pdf; Ontario Ministry of Education's School climate survey: A survey for school staff about: equity and inclusive education, and bullying/harassment, can be found here: http://www.edu.gov.on.ca/eng/safeschools/surveyteacher.pdf; Ontario Ministry of Education's School climate survey: A survey for parents and guardians about: equity and inclusive education, and bullying/harassment, can be found here: http://www.edu.gov.on.ca/eng/safeschools/surveyparent.pdf; and Ontario Ministry of Education's School climate survey: A survey for students in grades 7 to 12 about: equity and inclusive education, and bullying/harassment, can be found here: http://www.edu.gov.on.ca/eng/safeschools/survey7to12.pdf. The school climate survey that is for elementary students is not included in this list.

${ }^{14}$ As of April 21, 2021, the 'draft' working plan has never been finalized. On the Ontario Ministry of Education website (http://www.edu.gov.on.ca/eng/parents/safeschools.html), the 'Model Bullying Prevention and Intervention Plan' link is located under the heading 'Bullying and Intervention.' Clicking the link connects to the 'Model Bullying Prevention and Intervention Plan' webpage (http://www.edu.gov.on.ca/eng/document/curricul/prevent.html), where the final link to access the document remains. Clicking the link connects to the 'Working Draft: Safe and Accepting Schools Model Bullying Prevention and Intervention Plan' found at http:///www.edu.gov.on.ca/eng/document/curricul/BullyingPreventPlan.pdf.
} 
- Provide opportunities for regular check-ins with students at risk of engaging in bullying, and those who have witnessed or been affected by bullying.

- Align supervision plans to address where and when bullying happens, as identified through school climate surveys.

- Use "teachable moments" within a progressive discipline approach to address inappropriate behaviour. Consider mitigating factors like the student's age, the circumstances of the behaviour, and the student's history before determining the most appropriate way to respond to each situation. Consider a range of options to address the behaviour and help the student learn from his or her choices.

- Follow up after bullying incident(s) with students, parents, teachers and other school staff, where appropriate. (OME, 2013a, pp. 3-4)

These are just some of the issues that must be considered when drafting the Bullying Prevention and Intervention Plan in every school.

Additionally, the Ontario Ministry of Education revised Policy/Program Memorandum No. 144 on October 17, 2018 (OME, 2018a). The revised policy outlines the importance of maintaining positive climate and culture in schools. The 7 approaches listed are,

1. Students, school staff members, and parents feel safe, and are safe, included, and accepted;

2. All members of the school community demonstrate respect, fairness, and kindness in their interactions, building healthy relationships that are free from discrimination and harassment; 
3. Students are encouraged and given support to be positive leaders and role models in their school community;

4. Open and ongoing dialogue takes place between the principal, staff members, parents and students. All partners are actively engaged;

5. The learning environment, instructional materials, and teaching and assessment strategies reflect the diversity of all learners, as well as their language of instruction (English; French as a first language; French as a second language);

6. Every student is inspired and given support to succeed in an environment of high expectations; and

7. Bullying prevention and awareness - raising strategies for students and staff are reinforced through curriculum-linked programs. (p.2)

School boards are required to "establish their policies and guidelines on bullying prevention and intervention in accordance with subsection 302(3.4) of Part XIII of the Education Act" (p. 1). The Policy outlines 'suspension and expulsion for bullying' stating that "bullying is one of the activities for which suspension must be considered" (OME, 2018a, p. 3). The Policy also recommends expulsion when a second suspension for bullying occurs (OME, 2018a). Furthermore, principals must suspend a student and potentially expel them for incidents that take place under subsection 306(1) of the Education Act, including acts of bullying,

that are motivated by bias, prejudice, or hate based on race, national or ethnic origin, language, colour, religion, sex, age, mental or physical disability, sexual orientation, gender identity, gender expression, or any other similar factor. (OME, 2018a, p. 3) 
If an incident is based on the above criteria, suspension is mandatory, and expulsion is to be considered.

While considering the individual characteristics of a student who may participate in negative behaviours labelled as bullying, school boards also have to consider differences among the local population. For example, Policy 144 states, "boards have the flexibility to take into account local needs and circumstances, such as geographical considerations, demographics, cultural needs, and availability of boards and community supports and resources" (OME, 2018a, p. 7). Under this policy, boards must have clear "expectations for appropriate student behaviour [as set out in] the Provincial Code of Conduct" (p. 8) (to be discussed below).

Policy 144 suggests educators also review Policy/Program Memorandum No. 145, "Progressive Discipline and Promoting Positive Student Behaviour." While this Policy discusses serious instances, such as sexual assault, it also recognizes 'bullying' as its own behaviour (OME, 2018b). To promote positive behaviour, the Ontario Ministry of Education believes that "a whole school approach" is necessary to address racism, bullying, homophobia and gender-based violence (OME, 2018b). In this Policy, bullying is distinguished and is seen as its own negative behaviour, separate from racism, homophobia, or gender-based violence. The Policy also suggests that educators consider the following when addressing inappropriate behaviour: 1) the particular student and circumstances; 2) the nature and severity of the behaviour; and 3) the impact on students or other individuals in the school community (OME, 2018b, p. 5). The Policy specifically focuses on individual behaviour and how intervention may be able to "maintain a positive school environment in which students can learn" (OME, 2018b, p. 4). 
Most recently, the Ontario Government released a new initiative aimed at bullying prevention and reporting (OME, 2019a). The new initiative was an attempt to shift the school climate and culture to "one where everyone sees the inherent dignity and the value of a person, irrespective of their faith, heritage or orientation or race or their income, to build a more accepting and inclusive province" (OME, 2019a, para. 3). In this initiative, it was stated that students would be provided with school surveys to better understand their experiences, educators will be trained in 'anti-bullying and de-escalation techniques' and the definition of bullying in ministry policies will be reviewed to "ensure it reflects the realities of today" (OME, 2019a, para. 2). On February 26, 2020, the Ontario Ministry of Education provided an update - surveys to combat violence and bullying were available online and new programs were being created to promote positive mental health and wellbeing (OME, 2020). There is also funding for the creation of mental health and well-being programs, however, there is no clear outline when these programs will roll-out or how this initiative will guide students who are victims of behaviour recognized as bullying.

\section{Provincial and Local Codes of Conduct}

In following the Ontario Ministry of Education's mandate, every school board must implement their own Code of Conduct that is to follow the provincial standards under the Provincial Code of Conduct and School Board Codes of Conduct (OME, 2018c). Under this provincial standard, school climates are to be positive; "to foster a positive school climate that supports student achievement and wellbeing, school boards should focus on prevention and early intervention strategies to address inappropriate behaviour" (OME, 2018c, p. 2). The goals of the provincial code of conduct are, 
1. To ensure that all members of the school community, especially people in positions of authority, are treated with respect and dignity.

2. To promote responsible citizenship by encouraging appropriate participation in the civic life of the school community.

3. To maintain an environment where conflict and difference can be addressed in a manner characterized by respect and civility.

4. To encourage the use of non-violent means to resolve conflict.

5. To promote the safety of people in the schools.

6. To discourage the use of alcohol, illegal drugs and, except by a medical cannabis user, cannabis.

7. To prevent bullying in schools. 2000 , c. 12 , s. 3 ; 2012, c. 5 , s. 10 (1); 2017, c. 26, Sched. 1, s. 30 (2). (s. 301(2), Education Act, 1990)

The Code of Conduct applies to almost everyone who has contact with students who attend a publicly funded school, such as students, principals, teachers, early childhood educators, other school staff, school bus drivers, volunteers or community groups (OME, 2018c). Schools that have their own Code of Conduct must clearly acknowledge what behaviour is acceptable and unacceptable. ${ }^{15}$

\section{Conclusion}

This chapter has provided a summary of the legislative framework for Indigenous education in Canada as well as a brief history of the evolution of the legislative response to concerns about violence in schools and a summary of the current anti-bullying framework that is in place in the Ontario education system. The framework includes a

\footnotetext{
${ }^{15}$ The School Boards involved in this research created their own Codes of Conduct, however, for anonymity purposes, this information cannot be disclosed.
} 
general definition of bullying, but that definition is very broad, and the framework includes racist violence as part of the scope of activity captured under the bullying umbrella. Bullying is very complex and can encompass multiple meanings to different people and institutions (Ybarra et al., 2012; Broll \& Huey, 2015). In particular, it is important to consider how Indigenous youth are potentially impacted under the antibullying framework. The next two chapters discuss settler colonialism, education for Indigenous youth and outline the socio-political and intellectual context in which the antibullying framework, and its implementation, must be understood. 


\section{Chapter Three: Settler Colonialism and Its Impact on the Education of Indigenous Students}

\section{Broader Challenges of Equitable Access to Education for Canadian Indigenous Peoples}

Indigenous people in Canada live a unique and devastating experience of systemic oppression which must be understood in order to study the impact on Indigenous students of anti-bullying frameworks and other initiatives for the creation of so-called 'safeschools'. In this chapter, I trace the history of settler colonialism and the impact of education on Indigenous students. There is a discussion of curriculum offered and the hidden discrimination in education policies, which is linked to how educators perceive Indigenous youth in schools. These discussions inform a critical analysis of the Ontario anti-bullying framework, particularly with how it potentially impacts Indigenous youth.

\section{The Importance of Education}

Studies have indicated that obtaining a minimum level of education is closely linked to increased health and wellbeing (Hart, 2010; Kolahdooz et al., 2015; Browne et al., 2016). Individual health has been evaluated based on social factors such as gender, poverty, education and employment (Kolahdooz et al., 2015; Firestone et al., 2015). Being under-educated is associated with increased involvement in high-risk activities such as smoking, alcohol abuse and substance abuse. Residential school or 60s scoop ${ }^{16}$ experiences are also tied to these high-risk activities (TRC, 2015b). Many Indigenous people suffer from psychosocial problems because of their traumatic experiences

\footnotetext{
${ }^{16}$ The 60s scoop refers to the time between 1960-mid1980s where Indigenous children were "apprehended from their homes and communities without knowledge or consent of families or bands" (Sinclair, 2007, p. 66). Approximately $70 \%$ of the children who were removed were adopted into non-Indigenous homes (Sinclair, 2007). This period is due to the rise of Indigenous children in care in Canada; "a descriptor that is now applied to the whole of the [Indigenous] child welfare era, simplistically defined here as roughly the time from the waning of residential schools to the mid-1980s period of child welfare devolution and last closings of Indian residential schools" (p. 67).
} 
(Bombay et al., 2011, 2014); their trauma may be passed on to the next generation of family (Bombay et al., 2011, 2014). These high-risk activities remain prevalent in many Indigenous communities (Adelson, 2005; McCaslin \& Boyer, 2009; Firestone et al., 2015). Indigenous people navigate numerous factors including significant historical trauma compounded by issues associated with living on reserve, ranging from basic needs not being met (housing, potable water), lack of social and/or mental health supports, prevalence of lateral violence; political differences between band and community members, and low education levels (Nokiiwin Tribal Council, n.d.; Hart, 2010; Native Women's Association of Canada, 2011; Curtis et al., 2015; Kolahdooz et al., 2015; Browne et al., 2016).

Although many Indigenous youth grow up with the idea that an education provides great opportunities, this is not always the case. It is important to acknowledge that the education system has been historically a tool of assimilation (Battiste, 2013). In this aspect, there is a colonizing logic of the education system that must be recognized; the colonizing logic of the education system refers to the process by which schools and the curriculum taught, are based on, and penetrated by, ideologies developed during the residential school era (McGregor, 2017). Meyer (2010) also argues that colonization of the education system includes the structure/management of a "capitalist class system and a centralized and unaccountable political bureaucracy" (p. 830). In this research, it is necessary to understand educational development and its potential impacts on Indigenous youth. 


\section{History of Settler Colonialism}

On June 11, 2008, former Prime Minister Stephen Harper apologized on behalf of the Canadian Government for the various abuses Indigenous people suffered (Harper, 2008). The apology was viewed as a distraction (Corntassel \& Holder, 2008; Lightfoot, 2015). Although the apology appeared authentic (Corntassel \& Holder, 2008; Lightfoot, 2015), “the Canadian Government's practices of atonement reveal a strategic management of liability by framing past wrongs in terms of historically delimited, specific injuries rather that acknowledging the systemic and ongoing practices of colonialism" (Wakeham, 2012, p. 3). Since then, the Canadian state has made some efforts to correct past policies by proactively promoting Indigenous ways of being in an attempt to address the disadvantages Indigenous people face. These efforts include: promoting Indigenous culture as a whole, promoting concepts particular to Indigenous values within education, restorative justice programs, direct employment programs, job placement, and welfare to work programs (Hart, 2010; Kolahdooz et al., 2015; Browne et al., 2016). However, despite these measures, Indigenous people are still disadvantaged, discriminated against and not provided with equitable access to education, among other social services. To understand how this is possible, one must understand settler colonialism in Canada.

Understanding Indigenous politics, defined as an intersection of Indigenous history, trauma and culture with Western legality and ideas of homogeneity and civilization (Eudaily, 2004), requires an understanding of the history of Indigenous people and the impact of colonialism. Wolfe (2006) states that settler colonialism benefitted Europeans. Settler colonialism refers to the political and economic venture 
where European nations explored, made conquest, took over, settled in and exploited large areas of the globe (Wolfe, 2006; McPherson \& Rabb, 2011). Specifically, settler colonialism in the Canadian context refers to the European invasion whereby Indigenous people were dehumanized, families were separated, and their land was taken away (Backhouse, 1999; Mawani, 2009; Monchalin, 2016). European policy was imposed in everyday functions (Monchalin, 2016) and settlers attempted to destroy the sacred bond with the Earth held by the Indigenous people. The political take-over and removal of Indigenous peoples from their land precluded any idea of entering into partnerships with Indigenous groups (Wildcat, 2015).

Europeans categorized Indigenous people as savages and non-human in order to exploit their resources and survival skills in North America (Razack, 2015); as Sherene Razack (2015) acknowledges, the settler project that the Canadian state engages in views Indigenous people "as abject bodies always on the brink of death" (p. 59; Proulx, 2014). Canadian governments strategically developed laws and policies to keep Indigenous people trapped in the cycle of government systems that they depend on (i.e. Indian status, welfare). Craig Proulx (2014), Audra Simpson (2014, 2016) and Sherene Razack (2015) argue that settler colonialism is rigidly structured in precise ways to ensure that the settler is viewed positively, and Indigenous peoples are Othered. For example, the Canadian state regulated Indigenous freedoms and movement for decades, including requiring passes for Indigenous persons to leave their reserve and travel within Canada (CIRNAC, 2017).

When settlers gained control over land, "culture was the conceptual and necessarily essentialized space that stood in for complicated bodily and exchange-based 
relationships that enabled and marked colonial situations in Empire" (Simpson, 2007, p. 67). Simpson (2007) further argues that culture invoked a type of politics as it revolves around "governmental and disciplinary possession of bodies and territories" (p. 67). These are the two spaces which are occupied: land and the political sphere. For example, Simpson (2007) utilizes Captain Cook's account of his first interactions with people in what is now Australia. Cook's account refers to terra nullius ${ }^{17}$, informing others that "the Indigenous people of Australia had no form of land tenure because they were uncivilized, which meant the land belonged to no-one and was available for possession" (Simpson, 2007, p. 69), despite the fact that Australian Indigenous people were living on, sharing and using the land with Indigenous people/communities; their understanding of ownership and land use was diametrically opposed to that of Europeans. Cook's account was believed by Europeans, informing theoretical concepts, which then "emboldened the laws of nation-states" (Simpson, 2007, p. 70). Indigenous people and communities were unaware of the concept of individual property and thus were told that they were unable to own land because they had not claimed the land they lived on. Simpson (2007) further states that future claims of Indigenous occupation were disabled as "their voices were imperceptible, or unknowable, or unimportant" (p. 70). This is one example of settler violence which Indigenous peoples endured globally.

Indigenous people endure institutionalized violence as they are systematically disadvantaged from moving forward in Western society. Indigenous experiences "with trauma and violence happen on a consistent basis and are often hidden or ignored within

\footnotetext{
${ }^{17}$ Terra nullius refers to 'unowned land'; "under British colonial law, Aboriginal Australians had no property rights in the land, and colonization accordingly vested ownership of the entire continent in the British government" (Banner, 2005, p. 1). This concept remained in law up to 1992 (Banner, 2005).
} 
public consciousness" (Wildcat, 2015, p. 406). Furthermore, Proulx (2014) argues that non-Indigenous people fear the consequences of standing up to the State, thereby being complicit in "constructing Indigenous people as potential insurgents, terrorists and criminals threatening the security of the Canadian state" (p. 83). Thus, there exists a complicated web of factors, broad formations and systems of oppression that compound Indigenous experiences of violence (Sinclair, 2007; Simpson, 2007, 2011, 2014, 2016; Corntassel et al., 2009; Proulx, 2014; Day, 2015; Wildcat, 2015; Dietrich, 2017). Thus, any experiences of violence faced by Indigenous people is silenced through colonialist efforts made by the government to view Indigenous people in a negative light.

Corntassel et al. (2009) argue that "there is a danger in allowing colonization to be the only story of Indigenous lives" (p. 139). Moreover, settler's power is the narrative and "fundamental reference and assumption [...] imposing a view of the world that is but an outcome of perspective on that power" (Corntassel et al., 2009, p. 139). Simpson (2014) further reiterates that "the story that settler-colonial nation-states tend to tell about themselves is that they are new; they are beneficent; they have successfully 'settled' all issues prior to their beginning" (p. 177).

Canada's official discourse offers a different view than the one told by Indigenous people - "one that glosses over the colonial legacies of removing Indigenous people from their families and homelands when enforcing assimilationist policies, all of which were intended to eradicate Indigenous nations" (Corntassel et al, 2009, p. 138). Canada's settler-nation state operates "on the basis of a European conception of politics, which they then universalize so as to be able to extend authority over Indigenous lands and people and thus establish settler colonial rule" (Dietrich, 2017, p. 70). Yet, the Canadian 
state still implies that it is not a racist country (Sinclair, 2007) because of the acceptance of multiculturalism (Bannerji, 2020) and the advancements the Canadian Government has made to reconcile relationships with Indigenous people. However, the legacy of colonization remains. Sinclair (2007) draws on Young (1969) whose work looks at the socialization of minority groups in the United States of America. Young (1969) articulates that "minority children have more and more particular difficulties in defining a positive identity because minority status carries with it goal restriction" (p. 1103, as cited in Sinclair, 2007, p. 73). The viewpoint of Young (1969) can be correlated to Indigenous people in Canada. Being Indigenous in Canada (i.e. holding 'Indian Status') is believed to carry a lower status (and is seen in the reiteration of stereotypes) (Sinclair, 2007) and inequitable access to education. As referenced in the TRC (2015b) report on Legacy, "access to post-secondary education is not an option for the majority of Inuit young people or for First Nations youth living on reserve" (p. 69). Those First Nation youth who are able to attend school and who have parents who survived time in residential schools, most likely suffer from learning problems (TRC, 2015b). These problems are then blamed on the Indigenous student rather than having consideration for the systemic problems Indigenous youth endure as a result of colonization, residential schools or the 60s scoop era. As a result, Indigenous rhythms of life are stereotyped as unworthy of knowing by everyday Canadians (Dion, 2004, 2007) and political systems that nonIndigenous and Indigenous people move through operate according to the idea that the mainstream, Western systems are "preferable, more developed, sophisticated and civilized" [emphasis, my own] (Dietrich, 2017, p. 70). 
The political systems which have thus been created are based on European systems that disregard Indigenous customs, laws and knowledges. Laws, culture and social relations are all based on European systems. Scholars acknowledge the intricate nature of laws, culture and social relations and how "life itself is subject to politics, ready to be seized by power and to be controlled and managed so as to either be fostered or to be abandoned to death" (Dietrich, 2017, p. 69; Simpson, 2007, 2011, 2014, 2016; Rifkin, 2009; Day, 2015; Razack, 2015; Corntassel et al., 2009).

\section{The Impact of the Reserve System}

Indigenous people have not been given the same opportunities as non-Indigenous people. Their geographic space on reserves necessarily hinders their quality of life. This space is part of the social control imposed by the Canadian government; it is set-up to inhibit thriving on reserve. Razack (2002) states "space emerges out of spatial practices, the everyday routines and experiences that install specific social spaces" (p. 77). An example of the space one occupies includes, "the rhythm of daily life [...] how people know themselves in it, as well as how they are known in it, and what the space accomplishes in relation to other spaces" (p. 77). Further, the space one occupies creates meaning and maintains social order. Thus, the space Indigenous people occupy on reserves further perpetuates the idea that Indigenous people do not want to live in urban centres. However, this is not necessarily true. Rather, the placement of Indigenous people on reserve was a political and economic strategy by the Canadian government to keep them away from urban centres.

Unfortunately, many people who live on reserves in northern Ontario (and Canada, more broadly) do not live in good, or even acceptable conditions. Many reserves 
do not have adequate housing, resources (such as groceries or fuel), or even drinking water. For instance, "two-thirds of all First Nation[/Indigenous] communities in Canada have been under at least one drinking water advisory in the last decade" (Levasseur \& Marcoux, 2015, para. 1). The conditions on reserves have been referred to as "Third World", often compared to those in extremely poor countries, and stand in stark contrast to the majority of Canadians, especially those who live in urban centres, who enjoy a higher quality of life. This society benefits from clean water, adequate food and housing (Levasseur \& Marcoux, 2015).

It is well-known that living in poverty is positively correlated with poor outcomes for children. The longer a child lives in poverty, the harder it becomes to remove themselves from the pitfalls associated with poverty (McCaslin \& Boyer, 2009; LaPrairie, 2002). Many Indigenous people struggle not only with how poverty affects their daily lives, but also with finding hope and purpose within a system that has historically oppressed them (Battiste, 2013; Brownlee et al., 2014; Cherubini et al., 2010; Friedland \& Napoleon, 2015).

Economic infrastructure is almost non-existent on reserves, especially reserves in the far north. Isolation in the far north means food, water, and supplies must be flown in. This increases expenses, which are passed onto the Indigenous people, who are mostly dependent on government assistance systems, such as welfare, for survival (Adelson, 2005). The high costs of living deplete any finances and make moving off-reserve, either to an urban centre or rural community, more difficult (Adelson, 2005; McCaslin \& Boyer, 2009). When the cost of living on reserve is so high, Indigenous people cannot afford to save funds to leave their home communities. 
Funding for schools on reserve is extremely low or unavailable (Bombay et al., $2011,2014)$. This lack of funding results in a system of inadequate education and a selfperpetuating cycle of diminishing resources due to the difficulty in attracting and maintaining provincially qualified teachers. Service providers, such as teachers, are less likely to work in the challenging conditions found on reserves, especially isolated ones. This in turn provides the government an additional reason to not provide funds to remote northern reserves for education.

In many cases, the small student population is the reason given to explain that it is not feasible to build a high school in each reserve (Wilson, 2007). Indigenous children from remote reserves in northern Ontario are thus pushed out of their communities to attend secondary school elsewhere. Since many Indigenous students wanting secondary education are forced to move off-reserve to attend provincially-funded high schools or federally-funded Indigenous-only high schools, Indigenous students are funneled into an environment where they are more likely to face discrimination, harassment, violence and racism for a variety of reasons (Barrera, 2019).

Although not in northern Ontario, Barrera (2019) reported on 'the bullying problem' that impacts Six Nations School, thirty kilometres outside of Hamilton, Ontario. The school is federally-run by Indigenous Services Canada. Older boys in the school tormented younger boys — as young as children in junior kindergarten (Barrera, 2019). A boy named Kingston shared his story stating that he was kicked in the stomach, pushed, and called names, to give examples of some of the negative behaviours he faced (Barrera, 2019). His mother reported that the school administration and the federal bureaucrat who oversees the school failed to deal with the bullying problem in the school 
(Barrera, 2019). Instead of acknowledging the existence of bullying in the school, "teachers would punish Kingston for retaliating against his tormentors" (Barrera, 2019, para. 27). The administrators of the school did not consider the negative behaviours as problematic - either under the label bullying, as a form of lateral violence, or as harassment. The issues were labelled as conflict between students (Barrera, 2019). The federal government was pursued to apply the Ontario anti-bullying framework to the behaviour, but it is unclear if policies were followed. Rather, a complaint was made to the Canadian Human Rights Commission (result is yet unknown) (Barrera, 2019).

The education received on-reserve may be below provincial standards due to the lack of resources in the schools, including the difficulties of attracting accredited teachers (as mentioned earlier). This means that an Indigenous youth who moves to an urban centre for high school may not have the same academic or urban life skills as other students in the same grade (Eden, 2016). As such, if the high school an Indigenous youth attends does not offer additional resources or extra-curricular skill building, or the service provider (person/organization delivering the service) is not compassionately understanding of the holistic nature of the student and their individual struggles, the provider may be unable to assist the incoming youth with feeling welcomed into and able to fully participate in their new, but temporary, education community. The incoming youth may disengage from their program as a method of coping in an unsupportive environment. The fact that many Indigenous youth are behind in specific skills required for success in high school, such as reading, writing or mathematics (Eden, 2016), can be linked to the legacy of settler colonialism and the legacy of residential schools. 


\section{The Impact of Residential Schools}

The relationship between the State and Indigenous peoples since the imposition of a Westernized education system is a legacy from colonial take-over and the residential school system. Residential schools were one of the ways the Canadian state colonized Indigenous people (Nagy \& Sehdev, 2012). ${ }^{18}$ The first residential school opened in 1828 (Mohawk Institute Residential School in Brantford, ON). Its operation was taken over by the Canadian federal government in the 1880s. By 1931, there were a total of 80 residential schools operating across Canada (Canadian Geographic, 2019), with the last school closing in 1996 (The Gordon Residential School, Punnichy, Saskatchewan) (Nagy \& Sehdev, 2012; Canadian Geographic, 2019). During this time, residential schools registered more than 150,000 Indigenous children for the purpose of "killing the Indian in the child" as stated by Colonel Henry Pratt (CISDRC, n.d.). These residential schools were run by the Federal Government of Canada, often in conjunction with the Catholic, Anglican, Presbyterian and United Churches (Nagy \& Sehdev, 2012).

Most of the children who attended residential schools were forced from their families at a young age for the purported purpose of receiving a good education. However, these children experienced further subjugation, were provided "with an inferior education, often only up to grade five, that focused on training students for manual labour in agriculture, light industry such as woodworking, and domestic work such as laundry work and sewing" (UBC, 2009, para. 1; Nagy \& Sehdev, 2012; Chartrand et al., 2006; Eshet, 2016). Students attending these residential schools were neglected and most

\footnotetext{
18 Other ways the Canadian government colonized Indigenous peoples including segregating lands, implementing the reserve system, laws and policies that purposefully discriminate against Indigenous people and mandating education (Backhouse, 1999; Mawani, 2009; Monchalin, 2016).
} 
experienced disease, malnutrition, and lived in areas with poor ventilation and heating. Unfortunately, some children died as a result of their treatment in the schools, although the true number of deaths is unknown (Nagy \& Sehdev, 2012; Chartrand et al., 2006; Eshet, 2016).

Many children also experienced physical, sexual and emotional abuse from those who were responsible for their care and administrated the schools (Nagy \& Sehdev, 2012; Chartrand et al., 2006; Eshet, 2016). Although the practices and methods implemented to educate, and subsequently abuse, were not necessarily mandated by the Canadian federal government, there was enough knowledge of what was occurring within the schools to say the government's explicit purpose was to wipe out Indigenous culture, described as a “genocidal policy" (TRC, 2015b, p.6). Former Assembly of First Nations leader Phil Fontaine brought the horrific treatment of students in residential schools to light in the 1990s when he shared traumatizing experiences he faced in residential schools (Frum, 1990) on CBC's The Journal. He stated, "in my grade three class [...] if there were 20 boys, every single one of them [...] would have experienced what I experienced [...] some aspect of sexual abuse" (Frum, 1990, para. 1). Since Fontaine shared his story publicly, thousands of people have done the same. Sharing their experiences led to the creation of the TRC (as discussed earlier in chapter one) (TRC, 2015a).

Children whose parents were part of the residential schools and the 60s scoop are required to function without consideration for their unique histories (Milne, 2015). There is a connection between residential schools and educational/economic attainment (TRC, 2015b); "residential school survivors have less income than other Aboriginal people, and that their children have more difficulty in school" (TRC, 2015b, p. 70). Bombay et al. 
(2011) found that parental attendance in residential school "affected the quality of parenting received as children" (p. 369; Bombay et al., 2014). Also, children of residential school survivors show elevated depressive symptoms (Bombay et al., 2011, 2014). Milne (2015) states that youth "have to contend with the intergenerational effects of racial discrimination in schooling" (p. 271). Educators have expectations of parents without thinking about larger issues that may impact relationships; "legacies of racial discrimination against Indigenous Canadians in schooling have led to intergenerational mistrust of the school system" (Milne, 2016, p. 274). The gaps caused by residential schools remain because even though residential schools no longer exist, their legacies of distrust and tension are real, "creating barriers for Indigenous parents to establish quality connections with schools, affecting their ability to comply with educator expectations of active involvement and positive attitudes toward school/educators" (Milne, 2016, p. 275). Milne's (2016) study is relative to this project as one of the participants asked, 'how do we [teachers] expect them [Indigenous parents] to come into the classroom and have a positive experience with their child if they themselves have not had a positive experience?" (p. 276). Some Ontario school boards are trying to bridge this gap in trust by hiring Indigenous liaison workers, whose positions focus on supporting Indigenous families and students (Milne, 2016).

\section{The Impact of Streaming}

Indigenous students are also negatively impacted by more modern forms of racial discrimination, including disproportionate streaming towards workplace level courses. Indigenous youth attending high school are required to choose courses corresponding to their educational level and interests. There are three educational streams that shape which 
courses are offered: university, college or workplace (OME, 2018d). University-level courses are for those students who intend to attend university; college-level courses are for those interested in attending college; and workplace-level courses (also known as essential courses) are for those students intending on entering the workforce postgraduation (OME, 2018d). Kinnon (2016) reiterates, "the way we educate has a dramatic impact on how and what [students] learn on their academic abilities and achievements, and also on their post-high school futures" (p. 18).

Kinnon's (2016) study of inequity and academic streaming in Ontario found that "teachers can have lower expectations for students in the applied stream" (p. 82). In 2017, similar findings were published regarding Black students in Toronto (Draaisma, 2017); “a large number of black students are being streamed into applied instead of academic programs and they are suspended at much higher rates than their counterparts" (para. 1). Although this report focusses on Black students, Indigenous students are in a similar situation (OHRC, 2003). When students are targeted specifically because their teacher or fellow classmates view them negatively, it can contribute to "these students having reduced self-confidence, and correspondingly, lower academic performance" (Kinnon, 2016, pp. 82-83). Workplace or “essential/applied" stream cohorts are more likely to have "negative long-term consequences, including both lowered self-esteem and aspirations of students and lowered teacher expectations for them" (p. 189). This can become a self-fulfilling prophecy; if a student is constantly told they are [insert negativity here], they might start to believe what they are being told and thus behave in a negative way. 
Hallinan (1994) points out that instruction quality increases with the stream level; academic course curricula use critical thinking and engage students whereas applied course curricula omit the obligation to foster critical thinking (Kinnon, 2016). This finding suggests that students in applied or essential streams are "not expected to be as engaged with the material and may not be learning critical thinking skills" (Kinnon, 2016, p. 25). In a study completed by Boaler (2005), one participant called this categorization of students based on academic streams "a psychological prison", this psychological prison [...] people don't know what they can do, or where the boundaries are, unless they're told $[\ldots]$ it kind of just breaks all their ambition $[\ldots]$ particularly schools [...] where it's predominantly working-class kids whose parents don't necessarily have the ambition for them. And then if it's being reinforced in the classroom with the kind of 'yes, you're going to be a labourer for the whole of your life' then it means that they can't break out of that box. It's quite sad. (Boaler, 2005, p. 141)

Some Indigenous youth do not have family readily available and able to meet with the school to advocate on their behalf. As noted above, some Indigenous families struggle to enter schools given the historical trauma some families have faced (and still face) (Milne, 2016).

\section{The Impact of Curriculum}

It is important to confront a prevalent myth about Indigenous youth and education, that being: Indigenous youth do not want to obtain an education (Shankar et al., 2013). It is not that Indigenous youth do not want to participate in education, it is that the education they are expected to engage with often disregards Indigenous cultural views 
(Battiste, 2013; Shankar et al., 2013). Curriculum is based in the settler colonial logic of

the education system; settler colonialism's "project of replacement" (Tuck \&

Gaztambide-Fernández, 2013, p. 79; Dion, 2004, 2007; McGregor, 2017), whereby

Indigenous worldviews are replaced and erased over time by colonial educators

(Templeton \& Cheruvu, 2020). The curriculum Indigenous youth are taught "is written

largely from the perspectives and lived experiences of the White middle-class"

(Templeton \& Cheruvu, 2020, p. 134). Thus, Indigenous perspectives are missing

(Battiste, 2013). For example, two Indigenous views of learning, understanding and

maintaining positive wellbeing include Mino-Bimaadiziwin ${ }^{19}$ and

G'minoomaadozimin ${ }^{20}$, are generally not included in education curricula. These

perspectives could be integrated into education curricula for the benefit of all, not just

Indigenous people.

\footnotetext{
${ }^{19}$ Mino-Bimaadiziwin is the Anishinaabe concept that means to live the good life. According to this concept, the education of Indigenous people must be designed to teach all to thrive in today's world with the attitudes, skills, knowledge and intention to be to be Indigenous, rooted in relationship to the total environment (Seven Generations Education Institute, 2015). George Couchie, a retired Ontario Provincial Police Officer, is one of the founders of the Mino-Bimaadiziwin Training Camp. It is hosted annually by the Lakehead District School Board for Indigenous youth to learn about their history. Students are taught through the blanket exercise; students stand on blankets that represent the lands inhabited by indigenous people that eventually became Canada. The blankets "tell the story of how the land mass of North America was populated by Indigenous people, and then slowly, because of population crashes and them being forced onto reserves, you can see how much land was lost because of settler encroachment" (Rice, 2016, para. 3). Mr. Couchie stated that it helps Indigenous youth prepare for school, "I know a lot of times the teachers will [...] when it's a question about First Nations, they always ask the Native kids in the class and when I was going to school, I knew nothing about it and I was kind of embarrassed about it, so here we are talking about the strength of our community, our families, and why it is so important for Indigenous youth to be proud of who they are" (Fiddler, 2016, Video File 00:53-1:13). In the training camp, they learn about healthy relationships and the importance of drumming (Fiddler, 2016). The concept of Mino-Bimaadiziwin guides and helps engage Indigenous youth with their traditional teachings and connecting these teachings into their everyday life.

${ }^{20}$ G'minoomaadozimin is the First Nations concept explained by Nokiiwin Tribal Council in Thunder Bay, Ontario, that means 'we are living well'. This concept reflects the idea of safety but aims at enhancing health and safety beyond the workplace; "not just in the workplace [...] it originates from self, so we have to look at self, family, the home, our community. If we are well in those areas, then it will go into our workplace" (Garrick, 2017, para. 2). G'minoomaadozimin is about shifting attitudes and behaviours within Nokiiwin communities and beyond (Nokiiwin Tribal Council, 2019).
} 
For Indigenous people, it is important to feel spiritually, emotionally and mentally connected to their Indigenous identity (Firestone et al., 2015). When an Indigenous youth is disconnected from their Indigenous identity, their overall wellbeing is at risk (Curtis et al., 2015). Wilson (2007) acknowledges that Indigenous youth may not want to attend school with teachers who do not value or understand Indigenous traditions. Specific educational context is therefore critical when creating, adapting and implementing policies and curricula which provide Indigenous youth equitable opportunity to obtain an education. Although the Canadian education system is moving towards increasing acceptance of Indigenous culture in their schools (OME, 2019b), the question remains of whether or not Indigenous youth will be provided with equitable access to education and culturally relevant content.

\section{The Impact of Discriminatory Policies and Practices}

In July 2003, the Ontario Human Rights Commission published a report titled, “The Ontario Safe Schools Act: School Discipline and Discrimination” (OHRC, 2003). The purpose of the report was to determine if 'zero tolerance' policies had a "disproportionate impact on racial minority students and students with disabilities" (OHRC, 2003, para. 1). This report found there is a strong perception in the Greater Toronto Area, backed up with some informal evidence, that implementation of the policies is not equal for all students. An interviewee in the report noted that "students atrisk are being disproportionately impacted and it is necessary to address all the factors not only racism - that put children at risk" (OHRC, 2003, p. 27). The interviewee, a senior official at a school board in the Greater Toronto Area, summed up the multiple factors and their overlap well. They stated, 
kids who don't come to school regularly are not successful in school. If you are not successful in school, you don't feel as good about yourself. If you don't feel as good about yourself, you tend to act out. If you tend to act out, your behaviour is not acceptable, and on it goes. We know certain things. We have the information about who lives in areas with different socio-economic groupings. We know that kids who come from two-parent families generally do better in school than kids who come from one-parent families. We know that boys don't do as well on provincial tests in reading and math. We also know that boys learn differently from girls. We also know that far more boys get suspended than girls [...] Do I have a concern about the number of black boys in difficulties? Yes, I do. But I am also equally concerned about other students who are from other groups that find themselves in difficulty $[\ldots]$ There are a multitude of factors that can come into play in many issues when you have kids at-risk. I think that [racism] is one of the factors, but it is not the only factor. (as quoted in OHRC, 2003, p. 28)

There are many intersecting factors that need to be considered when educating Indigenous youth. Overlooking these factors puts Indigenous youth at a higher risk for being victims of serious behaviour that may be simply defined as bullying.

Indigenous families in particular have unique and fragile circumstances that many educators overlook (Wilson, 2007). There are many cultural reasons why Indigenous youth may not be present in school that also need to be considered. These cultural reasons for their absence could include: (1) not wanting to participate in a Western education system that has already harmed their population (i.e. residential schools, 60s scoop era); (2) not wanting to take risks of physical harm and encountering racism by leaving their 
family and community; and (3) not wanting to lose their cultural identity and therefore the opportunity cost might be too high. In sum, Indigenous youth then have lesser options for success.

It is unspoken "that racism is a pervasive and consistent element in the schooling experiences of Indigenous youth" (Castagno \& Brayboy, 2008, p. 950). Students experience racism in a number of ways and from a variety of sources (Castagno \& Brayboy, 2008). A common form of racial oppression against Indigenous youth in schools is the use of euphemisms (Castagno \& Brayboy, 2008); "issues of concern are presented in ways that do not make the majority or dominant social group uncomfortable" (Castagno \& Brayboy, 2008, p. 950). As Grant and Gillespie (1993) note, in the case of schooling, the problem would be the lack of success of [Indigenous] students in the present school system. [Indigenous] students are portrayed as having too many problems, thereby freeing educators from acknowledging that they and the system are the real problem. (p. 20)

Euphemisms are part of a larger culture of whiteness in most Canadian schools; "this whiteness is manifest in the predominantly White educational faculty, the social relations, the norms and expectations, and the inequitable access to resources and quality education within our school system" (Castagno \& Brayboy, 2008, p. 950). According to Kany’s work on euphemism, they are used "to disguise an unpleasant truth, veil an offense, or palliate indecency" (Kany in Gómez, 2009, p. 272). Using this idea, government policies were strategically developed to 'disguise the unpleasant truth' that Indigenous populations suffered from at the hands of the Canadian State; Indigenous populations were targeted by the Canadian state for genocide (TRC, 2015b). 


\section{A Critical Framework for Understanding the Potential Impacts of Colonialism on the Ontario Anti-Bullying Framework}

There is a need to be aware of the systemic sources of discrimination that are rooted in settler colonialism within the education system; the history of residential schools impacts the future generations of Indigenous youth and their education attainment. The Ontario Ministry of Education, their school boards, administration, and education staff, in addition to the children who attend the schools, and their parents/guardians, need to be aware of the danger of general policies for safety. This is important because the policies that are created by the school boards require anyone who interacts with the school to be aware of them. There is also a need to know how policies may disproportionately negatively impact Indigenous students. There is the danger of euphemism and other strategies that elide the impact of certain policies and actions on Indigenous people.

The amendments to the Education Act have the potential to impact Indigenous students in a way that further subjugates them both as perceived victims and perceived perpetrators of 'bullying'. The current Eurocentric education system in Ontario appears to provide surface-level protection for students, but it is unclear if it protects Indigenous people from the unique experiences of negative behaviour labelled as bullying and racism that they may face as a result of their social location. On the other end of the spectrum, Indigenous youth may be labelled as 'bullies' for defending themselves against racist behaviour from others, whether the negative behaviour is from fellow students, teachers, parents or any other personnel involved with the school system. In addition, Indigenous youth may be acting out unacknowledged systemic violence. 
The presence of racism may mean that Indigenous children are simultaneously more likely to be victims of behaviour recognized as bullying. For example, in Thunder Bay, Ontario, there are many Indigenous youth who fear they will be injured simply because they are Indigenous; students who attend Dennis Franklin Cromarty High School carry whistles in the event they are targeted by the outside community (McNeilly, 2018). There is a generalized problem with racism against Indigenous peoples in Thunder Bay (and in northern Ontario) (Prokopchuk, 2018), and youth may be disproportionately targeted. Rather than eradicate or minimize these systems of oppression, the Ontario Education Act may further marginalize Indigenous peoples.

\section{Criminalization of Indigenous Youth and Education}

The danger to Indigenous youth is amplified where incidents of negative behaviour labelled as bullying are escalated to involve police. This contributes to the ongoing problems of failure of Indigenous students to complete an education and instead becoming diverted to the school-to-prison pipeline. ${ }^{21}$ The school-to-prison pipeline refers to the impact that the education system and criminal system have on at-risk youth; "failing to provide education and mental health services for [the] most at-risk students drastically increases the likelihood that those children will end up with a criminal record rather than a high school diploma" (Kim et al., 2010, p.4; Raible \& Irizarry, 2010; Meiners \& Winn, 2010).

Scholars have argued that Indigenous people are over-criminalized (Cunneen, 2007, 2008; LaPrairie, 2002). "School criminalization teaches students not only that they

\footnotetext{
${ }^{21}$ Although this topic is not the focus of my research, there are real negative impacts on Indigenous youth which must be considered when navigating behaviours potentially targeted at them - criminalization is a possibility.
} 
have little recourse should the government violate their rights, but that they have few rights to begin with" (Hirschfield \& Celinska, 2011, p. 8). School criminalization also maintains a hierarchal structure between social and political order but may not effectively change student behaviour. Rather, it has the potential to reinforce instead, the detrimental effects police officers and other law enforcement agencies have on schools' social climates (Hirschfield \& Celinksa, 2011).

Under the provincial and local codes of conduct, law enforcement agencies have the authority to attend schools with the intent to educate students about how certain types of behaviour may have lasting criminal consequences. In 2008, Hirschfield stated that there was "increased collaboration between schools and the juvenile justice system, which eroded the traditional boundaries between the two institutions" (p. 83). This statement applies in 2021 as there continue to be overlapping boundaries between school safety and public safety, with the added possibility of intervention of law enforcement in the classroom. Overlapping boundaries weaken disciplinary action within the school as they allow other law enforcement the room to provide more stringent disciplinary mechanisms instead, with potentially longer-lasting effects (i.e. the potential to obtain a criminal record).

Information sharing between education and justice agencies allows schools to discipline students for 'outside legal entanglements', regardless of jurisdiction (Hirschfield, 2008). For example, in 2011, the Ontario Ministry of Education partnered with the Ministry of Community Safety and Correctional Services to create the Provincial Model for a Local Police/School Board Protocol. ${ }^{22}$ This protocol outlines the importance

22 The Protocol was last updated in 2015. 
of an effective partnership in promoting a safe and inclusive school environment, as well as promoting a positive school climate (OME, 2015). Section 8 of this protocol lists the occurrences requiring mandatory police notification. For example, at a minimum, police must be notified of deaths, physical assault causing bodily harm requiring treatment; sexual assault; robbery; criminal harassment; relationship-based violence; possessing weapons, including firearms; using weapons to cause or threaten personal harm; trafficking weapons or illegal drugs; possession of illegal drugs; hate/bias-motivated occurrences; gang-related occurrences; extortion; non-consensual sharing of intimate images; and bomb threats (OME, 2015). Section 8 also lists the issues where notifying police is discretionary, such as providing alcohol to minors; being under the influence of alcohol or illegal drugs; threats causing physical injury, including through social media, text messages, and e-mail; vandalism; and trespassing (OME, 2015). In the list provided, the term bullying does not occur, but there are examples of criminal behaviour which match the definition of bullying listed in the Education Act.

The amendments to the Education Act introduced by the Accepting Schools Act, 2012, in conjunction with the Safe Schools Act, 2000, allow school principals and teachers to determine how undesired behaviour will be labelled. These legislative changes provide principals and educators with a high amount of discretionary power over their students. The increased collaboration in these institutions allows surveillance of students through "performance monitoring and accountability; [...] education reforms like the [Accepting Schools Act], analogous to the criminal law itself, places the onus of responsibility for school crime $[\ldots]$ on the underperforming students, teachers and schools" (Hirschfield, 2008, p. 87). If teachers interpreting experiences of negative 
behaviour are racist, classist, or sexist, their biases can lead to Indigenous students being labelled as bullies and trouble-makers.

Further, students and teachers are not the only ones to bear the brunt of the 'crime control paradigm'; "security guards, police, and judges [are also] subjective actors prone to accept [and potentially over-use their power], but [also] capable of resisting, the imperatives of criminalization [thus,] the importation of criminal justice into schools involves a process of mutual accommodation" (Hirschfield, 2008, p. 94). There are intersecting institutions that are willing to intervene in schools. Law enforcement agencies may or may not recognize the potential that bullying hides intersecting issues, such as racism and violence. This is problematic in itself. When instances of racism occur, regardless of whether it is inside or outside of school, legal institutions may disregard the initial act and punish the student for defending him or herself. Hiding other issues under the bullying rhetoric implemented in Ontario's Education Act may mean that already marginalized individuals are falsely labelled as 'troubled individuals' and that label then easily leads to criminalization. When acknowledging Indigenous politics, combined with an Indigenous youth's unique experiences, it is clear that Indigenous youth have significant hurdles to overcome in society while trying to live their best possible lives without fear of criminalization. Indigenous youth are thus forced to balance their cultural identity, educational growth and personal wellbeing in a social context that disregards their existence.

\section{Conclusion}

In this chapter, I provided a review of some aspects of the history of colonial exploitation of Indigenous people in Canada. I then discussed areas of the education 
system that discriminate against Indigenous youth obtaining an education, including the ways the curriculum is written by policy makers at the provincial level and implemented by educators. Students are separated and segregated according to the stream educators believe they are qualified for. Lastly, I provided a critical discussion of the Ontario antibullying framework and how the policy may impact Indigenous youth. It is imperative to acknowledge that Indigenous youth, because they are devalued, are likely to be targets of racism, violence and harassment, which could be described as bullying behaviour; for the same reasons they are equally likely to be labelled as the bully. The following chapter includes a review of the academic bullying literature and a discussion of the theoretical framework I have derived from elements of this literature, which interrogates bullying as a label that may obfuscate racism, violence and harassment. 


\section{Chapter Four: A Review of the Bullying Literature and Theoretical Framework of Bullying as a Label that Obfuscates Racism, Violence and Harassment}

In this literature review, the bullying phenomenon is defined and critiqued in the context of the history and implementation of Dan Olweus' work on anti-bullying initiatives. Themes presented in the literature are identified and analyzed, such as aggression, psychological influences, educational environments, gendered behaviour, socioeconomic and cultural factors, and 2SLGBTQIA perspectives. There is also a discussion on educational influences and policy responses to bullying. An examination of this literature illustrates the interrelated nature of social and cultural influences that impact behaviour that is characterized as 'bullying' and the way in which application of the term 'bullying' can mask harassment, violence and racism.

In this chapter, I argue that bullying is not a real phenomenon that can be cured with treatment, but rather that the 'bullying' phenomenon is multi-faceted and socially constructed in a context of racism, classism, gender, violence and harassment. Recognizing that 'bullying' is socially constructed allows us to identify the ways in which ongoing colonialism within the education system may affect the impact on Indigenous students of responses to behaviour labelled as bullying.

\section{Origins of Bullying as a Phenomenon}

The 'bullying' phenomenon was first recognized in the $19^{\text {th }}$ Century in written literature (Koo, 2007). Stories were written that presented patterns of interpersonal violence which were considered a form of bullying by academic scholars (Koo, 2007; Lee et al., 2011, 2012). Bullying research began in earnest in the 1970s and was named by European scholars Peter-Paul Heinemann and Dan Olweus. In 1972, Heinemann, a 
Swedish scholar, referred to 'mobbning' which is the Swedish word for group violence against an individual (Pikas, 1989; Canty et al., 2016; Schott, 2014; Boulton \& Smith, 1994). Mobbning is used by Heinemann to reflect 'mob' meaning a 'loosely organized group' (Schott, 2014). Many scholars from the 1970s onwards and in contemporary society have accepted Heinemann's term mobbning without questioning the translation and the cultural reference/meaning from the Swedish language into English usage.

Olweus' work was also written in Swedish. In 1973, Olweus shifted the meaning of mobbning to reflect individuals, as well as groups, by adopting the English term 'bully' when his work was translated from Swedish to English (Olweus, 1994, 2013; Schott, 2014). Olweus' view is that "a student is being bullied or victimized when he or she is exposed, repeatedly and over time, to negative actions on the part of one or more other students" (1994, p. 1173). Additionally, Olweus (1994) defines bullying as intentional and harmful behaviour recognized as peer abuse. Olweus's view distinguishes bullying from other forms of abuse because the context and relationships with peers involved are considered (Olweus, 1994). Peer abuse involves a power imbalance where the abuser holds power over the others; however, the abuse might not be recognizable because the relationship is defined as friendship (Olweus, 1994).

Pikas (1989) acknowledges Heinemann's work on bullying and its shift to Olweus, however, he does not agree with Olweus' work that 'mobbning'/bullying should be used to describe individual acts. Pikas (1989) challenges Olweus because Olweus "labelled his investigation with the word mobbning without differentiating between the violence exerted by a single bully and that exerted by a group" (p. 96). In this view, Pikas (1989) acknowledges that bullying encompasses violence. Rather than name violent 
behaviours as violence, however, Pikas (1989) continues to label particular forms of violence as bullying. In this way, he fails to recognize 'bullying' incidents as violence created as a result of (or part of) racism, classism and sexism.

In response to the publication of Olweus' work, scholars began writing to dispel popular myths regarding bullying behaviours that Olweus reiterated in his academic work (Ringrose \& Renold, 2010; Sweet \& DesRoches, 2007; Walton, 2005a, 2005b, 2005c, 2011; Winton \& Tuters, 2015). Myths about bullying that were challenged include: bullying means the same thing to everyone, despite social and cultural differences (Lee et al., 2011, 2012) and that bullying is a life stage people go through in adolescence (Olweus, 1994; Boulton \& Smith, 1994; Olweus \& Limber, 2010). Expanding beyond Olweus' main focus on aggression and negative behaviour, some scholars attempt to discuss bullying behaviour as a psychological issue to be treated in conjunction with intersecting socio-cultural implications that manifest within interpersonal relationships (Kolbert et al., 2013). Other scholars view aspects of bullying that go beyond psychological assumptions, such as the social environment in which a person lives (Baker, 1998; Winton \& Tuters, 2015), while challenging the normative assumptions of sex and gender (Sweet \& DesRoches, 2007; Ringrose \& Renold, 2010). In the sections that follow, this chapter will consider these themes within the bullying literature and consider how the literature accepts bullying as its own primordial phenomenon, while also reflecting on the way in which bullying is socially constructed. The use of the term bullying may serve to mask the threshold between a behaviour already recognized as bullying and where it becomes viewed as a broader societal problem because it allows 
serious problems such as shaming, exclusion, gossiping, harassment, racism, classism and sexism to be minimized and labelled as bullying behaviour by isolated individuals.

\section{Bullying as Aggressive Behaviour}

Much of Olweus' anti-bullying work has been accepted and added onto since the 1970s. Olweus and many other scholars point to the notion that bullying is real, with identifiable causes and cures. Olweus' main assertion was that bullying is an issue of aggression and an imbalance of power in interpersonal relationships that is outgrown in adulthood, rather than an issue of situational and socio-cultural dimensions (Olweus, 1994; Boulton \& Smith, 1994; Olweus \& Limber, 2010). Others argue that bullying is done by "a top dog who exerts oppressive, mostly physically violent behaviour on one or more persons" (Pikas, 1989, p. 95; Farrington, 1993) disregarding social and/or cultural influences. There are two forms of aggression recognized: instrumental aggression and reactive aggression. Instrumental aggression is "goal-oriented in which harm to another can be a secondary result" (Abrams, 2010, para. 8). Reactive aggression is behaviour where the primary goal is to do harm to someone (Abrams, 2010).

There is a connection between instrumental and reactive aggression, and the bullying phenomenon. The bullying behaviour displayed may not have intent to harm but may be harmful and would thereby fall into the instrumental aggression category. Olweus (1994) argues that individuals can be aggressive to their friends which creates difficulty managing their friendships. This is relative to the temporary power struggle displayed in friendships discussed by Cornell and Limber (2015) and the iteration of power in friendships defined as peer abuse (discussed below). Pikas (1989) also states, 
"members of a mobbing group [..] are caught up with the idea of tormenting a victim" (p.96) and is a clear example of reactive aggression.

Olweus' (1994) work focused mainly on boys' aggression in school, furthering the idea that the concept of bullying is perceptible by others as something that happens, rather than acknowledging what the actions recognized as bullying represent. He argues that youths, specifically boys, enjoy violence; they are impulsive and like to dominate others. These results were found in instances where stress hormones (adrenaline and noradrenaline) were used on participants to determine if they showed aggression towards others around them. He further states that "if they [the bullies] are boys, they are likely to be physically stronger than boys in general and the victims in particular" (p. 1180). Scholars argue that male aggression is easier to recognize because they most often use physical means of violence (Olweus, 1994; Olweus \& Limber, 2010; Juvonen et al., 2013). The differences noted between boys/men who are bullies and boys/men 'in general' is not logical. In this instance, there is a hierarchy among men - men who are perceived as not masculine, masculine or hyper-masculine (McGinley, 2008). Olweus (1994) refers to men as bullies who show aggression — in this hierarchy, it would be men considered as hyper-masculine. Those men who are not aggressive or appear masculine 'in general' are then flipped to represent the spectrum of feminine traits, what is then socially constructed as the second sex (referring to women) (McGinley, 2008).

Aggression carried out by girls is harder to recognize because they most often use indirect methods to bully peers (i.e. emotional violence — girls use their popularity to encourage others not to be friends with a victim) (Olweus, 1994; Olweus \& Limber, 2010; Juvonen et al., 2013). Girls who are perceived as aggressive or 'mean' may have 
other issues going on of which peers/teachers/parents may not be aware. Thus, when a girl causes harm to a peer, their personal problems, cultural or social interactions may not be considered, but they may be labelled as a bully, either by their peers or by their teachers, which may follow them into young adolescence (Veenstra et al., 2014). Young women have multiple intersecting layers that need to be addressed, such as adolescence and cultural expectations, while also growing and adapting to a male-dominated society. However, these layers may be ignored when the label bully is readily available and easily understood in society, rather than gaining perspective on what is occurring in young women's lives. When women display instances of aggression, they are targeted and labelled as a 'bitch' or other derogatory slang, whereas, when men portray aggression, their masculinity is championed (Eriksen \& Lyng, 2018).

The review of the literature shows that there are positive social rewards towards men who are aggressive, acting out negative behaviour that is recognized as bullying. However, women who show the same types of behaviour are labelled as mean or called derogatory statements. The social expectations for men and women as it revolves around aggressive behaviour and what is classified as bullying behaviour are very different and have the potential to mask larger social problems, such as racism, violence and harassment (for example, it may be acceptable for an aggressive male to display these behaviours and earn praise from peers, however, the same cannot be said for women who instead are labelled 'mean girl' or 'bitch').

Elinoff et al., (2004) speak to Olweus' (1994) work, albeit 10 years later. Elinoff et al., (2004) acknowledge Olweus' bullying definition that includes aggression occurring over time and involving an imbalance of power; however, they go one step further and 
argue that "bullying is a form of aggression that is hostile and proactive, and involves both direct and indirect behaviours that are repeatedly targeted at an individual or group perceived as weaker" (p. 888). Elinoff et al., (2004) also perceive bullying as a real phenomenon. Although aggression is recognized as playing a large role in bullying behaviour, it is linked to anger and how people who are angry express their anger (Roberton et al., 2014). Aggression does not just happen. Many scholars state that anger is not socially acceptable (Abrams, 2010; Roberton et al., 2014), however, 'sugarcoating' anger as a form of hostility is accepted (Weaver \& Vescio, 2015). Some studies suggest that bullying behaviours point to the 'revenge is sweet' belief; bullies may become passive-aggressive towards their victims without recognizing the anger they are feeling or because they do not know how to cope with their negative feelings (Gini, 2006; Gini et al., 2008), which may be present due to outside factors, such as problems at home. Many scholars point out that passive aggressive behaviour is convenient and powerful (Brown, 2007; Weaver \& Vescio, 2015), connecting to Olweus and Elinoff et al.'s findings that bullying relationships have an imbalance of power.

The discussion of aggression adds to the research on bullying, however, it reinforces the notion that bullying is a real phenomenon. By contrast, recognizing that aggression is also socially influenced may contribute to the recognition that bullying is socially constructed. Aggression reflects behaviour that masks broader societal problems, such as racism, violence and classism. Although scholars Pikas (1989), Olweus (1994) and Elinoff et al., (2004) did not discuss the social construction of aggression, they did bring attention to the ways individuals share psychological traits and how society may cover up those traits to sustain hierarchies of privilege among classes, races and the 
sexes. Maintaining the hierarchy ensures that those viewed as powerful will continue to be viewed as such.

\section{Bullying as the Result of Individual Psychological Factors}

Another theme in the literature emerges as some scholars question what motivates students to participate in bullying behaviour. This line of inquiry reflects the belief that the bullying phenomenon is real. Many scholars believe psychological make-up influences a student's behaviour (Trzaskowski et al., 2012; D’Onofrio et al., 2013). Some scholars believe a clinical diagnosis is helpful and can determine which psychological treatments will cure the problem (Pikas, 1989). A clinical diagnosis to prevent bullying is

reflected in the Diagnostic Statistical Manual of Mental Disorders $-5^{\text {th }}$ Edition (DSM-5) (Elinoff et al., 2004). Bullying is one of the fifteen criteria listed in the DSM-5 (three or more criteria are needed to diagnose) under conduct disorder (Elinoff et al., 2004). Conduct disorder is where developmental stages are not passed when they are ageappropriate (American Psychiatric Association [APA], 2013). The other diagnosis is emotional disturbance (Elinoff et al., 2004). Emotional disturbance is when a person is so impaired that it interferes with their wellbeing (APA, 2013).

The criteria listed in the DSM-5 are very vague. Every individual develops differently — some may not reach developmental milestones at the same pace as their peers. The definition of 'personal wellbeing' is also vague and based on interpretation. The DSM-5 does not consider Indigenous perspectives of wellbeing, such as MinoBimaadiziwin and G'minoomaadozimin (as defined in chapter two). Indigenous ways of living are important in this context because the DSM-5 is a Westernized point of view of how people should develop. Vague medical diagnoses individualizes 
systemic problems, placing the blame on individuals for displaying behaviour that enables violence, harassment, racism and classism to continue on a wider scale (such as in educational settings). This reiterates the problem that the individual is the concern, not systemic social problems (Prewitt, 1988).

The arguments of Pikas (1989), Olweus (1994) and Elinoff et al., (2004) are concerning. While they help broaden the understanding that bullying is not a simple phenomenon, they also promote bullying as a real phenomenon, rather than recognizing how social systems create, allow and sustain negative behaviours. The meaning behind the negative behaviour may also be lessened if the behaviour taking place is labelled as bullying, rather than racism, violence or harassment. Their arguments also do not consider the variety of social realities in which individuals live. Social factors influence peoples’ psyches. For example, students living in lower class neighbourhoods might have parents who work longer hours to provide for them. If parents are working long hours, children might "live in impoverished language environments where fewer words are spoken and parents read less often" (Evans \& Kim, 2013, p. 43), which impacts a child's ability to understand language. It is argued that children in these areas might not receive as much attention, such as help with schoolwork from their parents, potentially lowering their academic output (Evans \& Kim, 2013). Furthermore, these neighbourhoods appear to have less 'social capital' and children living there are more often exposed to "crime, street traffic, have fewer places to engage in physical activity and less access to healthy foods" (Evans \& Kim, 2013, p. 44). When parents are unable to spend quality time with their children, the children might feel abandoned and lash out in ways defined as bullying (Bryner, 2001). These instances might be perceived as psychological problems (i.e. quiet, 
introverted at home and aggressive or physical with peers at school), rather than influenced by the social structures that surround them.

Disregarding the social environment in which a person lives creates the belief that if psychological factors can be fixed, bullying behaviours will stop. However, violent or aggressive behaviour that may be characterized as bullying is not simple, but rather a complex phenomenon that is impacted by intersecting social influences that help individuals mediate the social environment in which they live. It is the life experiences and meanings attached to those experiences that determine whether a person has a positive or negative outlook. It is argued that people with negative experiences are more likely to behave negatively towards others (Hopkins et al., 2013). These arguments often ignore the fact that racism, classism, harassment and violence exist in these circumstances, often intersecting with each other and making the situation even more complicated. Diagnoses of aggressive behaviour and psychological impairments hide these broader societal issues because so much focus is targeted on the individual to 'fix' their problem.

It is important to acknowledge that individuals' identities cannot be generalized to fit under a blanket statement or qualifier - a medical diagnosis based on vague criteria and interpretation, as described above, will not 'fix' bullying behaviour. Social environments, interpersonal relationships and culture are intersecting factors to be considered when discussing bullying phenomenon. These factors influence individuals who believe they have power and privilege to manipulate others, especially White youths. $^{23}$

\footnotetext{
${ }^{23}$ White fragility, a concept discussed by Robin DiAngelo is a state of mind where racial stress triggers displays of defensive behaviour, such as "anger, fear, and guilt, and behaviours such as argumentation,
} 


\section{Bullying as Gendered Behaviour}

Gendered behaviour is also an aspect of bullying discussed in the literature. For example, research shows that boys are more likely to engage in physical bullying, while girls are more likely to be swift, covert and manipulative (relative to aggressive behaviour discussed earlier) (Olweus, 1994; Olweus \& Limber, 2010; Elinoff et al., 2004). Olweus' view, however, does not consider learned gendered differences in bullying behaviour. Behavioural gender differences are socially constructed, suggesting that identified distinctions in bullying behaviour along gendered lines may also be socially constructed. The ways in which behaviour is perceived is relative to gender roles individuals present. Butler (1990) also recognizes that the construction of identity is relative to a performance. A person's cultural and social surroundings influence how gender roles are created and enacted (also connected to how a person's experiences affect their psychological state) (Sweet \& DesRoches, 2007; Ringrose \& Renold, 2010). Heteronormativity assumes that masculinity and femininity are the ideal roles to perform in society, disregarding the multiplicity of influences that allow gender roles to be fluid and ever-changing (Sweet \& DesRoches, 2007; Ringrose \& Renold, 2010). Olweus' antibullying work assumes heteronormativity, leaving socio-cultural and gender-specific issues out of the equation, thereby displacing those who do not meet the norm (Sweet \& DesRoches, 2007).

Gendered behaviours learned as a child are promoted in school (Ringrose \& Renold, 2010), thus they may not be recognized by school personnel as problematic, connecting back to Olweus' argument that aggression is learned behaviour that can be

\footnotetext{
silence, and leaving the stress-inducing situation. These behaviours, in turn, function to reinstate white
} racial equilibrium" (2011, p. 54). 
outgrown in adulthood. As it stands, the mainstream bullying definition does not consider "situational and socio-cultural dimensions of power along the lines of gender, race, class and sexuality" (Ringrose \& Renold, 2010, p. 576), thus heteronormative norms of masculinity and femininity are promoted (Sweet \& DesRoches, 2007).

Meyer (2008) agrees with Sweet and DesRoches (2007), however, Meyer (2008) focuses on gender bullying norms as 'gendered harassment'; this argument defines gendered harassment as behaviour that asserts traditional gender norms, different but related to the bullying phenomenon. ${ }^{24}$ Students who appear different from mainstream society may encounter negative behaviour by individuals who "wish to assert and defend their place in the heteronormative social order [and are thus] engaged in heterosexualized discourse that includes various forms of gendered harassment” (Meyer, 2008, p. 35). Existing stereotypes push the idea that those who do not perform traditional gender roles are perceived to be part of minority cultural groups, rather than recognize that gender performance is fluid and ever-changing (Butler, 1990; Meyer, 2008; Ringrose \& Renold, 2010). Many schools do not provide the option for students to learn about the fluidity of gender performance, but rather place high value on traditional masculine roles, such as strength, competitiveness, aggressiveness and being tough (Meyer, 2008).

It is difficult to 'stop bullying behaviour' recognized as gender harassment when these qualities are valued and demonstrate power in Western society. Many students who face gender harassment are told to 'get over it' (Walton, 2005a, 2005b, 2005c, 2011). Butler (1990) acknowledges that gender roles are constructed within a heterosexual matrix, allowing for only one dominant heterosexuality; if attitudes and behaviours

\footnotetext{
${ }^{24}$ Gendered harassment is recognized as "(hetero)sexual harassment, homophobic harassment and harassment for gender non-conformity (or transphobic harassment)” (Meyer, 2008, p. 34).
} 
accept this notion of gendered dominance in society, schools will be places where harassment occurs (Meyer, 2008; Walton, 2005a, 2005b, 2005c, 2011). Meyer (2008) agrees with Butler (1990) and Walton (2005a, 2005b, 2005c, 2011), reiterating that if students are "limited from developing their strengths because of the climate of the school, [then the] educational system has failed" (p. 39). Thus, it is arguable that bullying is not a social passage as one grows up, but rather there are intersecting frameworks such as school climate, culture, class and gender performance that impact a person's behaviour and experiences in society.

Also present among traditional gender roles in conjunction with negative behaviour is the notion of girl violence as a “'search for equivalence' and a desire to demonstrate that 'girls do it too'" (Ringrose, 2006, p. 406), backlash to the idea that women are more nurturing, caring and loving than men. The 'mean girl' role is also a way of performing gender at the time believed to be necessary 'vis-à-vis the masculine generic' — the gendered discourse is always seen as 'feminine lack versus excess' (Ringrose, 2006), similar to the heterosexual matrix to which Butler (1990) refers. Intersections of race, class and sexual orientation are also at play, but may not be recognized; "there are specific categories of femininity, which continue to produce normative and deviant girls with vastly different effects for different girls" (Ringrose, 2006, p. 419). This is relative to aggressive behaviour discussed earlier and the spectrum of women and men that are created by displaying aggression (women may be labelled as mean or as a 'bitch' or a bully, whereas men who show aggression may be considered hyper-masculine and be championed). The spectrum of differences among individuals potentially makes the bullying phenomenon difficult to study. 
The arguments by some researchers that bullying behaviour is normal or is carried out by boys more than girls (Olweus, 1994; Olweus \& Limber, 2010; Boulton \& Smith, 1994), have been called into doubt. Those arguments build on a number of faulty assumptions that have been critiqued: aggression is believed to be out grown; psychological traits are argued to be 'fixable'; schools and teachers assume they know what is best for children and can distinguish those who engage with learning compared to those who are uninterested; and that male behaviour is more likely to represent 'bullying behaviour' than female behaviour, disregarding the fact that gendered behaviour is socially ascribed.

\section{SLGBTQIA Perspectives on Bullying in Schools}

Since the traditional definition of bullying does not consider value systems other than heteronormativity, it is important to examine the bullying phenomenon through the lens of 2SLGBTQIA students and their experiences within school environments. Through a 2SLGBTQIA lens, gender policing is a method used to understand peer-to-peer aggression, drawing attention to the ways normative gender expectations operate as a way for peers to target each other, as well as for institutions, such as schools, to reproduce rules for normative expression (Payne \& Smith, 2013; Foreman, 2015). Gender policing is part of the behaviour labelled as bullying and is founded in a heteronormative and heterosexist culture that is reinforced through the institution and practices of schooling. Those who do not fit hegemonic norms are denied access to social power and popularity (Garland, 2000; Larcombe, 2002). Scholars Garland (2000), Larcombe (2002), Payne and Smith (2013) and Foreman (2015) acknowledge that aggression is a process of social positioning, which is reflective of cultural norms, whether for sexuality, gender, 
race or class.

With particular reference to 2SLGBTQIA students, their negative school experiences have been shaped by a discourse of bullying that focuses on psychological representations of bullies and victims, neglecting situational and socio-cultural dimensions of power that students are forced to manage at school (Payne \& Smith, 2013). The management of non-heterosexual identities within a heteronormative environment brings to light the fact that schools ignore the complex ways they maintain and sustain social processes relative to bullying behaviour and reinforce that it is acceptable to behave negatively towards an individual who does not conform to hegemonic beliefs and values. Allowing negative behaviour supports heteronormative values and boosts heteronormative social power, while marginalized individuals are potentially labelled as weak, reducing their social capital (Larcombe, 2002; Payne \& Smith, 2013). The dichotomy of labelling a person 'weak' relates to the hierarchy of sex (males/females). A heteronormative culture maintains power through a masculine lens, thus if a behaviour is not associated with heteronormativity or masculinity, it is 'Othered' and defined as part of the 'weaker sex' (Jackson, 2006).

Based on how Western society is structured, Othering is a factor Indigenous people and other minority groups encounter on a daily basis (McPherson \& Rabb, 2011; Monchalin, 2016). The Othering some people are subject to reinforces that the bullying behaviour they experience is 'normal.' It also diminishes any negative outcomes they have from the behaviour and adds to the beliefs that they are the reason for this behaviour — there must be something inherently 'wrong' with them, otherwise they would not be the target of bullying behaviour. 


\section{Bullying as Influenced by Socioeconomic and Cultural Factors}

How a person negotiates their everyday life is influenced by factors such as social location, class, race and gender. The treatment of bullying in much of the literature disregards socioeconomic and cultural dynamics, including Canadian Indigenous perspectives. Socioeconomic factors include class, the amount of money earned and the neighbourhood a person lives in (Evans \& Kim, 2013), while cultural dynamics refers to the fluidity of cultural change where everyday attitudes and beliefs shift (Morris et al., 2015).

Where scholars recognize that socioeconomic status has an impact on relationships among peers in school, it is argued that those individuals who come from a higher class family are more likely to dominate their peers from lower classes (Yoneyama \& Naito, 2003). For example, these students believe they have more to offer than students from lower classes. There are also individuals from lower social classes who portray behaviour identified as "negative". For example, single parenthood, low educational level of parents and low household income are factors that influence negative behaviour of children (Jansen et al., 2012).

The common factor that is discussed in the literature is that bullies want power over their peers (Jansen et al., 2012; Cornell \& Limber, 2015). Power differentials may be rooted in many different factors; "bullying is most often verbal or social and requires a determination of a power differential that requires an assessment of peer status, selfconfidence, or cognitive ability" (Cornell \& Limber, 2015, p. 334). Some scholars argue that individuals obtain power because they either belong to a higher class (i.e. higher socioeconomic status) or because they have many peers (either from a higher or lower 
class) (Jansen et al., 2012; Cornell \& Limber, 2015). Although the students might have power, it is noted that it is only temporary power. Cornell and Limber (2015) argue that “interpersonal power is not a static quality because it can vary across situations and circumstances" (p. 334). Thus, the 'power' a 'bully' believes to hold is dependent on how he/she views the reality of his/her everyday events at that time coupled with how his/her peers react to and mediate the events that determine their relationship/friendship.

These scholars also acknowledge that bullying may be difficult to define precisely because it overlaps with assault, extortion, hate crimes and sexual harassment (Cornell \& Limber, 2015). They note that "it [bullying] may be hard to draw the line between children's friendship squabbles and painful social ostracism” (p. 334). While it is a difficult phenomenon to define and legally interpret, they still urge policymakers to “combine education, school-based interventions and policy reform to develop cultural change" (p. 342). However, shifting social opinion about bullying behaviour may be difficult without first recognizing and addressing the cultural context in which the behaviour occurs, including a context of colonialism, racism, violence, harassment, sexism, classism and homophobia.

\section{Bullying as Influenced by Educational Environments and Teachers}

Another theme within the literature focuses on the way in which bullying may be influenced by educational environments and teachers. In particular, Olweus (1994) and Olweus and Limber (2010) consider the role of the school environment in their work on bullying. For example, smaller classrooms have been recommended as a mechanism to lessen bullying behaviour. This was the start of trying to determine if negative behaviour recognized as bullying could be managed in schools. However, this mechanism 
disregards the various social classes and cultures that are present in school environments. Smaller classrooms do not eliminate social and cultural differences amongst peers. Rather, it is argued, teachers with smaller classrooms are potentially better able to mediate differences or determine which students are engaged or not in learning (Olweus, 1994). This theme also does not address a teacher's perceptions, preconceptions, or potential prejudice, racist ideologies or bias. It is not possible to know the thoughts or mental images teachers have about their students. These ideas are shaped by their own background and life experiences. These experiences include many intersecting areas such as family history, education, work, culture or community. Teachers label students without recognizing their own outside influences, which impacts how a student views their learning experiences, thus, becoming part of a student's socially constructed reality of school. The teacher can also authenticate experiences of bullying behaviour, disregarding some experiences while legitimizing others.

Schools are believed to foster a community, regardless of student social status, cultural background and age (Morton, 2016). Baker (1998) argues that children must feel connected to the school they are attending. Scholars believe that if children are not attached or do not feel a sense of belonging to the school, their education is potentially at risk (Baker, 1998; Morton, 2016). Students as young as third graders who are engaged in the classroom are satisfied at school and have perceptions of a better school environment, have support from teachers and appear to have better home to school adjustments than those who are not engaged in learning (Baker, 1998). Scholars Pikas (1989), Olweus (1994) and Olweus and Limber (2010), however, do not consider that students who show a lower output could be faced with barriers in accessing resources, could be stigmatized 
by school personnel or could be shy. Rather, they assume that all students are suffering from some type of issue that requires fixing (and is fixable). Again, the children (or parents) are blamed for any potential problems they have, disregarding social structures and the construction of the education system.

Although Baker's (1998) work focuses on the psychological transition between home and school, her argument that schools help foster community engagement acknowledges that social factors influence relationships with peers. There are many intersecting elements, such as domestic life, cultural practices and values and social class, which are at play when determining why individuals engage or disengage with education. Thus, it cannot be assumed that all children will learn equally and that all teachers will teach the same.

Some scholars note that, currently, anti-bullying programs 'work' on components to shift individual values and beliefs, "attempting to compensate for the deficiencies in students' values and belief systems that lead them to act aggressively toward or impose power over their peers" (Payne \& Smith, 2013, p. 11; Walton, 2005a, 2005b, 2005c, 2011; Winton \& Tuters, 2015). Such an approach to anti-bullying programs brings 'character education' to the forefront. For example, individuals who have 'good character' express positive and acceptable behaviour, such as respect, tolerance and empathy, whereas individuals who show deviance are non-compliant and aggressive, such as those students who misbehave or do not promote heteronormativity (Larcombe, 2002; McGregor, 2008; Foreman, 2015; Winton \& Tuters, 2015). Thus, those who portray positive behaviour are also reinforcing hegemonic values that are accepted in society, whereas deviant behaviour does not. Anti-bullying programs are used in 
educational institutions to help children learn "character attributes that enable them to become caring and responsible adults" (McGregor, 2008; Payne \& Smith, 2013; Winton $\&$ Tuters, 2015). The problem with this view is that the 'good character' attributes reflect a hegemonic society where differences are reflected as problems that are curable with intervention and education. This reinforces hierarchies where whiteness, middle-to-upper class, educated individuals are viewed more positively in comparison to racialized populations, who may be poor and undereducated (as a result of Canada's history of segregation, colonization, and the experience of trauma endured by many of Indigenous residential school survivors) (TRC, 2015b). The 'good character' taught in school assimilates and erases Indigenous culture — to be a 'good character' is to not be Indigenous and to follow social rules without question (Sabzalian, 2019).

The education system might label children who deviate from the norm as problematic students, promoting negative behaviour that requires fixing. Students who disengage from school could be teacher-nominated 'troubled children' deviating from the 'good student' persona (Hashem, 2015). Those students who are labelled by teachers as deviant are potentially labelled as bullies (Hashem, 2015) who either have a learning impairment or psychological problems that need attention/a professional diagnosis (as discussed above). Several critiques of the practice of labelling children are identified in the work of Link and Phelan (2001) who note that students who are labelled at school (i.e. labelled as a bully) might start to believe they are problems in society, rather than acknowledge that society is failing them. Those students who believe the label might behave negatively, thus opening the doors for disciplinary measures to be put into place (i.e. detention, suspension or expulsion). 
How educators understand and react to/prevent bullying behaviour impact how the youth view and understand it as well (Baker, 1998). Labelling a person as a bully also has larger implications that impact youth. For instance, labels attached to an individual can influence their wellbeing and how they are treated by others. A name that a person is called at school could be relayed at home to parents, who could then perceive the person (the bully) not only as a threat in the school community, but as a potential larger problem in society. The student (i.e. bully) might have familial problems (or other personal issues) of which no one is aware.

Pratt and Danyluk (2017) point out that "a lack of critical reflection by servicelearners could play in widening existing educational gaps" (p. 1). Pratt and Danyluk (2017) focus on teachers working in Indigenous communities for the first time and their experience of culture shock; "in Canada, many pre-service teachers working for the first time in Indigenous communities are similarly overwhelmed by the differences in cultural traditions and overall living conditions" (Pratt \& Danyluk, 2017, p. 8). The teachers that travel to remote communities are adults. Reversing the situation — when Indigenous youth have no choice but to leave home to attend high school, they are young adolescents. Many young Indigenous adolescents face the same issues that the adult teachers have to face, albeit at a younger age — potential disconnect from family or from cultural traditions is also at stake.

Unfortunately, there is also the potential for an educator to reiterate colonial ideals towards Indigenous students where some, perhaps most, might not recognize the severity of the situation. Pratt and Danyluk (2017) assert the importance of selfreflection, otherwise some teachers" "pre-existing assumptions based on misinformation 
and racist stereotypes [may] guide their teaching" (p. 10). Focusing specifically on Indigenous people, teachers who have not confronted their own assumptions and beliefs about Indigenous people "risk passing these stereotyped ideas and beliefs onto their students" (Pratt \& Danyluk, 2017, p. 7).

\section{Systemic Factors}

Baker's (1998) work challenges Olweus' (1994) as Baker states that the culture of the school, its students and its employees, shape and constrain individual expression among others. Hyman and Perone (1998) and Kupchik and Ward (2014) also agree that "schools participate in violence problems when they fail to provide students with meaningful social contexts within which to function" (p. 36). Walton (2005c) further draws attention to the problems of bullying policies in schools, "educational policies and accompanying programs typify bullying as a problem of specific children who need specific interventions or punishments; there is no focus on systemic problems" (p. 29). Walton (2005a) argues that the wider context needs to be considered in bullying behaviour, "conceptualizations of bullying that are rooted in empirical approaches do not consider political, historical, cultural, discursive, and ideological threads that, woven together, make up the construct that is now widely known as bullying” (p. 112).

Winton and Tuters (2015) also agree that schools focus on individual problems of only certain individuals. They state that schools,

focus on the actions and consequences for 'specific' individuals rather than acknowledging the complex and multifaceted nature of bullying and the larger societal and systematic forces at play. Initiatives often refer to a "bully," "victim," or "bystander" suggesting clear distinctions exist between them. These distinctions 
over-simplify the nature of bullying and promote the conceptualization of bullying as a problem of "good" and "bad" individuals. Oversimplification contributes to the creation of standardized "one size" fits all policy and program solutions to bullying. (p. 127)

Cultural values influence how people interact with each other. Learning does not take place without social or cultural influences, and thus every-day activities are mediated by a person's experiences and the meanings they attach to them. Individual perception of a value system is also dependent on how interpersonal relationships flourish or fail. Those individuals who do not portray hegemonic values that society normalizes are dismissed as individuals who lack 'socio-moral competency' 25 and are believed to need re-alignment and re-education (Payne \& Smith, 2013). Winton and Tuters (2015) agree with Payne and Smith (2013); believing that behaviour labelled as bullying is an individual problem reflects the idea that only people who are responsible and can comprehend positive behaviour will not participate in behaviour defined as bullying (Winton \& Tuters, 2015). "Bullies" are thus stigmatized by social norms, policies and state institutions because they do not fit in with mainstream social standards. They are essentially forced to either fit in with hegemonic values or be different and non-conforming; thus, they are constantly under the critical eye of teachers, principals, peers, and the State. McGregor (2008) agrees with Baker (1998), and Hyman and Perone (1998) by acknowledging that hierarchies of power and privilege are reinforced in schools. McGregor (2008) argues that "the challenge for educators is to dismantle heteronormative frames through anti-homophobic or anti-oppressive pedagogies and

\footnotetext{
${ }^{25}$ Students lacking 'socio-moral competency' do not express care and responsibility (Payne \& Smith, 2013; Winton \& Tuters, 2015).
} 
practices" (para. 5). Winton and Tuters (2015) also advance this idea, and critique that schools are "not required to ensure critical examination of how power over others is exerted by institutions, governments and other groups in society and/or how dominant societal power relationships are reflected in bullying in schools" (p. 133, emphasis, original).

\section{Anti-Bullying Frameworks and the Identification/Construction of Bullies and Victims}

Scholars Larcombe (2002), Walton (2005a, 2005b, 2005c, 2011), McGregor (2008), Payne and Smith (2013), Foreman (2015), Winton and Tuters (2015), Payne and Hutzell (2017) and Hutzell and Payne (2018) have engaged in a critical analysis of the bullying literature, rather than accepting the standardized definition and approach to bullying. The more critical analysis of anti-bullying programs recognizes that these simplistic labels are forcing violent behaviour 'underground' rather than bringing the issues of systemic privilege and marginalization to the forefront (Larcombe, 2002; Walton, 2005a, 2005b, 2005c, 2011; McGregor, 2008; Payne \& Smith, 2013; Foreman, 2015; Winton \& Tuters, 2015; Payne \& Hutzell, 2017; Hutzell and Payne, 2018).

Within the bullying discourse, there is an ongoing process of "defining and recognizing bullying behaviours, distinguishing juvenile incivility from more serious forms of peer victimization and drawing boundaries around the 'bully' and 'victim' categories to make them socially and legally recognizable" (Foreman, 2015, p. 158). Having a definition of 'bullying' reifies its presence. Walton (2005a) argues that "bullying is more than an empirical matter - it is a social and political construction, rooted in ideological relations of power" (p. 113). 
Anti-bullying frameworks that are operational in schools are assumed to be in place to support victims of bullying and to lessen negative behaviour on a wider scale. However, "addressing broader issues of violence is limited by the very ways that bullying is conceptualized and by programs and policies that are anchored by such conceptualizations" (Walton, 2005a, p. 113). Walton (2005a) asserts the difficulties in dealing with 'bullying behaviour',

it is certainly not easy to transform schools into places where violence does not flourish. In some schools, it may seem impossible [...] the work of reducing violence in its various forms - racism, sexism, homophobia, classism, and so on — has been undertaken by a minority of administrators, teachers, parents, and students in some schools. (p. 113)

Winton and Tuters (2015) elaborate, "bullying often involves issues of marginalization and exclusion, including racism, yet policies and programs focus largely on bullying in general, avoiding issues such as racism, homophobia, etc.” (p. 127). Standardizing negative behaviour as bullying also ensures that every incident is treated the same (Winton \& Tuters, 2015); "bullying that conforms to dominant conceptions to acceptable and unacceptable behaviours $[\ldots]$ receive more attention whereas acts of bullying grounded in discrimination and oppression receive less focus" (p. 127). Using the label 'bullying' to define a spectrum of negative behaviours, and treating the incidents equally, is problematic and allows bullying rhetoric to obfuscate racism, homophobia, classism, and other violent behaviours. Moreover, marginalized victims of these violent behaviours may not be believed due to the social construction of victims and bullying. 
Victimization is a symbolic political process of exchange between those claiming to be victims and concerned individuals willing to accept or deny 'victim status';

“individuals are afforded or denied victim status based on their characteristics, behaviour or circumstances lining up with an accepted victim narrative" (Foreman, 2015, p. 160). Marginalized individuals are less likely to accept/obtain victim status, whereas individuals who follow hegemonic values are more likely to be believed (Walkate, 2011; van Wijk, 2013; Long, 2021). Heteronormative individuals are more likely to be "ideal victims" - innocent, vulnerable and without blame (Long, 2021).

Scholar Nils Christie (1928-2015) coined the term 'the ideal victim' through a criminological lens. The definition of an ideal victim refers to "a person or category of individuals who — when hit by crime — most readily is given the complete and legitimate status of being a victim" (van Wijk, 2013, p. 160). The status is believed to be given by 'the social system' (van Wijk, 2013). Long (2021) notes that colonialism and racism are overlooked in the ideal victim concept. Long (2021) also asserts that the worthiness of the victim is questioned; "worthiness is assessed in relation to socioeconomic, structural and demographic factors, as well as the perceived legitimacy and innocence of the victim [...] within a racially ordered society, worth is predicated on proximity to Whiteness" (p. 3). Relative to Long's (2021) work, Indigenous people are seen as perpetual suspects (due to colonization, residential schools, 60s scoop stereotypes that remain entrenched in social thought, and strategic government processes). The cumulative impact of these events limits Indigenous victim's power to make their case. 
Becoming the victim is a difficult task when the victim belongs to a minority group; the stereotype of the 'idea victim' identified by Christie, mistakenly assumes that "our normal reaction to victims would be a sympathetic one, while in reality any positive reaction to victim experience has to compete with an inclination to negative reactions" (Pemberton, 2016, p. 264). The negative reactions refer to society's acceptance of the victim as deserving (Walkate, 2011) and worthy (Long, 2021). Marginalized individuals are more often seen as undeserving of 'victim status' because they do not follow hegemonic social norms (Long, 2021). Indigenous youth and many Indigenous populations are labelled as deviant (Proulx, 2014). Also, the conceptualization of bullying behaviour does not support 'victim status' for those viewed as marginalized persons (rather, they are viewed as the bully). Nevertheless, for individuals recognized as minorities, such as Indigenous students and 2SLGBTQIA students, the suffering caused by behaviour labelled as bullying is real.

There are risks posed by Ontario's anti-bullying legislation and policies for Indigenous students. The policies may not necessarily benefit Indigenous youth if they are not deemed worthy of protection by the educator/supervisor involved, while at the same time the policies (by focusing on bullying), may make things worse by camouflaging the systemic sources of violence faced by Indigenous students. In this way, marginalized individuals may be further oppressed by social policies and programs that are supposed to provide education, lower stigmatization and assist with positive interactions among people of different backgrounds. 


\section{Recognizing Social Construction within the Policy-making Process}

The importance of recognizing the social construction of the concept of bullying takes on additional importance if one considers the ways in which the policy-making process itself is also subject to a process of social construction. To this end, it is worth considering the work of Scheurich (1994), who does not agree that social problems are discovered/uncovered/identified at which point policies then pop up to solve problems. Instead, Scheurich (1994) argues that social problems are constructed in ways to constrain policy solutions. He refuses to believe social problems exist naturally. Scheurich's (1994) notion of policy archaeology acknowledges that social problems are constructions, bringing forth complex groups of relations that create social problems and make spaces for policy solutions (which may include oppressive behaviours based on race, class or religion) (Scheurich, 1994). In the context of educational policies, he recognizes that certain issues are legitimized as social problems that need fixing.

Walton's (2005b) work on anti-bullying policies is in line with Scheurich's (1994). Walton (2005b) indicates, educational research constructs a discourse on bullying that appears to reflect objectified, coherent, and uniform propositions. However, it becomes clear that bullying is a construction embedded in discursive practice that arises from a network or system of institutional, historical, social and political relations. (p. 61) Walton's work (2005a) also recognizes that administrative careers depend on "being able to demonstrate that particular policies and programs have been implemented to ensure that all children are safe in school" (p. 112). He further argues that the goals of bullying 
reduction merely "contains, regulates and manages violence rather than addresses it" (p. 112, emphasis, original).

Trowler (1998) advances an argument similar to Scheurich (1994), however, it is from a political buy-in perspective. Trowler (1998) points out that policy makers "can and do constrain the ways in which we think about education in general and specific education policies in particular, through the language in which they frame policies" (p. 132). At the educational policy level, political leaders use language from other sectors such as marketing or business as a way to 'sell' and obtain buy-in of the drafted policy. Selling and achieving buy-in of the policy that revolves around various educational issues, such as anti-bullying initiatives, delivery of learning outcomes, the skills obtained in school, which "become part of everyday discourse and begin to structure the way people think about education" (Trowler, 1998, pp. 132-33).

Achieving buy-in at the policy creation level "excludes other possible ways of conceptualizing the nature of education" (Trowler, 1998, p. 133). This exclusion is due to the way education policies are marketed to government leaders, the way they are debated, amended and accepted. Political leaders thus have the option to expand upon largely accepted political dialogue or criticize the status quo. Criticizing the status quo, however, does not bode well when trying to earn public following, thus it is in their best interests to have certain policies accepted and passed in government, reinforcing social standards.

Turning more specifically to anti-bullying policies, scholars Akiba et al. (2002) argue that school system variables and social structures are not examined as factors that are associated with the bullying phenomenon. Furthermore, the platform of anti-bullying 
programs (i.e. Olweus' Bully Prevention Program ${ }^{26}$ ) avoids differentiation (Sweet \& DesRoches, 2007). This is problematic because "if specific identities are left out of the equation, heteronormativity is left untouched, the dominant assumption will be associated with ideas of male, White, heterosexual, and the strategies used still unfortunately reflect these unspoken yet excruciatingly felt norms" (p. 183). As Walton (2011) asserts, "common approaches in anti-bullying programs convey the idea that bullying is only behaviour because that is how it has come to be popularly considered, [yet] few stop to think otherwise" (pp. 131-132, emphasis, original).

\section{Concluding Discussion on the Bullying Phenomenon}

There is no clear reason why much of the academic literature on bullying accepts bullying as a unique phenomenon, rather than critically analyzing that bullying is a problematic label. Maintaining that bullying is real can obscure violence, harassment, homophobia, racism, classism and sexism. It also allows colonial power to be preserved as these issues are founded in colonial structures (i.e. law, police and educational systems function on the idea that all individuals should strive to be the same, using settler colonial ideals of White, heterosexual, males as the backdrop in which to compare difference).

The construction of bullying leaves Indigenous youth vulnerable in multiple ways: (i) they may be unlikely to be viewed as victims of bullying, because they are Othered, and therefore do not get the protection supposedly guaranteed under new antibullying provisions; (ii) because they are Othered, they are more likely to be labelled as bullies without consideration of the challenges they face, (and then may potentially end

\footnotetext{
${ }^{26}$ The Olweus Anti-Bullying Program is designed to improve peer relationships and make schools a positive environment for students to learn and grow by reducing 'bullying' problems among students (Olweus \& Limber, 2010).
} 
up in the school-to-prison pipeline); and (iii) racist behaviour may be minimized merely as 'bullying', rooted in individual malfeasance, and thus not recognized as a systemic problem rooted in settler colonialism.

The critical scholars who recognize that the concept of bullying pushes systemic behaviours out of the spotlight are most relevant to this dissertation. In my analysis, I will consider the ways in which my research findings resonate with scholars acknowledging limitations of law and policy (McGregor, 2008), Walton's (2005a, 2005b, 2005c, 2011) connecting to ideas that policies and programs in place are problematic because they rely on dominant social ideals and Winton and Tuters (2015), who outline that Ontario's 'onesize fits all' approach to bullying disregards Indigenous ways of being. Furthermore, I will draw on Milne $(2015,2016)$ who recognizes that education practices imposed on Indigenous people reflects systemic, modern-day colonialism. Milne $(2015,2016)$ reflects on how systemic colonialism impacts every aspect of life for an Indigenous person.

The analyses of Walton (2005a, 2005b, 2005c, 2011), McGregor (2008), and Winton and Tuters (2015) are helpful for my project as they each use different critical approaches to analyze how social processes function, while also analyzing anti-bullying initiatives the Ontario government has legalized. Walton (2005a, 2005b, 2005c, 2011) and McGregor (2008) frame their research through a 2SLGBTQIA lens, whereas Winton and Tuters (2015) frame theirs through a critical democracy lens, reflecting on neoliberal and neoconservative ideologies. These approaches will help frame the discussion of how Ontario's anti-bullying framework potentially impacts Indigenous students in northern Ontario. In particular, I will build on these critical approaches by considering the ways in 
which settler colonialism has structured the Ontario education system, the policies created under that system (including the anti-bullying framework) and the ways in which those policies are implemented. By explicitly recognizing the impact of settler colonialism on the education system, it is possible to more critically examine the ways in which the social construction of bullying may reinforce not just heteronormativity but also colonialism and particularly anti-Indigenous racism and violence within the education system. 


\section{Chapter Five: Methodology and Methods}

This chapter outlines the methodology and methods used in this study. I begin with a discussion of the ethical considerations taken prior to conducting this research project. I then describe how I obtained the participants in this study. I used qualitative methodologies to frame my thesis, utilizing a multi-grounded theoretical approach in this project. Data collection methods included interviewing (in-person and telephone) as well as one written response. I adopted some elements of the Two-Eyed Seeing approach when analyzing the interview data and legal policies. Each is described below.

\section{Ethics}

Prior to starting this research project, I considered the ethical implications of conducting research on issues relating to Indigenous people as a White academic. As stated in my introduction, I did not conduct this project "on" Indigenous people (TCPS2C.9, 2018). Rather, it is research on Ontario educational policy that may have negative impacts on Indigenous youth. With that said, however, it is important that the ethical dimensions of the history between Indigenous people and the Canadian state be recognized. We must also understand how the legacy of residential schools and ongoing colonialism continues to impact Indigenous people today and thereby also this research project.

There is no government or institutional funding for this project. This research is part of my doctoral program. My analysis and discussion were influenced by my working relationship with the Nokiiwin Tribal Council in Thunder Bay, Ontario and by the Indigenous researcher I consulted with. I hope that my dissertation speaks with Indigenous people. By interviewing educators in northern Ontario on the Ontario anti- 
bullying framework, this project aims to assist those working in the education system to consider whether they are promoting or breaking down barriers for Indigenous youth. While my dissertation is focused on the negative impacts of settler colonialism and the challenges faced by Indigenous students within a settler education system, a 'deficitmodel' approach (Tuck, 2009) should not become the default mode of analysis. I am not focusing on the 'damage' of Indigenous people or communities. Rather, this research exposes disproportionate injustices and oppression Indigenous youth may face in high school through understanding how educators understand and implement the Ontario antibullying framework. This research promotes survivance; moving beyond basic survival (Tuck, 2009) — and promotes reconciliation in Canada.

Before REB approval was obtained, I created separate ethics documents for the Indigenous education authority and the Catholic/Public school boards. Participation of the Catholic/Public school boards did not bring forward anonymity concerns as there are many Catholic/Public high schools in northern Ontario. Thus, the participants in this study from the Catholic/Public high schools remain anonymous. However, there are not many Indigenous-only high schools in northern Ontario. As such, anonymity was not guaranteed due to the lower numbers of educators in the Indigenous-only high schools. The educators from the Indigenous-only high schools needed to be aware that there was no guarantee of anonymity (further information provided below). Nevertheless, anonymity and confidentiality is strictly maintained for all participants. Formal approval for this research was obtained through the Carleton University Research Ethics Board-A (see Appendix A). 
Potential participants (see recruitment discussions following) were approached via mail or e-mail with an introduction to the study (see Appendix B). Upon expression of interest in participation, they received the appropriate consent form (see Appendix C). These forms were exchanged in person or by email and informed potential participants that participation in this study was entirely voluntary; participants were informed that they did not have to answer any questions they did not wish to answer, and that they would be able to withdraw up to 14 days post-interview. Once consent was established, interview details were finalized. Throughout the interviewing process, themes emerged; however, it was through the analysis of the interview transcripts that concepts and subthemes from the data were recognized.

It is important to note that one Director of Education wanted to provide an hour's training time to each of the high school teachers within their Board in lieu of compensation. They also wanted to pay me for completion of this work. Due to the nature of this research, this option was not explored further.

All data collected remains confidential and the anonymity of the research participants is strictly maintained. Identifiable data is stored securely in a password protected computer account as per the requirements of Carleton University policy. All data from individual participants was coded, so their anonymity is protected in any reports, research papers, thesis documents, and presentations that result from this work. Any communications and interview recordings were destroyed after the data was transcribed.

After the completion of this research, results will be provided to participants, the two Directors of Education who gave their permission for me to approach their school 
boards' high school teachers, and the principal of the Indigenous-only high school.

Additionally, there will be other opportunities to disseminate this research in academic publications, academic conferences, meetings and reports.

\section{Recruitment of Participants}

At the onset of my research, I made requests for participation to all school boards in northern Ontario. The geographic location cut-off for northern Ontario was Sudbury and Sault Ste. Marie, Ontario. Between March 2018 and May 2018, I contacted 12 school boards that are part of the Public and Catholic school systems and one Indigenous education authority where I had been formally introduced to the principal over a year earlier. I used purposive sampling techniques, such as the homogenous sampling method (Etikan et al., 2016); Purposive sampling is the "deliberate choice of a participant due to the qualities the participant possesses" (Etikan et al., 2016, p. 2). From the school boards I contacted, 10 Directors either said no or did not respond. After communicating via email for one month, two Directors provided me with permission to reach out to their high school teachers.

One Indigenous education authority participated in my research. Informally, I was introduced to the principal of one of the schools that is part of the education authority in 2017. I had informed them of my research and what my initial research ideas were. In 2018, I reached out to the principal via email. A formal meeting was scheduled. I prepared a package with my proposal and ethics documents. I brought tobacco with me. With the tobacco in my left hand, I asked respectfully if I could ask educators in the school for their knowledge. The principal agreed and thus allowed me the opportunity to ask educators to participate. There was one condition - I had to read Seven Fallen 
Feathers by Tanya Talaga. I gratefully accepted the book provided to me from the principal. The acceptance of my research proposal by the Indigenous school shows that there was a level of trust in my work. The agreement to be involved in this research also aligns with the TCPS-2, Chapter 9 (2018).

According to the TCPS-2 Chapter 9 (2018), "an organization may participate in research focusing on its members" (Article 9.4). By participating in this research, the principal of the Indigenous high school provided a knowledge base of Indigenous issues in northern Ontario (i.e. providing Seven Fallen Feathers to me to read). The principal wanted me to be aware of the hostile political climate in northern Ontario and more specifically, Thunder Bay, and to confirm that I knew about the 7 Youth Inquest. Knowing this information also provided me with a basic understanding of the politics educators in an Indigenous-only high school navigate. Nevertheless, the agreement of the Indigenous high school did not guarantee participation of all of its members, but rather the agreement allowed me to request participation of teachers in the school. Thus, no additional ethical protocols were required to be reviewed by the Carleton University REB. Although not from the onset of my research, I did learn about the importance of consulting with an Indigenous researcher to ensure cultural sensitivity in interpreting data that may impact Indigenous people (TCPS-2, Chapter 9, 2018); the consultation process is described later in this chapter).

After receiving permission from the Directors of Education and Indigenous high school principal to contact teachers, the recruitment plan was implemented. One school board distributed letters of participation on my behalf. I prepared 225 letters, which were sent to the administration office. The administration office sent the letters to their 
respective schools, and the letters were then distributed to high school teachers. The second school board approved my research proposal closer to the end of the school year. To save time, an e-mail with the letter of participation was forwarded from the administration office to all principals, which was then forwarded to all high school teachers (unknown number of potential participants). Upon receiving approval from the Indigenous high school's principal and after reading Seven Fallen Feathers, I provided the school with 45 invitations to participate.

\section{Sample Size}

In total, 12 educators responded. A Junior Kindergarten educator was unintentionally included. It is unclear how this error occurred, given the invitation to participate was extended to secondary-school educators only. Nonetheless, I included her responses as part of this project; her data showed that she was not aware of the issues Indigenous youth face. This information is important to publish as there may be others who are also unaware of the politics Indigenous people navigate in a colonial education system. Although this data is not generalizable, it does give insight into what some people may or may not know.

Although the number of participants is lower than desired, 12 participants is the number that the literature acknowledges as a 'saturation point' (Tuckett, 2004). Another point to acknowledge is that participants were invited to participate in March 2018, which was three months from the end of the school year (one month for the Indigenous education authority). ${ }^{27}$ The timeframe provided to participate may have been difficult for some interested participants (Rowley, 2012). I tried to provide as much notice as possible

\footnotetext{
${ }^{27}$ The Indigenous education authority provides longer school days, so students are not away from their family longer than necessary throughout the year (NNEC, 2014).
} 
for participants. Prior to travelling for interviews, I asked the administrative personnel to send a follow-up e-mail in hopes of recruiting more participants.

I chose to conduct semi-structured interviews for which I developed a written interview guide (see Appendix D). One participant requested the questions in advance to allow them a chance to reflect upon the issues in preparation for our upcoming discussion. Interviews took place at a location chosen by the participants: seven interviews were held at the schools where the participants were employed, three interviews took place in public areas and one interview was completed over the telephone. Interviews were audio digitally recorded and were approximately 45 to 120 minutes in length. The interviews for this study were completed between June 4, 2018 and June 14, 2018. The participant who provided their responses in writing sent them to me via e-mail on June 27, 2018.

As an incentive to participate, each participant received a $\$ 50$ gift card to a local restaurant, a local grocery store or gas station. Two participants declined the honorarium. I began the interviews with background questions: if they grew up with Indigenous individuals in their home communities or schools, how their teachers treated students in their classrooms, and why they decided to become teachers. After learning why these individuals chose to become teachers, I asked if they had knowledge or training in Indigenous ways of knowing, if they had any life experience that helps improve their teaching quality and if there is any other training they have that is relevant to the teaching discipline.

Once a personal picture was captured, I asked what their positions were at their schools, how their school defined bullying, and if and what they know about Ontario's 
anti-bullying framework. I also asked them if they believed the framework supported students. Focusing more on Indigenous issues, I asked what changes have been implemented in their respective schools since the recommendations from the TRC were published. I asked questions about the treatment of Indigenous youth in comparison to non-Indigenous youth when instances defined as bullying take place. I also asked if teachers believed Indigenous students bullied others or were bullied simply because they are Indigenous. Lastly, I concluded the study with questions on how to improve antibullying measures for Indigenous students in northern Ontario and asked if there was any further information the participants wanted to add to this study. Post-interview, participants were asked if they wanted to review their transcript; one participant said yes. After reviewing their transcript, they removed a large amount of data. This participant was fearful of exposure despite reminders of confidentiality and anonymity (more information is provided in the challenges and limitations section of the conclusion to this research).

Ten of the participants were female and two were male. Eleven participants were White. One identified as Métis (female). They were all highly educated, middle to upperclass Canadian citizens. They all have at least four years of professional educator experience, with the most experienced teacher having 38 years. Table 1 sets out the years of experience of each teacher. All participants attended undergraduate degree programs in Ontario. Eleven participants attended teacher's college in Canada and one attended in the United States of America. All participants are certified Ontario teachers through the Ontario College of Teachers (OCT). As part of their ongoing professional development, 
they regularly participate in training seminars and workshops, and attend conferences every year.

\section{Table 1}

\section{Participant Credentials}

\begin{tabular}{|l|c|c|c|}
\hline Pseudonym & Years of Experience & Position/Accreditation & Sex \\
\hline Mark & 10 & Teacher & Male \\
\hline Derek & 5 & Teacher & Male \\
\hline Meredith & 4 & Teacher & Female \\
\hline Christina & 14 & Teacher & Female \\
\hline Callie & 8 & Teacher & Female \\
\hline Arizona & 23 & Vice-Principal & Female \\
\hline April & 10 & Teacher & Female \\
\hline Miranda & 38 & Teacher & Female \\
\hline Izzie & 15 & Teacher & Female \\
\hline Jo & 15 & Principal & Female \\
\hline Lexie & 4 & Teacher & Female \\
\hline Amelia & & & Female \\
\hline
\end{tabular}

\section{Qualitative Methodologies}

Qualitative research is a way to explore and understand individual experiences that connect to larger social issues, complexities and underlying factors influencing individuals and society (Cresswell, 2009). Lichtman (2010) identifies description, understanding and interpretation as critical elements of qualitative research that are important because qualitative researchers "ask 'why' questions and questions that lead to a particular meaning" (p. 12). As a qualitative researcher, I wanted to obtain a deeper understanding of how the anti-bullying framework is implemented within the education 
system, while also examining the broader issue of how teachers are prepared to support Indigenous students.

\section{Multi-grounded Theoretical Approach}

Through the analysis I provide, there is an in-depth evaluation of the bullying label, its intersection with education policy through the Ontario anti-bullying framework and the potential impact of that framework on Indigenous youth. My analysis is informed by theoretical frameworks of settler colonialism and the social-construction of bullying. Using those theoretical frameworks along with a grounded theory approach allows me to answer my research questions on how educators understand, interpret and implement the Ontario anti-bullying framework when working with Indigenous students. Also, my experiences working with and teachings received from the Nokiiwin Tribal Council impacted my analysis. The work I engage in with the Nokiiwin Tribal Council includes teachings on reconciliation, community development, Spirit Building, ${ }^{28}$ understanding bullying and lateral violence in the workplace, and labour force participation. Listening to community members talk about their experiences helped inform this research data analysis. Also, I received Spirit Builder training from the Nokiiwin Tribal Council.

Using a grounded theoretical approach during data analysis allowed themes to surface from the data. Drawing on the themes, through consultation with an Indigenous researcher, I adopted some elements of a Two-Eyed Seeing approach (see below). The

\footnotetext{
${ }^{28}$ Nokiiwin Tribal Council Spirit Builders are positive mentors within the Nokiiwin Tribal council communities who promote traditional Indigenous values and teachings as well as knowledge exchange. Nokiiwin Spirit Builders are trained through their in-house "Our Journey Away from Lateral Violence" Training Program. These workers offer support for individuals working through their own personal struggles.
} 
type of work completed through the analysis phase of this project is relative to the multigrounded theoretical approach.

The multi-grounded theoretical approach is relatively new in academia as it emerged in 2003, through Cranholm and Goldkulh's paper, "Multi-Grounded Theory Adding Theoretical Grounding to Grounded Theory." Multi-grounded theory allows "an opportunity to draw on existing theories while still inductively analyzing data allowing the data to speak for themselves, drawing the researchers gradually toward a conclusion, yet still permitting the influence of existing theories that do not conflict with the data at hand" (Freeman, 2018, p. 1162). Cronholm (2004) states, "theory development should aim at knowledge integration and synthesis" (p. 2). Theory development in multi-grounded theory is described as follows: "the great strength of Grounded Theory, an inductive approach, and the antithesis of Grounded Theory, a deductive approach based on previous theory, should be harnessed together in the production of theory" (Freeman, 2018, p. 1163). I was able to apply outside information and literature to inform my interview questions and how I collected my data, utilizing data and theoretical frameworks beyond my own empirical research. In my dissertation, I identified several key conceptual frameworks that represented the deductive approach for the study. The information from the deductive aspect gave me a starting point from which to think about my topic.

Multi-grounded theory allowed this project to be grounded in previously developed theories of settler colonialism and the social construction of bullying. The theoretical insight that has been developed from this project combines theoretical components of settler colonialism and the social construction of bullying — the presence 
of settler colonialism informs the social construction of bullying and the implementation of anti-bullying frameworks leading to the term bullying being used to obfuscate racism, violence, and harassment; this applies to the critical analysis of the bullying label and its continuous impact on Indigenous youth. Once I had identified this preliminary theoretical insight, I returned to compare it against existing theories such as settler colonialism and the social construction of bullying (Cronholm, 2004).

\section{Interview Methods}

Interviewing is a face-to-face conversational practice "where knowledge is produced through the interaction between an interviewer and an interviewee" (Brinkmann, 2008, p. 471). It is short-term interaction between two strangers (or more) with "the explicit purpose of one person obtaining specific information from the other" (Neuman, 2010, p. 342). By conducting interviews with semi-structured questions, I wanted to obtain an in-depth understanding of the way some teachers choose their professions, are trained (such as why they choose different types of professional training over others), how they interpret and apply provincial and local anti-bullying frameworks and how they engage with the recommendations from the TRC regarding education.

I prepared an interview guide with semi-structured research questions. During the first two interviews, an error was recognized in the numerical order of the questions the hardcopy interview guide was printed with a duplicate question. This was rectified for the remaining interviews. Rowley (2012) acknowledges that semi-structured interviews have a "varying degree of adaptation of questions and question order to accommodate the interviewee" (p. 262). As participants were questioned, there were instances where answers had already been provided in discussion. One participant used the interview 
guide as a tool to help them answer the questions before they were asked. Although this participant went through the list, there were areas in the conversation where follow-up questions were asked.

\section{Telephone Interview Methods}

After conducting in-person interviews, one participant contacted a colleague who works in a different town, but is part of the same school board. I had already returned to Thunder Bay, Ontario, and the participant was not travelling to Thunder Bay in the near future, so we agreed to conduct a telephone interview. Contacting this participant by telephone allowed the interview to take place, whereas the geographic distance between us would have required several hours travel time.

\section{Written Response Methods}

One participant decided to answer the semi-structured questions in-writing. Answering the questions as questionnaires generally allows participants time to think about the questions and potential answers. Although the participant had more time to think about the questions and answers, the quality of the answers provided did not prove to be as rich in data as the responses of those who participated in-person.

\section{Transcription and Analysis}

After conducting the in-person and telephone interviews (11 interviews), I transcribed the audio recordings. Transcribing interviews is "an interpretive process that demands prolonged practice and sensitivity to many differences between oral speech and written texts" (Brinkmann, 2008, p. 472). Each transcription took approximately 4.72 hours to complete. 
To understand the thought processes for educators, regardless of their role (teacher or principal), I used a Grounded Theory approach for data collection (Charmaz, 1996) and a Multi-Grounded Theoretical approach for analysis (Cronholm, 2004). I adopted elements of a Two-Eyed Seeing approach as a broader strategy to ensure an appropriate approach to dealing with an issue of fundamental importance to Indigenous people. ${ }^{29}$ As a qualitative researcher, I am not neutral - I have my own opinions about the project I conducted and about the responses I received; however, I refrained from providing commentary throughout the interviews. Additionally, I do not and cannot assume how educators understand their surroundings and how their experiences have impacted their perspectives of society (and more specifically, their work environment and interactions with their students). Although I do not assume how or why participants provide certain responses, I am reflexive of my own position and acknowledge this in the introduction to this dissertation. After I collected data from participants, the sequential guidelines for Grounded Theory were followed, whereby I openly coded, completed the axial coding phase, then the selective coding phase, which steps were also reversed for analysis (Neuman \& Robson, 2014).

\section{Coding}

Using the Multi-Grounded Theory method, data collection and analysis are interwoven (Neuman \& Robson, 2014). After transcribing, I openly coded the data. The coding process was carried out by reading each of the transcripts and attributing a code to sentences, paragraphs and/or sections (Neuman \& Robson, 2014). I coded the themes

\footnotetext{
${ }^{29}$ I am not relying on a complete Two-Eyed Seeing approach because I did not involve Indigenous peoples or the Indigenous Education Authority from the outset of the research (Bartlett et al., 2012; Fortier, 2017). The project design was developed on my own, in consultation with my PhD committee.
} 
with bright highlighters. As I openly coded the transcripts, I acknowledged that I could create new themes in subsequent analysis. The themes found during the open coding stage were "at a low level of abstraction and come from the researcher's initial research question, concepts in the literature, terms used by members in the social setting, or new thoughts stimulated by immersion in the data" (Neuman \& Robson, 2014, pp. 331-332). The initial codes were written on hard copies of each transcript next to the related section. The following themes were recognized in the initial read-through of the data: surveillance of teachers, surveillance of students, restorative justice, online bullying, instruction by teachers, geographical resources, educational resources, segregation/separation of Indigenous students, teacher training, accuracy of history, definition of bullying, TRC policy, Other. At this point, I created analytical memos, where I wrote down various thoughts for consideration as I read through the transcripts (Neuman \& Robson, 2014, p. 338). Every theme I found had its own memorandum. This helped me decipher themes and provide a deeper analysis.

After the first round of highlighting, I separated the highlighted data into separate documents organized by themes to conduct the second read through of the data, referred to as axial coding (Neuman \& Robson, 2014). I began the second round of coding with initial codes and preliminary concepts. Axial coding is considered to be the phase where “a researcher asks about causes and consequences, conditions and interactions, and strategies and processes and looks for categories or concepts that cluster together" (Neuman \& Robson, 2014, p. 333). In this round, I highlighted quotations that had historical and contextual meaning towards Indigenous politics. Furthermore, the analytic 
memos now housed deeper thoughts on the relationships between the first round of open codes.

The final reading of the thematic data incorporates "scanning the data and previous codes and determining a core category around which the remaining categories all 'fit'" (Neuman \& Robson, 2014, p. 335). In this last section of coding, I decided whether or not the information presented fit into any of the themes. The data that did not fit into the themes was noted in its own analytic memo for discussion.

While coding the transcripts, I noted similarities and differences throughout the data. For example, I wanted to see if there were similarities between educator experiences and perceptions of marginalized youth. For example, some of the questions asked were,

a. Were there many Indigenous students in your school? If yes, did your teacher treat everyone the same in the classroom? Can you provide me with some examples?

b. Have you always wanted to be a teacher? If yes, why? If no, what caused you to want to become a teacher?

c. Can you tell me how Ontario's anti-bullying framework supports students? Can you provide me with some examples?

d. Can you describe any changes that have occurred at your school since the recommendations from the Truth and Reconciliation Commission have been published?

e. Are there groupings of students or teachers at your school? What do you think makes these groups unique? Are there friends among the various groups? How would you describe the boundaries between those groups? Do you think these 
group dynamics have changed since the recommendations from the TRC? If so, please provide me with one or more examples. What policy(ies) does your school adopt to provide a safe space for students?

Educator responses to these questions are detailed in the next chapters. The themes that are specific to answering my research question include growing up with Indigenous peers; understanding of Indigenous history and residential schools; awareness and understanding of the TRC's calls to action; indigenizing curricula; understanding bullying; understanding the Ontario anti-bullying framework; implementation of the Ontario anti-bullying framework in school; and teachers exercising discretion when it comes to the framework.

\section{Consultation Process}

In light of the fact that I am a White settler studying an issue that impacts Indigenous people, I tried to incorporate an approach in which cultural differences are understood and respected, particularly when understanding Indigenous culture alongside the Western perspective. This involved adopting elements of Two-Eyed Seeing.

Two-Eyed Seeing is a concept that was developed by Elder Albert Marshall in 2004. This approach brings forward an “'it's us, together' consciousness” (Bartlett et al., 2012, p. 335). Two-Eyed Seeing is defined as an approach by which people, learn to see from one eye with the strengths of Indigenous knowledges and ways of knowing and from the other eye with the strengths of Western knowledges and ways of knowing, and using both these eyes together, for the benefit of all. (p. 335)

This concept provides guidance to recognize differences, while acknowledging similarities between Westernized and Indigenous views. For example, Bartlett et al., 
(2012) suggest the following lessons when incorporating the Two-Eyed Seeing approach to critical analyses:

- acknowledgement that the Western culture must engage in co-learning journeys;

- that the co-learning journeys be guided by the Two-Eyed Seeing approach discussed above;

- that the co-learning journeys "do things" (rather than "just talk") in a creative, grow-forward way;

- that the people part of the co-learning journeys put forth their values, actions and knowledges for critical examination and discussion; and

- that the co-learning journey weaves back and forth between the worldviews under examination. (Bartlett et al., 2012, p. 334)

These lessons help critically examine social structures and their impact on citizens, particularly how Indigenous culture can be included and valued as an equal contributor in Westernized educational structures and curricula. Without critical consultation between the Western ways of seeing and the Indigenous ways of seeing and incorporating the Two-Eyed Seeing approach, historical understandings and Eurocentric views will remain prevalent and unchallenged in society.

Adopting part of the Two-Eyed Seeing approach, I consulted with an Indigenous researcher, while analyzing my interview transcripts. Discussions were had on a weekly basis and the researcher was financially compensated. This consultation process provided me with the opportunity to ask questions and discuss policy gaps. As we discussed data in the transcripts, we searched for places where both positive and negative impacts could be 
identified. As an academic, I am trained to be critical of social structures, laws/policies and their implementation in society. Listening to the Indigenous researcher, and searching for both positive and negative impacts was important to my analysis. Unlearning to always focus on negative impacts takes time and effort. Recognition of positive situations in both Western and Indigenous perspectives brings research back to the teaching of the Two-Row Wampum Belt, where Western and Indigenous knowledges are shared and developed based on peace, friendship and respect (4Seasons of Reconciliation, n.d.). Marsh et al. (2015) elaborates, "the application of the concept of Two-Eyed Seeing advocates for inclusion, trust, respect, collaboration, understanding, and acceptance of the strengths that reside in both Westernized and Aboriginal worldviews" (p. 4). Forbes et al. (2020) further acknowledges that Two-Eyed Seeing is not only a research methodology, "but rather a profound guiding principle that encourages self-reflection and emphasizes the transformational capacity of knowledge" (p. 2). In this research, the multi-grounded theoretical framework is complemented by the applied elements of the Two-Eyed Seeing approach.

As described earlier, I have been provided opportunities to learn about and see the impacts of legislation and how it impacts Indigenous people on reserve. The relationships developed with the Nokiiwin Tribal Council community members and employees have provided me with experiences I would not have had otherwise. For example, in addition to learning in community, I was able to attend a conference in Toronto, Ontario hosted by Nokiiwin, where I had an opportunity to meet First Nations leaders from Saskatchewan. I was also able to attend a conference in Winnipeg, Manitoba, hosted by the Canadian Society of Safety Engineers where I presented with Dr. Kristman on projects conducted 
with the Nokiiwin Tribal Council. At this conference, I was introduced to Indigenous leaders from Alberta and British Columbia. I am grateful for these learning opportunities and they have impacted my interpretation of this project's research data and how policy and laws that are in place are designed for (or against) Indigenous wellbeing.

\section{Conclusion}

Before conducting this project, many issues were considered. TCPS2 considerations of conducting research that impacts Indigenous people were at the forefront of this project. Recruitment of participants was unfortunately more difficult than anticipated, given the difficulty obtaining Director of Education approval. Nevertheless, there were 12 educators employed across northern Ontario who participated. This research used qualitative methods and methodologies and the Two-Eyed Seeing approach, incorporating both the Western and Indigenous perspectives.

In the chapters that follow, I provide a discussion of participant understanding of Indigenous history, culture and issues, and awareness and implementation of the Ontario anti-bullying framework in schools. These chapters outline the data to answer my research questions, how do educators in northern Ontario understand and implement the Ontario anti-bullying framework and how does it potentially impact Indigenous youth? 


\section{Chapter Six \\ Context: Colonial Educators and Indigenous Students}

In this chapter, I discuss the social and educational backgrounds of the research participants. Knowing where the participants come from is necessary to have a better understanding of their attitudes and behaviours towards Indigenous people. Awareness of participant history with Indigenous people will assist in assessing how they understand and implement the Ontario anti-bullying framework based on their differing perspectives.

During interviews, participants were asked where they grew up, and their high school and university experiences. They were then asked if there were Indigenous people in their home communities and if so, they were asked to describe the perceived attitudes of non-Indigenous community members towards them. They were then asked their history of why they became educators, the type of professional and non-professional training they have (unrelated to the anti-bullying framework), including unique life experiences that they believe impact their teaching. They were also asked if they are familiar with any Indigenous ways of knowing. They were asked these questions to gauge their understanding of the community they grew up in and to determine if stereotypes were learned before they attended post-secondary education/were employed with their school board. In conclusion, participants were asked about curriculum changes since the TRC published their calls to action. Awareness of educator narrative and experiences is necessary to critically reflect on their understanding and engagement of the Ontario antibullying framework in their schools and how their perceptions may impact Indigenous youth involved in negative behaviour labelled as bullying.

Themes that developed from the interview process include: the political and social atmosphere in northern Ontario is different from southern Ontario - not only is the 
geographical space different, the infrastructure and social expectations are different. Participants who were raised in northern Ontario referenced racism, harassment and violence against Indigenous people, whereas participants from southern Ontario who had moved to northern Ontario were not aware of Indigenous politics until their university or work experiences. Although not all participants were aware of Indigenous politics and the residential school era, it is apparent that most educators were, and they believe their schools are trying to indigenize curriculum in accordance with the TRC calls to action and recommendations. These themes and responses are discussed below.

\section{Current Qualifications for Becoming a Teacher}

The twelve participants in this study are certified teachers, having completed both an undergraduate degree and an education program at an accredited university or private institution (OCT, 2019). Only one participant, Mark, completed their education program in the United States because they were not accepted into a Canadian education program, while all other participants completed their education program in Canada, specifically in Ontario. Two of the twelve participants, Arizona and Lexie, are trained principals, comprising the roles of vice-principal and principal.

\section{Background of Participants}

Nine participants grew up in northern Ontario: Thunder Bay, Manitouwadge, Fort Frances, Cochrane and Sudbury areas. Three participants grew up in southern Ontario, all from the Greater Toronto Area. Each participant, along with their educational qualifications, are listed on page 101. Derek, Mark, Amelia, Callie, April, Miranda, Jo and Izzie are all classroom teachers. Meredith and Christina are teachers but are not in 
typical classroom roles. Arizona is a vice-principal, and Lexie is a principal. Callie is the only participant who identified as Indigenous.

Meredith teaches high school in an Alternative Education Program. Her office is not located on the high school grounds, but rather off-site. Her role is to support high school students who are finishing their diploma. She visits the local school on a weekly basis. In her off-site location, and within her role, she does not often deal with incidents of negative behaviour, although she does hear stories about bad behaviour between students and incidents occurring at the main school. Christina also does not have an assigned classroom. She was a classroom English teacher but transitioned to a literacy coach in the same school she taught at. April is the only participant who teaches Junior Kindergarten. In her role, she deals with incidents of negative behaviour between 4 and 5 year-olds. She teaches children how to be kind to one another.

\section{Growing Up with Indigenous Peers}

"How does one know if you are sitting with somebody who is Indigenous?" - Jo

"I was an ignorant kid, too. I didn't understand why things were the way they were, and I didn't have anyone to guide me towards that understanding, either." - Derek

One participant, Jo, who grew up in southern Ontario, responded with an insightful question when asked if they had attended school with Indigenous students. They questioned, "how does one know if you are sitting with somebody who is Indigenous?" This is an important question which should be considered because everyone else who responded assumed they knew what it meant to look like or 'be' an Indigenous person. Jo was the only one to bring up the underlying assumption even I was unaware of in my presentation of the question. 
Most of the participants acknowledged that Indigenous peers were walking the halls of their high schools, however, in most cases, they were not in the same classes. Others were unaware of the presence of Indigenous peers in their school. Only three participants recalled having Indigenous peers in their classes. Meredith, who grew up in northern Ontario, pointed out that Indigenous students were in essential courses and perhaps in her grade 9 gym class where the academic or applied stream did not matter. Christina, who also grew up in northern Ontario, pointed out the fact that her friend Rhonda ${ }^{30}$ was the only First Nations person in her academic courses that she can specifically remember. Using Rhonda as an example, Christina did not feel that teachers treated her any differently "she was a very good student, she was a serious student."

Callie also grew up in northern Ontario and reflected on her time as a child in the 70s; she remembers when a First Nations school near her closed down and kids were transferred to her school, kids were just kids. I didn’t even identify with First Nations communities or nonFirst Nations communities because [where I am from encompasses] a lot of little places, so I didn't even know the difference, to tell you the truth [...] I didn't recognize that there was a segregation.

Callie's time in school was very different from what other participants reported. She had Indigenous peers in her classroom and their culture/heritage was not questioned. Her observation could be because the Indigenous population where Callie grew up did not critique who was present in their community.

\footnotetext{
30 The friend's name has also been changed to remain anonymous.
} 
Derek reported that there were many Indigenous students at his northern Ontario high school. He remembered peers using derogatory statements, "people calling Indigenous people names $[\ldots]$ treating them poorly". He believes his peers' behaviour in high school could be due to the lack of knowledge and understanding of Indigenous history and the trauma Indigenous people have endured. Derek did not learn about Indigenous history until university. Reflecting on his experience in high school through to university he stated, "I'd be lying to say that I was always like, as empathetic as I am now. Like, I was an ignorant kid too. I didn't understand [Indigenous history] and I didn't have anyone to guide me towards that understanding either."

Amelia wrote that during her childhood in northern Ontario, she perceived "a tension between First Nations and White people; I definitely think there is systemic racism." She heard racist comments from her friends and sometimes family members but did not describe these statements in more detail. April, also from northern Ontario, was not sure if she went to school with Indigenous peers.

A big difference among the participants was the era when they were in high school. For example, Miranda, also from northern Ontario, noticed that only approximately $10 \%$ of the school population was Indigenous when she was in school. Miranda is the oldest of the participants in this study and thus may not have had many Indigenous peers in her school because of the fact that Indigenous youth were segregated to residential schools during her time. There is a common theme throughout the responses of those who stated they went to school with Indigenous youth: racism was present. 


\section{Community Demographics and Comments}

"Indigenous people were kind of invisible to me." - Meredith

"They talked about First Nations people like they were subhuman." - Christina

Connecting to participant experiences with Indigenous youth in school, I asked about broader community demographics and commentary. When participants were asked to describe their community demographics and education system, five participants pointed out and reflected on the racial slurs that were said to describe Indigenous people. All of these participants were from northern Ontario. Meredith described that there was a large Indigenous population in her community and in school, but that "it felt quite segregated and separated [...] and also even with social groups, it was quite segregated." She stated that the derogatory term "bogan" was used by herself, her peers and her parents. Meredith reflected on her experience in high school, "you know, even just the idea that my whole high school career, Indigenous people were kind of invisible to me." Christina echoed Meredith's experiences, stating that racism was accepted in her home community and that older generations "talked about First Nations people like they were subhuman." Christina and Meredith are from the same community and share many of the same experiences. Recognizing that racism was prevalent in their families, among their peers and even in their own behaviour growing up, was difficult for them to admit.

Arizona remembers her community held a lot of racist attitudes. She remembers the standoff at Anishinaabe Park over Indigenous land in 1974,

I do remember it happening [...] there were guns involved, which was quite violent for the time. Even though I don't think that there was uhhh a ton of violence, but 
my grandparents lived right down the street from there, so, I certainly remember the tension.

Arizona elaborated that violence against Indigenous people was high and they were targeted. Miranda, living in northeastern Ontario, shared her recognition that myths about Indigenous people were spread throughout communities. For example, Miranda stated that the idea of Indigenous people as lazy was the attitude in her community.

April also admitted that there was prejudice against Indigenous people in her northeastern community. She believed that it depended on the generation of the person making the statements,

the older generation [...] it was still that whole uhhh, they're dirty, they're no help to our community and stuff like that, I found that as the generations got younger, like my generation, we were more accepting towards them [Indigenous people], ummm, yeah, so I just found that when they were, like my Grandfather let's say, he's read [...] books on Indigenous residential schools, but he still has that mentality [of the older generation], but yet we're a little more open.

Tension between Indigenous people and White people existed and still remains prevalent. Amelia stated, "there is a systemic racism in our town to this day, and I hear it from many of my own friends and sometimes my family members."

Other participants had positive or neutral experiences in their community relating to Indigenous people. As an Indigenous person, Callie remembers growing up in her northern community positively, stating that teachers were caring and good to her. She compared her kindergarten teacher to her Grandmother. Lexie grew up in the north and brought forward the idea that Indigenous youth were not any different than other kids 
because everyone in her town was from somewhere else. In the community or at school, there was no difference in how youth were treated. Jo echoes this in her responses. Jo is not sure if she went to school with Indigenous people but worked at an Indigenous trading post in southern Ontario, so assumed that some Indigenous people lived nearby, "but I certainly wouldn't be able to tell you if I went to school with any of them."

The above responses show that most of the participants who grew up in northern Ontario had direct experience of racism against Indigenous people when they were growing up. Those from southern Ontario did not. The communities of the participants influenced their upbringing. Only one of the participants, Izzie, had moved as a child and thus had more than one influential community involved in her upbringing. As participants aged and learned about Indigenous history and politics, many shifted their thoughts about Indigenous people.

\section{Growing up in Southern Ontario}

“Moving up here [...] I feel like I've gone backwards in time." - Jo

Only three participants, Jo, Mark and Izzie, grew up in southern Ontario. They believed the communities they lived in did not discriminate against Indigenous people because they did not hear about them. Mark, for example, had never heard of residential schools until he was 19 years old and in university. Even in university, he believes he did not fully grasp Indigenous culture and politics until his employment in the north (discussed below). Growing up in his farming community, he did not experience any negativity about Indigenous people.

Jo admitted that her cultural upbringing is not comparable to northern Ontario. She stated, "in my hometown, if somebody were to say the ' $N$ ' word, [...] people would 
probably beat them up $[\ldots]$ when I moved up here $[\ldots]$ people would say the ' $N$ ' word, and nobody would do anything." She further reflected "moving up here [...] I feel like I've gone backwards in time."

Izzie also grew up in southern Ontario and attended the same university as Mark. Izzie had also not heard anything about residential schools until her undergraduate studies. Not hearing about residential schools until university was shocking for Izzie because she has a personal connection to Indigenous culture. Their cultural heritage interested her, so she was introduced to, and started a relationship with a local Indigenous community as a teenager (where residential schools were most likely not a topic of conversation). Before reaching out to the Indigenous community, she did not know that there were Indigenous people. According to Izzie, as a child she did not question races or classes; however, as she grew older, she reflected and became aware of embedded racism in society towards minority groups, specifically focusing on Indigenous people. Drawing on her personal connection's experience, she pointed out that,

[They were] automatically placed in a lot of essential-based, workplace classes, although [they are] quite bright, [they're] very hands-on, umm, so [they] struggled with math, but was fantastic in the shops, so that automatically became the assumption was that [they] needed to do essential English as well $[\ldots]$ one of the teachers $[\ldots]$ used to call [them] Chief on the basketball court, that was like [their] nickname. [Their coach] didn't realize how hurtful it was for [them] growing up and [they] didn't feel like it was [their] place to ever correct it.

She believed that Indigenous youth did not want to identify as Indigenous in school. She believed it was due to the shame that some youth felt. She stated that there were a lot of 
negative assumptions that Indigenous people were lazy or that they lacked family support. What she sees now is that there are open minds and people have become more aware of Canada's real history; a social shift is happening with younger generations.

Jo, Mark and Izzie all had very different upbringings in southern Ontario. Jo is from a small-town on the US-CAN/ON border, Mark is from a small farming community and Izzie moved communities, unaware of the cultural differences around her. Growing up in southern Ontario appears to be very different than in northern Ontario due to the presence of more diverse cultures and races in the south and more Indigenous people in the north. In this moment, it can be inferred that this is due, in part, to the historical placement of Indigenous communities in northern, rural, remote areas. Reflecting on where these participants grew up and the attitudes/behaviours they were exposed to of Indigenous people, impacted the way they viewed Indigenous culture and politics up until their experiences working with Indigenous students and communities in northern schools (to be discussed below).

\section{Political Understanding of Indigenous History and Residential Schools}

"It certainly is concerning [...] how much trauma there is and the trauma that you see in the streets." - Arizona

"They were trying to treat them like farm animals." - Mark

Reflecting on participant upbringing and location connects to their understanding of Indigenous history and residential schools. Two participants, Jo and Meredith, did not understand Indigenous politics when they started working at their school. Another participant, Mark, had some understanding, but did not grasp the ongoing impact of residential schools until employment at his school. However, with experience, all three became aware of the problems Indigenous people face. Despite growing up in the north, 
Meredith did not understand the political undertone of why Indigenous people were segregated, however, with time and experience at her employment, she has gained a better understanding. She stated, 'I feel like I've learned a lot about [the residential school legacy] since living [in a largely Indigenous community] and working here and just having that information has really changed my perspective and helped me be more empathetic and be more understanding."

The remaining eight participants, Christina, Callie, Arizona, Miranda, Izzie, Lexie, Amelia and Derek were aware of the history behind Indigenous politics and were able to describe the impact on Indigenous people. Arizona reflected on St. Mary's Residential School and the history of violence, and trauma Indigenous people endured and how self-medicating behaviour and alcoholism have been a direct result which individuals, and even subsequent generations, experience. Christina referenced the trauma endured. She reflected on current friendships she has with people whose parents are residential school survivors; their families are "very religious, their homes smell like bleach $[\ldots]$ that's the side they came out on." On the other side, she has been told residential school stories from homeless survivors and how their experiences led them to addictions and the inability to parent. Amelia opined that the government wanted to keep Indigenous people away from urban centres and therefore the reserve is where they remain.

Miranda, Izzie and Lexie referred to political take-over by European people. Miranda stated, "politically, [...] Europeans came in and said, 'hey, not right, you're savages, you don't know what you're talking about $[\ldots]$ and we're going to fix you because we know everything." Lexie also stated, "the government has badly underserved 
Indigenous people, poverty is rampant, umm, it's very, very challenging, to make things equal to what a non-Indigenous person has." Izzie reflected on a story she was told, "while communities thought, in conversation at the time that they were getting the land they traditionally used, they oftentimes weren't." Derek reflected on the disrespect Indigenous people received when the treaties were signed. He stated, there's a huge inequity with the way that the treaties have been signed $[\ldots]$ the Indian Act and all sorts of legislation that has really put, you know, Indigenous people, in an unfavourable position [... I'm fairly doubtful they got all they wanted when they settled on where their communities are.

Derek and Izzie claimed that the Treaties were not honoured; translations were not properly recorded.

Only one participant who grew up in the north, April, seemed not to understand either the historical trauma Indigenous people went through nor the political undertone of Indigenous history which continues to negatively impact them. When asked, she stated, "I know it has to do a lot with self-identification and whether they identify as Indigenous, but other than that, I'm not sure."

\section{Residential Schools}

Most of the participants were informed about residential schools but admitted that this was only due to the nationwide attention the TRC received. The following responses provide a synopsis of what participants knew at the time of their interviews. Meredith attributes the large focus on residential schools to the TRC as well as the deceased Canadian rockstar, Gord Downie. Meredith, growing up in the north, reflected on how 
her own family was unaware of the residential schools until Downie brought the issue to light.

Christina knew about the residential schools but not in great detail. Mark, coming from southern Ontario, gained some awareness through university courses that some of the residential schools were run by the Catholic Church and that youth were taken from their homes and treated like animals. He stated,

I look at it that they were trying to treat them like farm animals that if you take an individual from their home community, put them under these circumstances, then you're going to end up with someone who's prepared to live in modern Canadian society and they felt that it was not achievable by leaving them in their home communities. I know that there is a long history of abuse, uhh, in those institutions, $[\ldots]$ the breakdown of families $[\ldots]$ that resulted from taking these children from their home families so young. Umm, and I also know, I think it was up until [... the last] one closed in the $90 \mathrm{~s}$.

Mark also commented on brochures he purchased,

It's actually funny because I, not funny at all actually, but I, [obtained] some tourism brochures of the Dryden area from the 50s and 60s and they encourage you to go visit the Indian Residential School as a tourist attraction where they [...] encourage you to go and check out the MacIntosh Residential School and all the great things they are doing up there.

Mark used humour about the tour brochures he owns, then he quickly corrected himself. I wondered if his responses in this moment were provided as what he thought I wanted to 
hear, or if he was displaying irony or if he believed he provided socially acceptable responses. I am not sure.

Callie stated that there are two Indigenous communities where she lives in northern Ontario, of which she is from one of them. When asked about the residential school system, she responded, "the goal was to take the Indian out of the child [...] eliminate or assimilate the Indigenous people, cause it's easier to assimilate than it is to kill them off, cause that's the Western way of doing things." She further pointed out that she has personal relationships with residential school survivors, some of whom are family members and suffer from the effects of colonization and residential schools: "alcoholism, suicide, sexual assault within the family; and dysfunction within the family."

Arizona reflected on how Indigenous youth were stereotyped when she was a teenager and how often Indigenous people would drown. She stated, every other day, there was ummm, bodies showing up in the lake, so and so had drowned, and of course at that time, you really didn't pay much attention to it because it was such an everyday occurrence it felt like and you sort of blocked it out and you didn't know and, the commentary would be oh well they were probably drunk so they fell in the water and drowned $[\ldots]$ and it wasn't necessarily people you know, ummm, but as I've grown up [...] and I come to know different families and ummm, uhh things like that, it certainly is concerning as to, as to how much trauma there is and the trauma that you see in the streets and the umm, the people who you just want to reach out and help who are just hurting so badly. 
Arizona "really struggles with how a human being could do that [inflict violence and trauma onto Indigenous people in residential schools or at other times] to another human being." She continued,

when I mentioned it to one of my friends who is First Nations [...] his comment back to me was, 'but [A], they didn't see us as human beings, they saw us as savages, so it wasn't like they were treating another human being cruelly, they were dealing with savages.' And that was like, a stab right to my heart and I just thought, I still can't understand it $[\ldots]$ the issues that have come from it are longstanding, they're deep [...] I would hope that we could make a change and that by understanding what happened, that we can move forward and make things better.

Arizona, growing up and living in the north, mentioned that the trauma from the residential schools continues to impact some of her community members. When asked to describe the trauma she sees on the streets, she described residential school survivors struggling with addictions and the children of residential school survivors whose parents are either not around to care for them or have died who are also living on the streets, struggling with mental health and addictions.

Arizona further reflected on another friend's response growing up in the residential school era, he went to residential school, but he was also part of uhhh the 60s scoop, so he has talked about umm, not necessarily the trauma of the residential school as much as the trauma of being taken away from his family [...] I know that his, he knows that his mother ummm comes from Lac Seul, so the Sioux Lookout region [...] every once in a while he talks about it, and how awful it was to be taken from your family 
and never to see them again, and [...] ummm even though he says you know, he was raised by a great family, but none of that cultural piece.

The traumatic impact of residential schools, the 60s scoop and colonialism are felt through Arizona's description of her friend's stories and her own reflection.

Miranda, Izzie, Lexie, Derek and Jo all expressed a clear understanding of the residential school system. Miranda shed tears and pointed out that she is part of one of the first church groups that publicly apologized to Indigenous people for the violence and abuse they endured for decades; Derek stated, "Indigenous people put out their hand in trust and then European people just like really took advantage of them."

Miranda believes she is culturally aware of the vast differences between her students. She has been teaching at the same school for more than 25 years. When asked if she had any life experiences that improve her teaching quality, she reflected on the way she was raised, "it was really important to my parents that we umm, be accepting of people". With tears flowing down her cheeks, she reflected on her parents' upbringing, my grandfather was an Orangemen, and so, my Mom would never be allowed to talk to Catholic people and so, when her and Dad got together, they just made it really important that we didn't look at the colour of skin or any of that kind of stuff. If a person was nice to you, you were expected to be nice back.

Despite her parental influences and growing up in northern Ontario, she grew up unaware that the residential school system existed, probably because of the time when she was in school — when residential schools were also full.

Izzie's response is different from other participants. She reported positive critical reflection on residential school experiences. Izzie stated, "there's been interesting 
conversations, ummm about whether or not anything positive came out of them [the residential schools], and I think, sure there are some people who might have had ok experiences, but the policies that implemented them were terrible." Izzie is the only participant who posited that there might have been neutral residential school experiences. The response from Izzie does not negate the traumatic experiences of others. It is important to note that her response may have an unwillingness to comprehend the extent of the trauma that many Indigenous people experienced. This response may be a precursor to applying a Two-Eyed Seeing Approach, but it can also be seen as ignoring the importance of continued colonial impact through intergenerational trauma.

Teachers are not trained in university education programs to navigate Indigenous issues and politics, but rather they are trained to move through the Canadian education system, teaching the Canadian curriculum. While the timing of each participant becoming aware of residential schools differed, all of the participants, except April, reaffirmed that the purpose of the residential school system was to strip Indigenous children of their culture, and traditions.

\section{Life Experiences and Indigenous Ways of Knowing}

Building on participant understanding of Indigenous politics and culture, participants were asked what generalized training they have, whether professional or nonprofessional. I wanted to know any unique experiences which contributed to their teaching practices. I also asked if they had any experiences in Indigenous ways of knowing. I wanted to know if participants were aware of the various traditional methods Indigenous people use in teaching others and if so, if this knowledge was used in their 
classrooms. It became apparent that most participants understood some form of Indigenous ways of knowing/teachings/culture.

Participants shared their different learning journeys of Indigenous ways of knowing. Meredith expressed that she has no formal training on Indigenous ways of knowing. Christina has experiences with Indigenous culture; she was exposed to various Indigenous teachings, and was involved in pow wows, boxing and beading. Her other experiences with Indigenous culture included First Nations literature courses completed during her undergraduate studies.

Callie reflected on her experiences of post-secondary education through Seven Generations. She also reflected on her experiences with her Elder, I have my own Elder, my own female Elder that I've worked with from the time I was probably 12 or 13 years, so when I have questions and when I need help, I just turn to my Elders and we actually have two Elders in our high school now, so if we need Elders, we can go to them.

Further reflecting on ways of Indigenous knowing, she described her traditional method of contacting an Elder,

I take tobacco and I take a gift and I hand, I take it to my Elder and I ask my questions and it's very informal I guess $[\ldots]$ very grassroots or traditional $[\ldots]$ I've never taken a course on $[\ldots]$ that's not my belief $[\ldots]$ I also don't believe in paying Elders $[\ldots]$ I was taught that your gifts are to be shared.

Derek is aware of Indigenous ways of knowing but relied on people he knew for this information: "we're constantly immersed in different Indigenous knowledge through Elders, and Knowledge Keepers and you know, people that speak the language." When 
asked to describe a Knowledge Keeper, Derek stated, "someone with a particular skill [...] like snaring or like dancing, or singing, or fishing or you know, things like that, hunting." Although Derek is aware of Indigenous knowledge, he advised that he would reach out to those Keepers and Elders if he wanted to engage a traditional practice in his classroom.

Arizona has different experiences working with First Nations, Métis and Inuit youth. She does not work at an Indigenous-only school, but in a northern school board. In her capacity before becoming a vice-principal, she worked with Indigenous youth for over 20 years in various education roles where she attempted to close gaps that impacted Indigenous youth attending schools in her district. Izzie has many experiences with traditional Indigenous knowledge. She expressed that there is no way to obtain formal training around Indigenous ways of knowing without immersing oneself into Indigenous culture. This is important to point out because some participants thought they understood Indigenous knowledge by attending specialized professional development talks with academics or politicians (described below). Izzie stated, "I've attended a lot of ceremony $[\ldots]$ full moon ceremonies $[\ldots]$ sunrise ceremonies, seminars $[\ldots]$ in recent years, the bulk of my training comes from my students." Reflecting further on her teaching career, she pointed out that,

I try to be an open book with them [her students] and tell them to correct me and if I'm saying something that I'm assuming umm is true, uhh, we're in an interesting area because some of our students are Algonquin, some are Ojibway, some are Cree, so that kind of pan-Indigenous mentality definitely seeps in, so I'll say something and have a student say, actually, for us, it's a different teaching, so [...] 
so my students have been very good with kind of keeping me in line with what's true of our geography and of our population.

Izzie supports teachable moments in the classroom from everyone, not simply from teacher to student, but also student to teacher.

I asked Izzie if there were other life experiences that helped improve her teaching quality and she responded with "being a parent [...] I try to think about how, how would I want a teacher to approach me about that issue, right, and that kind of empathy factor that I wouldn't have had if I wasn't, if I wasn't a parent." Izzie points out that empathy is important for all educators.

Lexie advised that she received professional development training through her school board but elaborated that she does not have any Indigenous Studies additional qualification courses. However, she expanded on her personal growth around Indigenous issues through exposure to Indigenous culture and knowledge received from the Indigenous youth in her school. Mark reflected on the reconciliation presentation he attended of Dr. Miigaanwewidam James Sinclair, and the recommendations from the TRC. Dr. Sinclair's presentation was the only information he had received on traditional Indigenous teaching methods.

April's experiences with Indigenous culture are similar to Mark's. She has no training with traditional Indigenous values. However, she mentioned one professional development session where previous Indigenous Affairs Minister, Kevin Lamoureux, spoke to their school and critically evaluated how teachers promote curriculum. April stated, "he was talking about $[\ldots]$ how we need to change our thinking and incorporate $[\ldots]$ the truth and reconciliation". She received a pocket-sized reference booklet on the 
calls to action to help her incorporate change in her own teaching methods. Although April's role as a junior kindergarten teacher does not fall into the scope of my study of high school teachers, she advised that she does use the booklet. An example of how she references the booklet is by including Indigenous teachings into play time by connecting toys to the land. April's contribution to this study is valuable because she provides insight into early childhood education and how teachers are trying to include Indigenous culture in the classroom at an early age.

Lastly, Jo is a certified athletics coach guiding students/players into learning sportsmanship, such as leadership skills. She does not have any experience with Indigenous culture besides her time working at an Indigenous trading post growing up in southern Ontario. Although not related to Indigenous ways of knowing, Jo stated that she is gay and that may mean that she is better able to understand and empathize with minority groups who are managing difficult situations.

In the above responses, participants described their experiences that they believe helped their teaching career and also described any experiences or training with Indigenous ways of knowing. Two participants were immersed in Indigenous culture. The other participants reported experiences with Indigenous culture that emerged through their university education, job experience and exposure to Indigenous Elders, ceremonies and political leaders in a variety of contexts. They reported that these experiences exposed them to Indigenous methods and teaching in schools, and caused them to critically reflect on shifting their own teaching methods. 


\section{Reconciliation and TRC's Calls to Action}

"It's taken this long to recognize it, it's going to take this long to fix the problem [...] it's generations, and generations and generations." - Callie

Participants were asked what reconciliation meant to them and what it looked like in their respective schools. Nine participants responded with varying messages. The responses of Christina, Mark, Arizona and Callie each addressed a different understanding of what reconciliation is. Christina stated, "I would like to think that currently the government is saying, 'I don't know what to do, that this is so huge and so complex that I don't know what to do." Mark was also neutral in his response, but he addressed that there are government efforts being made to move forward, "reconciliation is an attempt to $[\ldots]$ deal with $[\ldots]$ the wrong moves socially and politically that the federal government has made, and so they are trying to reconcile those past ills and make good on what they've done." Arizona asserted that reconciliation is not single-sided; "we are all responsible for re-building those relationships."

Callie's response was more critical of the government,

The government has recognized that they screwed up and think that throwing money at everything is going to fix it [...] it's taken this long to recognize it, it's going to take this long to fix the problem [...] it's not going to be fixed and we're in a society of instant gratification, it's not going to happen [...] it's generations and generations and generations.

April, Miranda and Izzie provided responses that demonstrated positive conceptualization of the importance of and opportunity for reconciliation. April stated, "to learn from the past and make things better." Miranda stated, "helping both sides understand the parts they played and then coming to terms with that." Izzie reflected on 
the two-row wampum as a guide for reconciliation; she stated, reconciliation is "the idea of learning to walk side-by-side, respectfully [...] reconciliation is action-based [...] encourage cultural expression."

Izzie believes that her school was already on the right track when the recommendations from the TRC were published. Using an action-based approach, her school had already been teaching courses with Indigenous content, however, with the TRC's calls to action, her school has been engaged in whole-school training. For example, Izzie also acknowledged Murray Sinclair's work as the head of the TRC and his presentation at her school. She stated,

there's been a push for all of our staff to open up more and I don't think we would have done that without the TRC. I think now there's more [...] pressure for it to be a moral obligation for all teachers to be open to, umm, to our responsibility as Canadians. To right some of the wrongs, uhhh and to make our teaching more inclusive.

Across the province, Arizona stated that her school has "taken the Truth and Reconciliation calls to action 62 and 63 and embedded them in the social studies program" where the school board has encouraged teachers to build relationships with Elders in their communities.

In line with Izzie and Arizona's thoughts on widening the conversation, Derek also asserted that reconciliation is action-based work. He stated that more conversations are needed to understand, why things are the way they are and getting people out of that close-minded ignorance $[\ldots]$ making people allies. Indigenous people are great people. Like, 
they're strong and man do they have a sense of humour. I guess you have to have a good sense of humour to have the strength to be resilient for so long. Derek further reflected on the Canadian government's wrong-doings. He stated, "for Canada to realize where it went wrong $[\ldots]$ not just an apology, like action $[\ldots]$ moving forward together."

Jo was not aware of the TRC's calls to action until her most recent professional development day a few weeks before her interview. She stated that she was unaware because she does not like to listen to the news; it is too depressing. It was clear Jo had a sense of privilege because she chose not to educate herself about current Indigenous political issues and the potential impact on her life or her students' lives. Incorporating Indigenous culture into curriculum is part of the action plan to educate young generations on the impact of colonization, choosing to be ignorant is a barrier to incorporating Indigenous curriculum.

All nine respondents agreed that reconciliation is action-based. Rather than governments, institutions and individuals saying they understand and will try to recognize stereotypes and systemic issues that plague Indigenous people, these participants identified the need for there to be measurable action items in place. They realized that learning to deconstruct colonial ideals is a constant effort and wanted to ensure Indigenous traditions are also included in aspects of Canadian society. They agreed that it was not necessary to eliminate Western worldviews, but rather to additionally embrace Indigenous worldviews (and others). This is congruent to the Two-Eyed Seeing approach, which accepts and respects the two worldviews of the West and Indigenous culture, prospering together. 


\section{"We're trying" - TRC Influenced Changes, Student/Community Responses and Teacher Comfort Level}

"I think they recognize that we're trying." - Miranda

"If it's not localized, it's not authentic" - Izzie

"It does have to be in every class at every time because there are kids in here who haven't got a clue what you're living, they don't know, they don't understand, so that's what we're trying to do, to help all of you understand this horrible pathway that you were put on" - Miranda

Ten participants reported changes in the curriculum they teach since the TRC recommendations, along with feedback with how these changes were received. Curriculum changes have been made in English, History and Art credits that are offered in high schools. I asked participants to describe the changes. Two participants, Meredith and Izzie, from two different school boards, pointed out that there are not enough Indigenous educators to teach the new Indigenous content. All ten participants indicated they incorporated changes into their curriculum. While two did not provide any additional information on how it changed, the more detailed responses from the others are provided below.

The school board where Meredith, Mark, Christina, Arizona and Amelia are employed offers English with an Indigenous focus (ENG3C is now NBE3C). Christina stated, "every grade 11 college level student at our school has to take that as their English and there's been some like pushback within the community on that, it's been kind of a hot topic." She further stated, "some of the White kids, their parents didn't like that idea $[\ldots]$ one or two students $[\ldots]$ pushed back $[\ldots$ but $]$ the students all seemed to enjoy it."

When asked if there was any backlash when Indigenous content was brought into the courses, Christina reported, 
at the applied and essential level, there was very little, just a little, but at the university stream, some of the kids just absolutely flipped and rebelled and we told them when they were in grade 10 and I just think they didn't care - it was just June and they were like ah, whatever, maybe this will happen, maybe it won't $[\ldots]$ but when they came into 3U, their grade 11 university English, it was insane. There was a handful of kids, maybe 6 kids out of 25 kids that just every day would just like disrupt, complain $[\ldots]$ why is it being shoved down my throat? a lot of nonIndigenous kids feel like it is always being shoved down their throats. For example, we used to hold a First Nations cultural week and a lot of non-Indigenous kids had a big problem with that $[\ldots]$ ' no, I am not going to this traditional prayer, you cannot make me' $[\ldots]$ I'm getting the impression that they [the kids from the north] feel a little bit more singled-out as different. A lot of the parents were supportive, which was really nice.

Backlash from students was apparent at this school, but it is not clear how educators handled it other than cancelling First Nations cultural week and any other cultural events.

Educators also did not fully engage with the curriculum changes. Izzie spoke about the backlash that occurred; it was "not super negative, but more [...] selfish disappointment" because educators were not able to teach what they wanted to teach, rather they were required to adjust their course content. She further pointed out that these gaps are not with the youth, "the gap is with adults and they don't have the content knowledge and if they don't have the content knowledge, then they're uncomfortable with incorporating it."

Izzie's school incorporated Indigenous content many years ago, 
creating visual spaces, so we had murals painted $[\ldots]$ we did a huge focus on creating those spaces, now we're trying to move past that iconography, right, like how can we actually uhh incorporate that knowledge and those ways of thinking into lessons.

When asked which courses are taught that meet the TRC calls to action regarding Indigenous history, she stated, we teach Native History at the Grade 10 level. We have two Grade 9 Art that are Indigenous art classes. We have an English class that's kind of voices of Indigenous authors and culture. And then we have a, kind of more social justice-based course that's looking at contemporary issues in Indigenous communities.

Lexie, who is at the same school as Izzie focused on their school culture survey, where students are asked "specifically if they felt that Indigenous students were included as part of our school culture and we recognize that those students who did self-identify as Indigenous, did not feel welcome.” Their school works on improving its climate and culture, both for educators, staff and students. She shared the 'tell them from me' survey, which is a survey that the Ontario Ministry of Education requires school boards to distribute to determine a student's "sense of belonging and every year kids complete it and every year we can see that kids are starting to feel like they belong more, uhh, some of our First Nations students have gone from 0 attendance to full credit accumulation, which is awesome."

Derek reflected on his high school history class where World War I and World War II were taught, and both events did not last nearly as long as the residential school era. He stated, 
I think it's time to spend a little more time on something that lasted for like 100 years $[\ldots]$ did a lot of damage to Indigenous people $[\ldots]$ people need to be empathetic, they need to understand all the awful things that First Nations people have gone through.

Derek's statement reinforces the importance of teachers learning and understanding Indigenous history. The residential school era and its legacy were kept quiet for many years. Now curriculum is changing, and students are learning about the political take-over of Indigenous people by the Canadian state. It is also important for teachers to have an understanding that they might have to intervene, and handle instances of violence potentially faced by their Indigenous students, either through trauma that their family members endured historically or trauma that their own students face.

Since the publication of the TRC recommendations, Mark reports that he has tried to make Indigenous students in his class comfortable. He reiterated Dr. Sinclair's suggestion to say good morning and Boozhoo or good afternoon and Boozhoo. The other gesture Mark incorporates is to not call out Indigenous students when they are late for his class or for extracurricular sports. He also ignores Indigenous students who are absent from class. It is unclear if Mark ignores the presence or absence of Indigenous students at school because he does not want to draw attention to their behaviour, or if he identifies the school timetable runs counter to particular Indigenous approaches to time.

Miranda spoke about her approach, before the TRC's recommendations, to ensuring she incorporated Indigenous content in her history and geography teachings. She recounted an example of how her teaching style, 
opens up the eyes of the non-Indigenous kids in the room as to [...] the richness of the Indigenous culture [...] for the Indigenous kids in there, I think that they're, we're seeing more pride, more willingness to talk to the rest of us about what's going in their culture.

Miranda described a feeling of uneasiness from some of her students as they asked how much longer they have to talk about residential schools and other Indigenous issues? She asked those students,

what does your culture tell you about how long things are affected? And they looked at me and I said, 'c'mon, you guys know your culture' [...] 'seven generations'. I said, 'what generation are you? That's how long'.

Miranda believed that educators are trying to include Indigenous content, but that it may be overwhelming and that the teachers could feel out of place teaching the material, I think, my point of view is that they're just like, 'OK, we're in overload here, does it have to be in every class, every time?' [...] yes, it does have to be in every class at every time because there are kids in here who haven't got a clue what you're living, they don't know, they don't understand, so that's what we're trying to do to help all of you understand this horrible pathway that you were put on [...] I think one of the dynamics is we're still mostly non-native teaching the native course $[\ldots]$ where it's still the White person talking about your life, umm, but that being said, that, that most of the kids are very accepting of us who are non-native. I think they recognize that we're trying.

Furthering Miranda's point about White educators teaching Indigenous content, Meredith brought up the issue "that it is very difficult to find and retain First Nations teachers." 
She also spoke on behalf of some of her peers who have been put into positions where they are required to teach Indigenous culture. She stated,

I don't feel comfortable $[\ldots]$ teaching the culture that's not my own culture and not my own language, cause we've had situations at the elementary school where there's just, any given teacher is in for months trying to teach the native language courses because there's just no one else $[\ldots]$ there's no other $[\ldots]$ it's so hard to find those teachers.

Izzie's response is similar to Meredith, pointing out that there are not enough Indigenous teachers. In her school, there is one teacher who identifies as Indigenous, but they do not teach high school. Izzie would like to see more Indigenous educators; "I tell my students all the time that I want one of them to come back and take my job," She wants her students to become educated and teach youth in their community; she wants Indigenous youth to know that they can be successful. Despite a shortage of Indigenous teachers, participants believed that the course changes have impacted their co-workers and students. Miranda stated,

I'm seeing a positive impact over time. The first couple of groups that went through it [the course Aboriginal History in Canada] were just rolling their eyes and 'oh my god, you just put me in another history course,' like it doesn't matter if it's culturally based [Indigenous], or European, [...] it's a history course, but now [...] the kids are actually asking to go to those courses $[\ldots]$ this year was the pilot project for [the Indigenous English course ...] our Grade 11 English was less Shakespeare, more Canadian content, but specifically more Aboriginal Canadian content [...] students were not thrilled because it was, it was a change that was made at the 
administrative level, it was not something that they chose, they thought they were doing the regular English 3U and English 3C, ummm, but, you know, teachers did the best job that they could with the kids they have in front of them and they tried to make it interesting and relevant and ummm, you know, they were still teaching the grammar and all the rest of the stuff that you teach in an English class, it's just the focus was more on Aboriginal content.

Lexie advised that their school is in a very difficult territory; some of the Indigenous groups have not signed a treaty. For this school, it means that they choose not to acknowledge the land that their school is situated on. She stated,

we don't do treaty recognition in the school, we won't because it's, it would be very disrespectful to [a local Indigenous community], so when we do land recognition, it's challenging cause we have to recognize both as opposed to just one.

When asked for suggestions to improve their school's ability to meet the TRC's calls to action regarding Indigenous history and education, Izzie stated that her particular school needs,

to start honouring honorariums. I feel like it's still that judgment of training versus academic knowledge, right. If you're an Elder, you don't need to wave around a paper, you're an Elder and so your knowledge is your experience and, and your life is what should be honoured through an honorarium and if I'm asking you to give up a couple hours of your time, then I should be compensating you in some way [...] it's not a $\$ 10$ Tim's card.

Izzie also wants to see more Indigenous leadership. She stated, "right now, it's a team of really nice White women and that's it." She questioned whether this was due to 
the lack of trust Indigenous communities have with educators. Furthering the idea that there needs to be more leadership, April suggested, to "provide more training to our teachers [and get] parents in[volved ... we] have a very high Indigenous population [...] having more training will trickle down into our student population and they'll start talking about it and making that difference." Contrary to April, Arizona stated, truth and reconciliation needs to be a way of being, it's not just about one curriculum area, it's about how we do business every single day and that the whole thing needs to change [and] baby steps [...] every little bit helps, ummm, cause the more we do, the more we know and the more we know, the more we grow. It is clear that Arizona is aware of the importance of teaching others on Indigenous traditions.

Although the Indigenous Education Authority is not regulated by provincial legislation, Derek responded to the question about how to improve his school's response to the TRC calls to action. He advised that there is Indigenous content in every class. When asked about the type of courses that are offered through his high school, he responded, “applied, but we just started building an academic program as well.” Derek would not discuss the politics around having applied-only courses in his school.

Overall, the findings/themes from the data discussed in this chapter around curriculum changes point out that non-Indigenous youth and adults (whether educators or parents) have not all been accepting of the inclusion of Indigenous culture into the curriculum. Additionally, many participants referred to feeling personally uncomfortable teaching Indigenous content but did not explain if it was due to appearing racist or due to the inability to correctly disseminate Indigenous culture/teachings. Recognition that they 
are not qualified as an Indigenous educator is important and also shows that the connection to Indigenous communities may be lacking by the schools/educators. This also points to the recognition that teachers cannot simply take courses/receive credits to become a qualified Indigenous teacher. Rather, Indigenous knowledge is earned through experiences, whether with Indigenous communities or Indigenous students. Community connections with Indigenous groups where a trusting and respectful relationship exists are required to move forward, part of the Two-Eyed Seeing journey. These relationships take time to build, but the inclusion of Indigenous voices, stories and culture in the schools may help guide Indigenous youth to learn and trust teachers, guidance counsellors and other educational staff. Also, fostering these relationships demonstrates that respectful changes can be made to show that Indigenous people are part of Canadian society.

\section{Moving Off-Reserve for High School - Impacts on Indigenous Youth}

"Are you talking about [...] if this were to happen now?" - April

"You'll never replace the care and touch of a parent or family member." - Derek

The changes to curriculum post-TRC are intended to ensure Indigenous youth feel included in school. As the subject of my dissertation is Indigenous students in northern Ontario, and bullying, I asked participants to provide their perspectives on the issues Indigenous youth may be forced to navigate if they moved off-reserve to attend high school. The responses collected ranged along a spectrum of understanding that Indigenous youth need to move to earn an education to concern that moving off-reserve is not a good option for Indigenous youth as they move away from their familial support and friends. All participants believed there are problems faced by students moving from 
home, although one participant did not realize that this is the reality many Indigenous youth presently face. A summary of responses is provided below.

Meredith believed that trauma from residential schools impacts many of the youth who move off-reserve for school. With that said, she also stated, Indigenous youth "are more likely to attain a secondary school or post-secondary school diploma if they move off-reserve, but I think there's a lot of barriers along the way." When asked to describe the barriers she referred to, she stated, "no resources, no teachers, no facilities." She also commented that the population of her community is growing because people are choosing to move and attend school in her community; "our population of northern students is growing, especially because of what's happening in Thunder Bay.” Meredith is referring to the deaths of Indigenous youth at Dennis Franklin Cromarty High School, which is discussed in the context of my study.

Christina's response reflected on the policies that determine students' eligibility to attend school off-reserve. Many communities in the north will not allow their youth to move for high school until they have achieved at least eight Grade 9 credits. Christina stated,

those kids are just more ready. They are more equipped [to move], so coming out at 16,17 , instead of coming out at $13,14,15$, seems to be a big indication, but then there's the other factor of the fact that [some communities] are so invested in those kids $[\ldots]$ so you can't just say it's their age, they're also coming from that support that led them to come out at that age.

Callie's response resembled Christina's; "the students [have] to be very mature and responsible and independent before they come [for school]." 
Meredith's response about the growing population of northern students is reflected in Christina's discussion of a crisis pertaining to housing for students to attend school in the community. She stated, "students come here with nowhere to live." Christina also pointed out accessibility to resources as a barrier for Indigenous students coming off-reserve. She stated, "there are Indigenous kids who live in town, who have access to more resources and then there are Indigenous kids who come from the north, who have limited access to resources." This divide is economic, which Christina stated, gives the Indigenous town kids more confidence in school than other Indigenous students arriving from the north.

In Mark's teaching career in northern Ontario, he has "seen students who are very keen [...] very disciplined, very driven, I've also seen students who are afraid to even come in the classroom." He further stated that it "depends on the kid, depends on the family they're leaving." Mark also expressed his belief that some students never come to high school off-reserve; "they go to their reserve schools and then they just refuse to come to high school." He further reflected on the climate that his Indigenous students are subject to. Focusing on the northern town of Dryden, Ontario, he stated, "Dryden, I think, has a pretty racist reputation, which hasn't been helped by the fact that Senator Lynn Beyak calls Dryden home and there's been 'all of that' in the national news." Mark's reference is to Senator Lynn Beyak's comments in Senate in 2017 that, the positive aspects of residential schools ha[d] not been acknowledged [...] she wanted to "present a somewhat different side of the residential school story [... of people whose] remarkable works, good deeds and historical tales in the residential 
schools go unacknowledged for the most part and are overshadowed by negative reports. (Kohut, 2017, paras. 2-3)

Senator Beyak was one of the previous Vice-Chairs of the Fort Frances-Rainy River Board of Education, where "she participated in a roundtable for violence prevention in schools that led to the development of a code of ethics, which became a model for school boards across Ontario" (Senate News, 2019, para. 2). Although Senator Beyak is not Indigenous, she spoke positively about residential school experiences, ignoring the trauma that many Indigenous people endured.

Arizona reflected on the issue of systemic racism in education and how it impacts Indigenous youth attending school off-reserve. She questioned, systemic racism [...] if there is no school for them to attend in their home community, where they are supported by their families, umm, and they have to leave $[\ldots]$ why is that? Why is that happening? Especially in this day and age where we have access to technology and uhh, different ways of being able to do things, and why aren't we honouring those ummm Indigenous ways of knowing through land-based teachings at a secondary level or at a high school level, so that kids can learn and grow wise through what they're learning in their own home communities? She also stated that the curriculum taught may be different,

if you want to get right down to it, because ummm, the federal system doesn't necessarily teach Ontario curriculum. So, when they come here and they're in grade 9 and they've [perhaps] never had Ontario curriculum up to the end of grade 8, they're at a total disadvantage. 
Miranda's response echoed Arizona's. She stated that Indigenous youth "lose a huge support system." She elaborated,

it's a negative impact and I would say, in $85 \%$ of the cases, the kids go back north, they don't stay, they just, they can't cope with it [being away from home], they [... they miss their families so much and they, I don't know if the expectation is different here than it is up there in terms of academics, but they find that, they tell us that we're meaner or tougher on them.

Lexie's response resonated with Miranda's. She stated, “it's brutal.” She further explained,

it's just brutal cause they're living in boarding houses, there's not appropriate social structures, there's no supports, and then you know, umm, turning to drugs and alcohol to me, is logical, cause you're trying to self-medicate to take away the pain, $[\ldots]$ it's a very challenging situation $[\ldots]$ any kid who moves off reserve and gets their high school diploma should get a medal on top of it cause it's fricken brutal.

Izzie's response is also reflected in Meredith, Miranda and Lexie's. She provides two detailed examples. She referred to 1) the legacy of Shannen Koostachin and 2) the time it takes for Indigenous youth to travel to attend her school. Referring to Shannen, who was from Attiwapiskat First Nation in northern Ontario, she reflected,

she was in grade 7 or 8 . She petitioned the Canadian government and launched an online campaign with schools across Canada [...] she spoke in Parliament, umm and Charlie Angus really took her under his wing, and uhh, so [...] she was nominated for a peace prize, a children's peace prize award, and then she died in a car accident in Temagami [...] I feel like her experience really speaks to the 
experience of so many of our students and she really kind of shaped the way a lot of my kids here see education [...] she just thought it was amazing to have a library, to have a gym $[\ldots]$ and so it put a lot of it into perspective and she was fighting for an education $[\ldots]$ it's launched a campaign called Shannen's Dream. ${ }^{31}$

Izzie also pointed out the significance of bussing. She stated, our kids who live on the res who have to get up at 7 in the morning, they take a bus [...] it's a 1 hour 20 minute bus ride, about 1 hour 40 minutes of their time every morning, every night, in the winter, you know, -40 and then we look at why attendance is an issue. I wouldn't want to get up that early in the morning all the time and then we're putting 5 year old [children] on that bus to come in.

Izzie revealed that geographic spaces where Indigenous people live are far away from schools. Rather than blaming Indigenous youth for not attending school on a regular basis, she believed that the education system/bussing schedule disadvantages the youth. Despite the idea that the bus system was helpful and brought youth to school, it can also be seen as problematic given students may be overtired on the long journey to/from school. There are also many outside factors, such as home routine, diet/regular, healthy meals, sicknesses, and/or weather changes. They are also expected to be alert and function in the same manner as other students who do not travel for school.

Jo’s response reflected time away at school from family as a negative issue, but she tried to view participation in extra-curricular activities as a positive; "living closer to

\footnotetext{
${ }^{31}$ Shannen's Dream is a fund that helps Indigenous children obtain "the same education opportunities as others but in ways that respect their language and culture and considers that they may not be starting from the same place. Shannen Koostachin, her classmates, and their community of Attawapiskat fought for a new school for over three decades after a diesel spill near the school that was making students and teachers sick. Shannen sadly passed away in 2010 and never saw the new school that was built in 2014. With the support of her loving family, friends and community, Shannen's Dream was named in her honour because Shannen believed that all children deserved to go to a good school" (FNCFCS, 2019, para. 2).
} 
a school, they might be able to participate in some of the activities." Participation in sports/extra-curricular activities is accepted for youth. This is because of the skills that may be learned through sport, such as leadership, accountability, responsibility, organization, time management, respect and sportsmanship. However, participation for Indigenous youth living far away from school, may not be possible.

When April was asked about the impacts on education for Indigenous youth who move off-reserve to attend school, she reacted in shock and asked, "are you talking about [...] if this were to happen now?" I responded yes, to which she then stated, "oh my goodness, it would be horrible." She further explained, “it doesn't matter if you're being boarded with a great family, being away from your culture and your home, I think that that would be pretty intense $[\ldots]$ it would be hard to concentrate when you're thinking about home." It is clear that April has not come into contact with Indigenous youth who move to attend school — this is because her students are below 5 years of age, not 13 years or older. Also, she has not made the connection that choosing to leave home for high school is related to the residential school legacy.

Derek's students are all from the north. He recognized that some issues stem from students having boarding parents and the issues inherent to living with strangers, possibly unfamiliarity with their rules and norms. He stated, "some boarding parents are awesome $[\ldots]$ maybe some aren't [...] I wouldn't want to live in a stranger's house when I'm 13 years old either and follow whatever kind of rules that entails in a strange neighbourhood." He also reflected on whether or not it is a student's choice to leave their community for school. He stated, 
kids are choosing to leave their community, sometimes it's [...] you know, some might argue that it's not a choice, like they need to do it if they want to get their high school education. They can take distance ed courses, so it's not the same, like, so that is a choice and it isn't, but it's more or less kids are making the decision to leave and, you know, we're not pulling them out of there kicking and screaming type of thing and they're coming here and we're doing all we can to, to provide like a supportive environment for them to go to school. And for people to say, 'oh you're segregating them', it's like, 'well, they're not getting enough support in the provincial system and we'd rather have them at our school to help them deal with, maybe some of the potential trauma that they grew up with' [...] and our number one thing is we want to put kids back in touch with their identity and their culture. Derek elaborated on the reality that many Indigenous families deal with when their child is sent to school off-reserve. He stated, it's tough enough to let your kid leave when they're 13 years old, but then you put this like, this crazy violence in the mix [...] these parents just want to be able to send their kids to school in their own community, like every other kid in Canada. Indigenous Services Canada doesn't see it as feasible, or it hasn't been and now they're trying to figure it out.

Derek did comment that his school employs a transition worker now, who facilitates information sessions in the communities before students leave home for school. Derek explained that the transition worker "talk[s] to the kids about what life's like in [the city] and getting to know the kids before they come out, making that transition smoother." It was discussed that the transition worker is not Indigenous, which led to the next question 
about whether or not Indigenous youth were hesitant to talk to someone who is not Indigenous? His response was, "I'd say maybe [...] if you look at all the wrong-doing that the Canadian federal government has done to Indigenous people, I would be looking over my shoulder a little bit too, I wouldn’t be jumping and just ready to trust somebody." Recognizing the lack of trust most Indigenous people would have towards non-Indigenous people points out the need for relationship building with Indigenous groups by education institutions and educators before trying to convince youth to move off-reserve for school. Regardless of the care and concern Indigenous students receive at Derek's school, he stated, "you'll never replace the care and touch of a parent or family member." Derek refers to the inequity that Indigenous youth deal with living in an isolated environment. The issues of funding and geographic space are relative to the history of Indigenous politics and Indigenous placement on reserves.

It must be noted that the participants in my research may be different than other teachers they work with. They volunteered to participate in this type of research study. Their participation may indicate a higher level of investment in the well-being of their Indigenous students than among other teachers. However, there is difficulty in helping their Indigenous students succeed; the participants have been educated in a colonial education system and are expected to teach the colonial education system. The participants may not have the tools and/or skills to fully recognize (and appreciate) what systemic issues Indigenous youth are navigating, but their intentions and investment to help are present despite teaching in a colonial system that resists decolonization of education. 


\section{Conclusion}

In this chapter, participant backgrounds were explored to better understand their story and how they comprehend Indigenous history. To help develop a well-rounded response to my research question, I needed to understand the background of my participants, their knowledge of Indigenous issues and experience with Indigenous people and their attitudes about Indigenous issues and the calls to action. Based on the responses provided, three participants from northern Ontario and two participants from southern Ontario were less aware of Indigenous issues until they attended post-secondary education where they encountered critically meaningful and relevant information about Indigenous history and politics. I hesitate to say they learned Indigenous history and politics because an underlying theme of this data was that learning is a process that involves a level of introspection and empathy. Until participants had their own experiences that put Indigenous history/politics into perspective, they were unable to comprehend the expansive impact of residential schools and colonialism. It is noted that their job experiences, and other experiences with Indigenous people, impacted their views of Indigenous people, where they were able to shift away from stereotypes they once held and learn about and understand Indigenous culture and sometimes this only occurred when they moved into a new community.

Participants were generally knowledgeable about Indigenous politics, history, and culture but this knowledge was certainly increased as a result of teaching in schools with significant Indigenous populations. Many of the participants reported increased knowledge of Indigenous ways of knowing as a result of exposure to Indigenous students and Elders, in a school setting. Almost all participants expressed support for increasing 
Indigenous content in school curricula and identified ways in which their own teaching practices had incorporated Indigenous knowledge and methods. At the same time, many participants claimed that they were uncomfortable being the non-Indigenous teacher of new Indigenized content. A clear finding from the interview data was that there is a recognition among the participants of the shortage of Indigenous educators to teach Indigenous culture and traditions. Interestingly, all educators agreed that moving off reserve for high school may have devastating consequences for Indigenous youth due to lack of familial and community supports. However, there was at least one participant who was entirely unaware of the parallel of moving to attend a school away from a home community and the residential school legacy. The following chapter will specifically discuss data from participants as it relates to the Ontario anti-bullying framework and Indigenous youth. Following the presentation of this data, I will discuss and analyze my findings. Lastly, I will offer thoughts for directions for future research and the conclusion to this dissertation. 


\section{Chapter Seven: Awareness and Implementation of the Ontario Anti-Bullying Framework}

In this chapter, I draw on the interview data provided by participants to explore the implementation of the 2012 Ontario anti-bullying framework. Participants were asked: how they define bullying; how their school defines bullying; if they received training to understand the anti-bullying policy; if the anti-bullying framework is implemented in their schools, whether they encountered any incidents of bullying involving Indigenous students, how might they improve the anti-bullying framework and if there was additional information they would like to share around the anti-bullying framework? Their responses are provided below.

The key findings that came out of the data are that most participants define bullying according to the traditional, individual-focused definition: behaviour that is repeated and negative towards an individual. When asked to provide specific examples of bullying, participants provided examples of racist or violent behaviour. Examples of bullying behaviours that were discussed include physical violence between students, sexts [sexual text messages] sent between students and a break-up resulting in harassment. Anti-bullying training was reported by some participants, however, it was not rated well. Nonetheless, most participants reported that they believe (or assume) their schools have implemented the provincial framework, and most identified steps they take when confronted with behaviour identified as bullying. Interestingly, not all of the participants interviewed necessarily utilize the framework for every instance of bullying behaviour that they confront. Rather, several participants reported exercising their individual discretion in choosing how to deal with incidents labelled as bullying. Several participants, when asked how to improve anti-bullying measures, focused on how 
Indigenous youth might be more resilient and how positive relations can be created/fostered to include Indigenous youth and prevent them from incidents of negative behaviour.

\section{Participant Definition(s) of "Bullying"}

"People slap on the word bullying" - Jo

"I feel like it really minimizes what the actual issues are" - Izzie

To understand educator perspective and interpretation of 'bullying behaviour', I asked participants to provide their definition of bullying. I also asked participants to provide their school's definition of bullying. The responses below indicate that most participants adopt a traditional definition of bullying focused on individual actions as opposed to broader social context, although a minority do point to the need to consider broader causes of behaviour.

Meredith, Amelia, Christina and April, all from northern Ontario, appeared uncertain about how they would define bullying. Meredith stated, "I guess repeated and intentional actions that are meant to cause someone harm in one way or another, whether it is emotional or physical, yeah and I guess the whole idea of intent has to be there as well.” Amelia and April echoed Meredith's response. April further stated that her school's definition was, behaviour that is "repetitive in nature, that it continues $[\ldots]$ that it's targeting one person, there's probably a lot of other things too." When asked to describe what 'other things' included, she was not able to provide examples. Christina was also unsure of the definition. She stated, "I guess just anything where someone is made to feel attacked, or picked on, or less, it's physical, verbal, online [...] I think anything that is leading someone to not feel safe and comfortable." 
When Meredith was asked if incidents of bullying take place in the school, she stated, "it definitely happens daily [and that] the police are often at the school [responding to reports of violent behaviour], like every week." She asserted that part of teaching is also managing student behaviours, "even if you might interpret that as bullying, like [...] just saying please don't speak that way to each other, let's be kind with our words, or things like that." In this instance, it is important to note that not only does Meredith re-direct behaviour and language from the negative instance, but she is also outlining her expectations of how classroom behaviour should look.

Callie provided the school board's definition and her definition of bullying as feeling threatened or if negative behaviour occurred through "comments, either verbally or through social media, word of mouth." When asked for examples of bullying behaviour, Callie described an experience of rape that was so impactful, an entire family moved out of their community. For purposes of anonymity, the description is omitted. This example of conflating violent, criminal behaviour with bullying will be explored in my discussion and analysis chapter. Other examples she provided include: 1) relationship problems between teenagers and 2) an incident where a hockey player was treated differently among his peers. Examples of the comments that the hockey player faced, it's not that blatant, 'you're a bitch, I'm going to beat the shit out of you', right? Sometimes it's just those underlying little comments that you hear, especially with the boys $[\ldots]$ like for the boys it's more insecurities and so they try to be macho-y. Who can be louder and more destructive and more disruptive.

Arizona and Lexie appeared confident and clearly expressed their school board's definition of bullying. Arizona stated it as, 
any perceived action or threat or risk of harm [...] if a student even perceived that somebody was going to harm them and that this perception was ongoing $[\ldots]$ an ongoing perception, umm, that we would consider that a form of bullying and then be looking into how to handle that.

Lexie defined it as "any unwanted action that's occurring on a regular basis against someone else. Umm, which can look a lot of different ways to a lot of different kids." Lexie reported that incidents of bullying happen often, particularly between students in Grade 7, 8, and 9, who are navigating their social connections/dynamics, "some of them [their expressed behaviours] are very inappropriate [...] kids can be cliquey, kids can be evil, and we really are working hard to squelch it, but it does still happen, unfortunately."

Coming from the same school board as Lexie, both Izzie and Jo critiqued the definition of bullying. Izzie dislikes the term bullying; "I feel like it really minimizes what the actual issues are." However, to answer the question, she believed the school would define bullying as "targeted harassment." She further described her definition, to me bullying, umm, especially for the high school level, kind of connotes like playground silliness, and you know, my feelings get hurt and [...] there's a difference between playground umm, friendly, uhh jabs and harassment and, and that's where I think we need to make a better differentiation at the high school level. Her understanding of incidents labelled as bullying behaviour was differentiated between the sexes,

there was a group of girls who were really mean to another girl $[\ldots]$ it's the girls that we're really looking at for the bullying, the boys tend to just go outside and 
punch each other out and then everything's fine later on, the girls are the ones that we're seeing all of the mean, umm, self-esteem jabs.

When asked to describe the behaviour exhibited from the girls, she stated, this group of girls were very hard on one particular girl and [she] was starting to self-harm $[\ldots]$ the parents came in umm, and there were a lot of meetings on $[\ldots]$ how we could deal with it. [It was] the victim's graduating year, umm, so she attended all of her classes and two of the girls who are in that class were removed cause they could take it the following year, so they were removed and put in a different class and placed into that class the following year.

Another instance of harassment labelled as bullying was provided by Izzie, one time where a male student, a couple broke up and he was very aggressive in harassing and [was] unrelenting [towards his ex] and the police were involved in it and so, like a restraining order was placed and he was no longer allowed to be in her classes and that was done through the courts, so he was removed and placed on, like an independent learning program, so there are times that it happens.

In these examples, Izzie differentiated between displays of negative behaviour from boys and from girls. In one example, Izzie's school stepped in and assisted with measures to ensure a victimized student graduated. The final example she provided described an actual incident of harassment, which could not simply be framed as bullying because it was a criminal offence.

Arizona, who works as a vice-principal, also critically reflected on the definition of bullying and stated, "instead of being in a reactional mode and trying to umm, stop bullying $[\ldots]$ it's more about getting at the root cause and helping to support kids before 
it even happens." Arizona affirmed that negative behaviour labelled as bullying is not simple but did not provide an explanation on how to 'get at the root cause.'

Mark and Jo's responses to bullying are similar to Izzie's in that all three participants declared that the term creates an illusion of understanding. Jo stated, "society in general uses the word too frequently." She elaborated, "I feel like that kid's picking on me, so now I'm going to say, 'he's bullying me' or 'she's bullying me' and I feel like that does not help the people who are truly being bullied." Mark believed kids mock the definition, "because now under the slightest bit of stress, they [the students] are not afraid to shout out, 'he's bullying me', or 'she's bullying me', and then it becomes a joke." He further claimed, "it's hard to differentiate between bullying and the natural pecking order and societal kind of hierarchies."

When asked how his school tries to eliminate hierarchies, Mark responded in a way which did not elucidate on hierarchies but instead highlighted data specific to my research question, through treating students fairly and trying to role model positive interactions [...] you learn about it and you know about it, and for example, like blackmailing, including sexting and that sort of thing and they [the students], they're all quiet, I mean, anecdotal, I've had girls tell me that they receive multiple unsolicited sexts every week, photos from boys, so, so that, I mean, that isn't bullying specifically, but that you can probably appreciate how that would lead to any range of social issues in the school, bullying included.

Mark indicated that sending unsolicited 'sexts' to girls “isn't bullying specifically", however he referred to the sexting incidents in response to my question 
about bullying and appears to be grouping sexting and bullying together. While Jo did not provide her opinion on her school's definition of 'bullying,' her personal definition seemed to agree with Mark's, "this word bullying means anytime a student uhh, is being unkind to another student, then we use the label bullying and the students will quickly use that phrase." Jo elaborated,

"I think there are lots of incidents of bullying ummm and I think when it is my definition of bullying, I think it's underreported. I don't think it's reported. I think, like I said, in an instance where somebody is not kind to another person, we slap, people slap the word bullying on it and so on the surface it seems like there's lots of incidents being reported, when in fact, I think the true essence, when we are talking about bullying, that deeper rooted, I'm going to get you, and I'm going to poke at you, and poke at you, to make you uncomfortable, I don't think that gets reported nearly enough, or dealt with nearly enough."

Derek's school is not mandated to follow the Ontario anti-bullying framework. When asked to define bullying, he first responded "with us, we're so tight-knit, it's such a small group, that you know every kid and it feels like a family." He then provided his personal definition, "when one student makes another one feel lesser or someone pushes someone around, verbally, online, you know, physically.”

The definitions of bullying provided by participants are similar and comparable to the definition in the legislation and provincial policy documents — negative behaviour happens repeatedly "to cause physical, psychological, social or academic harm" (Education Act, 2012, s.1). With little exception, most referred to bullying as repeated behaviour, whether verbal or physical, that targets someone. Izzie, Arizona, Jo and Mark 
were notable as they critiqued the individual focus of the term bullying and pointed to the need to consider broader social context or "root causes". Mark, Callie and Izzie described examples of behaviour identified as bullying which were actually instances of harassment, sexual harassment and rape.

Christina also provided additional critique of the bullying definition, particularly as it related to Indigenous youth. Generally, she stated "those who are labelled as a bully are suspended." She spoke about an incident where four Indigenous boys violently assaulted another Indigenous boy outside of school. The four boys were suspended for five days. She elaborated that the boy who was attacked was sponsored from the north; “his education authority supported him and got him to the police, but he's not doing really well. He's fine physically, but he doesn't want to come back to school $[\ldots]$ he hopefully will come back in September." She further expanded that three of the boys who attacked him have been in care since a very young age and have been in juvenile detention. She referred to their school as the last secure place some of the troubled youth have. Boys, however, are not the only troubled youth. Christina referred to 'mean girls' who engaged in sexual harassment. She stated, we have girls that are mean girls and we've had an issue with umm, like texts of nudity this year $[\ldots]$ it's stopped, but part of the reason it's stopped is because the kids involved in that [those sending the texts], their education authorities have sent them home so independent of the school, their drinking and dangerous behaviour, the education authority said we [don't] feel confident that we can keep you safe, so they've returned home, so that's actually completely stopped.

Christina referred to sending naked pictures as bullying. She stated, 
the past 2 years is the first time I've known of that kind of bullying, with texting naked pictures $[\ldots]$ the boys were sending the naked pictures $[\ldots]$ it became a wide issue $[\ldots]$ we had one where they printed off the pictures and pasted them all over the bathrooms $[\ldots]$ it wasn't identifiable, but obviously people knew.

She also pointed out that alcohol and addiction issues are rampant in her community. Christina further explained that despite the issues in the community, there is a lot of support in place for the students who come from northern reserves because the education authorities are there as resources. She could not comment on whether the resources are used by the youth.

Overall, participants held different beliefs about what bullying behaviour looks like. Although Izzie dislikes the term 'bullying' because it minimizes the issues, she still confused harassment as bullying behaviour. Christina also included sexts, nudity and harassment as behaviour defined as bullying. Both the need to consider broader social context when considering bullying and the danger of having harassment and other forms of serious negative behaviour classified as bullying behaviour will be further explored in the upcoming discussion and analysis chapter.

\section{Training Concerning the Ontario Anti-Bullying Framework: 'Conditions of Employment' and 'Checking Boxes'}

Participant training concerning the Ontario anti-bullying framework was uneven. An interesting theme that emerged from participant discussion of the Ontario antibullying framework was that training was understood as mandatory to remain employed, but many did not remember receiving any formal training certification. Their responses are provided below. 
Five participants, Meredith, Christina, Arizona, Lexie, and Izzie were aware of the provincial framework. Both Meredith and Christina, from the same school board, attended a one-day training session, while the three others could not recall if they completed any training. The remaining seven participants, Mark, Amelia, Callie, Miranda, April, Jo, and Derek were not aware of the framework specifics.

Meredith was one of the few participants who remembered completing online training as she has a 'nice certificate' printed on the wall, however she does not remember the content of the training. She pointed out that some of these courses are required as a "condition of employment." She felt that she did not learn anything beneficial from this training. This sentiment was also provided by Christina who stated, "I've read it (the anti-bullying framework) [...] it doesn't stick that well [...] I don't think there's anything that I've thought 'woah, people don't know that.' It just seems like, 'yes, this is how to operate a school.",

Lexie believed the framework was implemented in the school; "I can't speak specifically because we have so much that's embedded, I can't tease out what's the framework and what's just good training and just good practice." Izzie believed staff meetings were a way to obtain knowledge about the anti-bullying framework. When asked if she has been provided with any formal training, she stated, "No, nothing formal. I mean, we've had the legislation, and we've talked about it, but nothing, no actual training”. Jo did not have any knowledge about the Ontario anti-bullying framework. When asked if she received formal training, she assumed that she had because "the Board likes to check boxes [...] but I could not tell you any specifics about it." April was not provided with any formal training. 
Derek, from the Indigenous education authority, did not know about the provincial legislation. He stated, "I am embarrassed to say it, but I don't know that much [...] I tried to even do a little bit of research and I didn't really come across much." Mark and Amelia stated they also did not know about the anti-bullying framework; however, Amelia provided information from the Safe Schools Act, 2000. Although Callie had missed training sessions, she stated that she knows about the zero-tolerance policy in the school and that there is a duty to report negative behaviour under the Safe Schools Act, 2000. Miranda was not trained on the framework; it was additional training she did not have time for and she already had a great deal of experience dealing with students' negative behaviours. She stated, "I'm an old teacher [...] if I see it [negative behaviour toward a student], I'm going to deal with it [...] refer it to the administration if they [the student] want it [the behaviour to be reported], but I prefer not to [hand it off], I try to handle it with the student myself."

\section{Implementation of the Ontario Anti-Bullying Framework in Schools}

Participants were asked about their knowledge of the implementation of the Ontario anti-bullying framework in their schools. While the above responses indicate that knowledge of (or training regarding) the specific elements of the general anti-bullying policy framework seems lacking, many participants understood what was required of them as individual teachers in their schools. Most participants reported that the framework was implemented or was being implemented in their school. The answers of the seven participants who reported above that they were not aware of (or not trained about) the Ontario anti-bullying framework, indicate that, despite not being able to explain the specifics of the provincial policy, the participants are in fact aware that there 
is a framework for dealing with incidents labelled as bullying behaviour. Responses are provided below.

Meredith was not sure if the Ontario anti-bullying framework is implemented, however she described steps for reporting negative behaviour to her principals, basically, trust that they would be familiar with the procedures to tell me what I have to do because, for example, if there is an incident with a student [...] that the principal has to investigate, if a student causes harm to another student or issues a threat or even swears at me, I have to fill out this form and sign it and give it to the principals and then they have to investigate further.

Christina also explained the procedures for reporting negative behaviour, "ensuring that communication is made to everyone involved, so that would be parents, guardians, so in our case that would be the education authorities, umm any teachers that were involved in the reporting." When asked to explain the process of communication, she responded, "everyone ends up in the office and they are spoken to individually to try to piece together what is going on, their families are phoned $[\ldots]$ decisions are made usually with input from the educational authorities." When asked if there were any procedures when contacting parents, she stated, we often have parents who are just like, oh well, figure it out, I can't deal with this and so you're like [...] we don't know how to figure this out, where is [a] safe place that we can get your child?

There was a disappointed tone in Christina's voice as she expressed concern for children who need help, but their parents were not willing or able to attend to their child. Hopeful that not all youth would end up on a negative pathway, Christina revealed that the anti- 
bullying framework is action oriented. She responded, "the Ontario anti-bullying framework forces you to address it [negative behaviour labelled as bullying] and [has] made school a safer place." Christina stated, "we definitely have bullying [...] It's not something that we let simmer. We have this program, which is supposed to lessen incidents of bullying." I asked Christina to explain the program. She described a software program that allowed every teacher access and ability to make communication notes about any enrolled student — their behaviour(s) or other circumstances that teachers should be aware of. The program that Christina referred to is viewed as a positive system to help teachers be aware and provide disciplinary action, if needed.

Miranda's response is similar to Christina's. Miranda implied that the antibullying framework supports students because it forces negative behaviour, whether inside or outside of the school, "to be dealt with in sort of a prescriptive manner." When asked how the Ontario anti-bullying framework supports students, she responded that it "provides a method where bullying can be dealt with [...] to try to ensure their [the students] safety in the building. And outside of the building because if they report when it's outside of the building, we have to deal with it."

Izzie reported that the anti-bullying framework is implemented in their school. Izzie referred to a similar protocol like Christina's mentioned above called the Pyramid of Intervention. The Pyramid of Intervention is a tool developed by the Ontario Ministry of Education 'Learning for All' Initiative designed for special education students with three instructional approaches: 1) universal design for learning; 2) differentiated instruction; and 3) the tiered approach to prevention and intervention (OME, 2013f, p. 24). Izzie explained, 
when we have students that we're worried about, the Pyramid of Intervention tells us who we should be reporting to, who we should be working with to try to support that student, umm, again, I really think that it's the, the main attitude that we use from the framework is for things to not be discipline based, but really looking at how we can support students.

Both of the examples provided by Christina and Izzie are administrative tools utilized by different schools with reported efficacy, though it is unclear if students are aware of these programs until an instance of negative behaviour occurs, or if student awareness would change the efficacy of the tools in any way.

Izzie continued to provide various examples of consequences students received when involved in instances of negative behaviour, such as suspensions, expulsions, students whose timetables are shifted, and if the incident occurred on social media, students have their cell phones taken away for the day. Lexie reiterated Izzie's discussion of consequences, "you get one warning, and then if you don't stop [the negative behaviour], you [have] consequence[s] because you've been told and you're choosing not to [listen]."

Mark and Callie, from the same high school, both assumed the framework is implemented. Mark could not confirm if the framework is implemented in his school. He unconfidently responded, 'I think it probably is. I think that if they've been handed direction from the provincial government, they probably followed it and hopefully are instituting it, but I don't see it anywhere specifically." Callie was also unsure. She advised that she listens, she reports the incidents and directs kids who to go see. She further elaborated that "I will go with them if they're having a hard time." She stated that 
her principal is very good at covering her classes if she is requested to attend with a child in crisis, providing support to her students. Callie also believed that students are aware of who they can reach out to for guidance when an instance of negative behaviour occurs, I think because they [the students] know [...] that they can be protected [...] that students are aware [...] that students have knowledge, right, they know who to go talk to, they know who to trust, they know what their rights are.

Amelia was unsure if the framework was implemented; however, she focused on her "duty to report and intervene when necessary in cases of bullying" under the Safe Schools Act, 2000. Amelia's response was very vague, but it is clear that she understands a teacher's duty to report and intervene.

Interestingly, Arizona, who works as a vice-principal in a school board's administration office, did not believe the framework was implemented across her board. She provided an example of a student forum that took place at a local school; "bullying was one of the biggest things that was brought up." At a different high school where negative behaviour occurred online during school hours, Arizona explained that while the board and school were dealing with the behaviour, she stated, not once did I hear a word about ummm, Ontario's anti-bullying framework [during the discussions on how to deal with the online instances], not once. I actually don't think the majority of our people [know about it], and I don't hear it in our meetings [...] I really don't hear it anywhere, so I'm thinking that the, the majority of our staff wouldn't even know about it.

Arizona stressed that if she did not hear about the anti-bullying framework through the discussions on how to handle online negative behaviour, many others would not have 
either. April, echoing this sentiment, stated that she believed the anti-bullying framework is not implemented in their school. Jo was not able to provide a response because she did not know if the framework was implemented.

Derek was unaware if his Indigenous high school had adopted the provincial antibullying framework. He also did not disclose any anti-bullying policies that are implemented at his school. He continued to describe how tight knit the students are who attend at his school and that they remain busy with activities. He stated, "if it ain't broken, don't fix it [...] our teachers and our staff go above and beyond to like, make connections with the kids and make them feel welcome." He discussed how difficult it must be for students to leave their home communities at ages as young as 13 years for the completion of high school, and that is part of the reason why his administration makes school culture important. Strong school culture makes a positive environment where fun activities and learning are combined.

\section{Ignoring the Framework - Teachers Using Their Own Discretion}

"We're not always going to go to the Ontario framework when we know something will work better for our kids." - Christina

Not all participants believed they were required to follow legislation and school policies at all times. This theme became apparent once I began collating participant responses, specifically when referring to responses to questions about the implementation of the Ontario anti-bullying framework in schools.

Meredith described her continuum of what she termed 'levels of bullying', wherein some behaviours are tolerated more than others. She explained her categorization, 
like name-calling, 'oh you're a fag', something like that [...] if I overheard a student say that to another student in my classroom, I wouldn't necessarily get on the phone right away and call parents, but if someone got pushed around because of his sexual orientation or if he got physically harmed then I would call parents [...] it's case by case.

Meredith disclosed that she would determine whether the behaviour is serious or not based on her own interpretation of context. Christina also stated that she will not always follow the anti-bullying framework, we're not always going to go to the Ontario framework when we know that something will work better for our kids. Like, I'm not saying we are always going to have the right answer, but there are definitely times where we will feel strongly that we know our kids and we know what's going to work better and we're going to ignore it. We're going to ignore the framework, we're not going to ignore the issue.

Christina pointed out that laws, policies and procedures are not always the answer to solving negative behaviours. Rather, some educators do what they feel is best for the student $[\mathrm{s}]$ based on previous experiences managing behaviour at school. She is aware of what the framework promotes in school, but she will not always abide by its guidelines if she feels they are not appropriate. At this juncture, it is clear that Christina does not simply accept policies and procedures as they are framed, but critically analyzes their use in certain situations and whether they are helpful for students from the north (northern isolated communities). 
Another facet of 'educator discretion' is resistance to change. Insight is provided by Arizona, who is from the same school board as Meredith and Christina. Arizona discussed how teachers are afraid of change. She described, what I find amazing is [...] you have policies in place and you should be following them, but maybe people aren't quite ready to receive what's in those policies or those procedure guidelines or they don't really or truly understand why would you do it that way $[\ldots]$ you can look at some of these documents like that policy [FNMI Framework], for example, and go OK, I totally get it now, this is why. So, it really talks about umm, the Indigenous ways of knowing and ummm, how it is different and that we need to honour that and we need to think about doing things in different ways and that our Indigenous kids aren't necessarily going to do things in the colonial way that we expect them to do. One of the things we need to remember, like when we're looking at things like grad rates and any of those kinds of indicators, that we're measuring them on a, on a colonial success scale, not necessarily on an Indigenous way of being success scale.

She explained that the First Nation Métis and Inuit framework speaks to a larger didactic lesson that society cannot compare Indigenous and non-Indigenous students and measure their output on a colonial success scale.

Another factor to consider is individual educator perspective. Although Miranda believed educators stick to the school board policy, "bullying is in the eye of the beholder, so if I feel that I've been bullied, then I have been bullied, but it is any kind of an act which involves a position of power with someone who is less powerful." Her 
statement acknowledged a student's experience of negative behaviour that is labelled as bullying.

Contrary to Miranda's earlier positive comments, she also provided generalized examples where she advised her students to self-censor their negative, bullying experiences. Miranda spoke about how teachers at her school have an open-door policy and advise students who do talk to them that there are certain situations where they have a duty to report. Miranda advised that she stops a student "at the point that I know that I'm going to have to report someone." Here, Miranda reported that she tries to give her teenage students space to talk to someone, but also removes herself from the situation if the student no longer wants to talk because the instance must be reported or if the student does not want an adult involved. Miranda's approach is designed to create a level of trust with her students, but it may result in underreporting of incidents of negative behaviour by warning students to stop discussing issues before she is legally bound to report the incidents.

I asked Miranda if she was involved in any incidents of bullying behaviour; she confirmed three separate instances. When asked to describe two of the situations, she explained, "one was an incident where one of the students was bullied by an older nonspecial ed student, he actually, he was vaping inside the building and he blew smoke in the student's face." Another example included,

[An] older student was telling [a] younger student, I think it was a grade 12 student with a grade 10 student [...] the younger kid felt intimidated and wanted to know what could he do, so in that situation, I tried to coach him on what responses he could give so the adults didn't seem to be involved in it. 
When asked if parents are involved in instances of bullying, Miranda stated that “if I can work with the students, then I don't always tell. I mean, I'm working with teenagers $[\ldots]$ sometimes the teenager needs to know how to solve the problem without mom or dad." Miranda is the only participant who warned students to stop talking about the incident once it was getting close to the point where she would have to report it. Miranda disclosed that she does not bring all instances labelled as bullying behaviour to the administration because of her belief that they do not handle the situation. I then asked Miranda how so-called bullying is lessened in the school if it is not referred to administration. She responded,

what I do is [...] umm, if I see something happening, I know that I will speak to the students involved. Umm, both of them, I always like to get both sides of the situation. Umm, bullying is bullying, but you still sometimes are [...] not that there's a reason to have it happen, but the student whose being bullied might not realize that whatever they said or did started the whole incident [...] I'm an old teacher, so I bypass administration and I contact parents myself. Ummm, I've, I've never felt the need to go to the police with anything cause usually it's, you know, sort of what I call schoolyard bullying, you know, my dad's bigger than your dad, and you're going to do what I say cause I'm bigger than you, that kind of thing [...] ummm but if it was something that I felt was serious, I have no problem approaching police about it, but I don't follow the chain of command.

As a follow-up question, I asked, 'what is the difference between an 'old school teacher' versus 'new' as it related to reporting incidents of so-called bullying?' She responded, "new teachers are more nervous of administration and so they feel pressured [... they] are 
less likely to contact parents. They don't want to deal with it either, it's like, pfft, I don't care."

It is clear that Miranda is upset with the lack of support provided by new teachers to students and by administration to new teachers. She made it known that she does not accept policies and procedures at face value, particularly when she believes her school administration also fails to acknowledge the framework. Rather, her 'old school teacher' mentality guides her in critically evaluating whether the framework is useful at the time of the incident. Miranda's comments indicate that some teachers (perhaps more experienced teachers) may be more likely to ignore the formal rules and implement their own approach to negative behaviour labelled as bullying behaviour.

Lexie answered similarly to Meredith, Christina and Miranda about not always following the framework policies of her school; Lexie stated that she questions whether incidents require formal intervention or a conversation. She described various situations, ranging from, "name calling to exclusion to umm, social pressure to do something inappropriate, umm, we resolve it usually with a warning, however, sometimes we use restorative justice ${ }^{32}$, it depends on the circumstance." As a follow-up question, I asked when restorative justice is used, and she responded, "it really is kind of [questioning] how significant it is [the behaviour/issue]? Can we just deal with it with a conversation? Or do we need to do something more formal?"

\footnotetext{
${ }^{32}$ Restorative practices in school come from the concept of restorative justice, which is a method of "dealing with criminal justice issues that focuses on repairing the harm done to people and relationships rather than on punishing offenders" (OME, 2010, p. 36). In schools, restorative practices allow all parties "to describe what has happened, how they feel about it, how it has affected them, and what they see as a solution" (p. 36). This method offers an alternative pathway to restoring the relationships that have been impacted, rather than simply disciplining students for negative behaviour and growing animosity between students.
} 
The responses above show that the participants are generally aware of what the anti-bullying framework requires them to do, yet some of them choose to ignore the framework and utilize what they think is the best approach to behaviour that may fall within the anti-bullying framework. Most participants know that there is a duty to report and intervene when negative behaviour occurs, yet some still choose to use their own discretion and interpretation on what classifies as bullying behaviour. In the next chapter, I discuss how the exercise of this discretion may be influenced by unconscious bias and settler colonialism dominant within the education system.

\section{Incidents Labelled as Bullying Behaviour Involving Indigenous Students}

"We're making strides as a country [...] but people are still ignorant and close-minded and racist" - Derek

Participants were asked about instances of bullying specifically involving Indigenous students and whether the events were managed differently than other events (i.e. was there a difference in the treatment of negative behaviour involving Indigenous to Indigenous, Indigenous to non-Indigenous, non-Indigenous to Indigenous or nonIndigenous to non-Indigenous students). Meredith, Christina, Mark and Amelia responded to this question. The responses provided are very different, ranging from suspension to restorative justice practices.

Amelia's response indicated that if Indigenous youth are involved in instances defined as bullying, they may be given other opportunities, such as "attend[ing] a restorative justice circle [...] or given traditional methods of punishment [such as detention], as being suspended may mean being sent back to their home communities if they are from the north.” Meredith's response was not as direct as Amelia's. She asserted that there are differences in how students are treated, referring to different supports 
available for Indigenous students in her school, such as the cultural room for Indigenous students.

Mark pointed out what he saw as the need for Indigenous youth to conform to Westernized, academic expectations, specifically referring to extracurricular activities. He stated, we're just trying [...] to get First Nations students to fit in, or to feel like they fit in or to feel like they're part [...] I guess I could give you, give you a solid example of Indigenous students treated differently. Last fall, there was a young boy on the football team, he came in two or three minutes late and I yelled at him, I reamed him out, told him the expectations, this, that and the other thing, right, and as I was done that, and I continued teaching, then a girl who I knew was from the north, came in like 10 or 15 minutes late and I didn't say anything to her and I felt like a jerk. Because there I am, having this huge expectation on this poor boy on the football team, and then I'm not going to say anything at all to this girl. So, I don't, as long as the kid shows up [...] I don't give kids trouble anymore for being late. Mark recognized his own limitations in noticing some student behaviours are not necessarily motivated by personal choice but could be the product of systemic factors. Additionally, Mark's decision to not address individual student behaviours in front of the group points out that he realized the limits of his teaching philosophy/scope. Another example he provided was from his tech class,

I have a lot of cameras in the class and I want to lend cameras out, and again with attendance, some students just hardly ever show up and then they're like, 'oh can I take a camera home for the weekend?' And then I'm like 'well, when am I going 
to see it again? Next week? The week after? You've been here once this week' so then you feel bad because there's someone whose there every day and you're like 'well, what do you want, I'll let you take anything because I trust you with it', but I, if you don't ever, if you hardly know someone and you don't establish trust with them, right, so there's another example of there being a difference.

Mark's account does not take into consideration outside factors that may impact attendance at school, such as funerals, cultural celebrations, or perhaps some of these students are not engaged in his class and thus do not show up. Continuing on from the example of a student borrowing a camera, Mark was asked if reliability comes up with all students. Mark responded,

students kind of marginalize themselves for a lot of different reasons, and it's hard to, you know students have poor attendance for a lot of different reasons and if they have poor attendance, then it is hard to rely on them in that fashion and at the same time, non-Indigenous students can, but its typically the non-Indigenous students whose not reliable or who never shows up, doesn't feel engagement to the level where they ask for a favour like that, I guess (borrowing a camera without being in attendance).

Mark made the claim that Indigenous students marginalize themselves and that because of this sporadic behaviour he finds it difficult to trust them with school assets, and yet he recognized many reasons for poor attendance. However, he did not consider the same reasons they have poor attendance as factors when deciding if a student may borrow a camera. Building trust and respect in Indigenous culture, and therefore with Indigenous youth, takes time and effort. This theme will be explored more in the next chapter. 
Mark was also asked if he noticed other teachers treating Indigenous students differently, he responded,

I think everyone does and I mean the students pick up on it too [...] I'm always erring on the side of inclusion and helping people feel accepted, so I think that's kind of, I mean I've been straight out pressured to try to keep a First Nation student on a basketball team by administration.

Mark's response reflected confusion — he cited differences in treatment by teachers, and then the focus shifted to inclusion of Indigenous students in extracurricular activities at all costs.

Miranda's response focused on the treatment of Indigenous students by nonIndigenous students and the possibility of the negative treatment being rooted in attitudes learned at home. According to Miranda, many of the comments made at school are heard at home. She stated,

that whole cultural thing still exists here [...] you hear it in the community where people talk about First Nations people or umm, French people and it's [...] absolutely that bullying is happening, not only because they are Indigenous, but certainly there are incidents where you know, Johnny who is non-Indigenous has heard something at home and thinks its ok to come in and say something here. Miranda's response, while acknowledging that Indigenous youth are treated differently, simplifies racism as a form of behaviour labelled as bullying. The treatment of racism as a bullying behaviour will further be explored in the discussion and analysis chapter.

Izzie's response confirmed that she was involved in three very serious instances of negative behaviour involving Indigenous youth. She described one incident: sexting 
between an ex-boyfriend and ex-girlfriend, where police were involved. Izzie referred to sexual harassment as an incident of negative behaviour labelled as bullying in her interview despite stating that she did not like the term bullying (i.e. see pg. 150).

With respect to dealing with bullying when she encountered it, Izzie believed that instances of bullying behaviour are handled positively when Indigenous youth are involved (either as the student performing the negative behaviour or receiving it), particularly when they participate in restorative practices. She reflected on encouraging community members to also be part of the conversation to help "students to see their behaviour [...] and I think more for the bully, right, more for the aggressor in the situation, it's changed positively that we're looking at what are those impacts."

Izzie recounted another incident directly related to an Indigenous student who lives off-reserve that points to the possibility of bullying or violence between Indigenous students and the complex factors behind such behaviour. Izzie recounted how the student (who does not live on reserve) would visit family/people from her band's reserve, she'll talk about 'our land' and that kind of language which other students who live there [on-reserve] have been very harsh with her about the fact that 'it's not your land, you don't live on the res, you have all this privilege', so umm, anytime she speaks up or gets involved in anything, umm, there's this kind of backlash and she's really been struggling with how to navigate that $[\ldots]$ interventions with the office and interventions $[\ldots]$ cause it's all families and then family get involved, yeah it's been a really interesting line to walk for her.

When asked to further describe the dynamics of on-reserve/off-reserve issues that the student had to deal with, Izzie stated, 
we've talked a lot with her family about it [...] it's kind of a tricky ground 'cause it also involves community and uhh, and parents of students who are also saying some pretty harsh things on social media. [...] that particular student knows that she should bring evidence of it to us, that we can't do anything with hearsay, but if she brings in the texts and screenshots things, then we can address them.

Izzie further described how the school's Aboriginal Liaison worker recognized the student's difficulty navigating stereotypes that are out of her control and tried to equip her with responses that she could use to address issues within her family/community that hopefully did not create larger barriers for her. As described by Izzie, they [the Aboriginal Liaison worker] explained to the student that there are limits to what young Indigenous women who live off-reserve have control over and that she may be stereotyped based on historical choices. The liaison worker helped develop a support system for her (the student) when she wanted to talk about on/off reserve political issues. Izzie commented that while they were able to assist this student, “it hasn't necessarily helped community-wise, umm, like aunts and parents are still pretty nasty with each other about it, but it's definitely helped in the school environment."

Reflecting on the issues that impact students on-reserve, Izzie also noted that the resources are different, which influences the ability of reserve students to participate in extracurricular activities,

If you live in town, then you can attend extracurriculars, you can go shopping, you can do the things you want to do, you can walk over to a friend's house, whereas if you are on the reserve, they have one small gas station that sells some snacks and that's about it, umm, you can't do extracurriculars because of that hour and half 
commute, so [...] I think it's more that kind of, 'you know, you talk about your res experience, but you get to leave the res when you want' and I think that's where some of that bitterness has come from and that you don't understand how lucky you are $[\ldots]$ but also trying to support the student.

In this example, Izzie indicated that students who are able to move on and off reserve may have a better chance of social and academic success than those who do not.

Izzie's final example of negative incidents referred to bussing to school for Indigenous students. Students commuting from their reserve have a one hour, twentyminute bus ride meaning they have earlier mornings, and need to be on the bus right after school to return home. The bus schedules do not change due to the distance traveled. At the time of the interview, one particular bus monitor was involved in some negative instances that took place on the school bus. Izzie stated, the bus monitor "is an adult, it's somebody who is hired by the bus company to make sure that the driver can drive and somebody else is dealing with issues on the bus, so it's a long trip [...] there's like 48 kids, I think on the bus." She further noted that forty-eight young students are a lot of bodies for one person to oversee on a lengthy bus ride. The issues involving the monitor included,

one of our students called the bus company out as racist [...] we realized a lot of the underlying issues are more policy based, but a lot of our kids had been feeling like they were being targeted by this bus monitor [...] 'why is she waking me up and not waking up the other kids?' and 'why is she telling me I can't open my water bottle?' [...] feeling like they were being harassed by a bus monitor for the year. 
Aside from the transportation issue, when asked if she thought Indigenous

students were bullied because they are Indigenous, she responded, not blatantly. Umm, I think there's still some of that uhh, stereotyping involved. I think there's still some assumptions that are made [...] kids aren't walking around yelling squaw or chief, right, like that kind of name-calling, I don't want to be your friend cause you're native, that - I don't think is happening anymore.

When talking about in-class participation with classmates, Izzie stated,

I do think there are assumptions made about some of our First Nation kids that they're going to be lazy or they're going to be shy [...] I think it's case-by-case, but I do think some of the kids who don't get included is based off of assumptions, umm and I definitely think teachers still assume that First Nation kids are shy [or] have anxiety $[\ldots]$ and that's a stereotype that we need to change.

Reflecting on a student she taught, she stated, one of my students told me a couple of years ago, 'you know, I really hate that people say I'm shy' $[\ldots]$ he's very traditional, he said, 'I've been taught that my role is to listen, I don't question you, I might question you in my head, but I'm not outright asking questions cause I'm going to process what you're saying and I'm going to reflect on it and then I'll, you know maybe then I'll have a question, but while you're talking, I'm not going to question you.'

As a follow-up question, I asked if any Indigenous students discussed eye contact, to which she replied,

Yes, that it makes them uncomfortable. That it, culturally, is not something that they would do. That, they get told that it's disrespectful and it makes them very 
uncomfortable because they're trying to be respectful [...] a lot of my kids, especially if they're struggling with something, the eye contact makes them emotional and so one of my students says all the time, cause I'm an eye contact person and let's get into it, and that face to face, and she said, 'Miss, I can't even, I can't cause I'll cry, and I don't want to' [...] a lot of them have commented on that being an issue. Same with physical touch, is another one that they don't like [...] one of the boys that I taught one time umm, said that one of his teachers, and he was really struggling with, touched his hair often, [in a 'hey, how's it going?' manner] and it really, really made him uncomfortable to have that, umm, done [...] so we had to have a conversation with the teacher about it.

Izzie pointed out that the Pyramid of Intervention (discussed earlier) was used for the above incident. Izzie advocated on behalf of the student and explained the problem to the teacher. The teacher apologized to the student and stopped. Here, the teacher was unaware of cultural differences, particularly how Indigenous youth do not appreciate unwanted touching.

Lexie shared a story when asked about TRC recommendations and their implementation in the school. She described a Native Studies course where Indigenous students were attacked on social media by a non-Indigenous student, I can tell you a little story $[\ldots]$ a really ugly racist incident earlier this year $[\ldots]$ happened about 7 o'clock at night on social media, by 9:30pm I had 7 texts from different people, like do you know this is going on, I came early [to work] the next morning 'cause I knew it was going to blow up, umm, I had a group of girls [...] and their teacher, their regular teacher who would've dealt with this kind of thing 
was off on leave, so umm, I had a group of girls and boys upstairs, mostly girls, but upstairs in the uhh, we also have a classroom now that's dedicated to Indigenous students, they were there, really quite upset, and we try to incorporate student voices as much as possible and we're really working on that, so I think it's a teaching moment, 'what do you guys want to do?', 'we want to have a circle and then we want to have a smudge', I said, 'OK, let's do that'. And I didn't lead it, I got our Child and Youth Worker to facilitate, but she didn't lead it, the kids lead it and uhh, super effective, like really kind of made them feel like they were heard, didn't really come to a resolution cause there isn't a resolution to hate, unfortunately, but afterwards we went outside, we had a smudge, a couple of the kids umm came and had lunch with me cause they really still felt kind of, quite upset, so I wanted to spend a little bit more time with them [...] it showed me that first of all, they're not afraid to embrace their culture, they're not afraid to defend their culture, and the allies in the room [non-Indigenous youth] were right there with them, it was heartening to me 'cause I could [see] there were more kids who were not Indigenous than there were Indigenous, so that was wonderful.

When asked to describe what was said over social media in this example, Lexie stated, a horrible racist slur, basically a kid who had barely attended the class and was going to fail, fail the Indigenous studies class, basically said umm, every terrible thing you can think of about First Nations people, you know drunken Indians on welfare, trying to steal our taxes, blah blah blah, this is what I want to say, but I know that if I say that, I'll fail the course [...] it was just awful. 
When asked if events labelled as bullying are managed differently with Indigenous youth, Lexie responded, “it depends. I'd like to say we always use restorative practices with our Indigenous kids, but they don't always want us to, they want us to treat them the same as we treat everybody else and we don't use restorative practices with everyone." It is important to note that restorative practices usually involve both parties. However, it is unclear if the student who made the posts was involved in the restorative justice exercise. As a follow-up question, I asked Lexie if she could provide insight on why students would want to be treated the same and if they saw differences in how they are treated in mainstream society? She responded,

I think that a school for them [...] is a safe place, and they feel comfortable saying I don't need to be different and I think also, that is the manifesto of every teenager in the world, where they don't want to be different than anybody else. So, these kids actually taking pride in their culture and actually celebrating it, to me, is a huge win.

Lexie's school specifically focuses on ensuring students from northern communities feel included and that their voices are heard.

From Derek's perspective, students are not treated differently at his school because all students are Indigenous. He described some fights over the past few years, but did not feel comfortable providing further details. When asked about direct involvement with any incidents of negative behaviour labelled as bullying, his response was "not really, not particularly [...] the bosses deal with that more than I do, but I usually hear about it "cause I work very closely with them [Indigenous youth]." Additionally, he commented on the fact that some students who are violent lose their chance to get their 
credits - some students are sent back to their home communities; "we try and give the kids as much flexibility as possible, but [...] we have to really draw a line in the sand when it comes to something like violence."

Derek commented that if instances of negative behaviour happened at a provincial school involving an Indigenous student, he hopes educators at that school "would take a little more care to understand why it happened and to make sure it [the motivation and the consequence to the negative behaviour] wasn't racist." He further reflected, "I think there's a lot of crimes that are racially motivated [...] I hate to say it, but it's the truth $[\ldots]$ we're making strides as a country $[\ldots]$ but people are still ignorant and close-minded and racist." In Derek's response, he shed a hopeful light: that teachers do or will take the time to determine any underlying factors for the negative behaviour(s) against Indigenous students (and others).

\section{Participant Suggestions to Potentially Improve Anti-Bullying Measures}

“It's going to take a long time." - Callie.

"Be proud of who you are, stand up for yourself, don't let somebody else push you around." - Derek

"It has to be slow and it has to be authentic, otherwise we break all of those relationships." - Izzie

Participants were asked to provide suggestions to potentially improve antibullying measures; the focus was not specific to Indigenous students. Eight participants responded. Several focused on building more resilience and strength of identity among Indigenous students, some suggested looking to greater community involvement or strengthening resources to assist Indigenous communities. Participant responses are provided below. 


\section{Recognize and Deal with 'Bullying Behaviour'}

Mark suggested Indigenous youth be coached on "how to deal when they do get bullied" and he subsequently drew parallels between the Civil Rights Movement in the United States and First Nations relations in Canada, stating that Canada should be "informing kids what their rights are under the law."

Callie opined, "it's going to take a long time," and Arizona believed that Indigenous students need to keep their history at the forefront and know "who they are and [have] that sense of belonging and identity." Arizona concluded that Indigenous youth should be proud of who they are and to build on their cultural heritage despite the past violence they have endured. It is important to recognize that Mark, Callie and Arizona each focused on the need for Indigenous students to become even more resilient, as a solution, rather than drawing on their knowledge of outside factors which impact Indigenous populations in the Canadian state or focusing attention on the potential bullies.

April suggested broadening the conversation about Indigenous history and antibullying procedures to include parents and students. Miranda suggested exposure on Indigenous issues during career day or other presentations in high schools to potentially improve anti-bullying initiatives. She stated this could potentially curb some of the Indigenous-directed bullying by "making sure that First Nations people are included as leaders $[\ldots]$ make them [and their successes] more visible."

Izzie addressed the need for Indigenous culture to be localized, for change to be driven at a grass-roots level. She asked, "how do communities want the bullying to be dealt with? What strategies do communities use?" She described how students can use a 
smudge pillow as an alternative to smudging indoors (due to fire code) when they feel they are a target of negative behaviour. The smudge pillows were "encouraged by a community member [...] it's that localizing [force], so what can we do? what are things that our students want? what are things that our communities want? [...] find[ing] ways to address it from a community standpoint." Izzie's response addressed improving antibullying initiatives by downplaying Western ideals and working from an Indigenous perspective.

The response from Lexie did not focus on any specific circumstances; her response was vague, "we have to consider mitigating circumstances all the time." She did not elaborate on what factors she was discussing but stated that in addition to Indigenous students there is "a large population of special needs students [and that she] has to navigate that too." Here Lexie pointed out the complexity of dealing with incidents of negative behaviour towards students of her large Indigenous population and also a large population of students with special needs in her school. In order to better navigate the unique issues Indigenous people (and others) have to endure, she requested, "better mental health supports generally for First Nations kids, better family supports for First Nations families [and] better child protection for First Nations." She did not disclose any further information. It is important to note that she puts the onus of dealing with negative behaviour back onto the Indigenous community at large and specifically points to familial issues and chose not to address more action on in-school supports.

Derek responded with simple and straightforward direction of action: "just educate." He described anti-bullying activities he personally conducted in his teacher placement, 
I did a bullying activity and uhh, you know, a couple different things, bang up an apple, 'how does this apple look?' 'Good, oh it looks good, still looks good.' You cut it open and it's bruised on the inside, that's what happens when you bully people, or like, 'what's with this paper? Can you see through it?' 'No.' 'Can you see through this paper?' 'Yeah.' That's bullying. Like, I can see right through that. Cause people push other people around because they're insecure. If you're confident with who you are, you love who you are, you're probably not going to go out of your way to make someone else's day miserable.

Derek provided a positive response regarding his school's leadership and their advice to the youth when they are involved in negative behaviour. He stated,

my leadership has said, and I value their guidance and mentorship more than anything, $[\ldots]$ you can't run [from things] [...] even if you think there's racism here, and sometimes it's challenging [...] we gotta teach our kids to be strong, we can't teach them to run, you can't run from it their whole life. They're not saying get into a fist fight, but like, you know, be proud of who you are, stand up for yourself, don't let somebody else push you around.

Based on his response, Derek recommends an area for growth: bolstering the empowerment of Indigenous youth should be prioritized. Although they may need guidance and education to tackle the systematic hurdles that are in place for social success, they should be hopeful that with proper mentorship, they will succeed.

The responses provided by participants do not explicitly respond to the question of how to potentially improve anti-bullying initiatives. The discussion was directed towards resiliency; Indigenous youth should be proud of their culture and learn to be 
resilient despite any negative behaviour/attitudes directed towards them. In this instance, the onus is on Indigenous people to curb larger systemic issues that resulted from colonization, the legacy of residential schools, the 60s scoop and any endured trauma impacting generations of Indigenous families.

Conversely, it was also recommended that community connections be strengthened between local Indigenous communities/people and non-Indigenous individuals so that non-Indigenous individuals could become aware of, and understand, Indigenous culture/history. Participants believed that youth learning about Indigenous culture in schools through lessons/amended curriculum may initiate a decrease in negative behaviour(s) and attitude(s) towards Indigenous youth. Overall, there emerged a hopeful message that educating non-Indigenous youth about Indigenous history/culture is an anti-bullying initiative which may shift social attitudes in a positive manner, where negative behaviour(s) and attitude(s) would be less likely directed towards Indigenous people (and others).

\section{Conclusion}

Chapter eight will provide a discussion of the relationships among the main themes that emerged from the findings reported in chapters six and seven and will identify how these findings contribute to our understanding of the potential impact of Ontario's anti-bullying framework on Indigenous students. By way of summary, the key findings to be discussed include how geographic location influences formative experiences, how most participants espoused the traditional conception of bullying reflected in existing academic literature, how several participants labelled incidents involving racism, violence or sexual harassment as bullying, even while those same 
participants noted that more complex conceptions of the bullying label are warranted, and lastly, the discussion will include participants' use of personal discretion in their practice of implementing the Ontario anti-bullying framework: depending on the context of the behaviour, they reported they sometimes believed they could identify a better approach to specific incidents than what was required under the framework. In the forthcoming discussion and analysis chapter, I will consider how this exercise of this discretion may cause problematic results for Indigenous students within the context of the settler colonial dominance of the education system. The conclusion to this study will follow with areas for future research. 


\section{Chapter Eight Discussion: Educator Appreciation of Indigenous Culture}

As outlined in the introduction of this dissertation, I am responding to the TRC's calls to action around education, "helping to bring awareness of the ongoing and negative repercussions of a colonial past" (Pratt \& Danyluk, 2017, p. 6). There is currently a lack of scholarly analysis with any focus on the 2012 Ontario anti-bullying framework and no works with an inquiry on its potential impact upon Indigenous youth. My dissertation attempts to fill that void in the scholarly literature by studying the important factor of educator understanding and perceptions of the legacy of colonialism and how an educator's level of comfort/understanding of these concepts affects the implementation of the anti-bullying policy. Although behaviours labelled as bullying impact all children, there are devastating and unique factors that impact Indigenous youth attending high school, both those outside their home communities and those who are local, and this population is my focus for this dissertation.

In this chapter, I discuss the key themes that have emerged through the analysis of my research data. The overarching themes of my findings are: the geographical differences between those participants from northern and southern Ontario and their engagement with Indigenous culture and peers; the shared, general definition of bullying among participants and the implications for the implementation of the anti-bullying framework; and 'educator discretion' and how it can either address or reproduce settler colonialism within the education system. Subthemes that I discuss include: the mislabelling of racist/anti-Indigenous harassment and violent behaviour as bullying, and the potential bias of educators/staff members and how this may affect Indigenousinclusive education. 
Within each theme identified above, I address connections to scholars I introduced in chapter four, specifically McGregor (2008), Walton (2005a, 2005b, 2005c, 2011), and Winton and Tuters (2015). These scholars agree that bullying behaviour is more complex than presented in the initial work of Olweus (1994). McGregor, Walton, and Winton and Tuters look at the larger picture of social structures and how the concept of bullying behaviour is socially constructed to reinforce existing hierarchies in society. McGregor (2008) and Winton and Tuters (2015) focus on the policies of bullying, while Walton (2005a, 2005b, 2005c, 2011) focuses on anti-bullying legislation and its impact on 2SLGBTQIA youth. My dissertation builds on their work to the extent that it examines the complexity of the relationship between law and incidents of behaviour labelled as bullying, but my focus differs from these works in that I examine the 2012 Ontario anti-bullying framework and the potential impact of its implementation on Indigenous youth in northern Ontario.

My work highlights the importance of teacher perception because their perception impacts how negative behaviour is understood and addressed through the Ontario antibullying framework. Their perceptions were also developed as a result of growing up in a colonial education system (Dion, 2004, 2007; Battiste, 2013). I note that because of the qualitative nature of my study, the findings cannot discuss direct causality, and are not generalizable to the larger educator population due to the sample size.

\section{Geographic Differences between Educators and the Engagement with Indigenous Culture}

In my research, participants who were from southern Ontario differed from northern Ontario participants in two important ways. These were the general lack of exposure to Indigenous history or colonial legacy in their elementary and secondary 
education, as well as a lack of experience of Indigenous culture (for various reasons) among teachers from southern Ontario. In contrast, those participants who were from northern Ontario all had a greater understanding of Indigenous politics and culture, and more interactions with Indigenous peers. However, both groups reported that they did not develop an appreciation of the issues created by residential schools or colonial legacy until they were in university or even later when they began working directly with Indigenous youth in their schools, with the exception of one participant who is Indigenous and was already aware of these issues.

I interrogated my participants' knowledge of Indigenous issues in their early years as part of a broader inquiry into how they utilize their knowledge of Indigenous history when dealing with incidents labelled as bullying. My findings were that there is no relationship between formative experiences and educator definitions of bullying; once the educators in this study started teaching in schools with large Indigenous populations, they became more aware of the challenges faced by Indigenous peoples and their perspectives of Indigenous youth became more positive. Notwithstanding this, the definitions of bullying provided by my participants did not reflect their understanding of the challenges faced by Indigenous students. Rather, most of my participants reiterated the standardized definition of bullying that promotes individual factors and asserts those factors can be changed by being kind to peers. This uncritical approach to defining bullying, notwithstanding the critical understanding of the challenges faced by Indigenous students, may lead to the unintentional reproduction of settler colonialism in education through the implementation of anti-bullying initiatives.

As discussed in chapter six, some participants were aware of violence and discrimination against Indigenous people. For example, Arizona recalled the drownings 
of Indigenous youth and April reported that generational differences impacted how others spoke about Indigenous people. These are two examples from northern participants who were exposed to systemic racism against Indigenous people earlier in their lives than southern participants. These northern participants had pre-existing knowledge and exposure to Indigenous issues. Some of the participants who were from southern Ontario, reported they experienced a type of 'culture shock' when they moved to northern Ontario for work and personally became aware of the issues Indigenous populations continue to experience.

Participants reported that their school boards were being proactive in trying to include Indigenous culture in their teaching curriculum even prior to the announcement of the TRC calls to action. Rather than simply reiterating the Western viewpoints of the Ontario Ministry of Education, the two participating school boards were already including Indigenous culture and shifting curriculum with Indigenous-focused English, History and Art classes. These school boards recognized the need to decolonize their approach to education for their student population (Battiste, 2013) attempting to unlearn racist behaviours; "racism as a learned or acquired set of behaviours can be unlearned" (Battiste, 2013, p. 138) and the education system, although based on colonial logic, may be able to shift the minds of some youth by the influence of educators in the classroom. Nonetheless, the participants also reported examples of individual, and structural systemic racism in their schools. For example, Arizona referred to a teacher who blamed their Indigenous students for always being late and missing math in the morning. Another example was provided by Lexie where a non-Indigenous student criticized a Native Studies course over social media using stereotypically racist language. 
In these instances, both Arizona and Lexie coached the educator and student on how to accommodate and include Indigenous students in the colonial education system. Arizona had a one-on-one conversation with the educator about adjusting her timetable. Rather than blame the Indigenous students for not learning the math taught during the lesson, Arizona coached the educator to be aware of the cultural rhythms and to shift their timetable. She also referenced the idea that it may be a Grandma caring for more than one grandchild. Lexie coached the student through the restorative justice practices employed through the school. She did mention a class-wide restorative justice circle to move forward from the incident, but it was not clear if she was directly involved in the circle other than in her capacity as the principal of the school. Lexie's account allowed the Indigenous youth to lead the restorative justice circle, ensuring the youth's voices were heard.

These instances occurred in different areas of northern Ontario and suggest that some participants attempt to mitigate overt negative behaviour targeted towards Indigenous youth and try to include Indigenous voices in the process. In both instances, Arizona and Lexie supported Indigenous youth's learning by re-structuring education processes that would have typically been managed differently (i.e. perhaps math would have remained the first lesson and those Indigenous youth would not have learned the math skills required for success or rather than engage in restorative justice practices, traditional methods of discipline would have been preferred, disallowing the Indigenous youth the opportunity to share their feelings about the negative behaviour they experienced). Both educators attempted to decolonize the process of educating (Battiste, 2013) so their Indigenous students were included. 
There was a general knowledge among the participants concerning Indigenous history, culture and politics; participant understanding is informed by dominant discourses (Dion, 2007) and influenced by their upbringing. Despite this knowledge, however, April and Mark did not appear to have made the link between the history they were teaching in the curriculum and the current situation of some of the Indigenous students in their own classrooms. Although April teaches Junior Kindergarten students, it was apparent that she did not understand the historical trauma Indigenous people navigate. For example, her response to my question about moving off-reserve for high school, she asked, "are you talking about [...] as if it were to happen now?" to which I responded "yes." She stated in shock, "oh my goodness, that would be horrible." Another example of not understanding the continued impact of Indigenous history/politics on his Indigenous students is Mark's expression of not lending out cameras to Indigenous students in his tech class because he does not see them on a daily basis; I assume his students could be absent due to cultural factors. Mark's example is one that shows the impact of systemic colonialism in the education system. Mark is part of a Western education system that expects students to be present every day and thus builds in assumptions when that expectation is not met; the Western education system does not consider different Indigenous needs, rhythms and practices. Thus, Mark's unwillingness to lend out cameras to Indigenous youth who are not present daily is based on the dominant discourse of what Mark knows; Mark was taught in and teaches in a colonial education system that requires attendance to prove dedication to learning and trust in the education system (Dion, 2004, 2007). Dedication to learning and trusting the education system also shapes trusting relationships with educators. Indigenous students are disadvantaged by assumptions educators may make and are thus forced to either 
conform to the Western system or lose out on important opportunities. Mark's response to the repeated absence of his Indigenous student is an example of one of the ways that settler colonialism in the education system is manifested in individual responses.

These responses shine light on the fact that some educators in this study did not recognize the vulnerable status of Indigenous youth who move or commute for high school. For example, attending school off-reserve and living in an off-reserve community may render Indigenous students even more vulnerable to Western points of view where trauma is ignored/forgotten (Milne, 2015, 2016). Nonetheless, most of the participants in this project were aware of the issues that have impacted and continue to affect Indigenous youth. However, the time at which they became aware of Indigenous issues was not consistent among the participants. Many of the participants did not have extensive experience with or first-hand knowledge of Indigenous culture at the beginning of their careers. It was upon employment with a school board that has a higher proportion of Indigenous enrollment that most participants gained or had a renewed interest in experiencing Indigenous culture and working with Indigenous youth.

This finding raises a question about whether or not educators who are employed in southern Ontario schools - who may have less exposure to Indigenous students/culture and therefore less reason to seek out and experience Indigenous culture — understand the impact of Indigenous history/politics on Indigenous youth, particularly if they have only a few visible Indigenous students? Dion (2007) argues that the majority of Canadian educators "have a limited understanding of Aboriginal people, history and culture" (p. 330). An absence of knowledge about Indigenous people may make it difficult to understand Indigenous perspectives of violence. Asking someone who comes from a Western-centric society, who has grown up with negative stereotypes, and who 
does not have an understanding of Indigenous culture/history/politics, to recognize the historical trauma Indigenous populations have faced, is already a difficult task. Social problems may be blamed on the individual experiencing them, thus when someone in a 'lower class' cannot solve the problems they face, they may be subsequently blamed for the existence of the problem (Palmater, 2011). In addition, it is even more difficult to begin to unlearn/deconstruct the stereotypes which are perpetuated in current Westerncentric society (Battiste, 2013). Those individuals who attempt to do this are starting to unpack the difficulties Indigenous populations navigate.

Although none of the participants reported blaming their Indigenous students for their position in society, the participants did hold their students accountable for meeting provincial educational standards, thus the onus to succeed in an alien school system founded in colonialism is on the Indigenous student. Notably, only one educator, Arizona, cited the First Nation, Métis and Inuit Education Framework that is available for educators to reference when teaching Indigenous students. However, she described it as lip service of the Ontario Ministry of Education. She added that there needed to be educator buy-in/appreciation of Indigenous culture if Indigenous students were going to have a chance at success in a colonial system.

Although educators in this study did show a concern for their Indigenous students, the lack of appreciation and consideration of Indigenous history and culture are still a valid concern in northern Ontario. Dion (2004) argues "Canadians 'refuse to know' that the racism that fueled colonization was a result of a system which benefits all nonAboriginal people" (p. 58). The 'refuse to know' can be seen in the colonial education system and is related to the lack of understanding and appreciation of Indigenous cultures. This lack of cultural appreciation and deeper understanding of Indigenous 
cultures can be seen in the examples provided by Izzie about how two things, such as lack of eye contact or touching a student's hair, can have vastly different meanings. These examples, taken for granted in Western culture, can be seen as disrespectful in Indigenous culture. These examples show a superficial understanding of Indigenous culture among some educators. The example of touching a student's hair was also not considered inappropriate, which is problematic regardless of cultural differences. But, as my discussion below demonstrates, these superficial understandings did not translate into a deeper systemic understanding of the implications of these different meanings for the educational experience of Indigenous students.

There were other indications of behaviour stemming from the failure to appreciate the way in which Indigenous culture, history and experience may impact student behaviour. One example is Mark's description of his conflicted response to accommodating the late arrival in gym class by an Indigenous student compared to the tardiness of a member of the football team he coached. Rather than voice his concern for the late arrival of the Indigenous student, as he did for the member of the football team, Mark remained silent. He also does not recognize that the stamp of time he expects Indigenous youth to follow is based on settler colonial frames of reference (Rifkin, 2017). Rifkin (2017) states, "there is no such thing as an absolute time that applies everywhere at once" (ix). Temporal experience is based on "one's perception and material experience of patterns of individual and collective memory, the legacies of historical events $[\ldots]$ and the length and character of the timescales in which current events are situated" (Rifkin, 2017, ix). Understanding of, and consideration for, the Indigenous youth's adaptability to school off-reserve should be recognized by Mark and other educators. However, because Indigenous youth are expected to obtain education off-reserve, they are forced to adapt to 
Western ideologies of time. Mark reported being conflicted by his different responses to the tardy arrivals of the Indigenous and White students. Mark's responses suggest that he remains uncertain about how to navigate an education system rooted in settler colonialism, particularly when there are Indigenous youth involved who are also navigating an education system that is not established for Indigenous cultural differences to prosper.

Notwithstanding these examples, and as noted above, most participant responses demonstrated an appreciation for the issues faced by Indigenous students and their potential negative impact on an individual level. However, as will be discussed below, the absence of a deeper systemic understanding of the colonial logic of education meant that the participants were not able to perceive the potential negative impacts on Indigenous students of the implementation of anti-bullying frameworks in their schools.

\section{The Danger of the Failure to Recognize the Impact of Settler Colonialism on the Education System}

This brings us to a consideration of the broader policy context in which the antibullying framework was developed and has been implemented. To understand educator perspectives of bullying, it is helpful to return to the context in which the anti-bullying framework was developed. As noted by Walton (2011) and McGregor (2008), the Ontario anti-bullying framework policy was created out of an emerging discourse of safety for all students, to ensure the safety of all students and to facilitate an environment conducive to learning. As noted in chapter two, it was constructed in response to the social environment present at the time following the deaths of Hubley and Wilson. The role of the anti-bullying framework promoting the safety of students in school was repeated by a number of participants. For example, Miranda believed the framework 
created safety in the school for students and also gave them a safe space to report any incidents of negative behaviour they encountered, whether it was in or outside of the school. Christina also referred to safety under the anti-bullying framework, calling it 'action-oriented' to address negative student behaviour(s) at their onset if they are reported to an educator/staff member.

Although the lives of Hubley and Wilson are important to consider, there was no apparent consideration for Indigenous youth when the anti-bullying framework was discussed prior to enactment. In addition, by contrast to the focus on school safety, there does not appear to have been any consideration of the impact of settler colonialism in the formation of the anti-bullying framework. This is important, but not surprising, because as Walton (2011) suggests, not all perspectives are considered by policy-makers or the educators who enforce the policy. Although Walton (2011) refers to perspective of 2SLGBTQIA students, the same can be stated here; "discussing issues [...] of social difference is difficult and controversial" (p. 137). Rather than have critical discussions, Walton (2011) argues that,

from an administrative standpoint, it therefore seems pragmatic as a strategy for evading controversy to draft policies that refer to bullying as generic behaviour. The problem simply put, is this: although masquerading as providing protection for all students, generic policies do not address the specific ways that particular children, and not others, are continual targets of peer violence. (p. 137)

I argue that many people involved in the education system do not want to have critical, reflexive conversations about the historical violence and trauma Indigenous populations endured in residential schools/60s scoop eras and/or how settler colonialism is reinforced in policy because it likely does not interfere with their children's education. It is easier to 
ignore these issues. Relative to bullying, negative behaviour in schools may be ignored if it involves Indigenous youth. It is easier to ignore issues of racism than discuss the behaviour. However, social context is important; Indigenous perspective and the history of settler colonialism need to be included and discussed (Battiste, 2013) when considering responses to negative behaviours in school, particularly when Indigenous youth are involved.

As noted in chapter two, settler colonialism is reinforced in the education system through the erasure - by exclusion in the curriculum — of the profundity of the Indigenous experiences/history, which reinforces the subjugation of Indigenous people (Dion, 2004, 2007; Wilson, 2007; Battiste, 2013). Overlooking Indigenous history/politics/culture is part of the Canadian state's erasure of Indigenous culture (Dion, 2004, 2007; Nagy \& Sehdev, 2012; Battiste, 2013). In addition, the history of residential schools and the 60s scoop era had an impact on all those who grew up during this time. Milne (2015) reported that families which suffer from the intergenerational trauma of those events are still required to function within the education system without public acknowledgment of the true extent of the experiences Indigenous people endured in school. When Indigenous youth are required to attend schools, which do not acknowledge the generational legacies of that era by the Canadian state, their unique histories are ignored, and they are expected to learn within a colonial curriculum.

Disregarding Indigenous history in school curricula sends a message to the entire student body: Indigenous culture, history and the impact of trauma on the Indigenous population due to colonialism, are unimportant. My research findings provide evidence of this message resonating despite more recent attempts to amend the curriculum. For 
example, Christina referred to multiple instances of resistance to Indigenous-inclusive content: students were not accepting of the introduction of Indigenous-inclusive content in the university stream English courses and non-Indigenous students refused to participate in Indigenous culture week to an extent that it was cancelled the following year. These examples also suggest that the school addressed the curriculum change and did not cancel those courses because they were mandated by the Ontario Ministry of Education — the participating school boards were making the amendments earlier than required. However, the cancellation of the Indigenous culture week — not a requirement of the Ontario Ministry of Education — has not been reconsidered, sending a message to the student body that unless the change is required, there will not be an Indigenous cultural week. This message reinforces the idea that Indigenous culture is not a priority (Dion, 2004, 2007) and may leave Indigenous students feeling unsupported in a school that claims to include and support Indigenous students.

My research also provided examples of the impacts of the failure to fully appreciate the importance of Indigenous history and culture: as noted above, Mark did not address cultural factors as to why his Indigenous students are absent or late for class; Izzie reported having to teach another educator about the disrespect inherent in touching a student's hair, and the need to respond differently to not receiving eye contact from an Indigenous student; Amelia noted that Indigenous students are sent back to their home communities if the restorative justice practices do not succeed in instances of bullying.

All of these examples blame the Indigenous student, rather than reflecting on the systemic settler colonial foundations of the education system. Indigenous youth are blamed for not meeting Western standards of time; Dion (2007) states that there is fear in the system, "the fear of offending, the fear of introducing controversial subject material, 
the fear of introducing content that challenges students' understanding of the dominant stories of Canadian history" (p. 331). What is seen in my research is that Indigenous youth are blamed for not speaking up to educators for both touching of their hair or providing reasons why they do not provide eye contact; and Indigenous youth are blamed if the restorative justice practices fail. These examples blame youth for the settler colonial foundations of the school system that promotes Western time management, giving eye contact when spoken to, or acceptance of traditional modes of discipline (suspension or expulsion). For Indigenous students who move away from home for high school, they are expected to follow rules that allow them to attend school off-reserve (i.e. following Westernized ideologies of time as discussed by Rifkin, 2017), in addition to succeeding in a Western school system. These rules may be viewed as a way to manage Indigenous youth - how well they are able to adapt to a new geographic location, to a new school, to new friends, and to a new education system (as opposed to on-reserve learning). Indigenous youth are trying to adapt to an entirely new life, while trying to navigate social systems that exclude Indigenous student success. There is a lot at stake when Indigenous youth leave their home communities for an education. As such, educators need to be reflexive of the broader context which Indigenous youth must navigate and be aware that their actions (or inactions) impact their Indigenous students' futures.

At the same time, positive instances of the consideration of cultural differences were reported, such as Meredith, Callie, Christina and Izzie's references to their schools' cultural rooms designated for Indigenous students and the references to the application of restorative justice practices in response to bullying incidents involving Indigenous students. These examples show that some participants believed their schools were trying 
to include, support and accommodate Indigenous youth who attend high school offreserve despite teaching in a system that is based on colonialism.

In the context of an educational system rooted in settler colonialism, that colonialism is perpetuated when educators do not properly identify and denounce racist or violent behaviour. Minimizing negative behaviour towards Indigenous youth by attaching the generic label of bullying reinforces and reproduces the foundations of settler colonialism in the education system identified by Wilson (2007), Battiste (2013), and Simpson $(2014,2016)$. This danger will be further explored below with reference to participant understandings of the definition of bullying.

\section{Educator Definition of Bullying}

Similar to Walton's work, my research findings indicate that participants hold a very general understanding of what the term bullying means, based on standardized definitions reflected in the anti-bullying legislation and mainstream scholarly literature. In the legislation, bullying is defined as aggressive and typically repeated behaviour by a pupil (Education Act, 2019, s.1[1.1]). In academia, the mainstream definition of bullying is based on Olweus' (1994) work suggesting that students who are repeatedly exposed to negative actions by one or more students are victims of bullying.

Olweus (1994), Boulton and Smith (1994) and Olweus and Limber (2010) see aggression as an issue which affects individuals and fail to recognize that society is composed of groups of individuals who are ordered by norms and values which are often defined by Western systems. Meredith, Amelia, Christina, April, Miranda and Derek were uncertain about which specific factors were included in the bullying definition, however their responses all listed individual actions or words which cause physical or 
psychological harm. They also referred to the idea that these behaviours can be changed with intervention by reminding students to be kind to each other. Callie, Lexie and Izzie also referred to individual behaviours, suggesting they can become larger relationship problems when teenagers are 'navigating their social connections'. These comments reflect Olweus' definition of 'bullying as friendship' where power imbalances between peers are present (Olweus, 1994). Interestingly, this type of relationship is also defined by Olweus as peer abuse. This also echoes with the work of Cornell and Limber (2015) who discuss temporary power struggles between friends and the difficulty of defining bullying examples in these relationships.

Mark was the only participant to explicitly refer to "natural pecking order and societal hierarchies" when referring to whether or not Indigenous youth integrate with other students at school. In this comment, he was referring to the tendency of Indigenous students to stick together and he attributed this to their shared qualities. Mark's reference to group structures echoes the work of Olweus (1994, 2013), Olweus and Limber (2010) and Lee et al. $(2011,2012)$. These authors argue that behaviours considered to be bullying are targeted at certain individuals who are considered to show lesser qualities, such as members of marginalized groups, and disregard larger societal influences. I assert their argument falls short of recognizing larger social structures which are introduced at a young age and reinforced by external conditioning, such as youth establishing a hierarchy among peers based on socially constructed ideas about race, class and socioeconomic status (McGinley, 2008).

A lack of consistent anti-bullying training may have had an impact. It appears that, when the Ontario anti-bullying framework came into effect in 2012, there was not a 
single standardized training session on the new policy for staff/educators by the Ontario Ministry of Education; it was left up to each school board to ensure their educators knew about the framework. As a result, some participants reported receiving training and others did not. Some participants were required to take an online webinar course on the Ontario anti-bullying framework, which they referred to as uninformative, but a 'condition of employment'. Some participants reported not participating in any training at all. For example, Miranda, who reported relying on her discretion when deciding how to deal with bullying incidents, pointed out that she does not have time for additional training on the Ontario anti-bullying framework. Some participants therefore had to draw from their own understanding of what the framework intends to achieve. Without any coaching, these participants adopted an individualized approach to implementing the policy based on their own understanding of it; this understanding relied upon mainstream assumptions of the meaning of bullying and an educator's individualized case-by-case assessment of the negative behaviours brought to their attention.

My findings concerning the shared general definition of bullying among my participants supports Walton's argument that when people hear the word bullying, there is an assumption that the observer automatically knows what behaviour has taken place, such as 'someone's feelings were hurt'. This assumption is based on pre-existing ideas of what bullying behaviour is. Walton's argument is confirmed in my analysis of responses of participants who believed they could recognize bullying when they were confronted with examples of it, regardless of a lack of meaningful training on the anti-bullying policy. Contrary to this belief, some participants shared examples which seemed obvious to me as forms of negative behaviour which they did not recognize as such. Examples 
include Izzie's statement of boys punching each other during a break, and Callie's recounting of hazing on the high school hockey team, and their shared dismissal of these examples as part of a problematic 'boys will be boys' approach. One problem this individualizing of policy interpretation creates is that it hides the issue of inconsistencies in implementation yet appears to parents and the broader community that the bullying problem is being confronted.

The issues with using general academic definitions within policy are critiqued by McGregor (2008), Walton (2005a, 2005b, 2005c, 2011), and Winton and Tuters (2015). Standardized definitions, while they may be efficient, have the potential to overlook real problems because they tend to be vague. The problem with vague, standardized definitions occurs in the implementation phase, where almost any and all behaviours could be characterized under the standardized term, depending on how the particular incident is perceived (Winton \& Tuters, 2015). Specifically referring to experiences of Indigenous youth in classrooms, a potential danger arises that some teachers unintentionally reinforce the settler colonialist foundations of the education system by not considering cultural factors, and minimizing both schoolyard violence and harassment of Indigenous students. On the other hand, persisting settler colonialist stereotypes and assumptions may lead educators to inaccurately identify the Indigenous student as the bully in an altercation. Educators may also use colonial stereotypes of Indigenous students as a way to manage how they should be.

Educators who label harassment, violent and racist behaviours as bullying may cover up the harmful impact of these behaviours. When educators allow these behaviours to take place without critical reflection on context, Indigenous youth are potentially discriminated against. The failure to critically recognize the behaviour other than bullying 
reinforces the dominant discourse Dion $(2004,2007)$ refers to; educators in this study were aware of the mainstream definition of bullying and most did not question it. Those who did critique it still confused harassment, assault, and racism as bullying. Relating to this research, Indigenous youth may be targeted by racist behaviour that is mislabelled as bullying behaviour; in addition, assumptions can easily be made that Indigenous students are likely to be the aggressor based solely on negative stereotypes (Long, 2021).

Educators who use their discretion to nominate students as bullies, based on observed student behaviour, may be constructing the label based on their own life experiences (Baker, 1998).

Walton's (2005a) critical analysis of bullying “shifts, ruptures and destabilizes dominant understandings of those sets of behaviours, particularly among children, that are now routinely called bullying" (p. 60). Six years later, still critically analyzing bullying work, Walton (2011) stated, "research on bullying rarely investigates the conditions by which discourse on bullying has emerged" (p. 138). The findings reported in chapters six and seven indicate that teacher perspectives on bullying are similarly unlikely to consider the perspectives of Indigenous youth and the conditions under which negative behaviour involving Indigenous youth emerge.

The mainstream definition of bullying has the potential to minimize racist behaviours which are targeted towards Indigenous people as individual acts of negative behaviour. However, by individualizing and minimizing negative behaviour which is racist, educators may reinforce a settler education system. Although educators have been mandated to be inclusive of Indigenous perspectives, minimizing racist behaviour — or not addressing it at all — allows a system where colonial attitudes and behaviours persist. 
Walton (2005c) and Winton and Tuters' (2015) criticize bullying policies as policies for certain students and not for others. Walton (2010) argued that educators "ignor[e] specific forms of bullying that targets specific students" (p. 148). Addressing homophobic violence, Walton (2011) reported that it "is pervasive in public schools, yet mostly unaddressed, if not ignored completely" (p. 137) which is a point to be paralleled in this study: negative behaviour, such as harassment, violence and racism that is targeted towards Indigenous youth occurs in the education system and has the potential to go unaddressed as racism or be ignored completely, reinforcing colonial education. An example of ignoring and unaddressing racism towards Indigenous youth is Christina's confirmation that the school cancelled Indigenous cultural week because non-Indigenous students refused to participate. Rather than teach non-Indigenous students the importance of cultural differences, the school cancelled the event.

It is also important to recall that, as discussed in Chapter four, an educator's understanding and reaction to negative behaviour labelled as bullying have an impact on how the student body views and understands the negative incidents (Baker, 1998). Negative behaviour which goes unaddressed by educators becomes accepted and, even if labelled as bullying behaviour, is less likely to be challenged as harassment, violence and/or racist behaviour.

Walton (2005a, 2005b, 2005c) argues that educators need to critically reflect on what behaviour is observed, rather than simply lumping racist, violent or harassing behaviour under the term bullying. Most educators in this study did not critique the legislation's definition or their own understanding of the term bullying. They tended to accept the generic definition that lumps racist, violent or harassing behaviour under the term bullying. However, a few participants did express problems with the standardized 
definition. Arizona stated that the definition of bullying does not "get at the root cause", although her opinion of the root cause was not provided, while Izzie reported that she believed the standard definition "minimizes the real issues taking place between students". Even though the above educators did critique the definition, they still seemed to obfuscate criminal behaviour, such as sexual harassment, rape, and targeted harassment as simply bullying behaviour, in the manner that McGregor, Walton, and Winton and Tuters, warned against. I will discuss below each example of obfuscation provided by participants and how this type of obfuscation may contribute to the reiteration of settler colonialism within the implementation of the anti-bullying framework.

\section{Mislabelling of Harassment and Violent Behaviour as Bullying}

\section{Sexual Harassment and Assault}

When participants were asked to provide their own definition of bullying, some educators provided examples of incidents which described overt sexual harassment and/or sexual assault. The Ontario Education Act does not define sexual harassment or harassment; however, sex and sexual orientation are among the list of factors that must be evaluated when responding to incidents labelled as bullying. Negative behaviour motivated by sex or sexual orientation should be treated differently/more severely than other forms of negative behaviour, pursuant to section 310(1)(7.1-7.2) of the Ontario

\section{Education Act.}

When asked to describe instances of bullying, one educator mentioned a case that she termed as "ongoing" and described this as one in which a student was raped. Participants also included references to sexual harassment behaviours, such as the distribution of unsolicited photos or sexts, as examples of bullying behaviour. Another 
example came from Christina, who referenced the non-consensual capturing and sharing of explicit photos through text messaging as a form of bullying behaviour. The same photos were reported to have been posted in student bathrooms. The participant responses suggest that it is easier to define sexual harassment behaviour as bullying, rather than dealing with the repercussions of the alternative. This finding confirms the work of Walton, McGregor, and Winton and Tuters by demonstrating that sexual harassment may be minimized as bullying behaviour.

\section{Targeted Harassment and Physical Violence}

Targeted harassment was exemplified as a form of bullying behaviour by Izzie. She claimed to dislike the word bullying and justified her dislike of the term by stating that young adults need to recognize there are legal consequences for negative behaviour. The implication is that she has seen instances of bullying that should trigger legal consequences and thus should not be defined as bullying. As Izzie continued in her interview, she identified the seriousness of negative behaviour, but she conflated it with the term bullying and gave the example of boys punching one another during a break as bullying rather than violence. Additionally, she conflated violence with bullying in a dispute where police had become involved between two students who were previously in a relationship. She did later link interpersonal problems and negative behaviour to instances of psychological distress, which led to self-harming behaviour among female students, and referred to this as a result of violence against those students. Lastly, Callie recounted an example of a violent and verbally abusive incident against a member of the school hockey team as an instance of bullying. The above examples are instances of violence and harassment which were mislabelled as bullying by the participants. They 
show there has been a conflation between harassment, physical violence and bullying. My findings thus support the concern of the negative impact of minimizing negative behaviour within the anti-bullying framework identified by Walton, McGregor, and Winton and Tuters.

\section{Racism}

My participants did not report any specific incidents of racist behaviour targeting individual Indigenous students. However, they did report racist incidents. There were a few examples provided from both school boards when the Indigenous population was targeted through the actions of non-Indigenous students: for example, as noted above, participants reported backlash to the university stream English course by non-Indigenous students when Indigenous content was introduced, resistance to Indigenous cultural week at a school (which was subsequently cancelled), and the instance of a non-Indigenous student who posted an anti-Indigenous tirade on social media. Contrary to the mainstream bullying literature which focuses on bullying as individualized instances of negative behaviour, these are examples of how larger societal factors marginalize and manage Indigenous people. Another example was provided through Miranda's response regarding negative comments towards Indigenous youth having been learned at home and then disseminated at school. Although none of these examples are targeted towards a specific Indigenous student, they reflect racism and harassment towards Indigenous people.

Similar to bullying behaviour motivated by sex, gender, or sexual orientation, bullying behaviour motivated by prejudice, bias, or hate based on race is also subject to harsher penalties under the Ontario Education Act (s. 310(1)(7.1-7.2)). However, it is not at all clear that this difference in the available punishments for racist behaviour labelled 
as bullying adequately addresses the seriousness of that behaviour. Nor is it clear what the criteria for racially-motivated bullying are and what threshold must be met to warrant the more serious consequence. The framework also does not address the motivation behind the behaviour and educators are not equipped to assess this.

Behaviour that is based on race has serious implications, particularly for Indigenous youth. If educators diminish race-based negative behaviour simply as bullying, the potential danger arises that some educators may reinforce the colonialist foundations of the education system. It is difficult to recognize the systemic problems in the education system; many educators may not see the colonial logic of education and accept the validation of the anti-bullying framework by government. This passive acceptance of policy is a way to manage Indigenous youth and reinforce colonialism. Educators may unknowingly traumatize another generation of Indigenous students. As McGregor, Walton, and Winton and Tuters suggest, educators need to be self-reflexive and critically aware of the behaviours they allow in their classrooms and schools.

\section{Educator Discretion}

With the exception of April, the Junior Kindergarten teacher, all high school educators had a working knowledge of the Ontario anti-bullying framework; participants were generally aware of the anti-bullying framework objectives, yet some of them chose to forego the framework and utilize what they believed was the best approach in dealing with instances labelled as bullying based on their placement in the classroom, interactions with individual students and classroom/school context. Most participants knew of the duty to report when negative behaviour occurs, yet some still chose to use their own discretion and interpretation on what classifies as negative behaviour. Many felt their 
ability to understand their students, and the contexts of incidents, was more nuanced than that of administrators, and yet some of these educators were the same ones who obfuscated racism, violence, targeted harassment, or sexual misconduct with the label of bullying. For example, Miranda referred to her 'old school teaching approach', where she deals with negative behaviour herself rather than passing it on to administration.

Additionally, Christina stated that she may not reference the framework for advice if she believes that she knows "what works better for [her] kids".

Here is where potential educator bias and educator discretion meet. The exercise of discretion in implementing the anti-bullying framework raises the concern that this discretion may be influenced by unspoken bias that is developed in the settler-colonial context within which the education system has developed. The data from my interviews provides evidence that teacher attitudes may be impacted by the dominant settler colonial education framework (e.g. dismissing factors of why an Indigenous student is late and dismissing negative behaviour towards Indigenous students that teachers become aware of through conversation with their students). This dominant settler colonial framework may influence the exercise of discretion of educators (and subsequently may be viewed as a way of managing their Indigenous students) when they decide whether or not they report negative behaviour, and how negative behaviour is framed and navigated in the school system.

Educators use their discretion to ensure authority/power over students by deciding (consciously or unconsciously) which behaviour/actions are classified as bullying versus racism, harassment or violence. By diminishing the impact of these negative behaviours as bullying, educators may use their power as authority figures to minimize negative behaviour. Conversely, they are able to use their power of authority to help prevent and 
speak out against negative behaviour, and thereby provide a positive example of what is acceptable behaviour in their classroom. Thus, educators can use their discretion as a tool through action or in-action.

Some educators may reinforce a colonial education system under the Ontario antibullying framework due to the broad bullying term that educators are required to enforce, particularly if they implement it without consideration of the context of their Indigenous students. If educators fail to critically examine instances of negative behaviour, they may minimize it, conflating racist, violent or harassing behaviour as bullying behaviour and therefore reinforce the foundations of a settler education. When dealing with negative behaviour, it is difficult to address racism (Dion, 2004, 2007; Battiste, 2013) — surface and underlying — under the broad umbrella term of bullying because of educator discretion. Discretion allows unconscious racism and stereotypes to continue in the education system. Educators may then reinforce settler colonial foundations of the education system and also individualize the problem towards Indigenous students by blaming them for any negative behaviour they may face, rather than call out harassing and violent behaviour that is racist.

It is possible that some educators may consciously or unconsciously hide behind the legislation to justify minimizing negative behaviour Indigenous youth potentially endure. It could be easier for an educator to justify the negative behaviour as bullying rather than to categorize it as racist, harassing or violent behaviour and have to deal with the consequences. An example of this can be found in Miranda's recounting of an instance when a student was confiding in her about negative behaviour and she reminded them that if they divulged further information, she would have to follow through with 
reporting the incident to administration. In this way, Miranda was asking the student if they were ready to face the consequences of reporting the negative behaviour.

Educators need to be aware of the ongoing implications of settler colonialism in their classroom (Dion, 2004, 2007; Meyer, 2010; Battiste, 2013; McGregor, 2017). Educators are trained to teach students based on the mandated curriculum and ensure students follow policies that promote a safe and inclusive learning space. Educators are not currently required nor equipped to confront the realities Indigenous youth navigate or the stereotypes that the legacy of the residential schools/60s scoop has left (Milne, 2015, 2016).

\section{Conclusion}

The main themes of this study were produced by the data presented in Chapters six and seven, and discussed here. These themes are: growing up in different geographic locations of northern and southern Ontario impacted the time at when knowledge and appreciation of Indigenous culture came to light; the term bullying is understood by educators in the way Olweus presents as based on individual factors; some educators conflated behaviours of assault, harassment and violence as bullying; and educators, if involved in evaluating instances of negative behaviour between their students, used their understanding and perceptions of 'bullying' and their students, to determine consequences for the negative behaviour.

The conflation of negative behaviours such as sexual harassment, racism towards Indigenous people on social media (and reported in school), and violence as bullying is present in this study. Although some educators pointed out the problems with the generalized term of bullying, they still used it without critical consideration. This finding validates the concerns expressed by Walton, McGregor, and Winton and Tuters that 
violent behaviour may be minimized as bullying behaviour. My argument goes further to suggest that settler-colonialism and anti-Indigenous racism may be diminished or obfuscated through such an uncritical understanding of and implementation of antibullying measures.

Understanding how educator discretion is used within policy implementation is an issue schools and school boards must grapple with. There is a potential danger that an educator who does not have an understanding and appreciation of Indigenous history and culture, may exacerbate instances of negative behaviour directed towards Indigenous youth and/or may reinforce a settler education. Alternatively, an educator who appreciates Indigenous history and culture, has the potential to turn instances of negative behaviour into teachable moments for all involved. As such, it is imperative that educators be aware of the unique histories Indigenous people have and how their history influences their education and future. Educators have the ability to make positive change; there is a hopeful message that educators can teach their students to think differently about Indigenous people and that those lessons will lower instances of negative behaviour directed towards Indigenous youth. The conclusion and future research ideas from this study follows in chapter nine. 


\section{Chapter Nine: The Process of Self-Reflexivity}

In this dissertation, I asked three main research questions: how do teachers understand and implement Ontario's anti-bullying framework; how are their approaches influenced by their backgrounds and experiences; and do they perceive differences in the implementation of the anti-bullying framework to Indigenous and non-Indigenous youth? Through 11 interviews and one written response, participants provided a plethora of information, some which was very emotional and self-reflexive. Through the data, I gained educator perspectives of Indigenous history/politics/culture, their understanding of the term 'bullying' and their perception and implementation of Ontario's anti-bullying framework.

My first two research questions go hand-in-hand regarding how educators understand and implement Ontario's anti-bullying framework and if their approaches to understanding the framework are influenced by their formative years. There are four significant findings from this data:

1. Geographic location between northern and southern Ontario impacted when participants were exposed to and gained an appreciation for Indigenous culture;

2. Notwithstanding \#1, participants showed an increased appreciation for Indigenous history/culture/politics after they started working in schools with a significant population of Indigenous students and at that point there was not an appreciable difference based on their backgrounds in their approaches to Indigenous people;

3. Notwithstanding \#2, most participants relied upon a standardized, mainstream definition of bullying which focuses on individual causes rather than systemic issues such as racism and settler colonialism; and 
4. Some participants reported relying on their teaching experience and knowledge of their students to exercise their discretion, as opposed to procedures mandated under the anti-bullying framework, when dealing with actions that may be labelled as bullying.

Participant reliance on the standardized, mainstream definition of bullying supports the views of authors in the theoretical framework discussion in chapter four. Authors McGregor, Walton, and Winton and Tuters argue that educators fail to distinguish the social construction of bullying. Furthermore, negative behaviours, such as sexual harassment, violence and racism, are conflated with bullying behaviour. The results of this study also revealed that participants failed to identify the social construction of bullying and obfuscated sexual harassment and violent behaviour with the term bullying.

Interestingly, participant appreciation of Indigenous history and culture (finding \#2), when combined with participant reliance on the standard, mainstream definition of bullying (finding \#3), indicates that even participants who were aware of the challenges faced by Indigenous students, did not recognize that mainstream conceptions of bullying may work to disadvantage Indigenous students. The cumulative impact of these findings suggests a new theoretical insight derived from the data concerning the way in which the mainstream discourse of bullying may act to reinforce the settler colonial foundations of the education system. The reproduction may be facilitated by all educators - even those who are aware of the critiques of the way in which Indigenous youth are disadvantaged within that system. 
The third research question is more difficult to answer than the first two. Participants in the study provided some examples of differential treatment of Indigenous students as part of processes aimed at accommodating Indigenous practices and learning more generally. For example, participants from both school boards discussed cultural rooms dedicated to Indigenous youth. The rooms have special Indigenous names (not listed for anonymity), where there is food, study space and a tutor. Similarly, participants reported some incidents where Indigenous students were treated differently in the aftermath of bullying incidents. Amelia and Meredith described the options of participating in a restorative justice/healing circle rather than receiving traditional methods of punishment (i.e. suspension, expulsion). Another example is that Izzie and Lexie used smudging pillows and restorative practices to guide Indigenous youth when an instance of harassment took place over social media targeting the larger Indigenous population, practices that typically would not be engaged with non-Indigenous students. Notwithstanding these examples, the answer to the third research question is that educators did not report any substantive differences in terms of how they defined or understood "bullying" when implementing the framework in instances of negative behaviour involving Indigenous youth.

The fact that participants viewed bullying incidents involving both Indigenous and non-Indigenous students through the same individualized lens is further evidenced by the responses that participants provided when they were asked how to improve the antibullying framework. Most of the participants who responded to this question thought Indigenous students might benefit from being more resilient. These suggestions ignored the larger societal conditions which work to create inequitable circumstances among 
Indigenous students. Participants discussed resiliency as both the responsibility of Indigenous youth, as well as the solution to the political issues they navigate. The onus of moving past the trauma Indigenous people experience is thus put on the shoulders of Indigenous youths.

Participants viewed resiliency as a way to improve anti-bullying measures for Indigenous youth rather than offering suggestions to improve the behaviours of nonIndigenous students and educators. Indigenous students, particularly those attending school away from their home communities have already been put into uncomfortable, and vulnerable, positions just to be able to compete for an equal education. Requiring Indigenous youth to take responsibility for making themselves less attractive targets of negative behaviour is inequitable.

\section{Moving Forward}

It is key to keep the potential impact of anti-bullying initiatives on Indigenous youth in mind because they may suffer additional psychological and emotional harms from racist behaviours, which can impact their educational success and future employment opportunities. Educators must also keep in mind that, in many cases, they are teaching children of residential school survivors. Some parents and Indigenous families who suffer from traumatic experiences of residential schools and the 60s scoop are not equipped to stand up to an educator (Milne, 2016) or to provide other support for students. Thus, educators need to consistently be reflexive of their own attitudes, assumptions and values when teaching Indigenous students.

The need for educator self-reflection is heightened by the fact that it is very unlikely that a unified approach by all educators as to how the anti-bullying framework 
should be implemented in schools will develop - everyone brings their own unique experiences to their classroom. The question is whether or not educators can critically evaluate their experiences, attitudes and assumptions and how these may impact the students they teach, particularly Indigenous students. It is important that educators recognize that they may minimize negative behaviour, such as sexual harassment, violence and racism, by naming it bullying despite the fact that the Ontario legislation requires harsher consequences when behaviour is motivated by sex, sexual orientation or race. The marginalization of anti-Indigenous racism serves to further reinforce settler colonialism within the education system.

It is important that educators sincerely self-reflect on their familial legacy and their childhood growing up. Recognition that educators bring some of their familial perspective to the classroom is part of the self-reflection process. Once involved in a multicultural classroom, particularly with Indigenous students, educators need to be selfreflexive, critically evaluate the curriculum they are required to teach and think about how to actively engage their students, both Indigenous and non-Indigenous. This selfreflexive process speaks to the Two-Eyed Seeing approach, trying to integrate their [the educator's] background, while appealing to their students (Korteweg \& Root, 2016).

Furthermore, educators need to recognize that their perspectives on Indigenous history/culture may change once they are exposed to Indigenous culture or involved with Indigenous students. The self-reflexive exercise reveals their own biases, where they may reflect on their position of privilege and family background/opinions. These biases need to be taken into consideration when reflecting on how policies are implemented in school. The self-reflexive exercise also gives an opportunity to reflect on the curriculum, while 
mitigating behaviours and incorporating cultural differences present in classrooms. Having a broader understanding of the students in the classroom, specifically having an understanding of and engaging in Indigenous culture, may help to open the minds of educators, who may then open the minds of their students to challenge negative stereotypes about Indigenous people.

\section{Strengths, Limitations and Challenges of this Study}

This study responds to the calls to action from the TRC regarding Indigenous education. More specifically, it addresses the lack of discussion of the potential impact of the 2012 anti-bullying framework on Indigenous students; this study enables the conversation to begin. It additionally provides a unique opportunity for northern educators to give their perspectives on how Indigenous youth may be impacted by discipline under the Ontario anti-bullying framework.

A limitation to this study is the small sample size of 12 educators, which limits the ability to make any generalizations from this data. This small sample size may be directly attributable to a number of challenges involved in conducting research about the treatment of Indigenous students. This project has the potential to move educational standards forward in a positive way, but there was extreme difficulty in recruiting school boards to participate. Although there is no conclusive evidence, it seems clear that there was apprehension among school board administrators about participating in this project. As a former member of Thunder Bay's Anti-Racism and Respect Committee, I was introduced to many educators who wanted to participate in this project, however, without Director of Education approval, I was not able to contact those people. Although I contacted 12 school boards, only two Directors of Education responded to my request; 
ten Directors rejected my request or did not respond. I speculate that lack of interest in my project is related to the political climate in Thunder Bay and northern Ontario given the political and legal issues that have plagued Thunder Bay since 2000, when the first Indigenous youth died attending Dennis Franklin Cromarty High School. Since that time, the political climate in Thunder Bay has been difficult and racism is prevalent.

Another challenge is that it takes time to develop relationships with Indigenous groups, specifically Indigenous education authorities. I was introduced to the principal of the Indigenous school that participated over 1.5 years in advance of formally asking, with tobacco in my left hand, if I could ask teachers in the school to share their knowledge. Building a respectful relationship takes time and trust. Although I was hopeful to include more Indigenous education authorities, it was not feasible given the amount of time available to complete this project.

A third challenge for this project is the fear of exposure among potential participants. While completing the interviews, one participant was fearful of being exposed, despite multiple reassurances of confidentiality and anonymity. It was clear this person wanted to provide in-depth responses and that they did not want to remove themselves from the project; however, post-interview and after review of their transcript, they requested the removal of a large amount of data. Removal of this data did not have a substantive impact on the results of this study because other participants reiterated similar messages. Nonetheless, removal of the data did impact the number of specific examples of negative behaviour available for the discussion of the politics and barriers that Indigenous youth must navigate. 


\section{Future Research}

As this project reaches its conclusion, there are many avenues that can be followed to conduct further research. Additional research projects might include expanding the current research to a larger number of teachers in a wider geographical area to continue to investigate how educators understand and implement the anti-bullying initiatives put in place by the Ontario anti-bullying framework. Specifically, an investigation of how educators in southern Ontario understand and implement the Ontario anti-bullying framework and its potential impact on Indigenous youth could be engaged. In addition to educators, principals and other administrator perspectives could be obtained by those employed by Public, Catholic or private school boards mandated under the Ontario Education Act. Obtaining the opinions of administrators, principals and educators who are employed with Indigenous Education Authorities on their bullying policies would provide a complementary perspective to this study. Lastly, and most pressingly, inclusion of Indigenous youth voices is an important approach to take when studying anti-bullying initiatives. I think an important next step is to conduct case studies with Indigenous students and their families to assess how anti-bullying initiatives in school impact them individually, as families and also as a community.

\section{Relationship Building with Indigenous Groups}

Scholars are only recently becoming enlightened by the knowledge and wisdom Indigenous community members bring to academic literature (Pratt \& Danyluk, 2017) and how important Indigenous stories are for community growth (O'Loughlin et al., 2020). There are many factors to think about when approaching Indigenous communities for knowledge. Building relationships with Indigenous communities involves trust. As 
Pratt and Danyluk (2017) state: "it should not be too surprising that the issue of trust sits at the core of today's educational issues in Indigenous education" (p. 20).

As Godlewska et al. (2010) point out, ignorance exists because people are unaware of the truth about Canada's relations with Indigenous people. This ignorance comes from "omissions, silences, nationalist self-congratulation, apology, problematic placement, the continuance of colonialist narrative and the relegation of [Indigenous peoples]" (Godlewska et al., 2010, p. 436). The findings from this dissertation show, however, that even those who are aware, may not take Indigenous history, and particularly the history of settler colonialism, into account when assessing student actions. Thus, it is even more important that educators develop relationships with Indigenous people/communities/organizations to experience Indigenous culture first-hand and develop deeper appreciations of Indigenous history, culture and experiences. Moving towards an accepting and trusting relationship takes time and patience; people should not expect anything in return for the development of a relationship — the relationship itself is something to honour and respect. As the bullying debate moves forward, the voices of Indigenous people need to be included in the discussion.

\section{Concluding Thoughts: Ontario's Anti-Bullying Framework and the TRC}

The TRC asks and recommends that schools support equitable education through the inclusion of Indigenous culture, traditions and literary and artistic works in schools (TRC, 2015a). Equitable education requires more than just inclusive material in a class; it begins in the atmosphere of the space between classes (spare rooms/hallways/off school property). Thus, the anti-bullying framework could support the implementation of real change based on TRC recommendations around inclusive education. However, I am 
deeply concerned with Ontario's anti-bullying framework. Without an understanding that some behaviour labelled as bullying involves racism, classism, homophobia, harassment, and violence, the reiteration of negative behaviour towards Indigenous youth will not be addressed adequately.

Understanding and implementation of the TRC recommendations will remain ineffective without critical reflection of the negative behaviour(s)/attitude(s) displayed towards Indigenous people. If educators do not engage in identifying and appropriately addressing racist and violent behaviour under the anti-bullying framework, educators may allow negative behaviour towards Indigenous youth to continue. The contribution of the anti-bullying framework to the ongoing failure of the education system to adequately identify and address racist and violent behaviour teaches students that programs that purport to protect them, such as the anti-bullying framework, provide only lip service to this goal. This lip service negates any positive attempts for change requested through the TRC calls to action, despite national efforts to improve education for Indigenous youth.

Despite this study's small sample size, it has the potential to make a large impact — the school boards that participated want to know the results. This dissertation has the potential to make participant educators (and others in their school boards) aware of the settler education foundational problems that exist. Furthermore, this dissertation shows how settler colonial problems may be exacerbated by educators, and subsequently blame Indigenous students for negative behaviour they may encounter. Hopefully this dissertation will provide educators with the knowledge to be critically reflexive of the context Indigenous youth navigate and may guide educators in identifying behaviour that involves racism, harassment and violence, rather than minimizing the behaviour under 
the term bullying, reinforcing a settler colonial education system. Although it is only a small step, if educators become critically reflexive and call out racist behaviour towards Indigenous youth at school, this will show that the TRC's call to action around equitable education for Indigenous youth is appreciated and accepted by educators. Also, it is the start to building respectful relationships between Indigenous youth and their peers/educators. Although starting in the classroom, the respectful relationships developed through learning have the potential to move into other social spaces outside of the school. 


\section{References}

4Seasons of Reconciliation. (n.d.). https://www.4seasonsreconciliation.ca/

Abrams, M. (2010). Learn the difference between anger, aggression, and violence. In Anger management in sport: Understanding and controlling violence in athletes. Human Kinetics.

Adelson, N. (2005). The embodiment of inequity: Health disparities in Aboriginal Canada. Canadian Journal of Public Health, 96(2), 45-61. https://doi.org/10.1007/BF03403702

Akiba, M., LeTendre, G. K., Baker, D. P., \& Goesling, B. (2002). Student victimization: National and school system effects on school violence in 37 nations. American Educational Research Journal, 39(4), 829-853. https://doi.org/10.3102/00028312039004829

American Psychiatric Association (APA). (2013). Diagnostic and statistical manual of mental disorders. ( $5^{\text {th }}$ ed.).

Backhouse, C. (1999). Colour-coded: A legal history of racism in Canada, 1900-1950. University of Toronto Press.

Baker, J.A. (1998). Are we missing the forest for the trees? Considering the social context of school violence. Journal of School Psychology, 36(1), 29-44. https://doi.org/10.1016/S0022-4405(97)00048-4

Banner, S. (2005). Why Terra Nullius-Anthropology and Property Law in Early Australia. Law \& Hist. Rev., 23, 95.

Bannerji, H. (2020). On the dark side of the nation: Politics of multiculturalism and the 
state of 'Canada'. In The Ideological Condition: Selected Essays on History, Race and Gender (pp. 364-393). Brill.

Barrera, J. (2019). Federally run Six Nations school has a bullying problem that's gone unaddressed for years, parents say. Canadian Broadcasting Corporation. https://www.cbc.ca/news/indigenous/six-nations-school-bullying-1.5334010

Bartlett, C., Marshall, M., \& Marshall, A. (2012). Two-Eyed Seeing and other lessons learned within a co-learning journey of bringing together indigenous and mainstream knowledges and ways of knowing. Journal of Environmental Studies and Sciences, 2(4), 331-340. https://doi.org/10.1007/s13412-012-0086-8

Battiste, M. (2013). Decolonizing Education: Nourishing the Learning Spirit. Purich Publishing Ltd.

Bhattacharjee, K. (2003). The Ontario Safe Schools Act: School discipline and discrimination. Ontario Human Rights Commission.

Boaler, J. (2005). The 'psychological prisons' from which they never escaped: The role of ability grouping in reproducing social class inequalities. FORUM, 47(5), 135143. https://doi.org/10.2304/forum.2005.47.2.2

Bombay, A., Matheson, K., \& Anisman, H. (2011). The impact of stressors on second generation Indian residential school survivors. Transcultural psychiatry, 48(4), 367-391.

Bombay, A., Matheson, K., \& Anisman, H. (2014). The intergenerational effects of Indian Residential Schools: Implications for the concept of historical trauma. Transcultural psychiatry, 51(3), 320-338. 
Boulton, M.J., \& Smith, P.K. (1994). Bully/ victim problems in middle-school children: Stability, self-perceived competence, peer perceptions and peer acceptance. British Journal of Developmental Psychology, 12, 315-329. https://doi.org/10.1111/j.2044-835X.1994.tb00637.x

Boudreau Morris, K. (2017). Decolonizing solidarity: cultivating relationships of discomfort. Settler colonial studies, 7(4), 456-473.

Brean, J. (2017, May 11). Ontario school board tosses Shakespeare for indigenous writers. National Post. https://nationalpost.com/news/canada/ontario-schoolboard-tosses-shakespeare-for-indigenous-writers

Brinkmann, S. (2007). Could interviews be epistemic? An alternative to opinion polling. Qualitative Inquiry, 13(8). 1116-1138. https://doi.org/10.1177/1077800407308222

Broll, R., \& Huey, L. (2015). “Just being mean to somebody isn't a police matter”: Police perspectives on policing cyberbullying. Journal of school violence, 14(2), 155176. https://doi.org/10.1080/15388220.2013.879367

Brown, L. M. (2007). Patriarchy matters: Toward a gendered theory of teen violence and victimization. Violence against Women, 13, 1249-1274. https://doi.org/10.1177/1077801207310430

Browne, A.J., Varcoe, C., Lavoie, J., Smye, V., Wong, S.T., Krause, M., Tu, D., Godwin, O., Khan, K., \& Fridkin, A. (2016). Enhancing health care equity with Indigenous populations: evidence-based strategies from an ethnographic study. BMC Health Services Research, 16, 544. https://doi.org/10.1186/s12913-016-1707-9 
Brownlee, K., Martin, J., Rawana, E.P., Harper, J., Mercier, M., Neckoway, R., \& Friesen, A. (2014). Bullying behaviour and victimization among aboriginal students within Northwestern Ontario. First Peoples Child \& Family Review, 9(1), 38-52. https://fpcfr.com/index.php/FPCFR/article/view/225

Bryner, C. L. (2001). Children of divorce. The Journal of the American Board of Family Medicine, 14(3), 201-210. https://doi.org/10.1037/e610082007-001

Burke, A. (2011). Gay Ottawa teen who killed himself was bullied. Canadian Broadcasting Corporation. https://www.cbc.ca/news/canada/ottawa/gay-ottawateen-who-killed-himself-was-bullied-1.1009474

Butler, J. (1990). Gender trouble. Routledge.

Canadian Geographic. (2019). History of residential schools. Indigenous peoples atlas of Canada. Retrieved September 1, 2019, from https://indigenouspeoplesatlasofcanada.ca/article/history-of-residential-schools/

Canty, J., Stubbet, M., Steers, D., \& Collings, S. (2016). The trouble with bullying Deconstructing the conventional definition of bullying for a child-centred investigation into children's use of social media. Children and society, 30(1), 4858. https://doi.org/10.1111/chso.12103

Carlisle Indian School Digital Resouce Centre (CISDRC). (n.d.). "Kill the Indian, and Save the Man": Capt. Richard H. Pratt on the Education of Native Americans. http://carlisleindian.dickinson.edu/teach/kill-indian-and-save-man-capt-richard-hpratt-education-native-americans. 
Cassidy, W., Jackson, M., \& Brown, K.N. (2009). Sticks and stones can break my bones, but how can pixels hurt me? School Psychology International, 30(4), 383-402. https://doi.org/10.1177/0143034309106948

Castagno, A.E., \& Brayboy, B.M.J. (2008). Culturally responsive schooling for Indigenous youth: A review of the literature. Review of Educational Research, 78(4), 941-993. https://doi.org/10.3102/0034654308323036

CBC (2017). After seven student deaths, Indigenous educator looks to on-reserve schooling as a solution. Cross Country Checkup, CBC. https://www.cbc.ca/radio/checkup/blog/after-seven-student-deaths-indigenouseducator-looks-to-on-reserve-schooling-as-a-solution-1.4001092

CBC Radio (2018, December 14) Thunder Bay Police 'stopped seeing Indigenous peoples as humans,' says Anishinaabe podcast host. CBC Radio. https://www.cbc.ca/radio/day6/episode-420-racism-in-thunder-bay-brexit-vseverything-competitive-karaoke-geoengineering-and-more-1.4944729/thunderbay-police-stopped-seeing-indigenous-people-as-humans-says-anishinaabepodcast-host-1.4944743

Charmaz, K. (2006). Constructing grounded theory: A practical guide through qualitative analysis. London, UK: Sage.

Chartrand, L. N., Logan, T. E, \& Daniels, J. D. (Eds.). (2006). Métis history and experience and residential schools in Canada. Aboriginal Healing Foundation.

Cherubini, L., Hodson, J., Manley-Casimir, M., \& Muir, C. (2010). 'Closing the gap' at the peril of widening the void: Implications of the Ontario Ministry of 
Education's policy for Aboriginal education. Canadian Journal of Education, 33(2), 329-355. http://www.jstor.org/stable/canajeducrevucan.33.2.329

Cornell, D., \& Limber, S.P. (2015). Law and policy on the concept of bullying at school. American Psychologist Association, 70(4), 333-343. https://doi.org/10.1037/a0038558

Corntassel, J, Chaw-win-is, \& T'lakwadzi. (2009). Indigenous storytelling, truth-telling, and community approaches to reconciliation. ESC: English Studies in Canada, 35(1), 137-159. https://doi.org/10.1353/esc. 0.0163

Corntassel, J., \& Holder, C. (2008). Who’s sorry now? Government apologies, truth commissions, and Indigenous self-determination in Australia, Canada, Guatemala, and Peru. Human rights review, 9(4), 465-489.

Coroner's Act, R.S.O. 1990, c. C.37 O. Reg. 266/14

Cresswell, J. (2009). Research design: Qualitative, quantitative, and mixed methods approaches ( $3^{\text {rd }}$ ed.). Sage.

Cronholm, S. (2004). Illustrating multi-grounded theory - Experiences from the grounding processes. Proceedings from 3rd European Conference on Research and Methodology for Business and Management Studies (ECRM '04), Reading, UK: Reading University.

Crown-Indigenous Relations and Northern Affairs Canada (CIRNAC). (2017). First Nations in Canada. Government of Canada. http://rcaanccirnac.gc.ca/eng/1307460755710/1536862806124 
Crown-Indigenous Relations and Northern Affairs Canada (CIRNAC). (2019). Specific claims. Government of Canada. https://www.rcaanccirnac.gc.ca/eng/1100100030291/1539617582343

Cunneen, C. (2007). Criminology, human rights and Indigenous peoples. Sociology of Crime, Law and Deviance, 9, 243 - 265. https://doi.org/10.1016/S15216136(07)09010-0

Cunneen, C. (2008). Criminology, criminal justice and Indigenous people: A dysfunctional relationship? Current Issues in Criminal Justice, 20(3), 323 - 336. https://papers.ssrn.com/sol3/papers.cfm?abstract_id=2211076

Curtis, E., Wikaire, E., Kool, B., Honey, M., Kelly, F., Poole, P., Barrow, M., Airini, S.W., \& Reid, P. (2015). What helps and hinders indigenous student success in higher education health programmes: A qualitative study using the Critical Incident Technique. Higher Education Research \& Development, 34(3), 486-500. https://doi.org/10.1080/07294360.2014.973378

D’Onofrio, B.M., Lahey, B.B., Turkheimer, E., \& Lichtenstein, P. (2013). The critical need for family-based, quasi-experimental designs in integrating genetic and social science research. American Journal of Public Health, 103(1), 46-55. https://doi.org/10.2105/AJPH.2013.301252

Day, I. (2015). Being or nothingness: Indigeneity, antiblackness, and settler colonial critique. Critical Ethnic Studies, 1(2), 102-121. https://doi.org/10.5749/jcritethnstud.1.2.0102 
Diaczuk, D. (2019). Reinvestigation into nine Indigenous deaths to focus on 'finding the truth'. TBNewsWatch. https://www.tbnewswatch.com/local-news/reinvestigationinto-nine-indigenous-deaths-to-focus-on-finding-the-truth-1752120.

Diaczuk, D. (2021). OIPRD reinvestigation report into nine Indigenous deaths expected in June. TBNewsWatch. https://www.tbnewswatch.com/local-news/oiprdreinvestigation-report-into-nine-indigenous-deaths-expected-in-june-3649536.

DiAngelo, R. (2011). White fragility. International Journal of Critical Pedagogy, 3(3), 54-70. https://libjournal.uncg.edu/ijcp/article/view/249

Dietrich, R. (2017). The biopolitical logics of settler colonialism and disruptive relationality. Cultural Studies $\leftarrow \rightarrow$ Critical Methodologies, 17(1), 67-77. https://doi.org/10.1177/1532708616638696

Dion, S. D. (2004). (Re) telling to disrupt: Aboriginal people and stories of Canadian history. Journal of the Canadian Association for Curriculum Studies, 2(1).

Dion, S. D. (2007). Disrupting molded images: Identities, responsibilities and relationships - teachers and indigenous subject material. Teaching Education, 18(4), 329-342.

Doige, L. A. C., (2003). A missing link: Between traditional Aboriginal education and the Western system of education. Canadian journal of native education, 27(2), 144.

http://schoolandsociety.weebly.com/uploads/1/1/5/2/11522132/a_missing_link__between_traditional_aboriginal_education_and_the_western_system_of_educati on.pdf 
Draaisma, M. (2017). Black students in Toronto streamed into courses below their ability, report finds. Canadian Broadcasting Corporation.

https://www.cbc.ca/news/canada/toronto/study-black-students-toronto-yorkuniversity-1.4082463

Drummond, D. \& Rosenbluth, E. K. (2013). The debate on First Nations education funding: Mind the gap. School of Policy Studies, Queen's University.

Eden, D. (2015). Ruling on the motions concerning the scope of the inquest from the families, Nishnawbe-Aski Nation, Northern Nishnawbe Education Council, and the Provincial Advocate for Children and Youth. Falconers LLP. http://www.falconers.ca/wpcontent/uploads/2015/10/Ruling-on-the-Motionsconcerning-the-scope-of-the-Inquest-fromthe-Families-NAN-NNEC-and-PACY.April-14-2015.-saved-on-May-12-2015.pdf

Eden, D. (2016). Verdict explanation. Inquest into the deaths of seven First Nations youths: Jethro Anderson, Reggie Bushie, Robyn Harper, Kyle Morriseau, Paul Panacheese, Curran Strang, Jordan Wabasse (CanLII 66257) ON OCCO.

Education Act, Revised Statutes of Ontario (1990, c. E.2). Retrieved from the Government of Ontario website: https://www.ontario.ca/laws/statute/90e02 Elinoff, M.J., Chafouleas, S.M., \& Sassu, K.A. (2004). Bullying: Considerations for defining and intervening in school settings. Psychology in the Schools, 41(8), 887-897. https://doi.org/10.1002/pits.20045

Eriksen, I.M., \& Lyng, S.T. (2018) Relational aggression among boys: blind spots and hidden dramas. Gender and Education, 30(3), 396-409. https://doi.org/10.1080/09540253.2016.1214691 
Eshet, D. (2016). Stolen lives - The Indigenous Peoples of Canada and the Indian residential schools. Facing History and Ourselves.

Etikan, I., Musa, S. A., \& Alkassim, R. S. (2016). Comparison of convenience sampling and purposive sampling. American journal of theoretical and applied statistics, 5(1), 1-4. https://doi.org/10.11648/j.ajtas.20160501.11

Eudaily, S. P. (2004). The present politics of the past: indigenous legal activism and resistance to (neo) liberal governmentality. Routledge.

Evans, G. W., \& Kim, P. (2013). Childhood poverty, chronic stress, self-regulation, and coping. Child Development Perspectives, 7(1), 43-48.

https://doi.org/10.1111/cdep.12013

Falconers LLP. (2019). Inquest into the Death of Seven First Nations Youth. https://falconers.ca/casestudy/inquest-into-the-death-of-seven-first-nations-youth/

Farrington, D. P. (1993). Understanding and preventing bullying. Crime and Justice, 17, 381-458. https://www.journals.uchicago.edu/doi/abs/10.1086/449217

Ferguson, B., \& Gordon, M. (2016). Accepting schools expert panel end of mandate report. Ontario Ministry of Education. http://www.ldao.ca/wpcontent/uploads/Accepting-Schools-Expert-Panel-End-of-Mandate-Report.pdf

Fiddler, W. (2016). First Nation students in Thunder Bay learn meaning of 'mino bimaadiziwin'. APTN National News. https://aptnnews.ca/2016/08/23/firstnation-students-in-thunder-bay-learn-meaning-of-mino-bimaadiziwin/

Findlay, G. (Host). (2016, November 11). Death in Thunder Bay: No foul play (Season 42) [TV series episode]. The Fifth Estate. CBC. 
Firestone, M., Smylie, J., Maracle, S., McKnight, C., Spiller, M., \& O’Campo, P. (2015). Mental health and substance use in an urban First Nations population in Hamilton, Ontario. Canadian Journal of Public Health, 6, e375-e381. https://doi.org/10.17269/CJPH.106.4923

First Nations Child and Family Caring Society (FNCFCS). (2019). Shannen's Dream. The Caring Society. https://fncaringsociety.com/shannens-dream

Forbes, A., Ritchie, S., Walker, J., \& Young, N. (2020). Applications of Two-Eyed seeing in primary research focused on Indigenous health: a scoping review. International Journal of Qualitative Methods, 19, 1609406920929110.

Foreman, V. (2015). Constructing the victim in the bullying narrative: How bullying discourses affirm rather than challenge discriminatory notions of gender and sexuality. Crime Media Culture, 11(2), 157-176.

https://doi.org/10.1177/1741659015588404

Fortier, C. (2017). Unsettling methodologies/decolonizing movements. Journal of Indigenous Social Development, 6(1).

Freeman Jr, S. (2018). Utilizing Multi-Grounded Theory in a Dissertation: Reflections and Insights. Qualitative Report, 23(5).

Friedland, H., \& Napoleon, V. (2015). Gathering the threads: Developing a methodology for researching and rebuilding Indigenous legal traditions. Lakehead Law Journal, 1(1), 17-44. https://lj.lakeheadu.ca/article/view/1408/726

Frum, B. (Host). (1990, October 30). The Journal. Phil Fontaine's shocking testimony of sexual abuse [TV series episode]. The Journal. Canadian Broadcasting Corporation. 
Garland, D. (2000). The culture of high crime societies. British Journal of Criminology, 40, 347-375. https://doi.org/10.1093/bjc/40.3.347

Garrick, R. (2017). Nokiiwin's G'minoomaadozimin initiative aims at enhancing health and safety beyond the workplace. Anishinabek News.ca. http://anishinabeknews.ca/2017/01/25/nokiiwins-gminoomaadozimin-initiativeaims-at-enhancing-health-and-safety-beyond-.

Gini, G. (2006). Bullying as a social process: The role of group membership in students' perception of inter-group aggression at school. Journal of School Psychology, 44(1), 51-65. https://doi.org/10.1016/j.jsp.2005.12.002

Gini, G., Albiero, P., Benelli, B., \& Altoé, G. (2008). Determinants of adolescents’ active defending and passive bystanding behaviour in bullying. Journal of Adolescence, 31(1), 93-105. https://doi.org/10.1016/j.adolescence.2007.05.002

Godlewska, A., Moore, J., \& Bednasek, C.D. (2010). Cultivating ignorance of Aboriginal realities. The Canadian Geographer, 54(4), 417-440.

https://doi.org/10.1111/j.1541-0064.2009.00297.x

Goldkuhl, G., \& Cronholm, S. (2003, March). Multi-grounded theory-Adding theoretical grounding to grounded theory. In 2nd European Conference on Research Methodology for Business and Management Studies, Reading University, Reading, UK (pp. 88-111).

Gomez, M.C. (2009). Towards a new approach to a linguistic definition of euphemism. Language Sciences, 31, 725-739. https://doi.org/10.1016/j.langsci.2009.05.001 Government of Canada. (TCPS2-C.9). (2018). Panel on Research Ethics. TCPS 2 (2018) 
- Chapter 9: Research Involving the First Nations, Inuit and Métis Peoples of Canada. https://ethics.gc.ca/eng/tcps2-eptc2_2018_chapter9-chapitre9.html

Grant, A., \& Gillespie, L. (1993). Joining the circle: A practitioners' guide to responsive education for native students. ERIC/CRESS.

Hall, A. (2011). Treaties with Indigenous Peoples in Canada. The Canadian Encyclopedia. https://thecanadianencyclopedia.ca/en/article/aboriginal-treaties

Hallinan, M. T. (1994). School differences in tracking effects on achievement. Social Forces, 72(3), 799-820. https://doi.org/10.2307/2579781

Harper, S. (2008, June 11). Statement of apology - to former students of Indian Residential Schools. Government of Canada. https://www.aadncaandc.gc.ca/DAM/DAM-INTER-HQ/STAGING/textetext/rqpi_apo_pdf_1322167347706_eng.pdf

Hart, S.M. (2010). Self-regulation, corporate social responsibility, and the business case: Do they work in achieving workplace equality and safety? Journal of Business Ethics, 92, 585-600. https://doi.org/10.1007/s10551-009-0174-1

Hashem, M. (2015). Bullying and labelling as communication tools of control and domination. Journal of Arab \& Muslim Media Research, 8(2), 117-146. https://doi.org/10.1386/jammr.8.2.117_1

Hirschfield, P. J., \& Celinska, K. (2011). Beyond fear: Sociological perspectives on the criminalization of school discipline. Sociology Compass, 5(1), $1-12$. https://doi.org/10.1111/j.1751-9020.2010.00342.x 
Hirschfield, P.J. (2008). Preparing for prison? The criminalization of school discipline in the USA. Theoretical Criminology, 12(1), 79-101. https://doi.org/10.1177/1362480607085795

Hopkins, L., Taylor, L., Bowen, E., \& Wood, C. (2013). A qualitative study investigating adolescents' understanding of aggression, bullying and violence. Children and Youth Services Review, 35, 685-693.

https://doi.org/10.1016/j.childyouth.2013.01.012

Howlett, K. (2011, November 30). McGuinty gets tough on bullying with new legislation. The Globe and Mail.

https://www.theglobeandmail.com/news/politics/mcguinty-gets-tough-onbullying-with-new-legislation/article4179793/

Hoy, W. K. (1990). Organizational climate and culture: A conceptual analysis of the school workplace. Journal of educational and psychological consultation, 1(2), 149-168. https://doi.org/10.1207/s1532768xjepc0102_4

Hutzell, K. L., \& Payne, A. A. (2018). The Relationship between Bullying Victimization and School Avoidance: An Examination of Direct Associations, Protective Influences, and Aggravating Factors. Journal of School Violence, 17(2), 210-226. https://doi.org/10.1080/15388220.2017.1296771

Hyman, I.A., \& Perone, D.C. (1998). The other side of school violence: Educator policies and practices that may contribute to student misbehaviour. Journal of School Psychology, 36(1), 7-27. https://doi.org/10.1016/S0022-4405(97)87007-0

Indian Act, Revised Statues of Canada (1985, c. 1-5). Retrieved from the Justice Laws website: https://laws-lois.justice.gc.ca/eng/acts/i-5/ 
Indigenous Services Canada (ISC). (2018a). Elementary and secondary education program. Government of Canada. https://www.sacisc.gc.ca/eng/1450708959037/1531319458607

Indigenous Services Canada (ISC). (2018b). First nation education partnerships and agreements. Government of Canada. https://www.sacisc.gc.ca/eng/1308840098023/1531400115587

Jackson, S. (2006). Interchanges: Gender, sexuality and heterosexuality: The complexity (and limits) of heteronormativity. Feminist theory, 7(1), 105-121. https://doi.org/10.1177/1464700106061462

Jansen, P.W., Verlinden, M., Dommisse-van Berkel, A., Mieloo, C., van der Ende, J., Veenstra, R., Verhulst, F.C., Jansen, W., \& Tiemeier, H. (2012). Prevalence of bullying and victimization among children in early elementary school: Do family and school neighbourhood socioeconomic status matter? BMC Public Health, 12, 1-10. https://doi.org/10.1186/1471-2458-12-494

Juvonen, J., Wang, Y., \& Espinoza, G. (2013). Physical aggression, spreading of rumors, and social prominence in early adolescence: Reciprocal effects supporting gender similarities. Journal of Youth Adolescence, 42, 1801-1810. https://doi.org/10.1007/s10964-012-9894-0

Kim, C. Y., Losen, D. J., \& Hewitt, D. T. (2010). The school-to-prison pipeline: Structuring legal reform. NYU Press.

Kinnon, E. (2016). (In)Equity and academic streaming in Ontario: Effects on students and teachers and how to overcome these [Unpublished master's thesis]. University of Toronto. 
Kohut, T. (2017). Tory senator defends residential school system, says good work 'unacknowledged.' Global News. https://globalnews.ca/news/3298332/senatorlynn-beyak-residential-schools/

Kolahdooz, F., Nader, F., Yi, K.J., \& Sharma, S. (2015). Understanding the social determinants of health among Indigenous Canadians: Priorities for health promotion policies and actions. Global Health Action, 8, 27968. https://doi.org/10.3402/gha.v8.27968

Kolbert, J.B., Crothers, L.M., \& Wells, D.S. (2013). Evolutionary psychological models for predicting bullying and implications for intervention. In J. Lepinski and L.M. Crothers (Eds.) Bullying in the Workplace: Causes, Symptoms and Remedies. Routledge.

Koo, H. (2007). A time line of the evolution of school bullying in differing social contexts. Asia Pacific Education Review, 8(1), 107-116. https://doi.org/10.1007/BF03025837

Korteweg, L., \& Root, E. (2016). Witnessing kitchenuhmaykoosib inninuwug's strength and struggle: The affective education of reconciliation in environmental education. Canadian Journal of Environmental Education (CJEE), 21, 178-197.

Kupchik, A., \& Ward, G. (2014). Race, poverty, and exclusionary school security: An empirical analysis of U.S. elementary, middle and high schools. Youth Violence and Juvenile Justice, 12(4), 332-354. https://doi.org/10.1177/1541204013503890

Kutsyurba, B., Klinger, D.A., \& Hussain, A. (2015). Relationships among school climate, school safety and student achievement and well-being: a review of the literature. Review of Education, 3(2), 103-135. https://doi.org/10.1002/rev3.3043 
LaPrairie, C. (2002). Indigenous over-representation in the criminal justice system: A tale of nine cities. Canadian Journal of Criminology, 56(4), 181-208. https://www.researchgate.net/publication/282283322_Aboriginal_overrepresentation_in_the_criminal_justice_system_A_tale_of_nine_cities

Larcombe, W. (2002). The 'ideal' victim V successful rape complaints: Not what you might expect. Feminist Legal Studies, 10, 131-148. http://doi.org/10.1023/A;1016060424945

Lee, S., Smith, P. K., \& Monks, C. P. (2011). Perceptions of bullying-like phenomena in South Korea: A qualitative approach from a lifespan perspective. Journal of Aggression, Conflict and Peace Research, 3(4), 210-221. https://doi.org/10.1108/17596591111187738

Lee, S., Smith, P. K., \& Monks, C. P. (2012). Meaning and usage of a term for bullyinglike phenomena in South Korea: A lifespan perspective. Journal of Language and Social Psychology, 31(3), 342-349. https://doi.org/10.1177/0261927X12446602

Legislative Assembly of Ontario. (2011). Minutes of Proceedings. $40^{\text {th }}$ Parliament, $1^{\text {st }}$ session. Retrieved from the Legislative Assembly of Ontario website: http://www.ola.org/en/legislative-business/house-documents/parliament40/session-1/2011-12-07/hansard\#PARA27

Legislative Assembly of Ontario. (2012). Bill 13, Accepting Schools Act, 2012, Royal assent received. $40^{\text {th }}$ Parliament $40,1^{\text {st }}$ session. Retrieved from the Legislative Assembly of Ontario website: https://www.ola.org/en/legislativebusiness/bills/parliament-40/session-1/bill-13/status 
Levasseur, J., \& Marcoux, J. (Writers). (2015, October 14). Bad water: 'Third World' conditions on First Nations in Canada [TV series episode]. CBC News. Canadian Broadcasting Corporation.

Lichtman, M. (2010). Qualitative research in education: A user's guide (2nd ed.). Sage. Lightfoot, S. (2015). Settler-state apologies to indigenous peoples: A normative framework and comparative assessment. Journal of the Native American and Indigenous Studies Association, 2(1), 15-39.

Link, B., \& Phelan, J. (2001). Conceptualising stigma. Annual Review of Sociology, 27, 363-385. https://doi.org/10.1146/annurev.soc.27.1.363

Long, L. J. (2020). The ideal victim: A critical race theory (CRT) approach. International Review of Victimology, 0269758021993339.

Marsh, T. N., Cote-Meek, S., Toulouse, P., Najavits, L. M., \& Young, N. L. (2015). The application of two-eyed seeing decolonizing methodology in qualitative and quantitative research for the treatment of intergenerational trauma and substance use disorders. International Journal of Qualitative Methods, 14(5), 1609406915618046.

Mawani, R. (2009). Colonial proximities: Crossracial encounters and juridicial truths in British Columbia, 1871-1921. UBC Press.

McCaslin, W. D., \& Boyer, Y. (2009). First Nations communities at risk and in crisis: Justice and security. Journal of Aboriginal Health, 5(2), 61-87. https://doi.org/10.3138/ijih.v5i2.28983 
McGinley, A. C. (2008). Creating masculine identities: Bullying and harassment because of sex. University of Colorado Law Review, 79(4), 1151-1242. http://scholars.law.unlv.edu/facpub/18

McGregor, C. (2008). Norming and $<$ re $>$ forming: Challenging heterornormativity in educational policy discourses. Canadian Journal of Educational Administration and Policy, 82. https://www.umanitoba.ca/publications/cjeap /articles/mcgregor.html

McGregor, H. E. (2017). One classroom, two teachers? Historical thinking and Indigenous education in Canada. Critical Education, 8(14).

McNeilly, G. (2018). Broken Trust - Indigenous people and the Thunder Bay Police Service. Office of the Independent Police Review Director. http://oiprd.on.ca/wpcontent/uploads/OIPRD-BrokenTrust-Final-Accessible-E.pdf

McPherson, D. H., \& Rabb, D. (2011). Indian from the Inside: Native America Philosophy and Cultural Renewal. $2^{\text {nd }}$ ed. McFardland \& Company, Inc.

Meiners, E. R., \& Winn, M. T. (2010). Resisting the school to prison pipeline: The practice to build abolition democracies. Race Ethnicity and Education, 13(3), 271276. https://doi.org/10.1080/13613324.2010.500832

Meyer, E.J. (2008). A feminist reframing of bullying and harassment: Transforming schools through critical pedagogy. McGill Journal of Education, 43(1), 33-48. https://doi.org/10.7202/019572ar

Meyer, H. D. (2010). Local control as a mechanism of colonization of public education in the United States. Educational Philosophy and Theory, 42(8), 830-845. 
Milne, E. (2015). Renegotiating Family-School Relationships Among Indigenous Peoples in Southern Ontario. UWSpace. http://hdl.handle.net/10012/9810

Milne, E. (2016). "I have the worst fear of teachers": Moments of inclusion and exclusion in family/school relationships among Indigenous families in Southern Ontario. Canadian Review of Sociology, 53(3), 270-289. https://doi.org/10.1111/cars. 12109

Ministry of Indigenous Affairs (2017). First Nations and treaties map. Queen's Printer for Ontario. https://files.ontario.ca/treaties_map_english.pdf.

Ministry of Indigenous Affairs (2019). In the spirit of reconciliation. Indigenous peoples in Ontario. Queen's Printer for Ontario. https://www.ontario.ca/document/spiritreconciliation-ministry-indigenous-relations-and-reconciliation-first-10years/indigenous-peoples-ontario

Monchalin, L. (2016). The colonial problem. An Indigenous perspective on crime and injustice in Canada. University of Toronto Press.

Morris, M.W., Hong, Y., Chiu, C., \& Liu, Z. (2015). Normology: Integrating insights about social norms to understand cultural dynamics. Organizational Behaviour and Human Decision Processes, 129, 1-13. https://doi.org/10.1016/j.obhdp.2015.03.001

Morton, B.M. (2016). The power of community: How foster parents, teachers, and community members support academic achievement for foster youth. Journal of Research in Childhood Education, 30(1), 99-112.

https://doi.org/10.1080/02568543.2015.1105334 
Nagy, R., \& Sehdev, R.K. (2012). Introduction: Residential schools and decolonization. Canadian Journal of Law and Society, 27(1), 67-73. https://doi.org/10.3138/cjls.27.1.067

Nagy, R. (2014). The truth and reconciliation commission of Canada: Genesis and design. Can. JL \& Soc., 29, 199.

Native Women's Association of Canada (NWAC). (2011). Aboriginal lateral violence. What is it? Aboriginal Lateral Violence. https://www.nwac.ca/wpcontent/uploads/2015/05/2011-Aboriginal-Lateral-Violence.pdf.

Neuman, W. L. (2010). Social research methods: Qualitative and quantitative approaches (7th ed.). Pearson Higher Education

Neuman, W. L., \& Robson, K. (2014). Basics of social research. Pearson Canada Nokiiwin Tribal Council. (2019). Our Respectful Community - G'Minoomaadozimin. Health and Safety Policy. http://www.nokiiwin.com/article/zero-tolerance-policy4259.asp

Nokiiwin Tribal Council. (n.d.). Spirit builder: Our journey away from lateral violence. http://www.nokiiwin.com/article/our-journey-away-from-lateral-violence4254.asp

Northern Nishnawbe Education Council (NNEC). (2014). Dennis Franklin Cromarty High School. http://www.nnec.on.ca/index.php.dennis-franklin-cromarty-highschool/

Nurwisah, R. (2011). Mitchell Wilson suicide: Boy's death raises bullying concerns. The Huffington Post Canada. https://www.huffingtonpost.ca/2011/09/29/mitchellwilson-suicide-disabled-bullying_n_987070.html 
O’Loughlin, RA., Gilbeau, A., \& Kristman, VL. (2020). Safety in the workplace: Responses from Nokiiwin Tribal Council Community Members [Conference presentation]. St. Joseph's Centre for Applied Health Research. https://www.lakeheadu.ca/sites/default/files/uploads/3694/Safety in the Workplace CAHR Poster Presentation - February 72020 - FINAL (1).pdf O’Loughlin, RA, Kristman, VL, \& Gilbeau, A. (2021). Inclusion of Indigenous workers in workplace mental health. Equality, Diversity and Inclusion: An International Journal. Special Issue on Inclusion and Disability in the $21^{\text {st }}$ Century. Ahead of print.

Olweus, D. (1994). Annotation: Bullying at school: Basic facts and effects of a school based intervention program. Journal of Child Psychology and Psychiatry, 35(7), 1171-1190. https://doi.org/10.1111/j.1469-7610.1994.tb01229.x

Olweus, D. (2013). School bullying: Development and some important challenges. Annual Review of Clinical Psychology, 9, 751-780. https://doi.org/10.1146/annurev-clinpsy-050212-185516

Olweus, D., \& Limber, S.P. (2010). Bullying in school: Evaluation and dissemination of the Olweus Bullying Prevention Program. American Journal of Orthopsychiatry Mental Health and Social Justice, 80(1), 124-134. https://doi.org/10.1111/j.19390025.2010.01015.x

Ontario College of Teachers (OCT). (2019). Becoming a teacher: Requirements. Ontario College of Teachers. http://oct.ca/becoming-a-teacher/requirements 
Ontario Human Rights Commission (OHRC). (2003). The Ontario Safe Schools Act: School discipline and discrimination. OHRC. http://www.ohrc.on.ca/en/book/export/html/2471

Ontario Ministry of Education (OME). (2007). Ontario First Nation, Métis, and Inuit Education Policy Framework. Queen's Printer for Ontario. http://www.edu.gov.on.ca/eng/aboriginal/fnmiframework.pdf.

Ontario Ministry of Education (OME). (2010). Caring and safe schools in Ontario. Supporting students with special education needs through progressive discipline, kindergarten to grade 12. Queen's Printer for Ontario. http://www.edu.gov.on.ca/eng/general/elemsec/speced/caring_safe_school.pdf Ontario Ministry of Education (OME). (2013a). Working draft: Safe and Accepting Schools Model Bullying Prevention and Intervention Plan. Queen's Printer for Ontario. http://www.edu.gov.on.ca/eng/document/curricul/BullyingPreventPlan.pdf Ontario Ministry of Education (OME). (2013b). Promoting a positive school climate: A resource for schools. Queen's Printer for Ontario. http://www.edu.gov.on.ca/eng/parents/IntroDocEng.pdf

Ontario Ministry of Education (OME). (2013c). School climate survey. A survey for school staff about: equity and inclusive education, and bullying/harassment. Queen's Printer for Ontario. http://www.edu.gov.on.ca/eng/safeschools/surveyteacher.pdf Ontario Ministry of Education (OME). (2013d). School climate survey. A survey for parents and guardians about: equity and inclusive education, and 
bullying/harassment. Queen's Printer for Ontario.

http://www.edu.gov.on.ca/eng/safeschools/surveyparent.pdf

Ontario Ministry of Education (OME). (2013e). School climate survey. A survey for students in grades 7 to 12 about: equity and inclusive education, and bullying/harassment. Queen's Printer for Ontario. http://www.edu.gov.on.ca/eng/safeschools/survey7to12.pdf

Ontario Ministry of Education (OME). (2013f). Learning for all. A guide to effective assessment and instruction for all students, kindergarten to grade 12. Queen's Printer for Ontario. http://www.edu.gov.on.ca/eng/general/elemsec/speced/LearningforAll2013.pdf Ontario Ministry of Education (OME). (2015). Provincial model for a local police/ school board protocol. Queen's Printer for Ontario. http://www.edu.gov.on.ca/eng/document/brochure/protocol/protocol.html Ontario Ministry of Education (OME). (2018a). Bullying Prevention and Intervention, Policy/Program Memorandum No. 144. Queen's Printer for Ontario. http://www.edu.gov.on.ca/extra/eng/ppm/144.pdf

Ontario Ministry of Education (OME). (2018b). Progressive Discipline and Promoting Positive Student Behaviour, Policy/Program Memorandum No. 145. Queen's Printer for Ontario. http://www.edu.gov.on.ca/extra/eng/ppm/145.pdf Ontario Ministry of Education (OME). (2018c). The Provincial Code of Conduct and School Board Codes of Conduct, Policy/ Program Memorandum No. 128. Queen's Printer for Ontario. http://www.edu.gov.on.ca/extra/eng/ppm/128.pdf. 
Ontario Ministry of Education (OME). (2018d). The Ontario Curriculum Grades 9 to 12. Course Descriptions and Prerequisites. Queen's Printer for Ontario. http://www.edu.gov.on.ca/eng/document/curricul/secondary/descript/descri9e.pdf Ontario Ministry of Education (OME). (2019a). Ontario takes new actions to combat bullying in schools. New initiatives aimed at bullying prevention and reporting. Queen's Printer for Ontario. https://news.ontario.ca/en/release/54753/ontariotakes-new-actions-to-combat-bullying-in-schools.

Ontario Ministry of Education (OME). (2019b). Indigenous education strategy. Queen's Printer for Ontario. http://www.edu.gov.on.ca/eng/indigenous/

Ontario Ministry of Education (OME). (2019c). 2019:B18, Memorandum - The reciprocal education approach. Ministry of Education.

Ontario Ministry of Education (OME). (2020). Ontario combatting bullying in schools through student surveys. Queen's Printer for Ontario. https://news.ontario.ca/en/release/55907/ontario-combatting-bullying-in-schoolsthrough-student-survey

Palmater, P. (2011). Stretched beyond human limits: Death by poverty in First Nations. Review of Social Policy, 65-66, 112-127. https://crsp.journals.yorku.ca/index.php/crsp/article/view/35220/32057

Palmater, P. (2014). Genocide, Indian policy, and legislated elimination of Indians in Canada. Aboriginal Policy Studies, 3(3), 27-54. https://doi.org/10.5663/aps.v3i3.22225 
Payne, A. A., \& Hutzell, K. L. (2017). Old wine, new bottle? Comparing interpersonal bullying and cyberbullying victimization. Youth and Society, 49(8), 1149-1178. https://doi.org/10.1177/0044118X15617401

Payne, E., \& Smith, M. (2013). LGBTQ kids, school safety, and missing the big picture: How the dominant bullying discourse prevents school professionals from thinking about systemic marginalization or ... why we need to rethink LGBTQ bullying. QED: A Journal in GLBTQ Worldmaking, Inaugural Issue, 1-36. https://doi.org/ 10.14321/qed.0001

Pemberton, A. (2016). Dangerous victimology: My lessons learned from Nils Christie. Temida, 19(2), 257-276.

People for Education. (2017). Indigenous education. In People for Education's Annual Report 2017. https://peopleforeducation.ca/wp-content/uploads/2017/06/P4EIndigenous-education-2017.pdf

Pikas, A. (1989). A pure concept of mobbing gives the best results for treatment. School Psychology International, 10, 95-104. https://doi.org/10.1177/0143034389102003

Plan for Care and Opportunity Act, Statutes of Ontario. (2018, c.8 - Bill 31). Retrieved from the Government of Ontario website: https://www.ontario.ca/laws/statute/s18008

Pratt, Y. \& Danyluk, P. J. (2017). Learning what schooling left out: Making an Indigenous case for critical service-learning and reconciliatory pedagogy within teacher education. Canadian Journal of Education, 40(1), 1-29. https://www.jstor.org/stable/90002335 
Prewitt, P. W. (1988). Dealing with Ijime (bullying) among Japanese students. School Psychology International, 9, 189-195. https://doi.org/10.1177/0143034388093003

Prokopchuk, M. (2018). 'Racist attitudes' contributed to poor Indigenous death investigations by Thunder Bay police, report says. Canadian Broadcasting Corporation. https://www.cbc.ca/news/canada/thunder-bay/thunder-bay-oiprdreport-1.4942388

Promoting Relationships and Eliminating Violence Network (PrevNET). (2019). Bullying - What we know and what we can do. PrevNET. https://www.prevnet.ca/bullying

Proulx, C. (2014). Colonizing surveillance: Canada constructs an Indigenous terror threat. Anthropologies, 56, 83-100. https://www.jstor.org/stable/24469643

Raible, J., \& Irizarry, J. G. (2010). Redirecting the teacher's gaze: Teacher education, youth surveillance and the school-to-prison pipeline. Teaching and teacher education, 26(5), 1196-1203. https://doi.org/10.1016/j.tate.2010.02.006

Razack, S. (2002). Race, space and the law: Unmapping a white settler society. Between the Lines

Razack, S. (2015). Dying from improvement: Inquests and inquiries into Indigenous deaths in custody. University of Toronto Press.

Rice, W. (2016). Blanket exercise teaches history from an Indigenous perspective. CBC/ Radio-Canada. http://www.cbc.ca/news/canada/ottawa/blanket-exercise-teacheshistory-from-an-indigenous-perspective-1.3400940. 
Rifkin, M. (2009). Indigenizing Agamben: Rethinking sovereignty in light of the "peculiar" status of native peoples. Cultural Critique, 73, 88-124. https://www.jstor.org/stable/25619838

Rifkin, M. (2017). Beyond settler time: Temporal sovereignty and indigenous selfdetermination. Duke University Press.

Ringrose, J. (2006). A new universal mean girl: Examining the discursive construction and social regulation of a new feminine psychology. Feminism \& psychology, 16(4), 405-424. https://doi.org/10.1177/0959353506068747

Ringrose, J., \& Renold, E. (2010). Normative cruelties and gender deviants: The performative effects of bully discourses for girls and boys in school. British Educational Research Journal, 36(4), 573-596. https://doi.org/10.1080/01411920903018117

Roberton, T., Daffern, M., \& Bucks, R.S. (2014). Beyond anger control: Difficulty attending to emotions also predicts its aggression in offenders. Psychology of violence, 5(1), 74-88. https://doi.org/10.1037/a0037214

Rose, N. (2001). The Politics of Life Itself. Theory, Culture \& Society, 18(6), 1-30.

Rowley, J. (2012). Conducting research interviews. Management research review, 35(3/4), 260-271. https://doi.org/10.1108/01409171211210154

Sabzalian, L. (2019). Indigenous children's survivance in public schools. Routledge. Safe Schools Act, Statutes of Ontario (2000, c. 12 - Bill 81). Retrieved from the Government of Ontario website: https://www.ontario.ca/laws/statute/s00012

Scheurich, J. J. (1994). Policy archaeology: A new policy studies methodology. Journal of education policy, 9(4), 297-316. https://doi.org/10.1080/0268093940090402 
Schott, R., (2014) The social concept of bullying: Philosophical reflections on definitions. In R. Schott \& D. Søndergaard (Eds.), School Bullying: New Theories in Context, 21-46. Cambridge University Press.

Scully, A. (2012). Decolonization, reinhabitation and reconciliation: Aboriginal and place-based education. Canadian Journal of Environmental Education, 17, 148158. https://cjee.lakeheadu.ca/article/view/1113

Senate News. (2019). Senator Lynn Beyak Biography. Senate of Canada. https://sencanada.ca/en/senators/beyak-lynne/

Seven Generations Education Institute. (2015). What is Mino-bimaadiziwin? Seven Generations Education Institute. http://www.7generations.org/?page_id=2822 Shankar, J., Ip, E., Khalema, E., Couture, J., Tan, S., Zulla, R.T., \& Lam, G. (2013). Education as a social determinant of health: Issues facing Indigenous and visible minority students in postsecondary education in western Canada. International Journal of Environmental Research and Public Health, 10, 3908-3929. https://doi.org/10.3390/ijerph10093908

Simpson, A. (2007). On ethnographic refusal: Indigeneity, 'voice' and colonial citizenship. Junctures, 9, 67-80. https://junctures.org/index.php/junctures/article/view/66/60

Simpson, A. (2011). Settlement's secret. Cultural Anthropology, 26(2), 205-217. https://doi.org/10.1111/j.1548-1360.2011.01095.x

Simpson, A. (2014). Mohawk interruptus: Political life across the borders of settler states. Duke University Press. 
Simpson, A. (2016). Whither settler colonialism? Settler Colonial Studies, 6(4), 438-445. https://doi.org/10.1080/2201473X.2015.1124427

Sinclair, M. (2018). Thunder Bay Police Services Board Investigation. Report for the Safety, Licensing, Appeals and Standard Tribunals Ontario. https://slastotsapno.gov.on.ca/ocpc-ccop/wpcontent/uploads/sites/5/2018/12/TBPSB_Investigation_Final_Report_-_ENFINAL-1.pdf

Sinclair, R. (2007). Identity lost and found: Lessons from the sixties scoop. First Peoples Child and Family Review, 3(1), 65-82. https://fpcfr.com/index.php/FPCFR/article/view/25

Statistics Canada (StatsCan). (2019). Census metropolitan area of Thunder Bay. Focus on Geography Series, 2019 Census, Government of Canada.

Sweet, M.E., \& DesRoches, S. (2007). Citizenship for some: Heteronormativity as cloaked bullying. Journal of Gay and Lesbian Social Services, 19(3-4), 173-187. https://doi.org/10.1080/10538720802161680

The Canadian Press. (2011). Anti-bullying bill aims to make Ontario schools safer. Canadian Broadcasting Corporation. https://www.cbc.ca/news/canada/toronto/anti-bullying-bill-aims-to-make-ontarioschools-safer-1.1007272

Templeton, T. N., \& Cheruvu, R. (2020). Childhood innocence for settler children: Disrupting colonialism and innocence in early childhood curriculum. The New Educator, 16(2), 131-148. 
Trowler, P.R. (1998). Academics responding to change. New higher education frameworks and academic cultures. Society for Research into Higher Education, ERIC.

Truth and Reconciliation Commission (TRC). (2015a). Honouring the Truth, Reconciling for the Future. National Centre for Truth and Reconciliation. http://nctr.ca/reports.php.

Truth and Reconciliation Commission (TRC). (2015b). Canada's Residential Schools: The Legacy. The Final Report of the Truth and Recociliation Commission of Canada. Vol. 5. ISBN 978-0-7735-4660-8

Truth and Reconciliation Commission (TRC). (n.d.). What is the TRC? Truth and Reconciliation Commission of Canada. www.trc.ca/about-us/faqs.html

Trzaskowski, M., Zavos, H.M.S., Haworth, C.M.A., Plomin, R., \& Eley, T.C. (2012). Stable genetic influence on anxiety-related behaviours across middle childhood. Journal of Abnormal Child Psychology, 40, 85-94. https://doi.org/10.1007/s10802-011-9545-z

Tuckett, A. G. (2004). Qualitative research sampling: the very real complexities. Nurse researcher, 12(1), 47-61. https://doi.org/10.7748/nr2004.07.12.1.47.c5930

Tuck, E. (2009). Suspending damage: A letter to communities. Harvard Educational Review, 79(3), 409-428.

Tuck, E., \& Gaztambide-Fernández, R. A. (2013). Curriculum, replacement, and settler futurity. Journal of Curriculum Theorizing, 29(1). 
TVO Current Affairs (2017). Why Indigenous students risk leaving home for their education. TVO.org. https://www.tvo.org/article/why-indigenous-students-riskleaving-home-for-their-education

University of British Columbia (UBC). (2009). The residential school system. Indigenous Foundations.

http://indigenousfoundations.arts.ubc.ca/the_residential_school_system/.

van Wijk, J. (2013). Who is the 'little old lady'of international crimes? Nils Christie's concept of the ideal victim reinterpreted. International review of victimology, 19(2), 159-179.

Veenstra, R., Lindenberg, S., Huitsing, G., Sainio, M., \& Salmivalli, C. (2014). The role of teachers in bullying: The relation between antibullying attitudes, efficacy, and efforts to reduce bullying. Journal of Educational Psychology, 106(4), 1135. https://doi.org/10.1037/a0036110

Wakeham, P. (2012). Reconciling "terror": managing indigenous resistance in the age of apology. American Indian Quarterly, 36(1), 1-33.

Walklate, S. (2011). Reframing criminal victimization: Finding a place for vulnerability and resilience. Theoretical Criminology, 15(2), 179-194.

Walton, G. (2005a). Bullying widespread. A critical analysis of research and public discourse on bullying. Journal of School Violence, 4(1), 91-118. https://doi.org/10.1300/J202v04n01_06

Walton, G. (2005b). The notion of bullying through the lens of Foucault and critical theory. The Journal of Educational Thought (JET)/Revue de la Pensée Educative, 55-73. www.jstor.org/stable/23767482 
Walton, G. (2005c). The Hidden Curriculum in Schools: Implications for Lesbian, Gay, Bisexual, Transgender, and Queer Youth. Alternate Routes: A Journal of Critical Social Research, 21. http://www.alternateroutes.ca/index.php/ar/article/view/20362

Walton, G. (2011). Spinning our wheels: Reconceptualizing bullying beyond behaviourfocused approaches. Discourse: studies in the cultural politics of education, 32(1), 131-144. https://doi.org/10.1080/01596306.2011.537079

Weaver, K.S., \& Vescio, T.K. (2015). The justification of social inequality in response to masculinity threats. Sex Roles, 72(11-12), 521-535. https://doi.org/10.1007/s11199-015-0484-y

Wildcat, M. (2015). Fearing social and cultural death: Genocide and elimination in settler colonial Canada - an Indigenous perspective. Journal of Genocide Research, 17(4), 391-409. https://doi.org/10.1080/14623528.2015.1096579

Wilson, J.B. (2007). First Nations education: The need for legislation in the jurisdictional gray zone. Canadian Journal of Native Education, 30(2), 248-256. https://search.proquest.com/openview/d7296048f796811dfb34bba819a78ebe/1?p q-origsite $=$ gscholar\&cbl $=30037$

Winton, S., \& Tuters, S. (2015). Constructing bullying in Ontario, Canada: A critical policy analysis. Educational studies, 41(1-2), 122-142. https://doi.org/10.1080/03055698.2014.955737

Wolfe, P. (2006). Settler colonialism and the elimination of the native. Journal of Genocide Research, 8(4), 387-409. https://doi.org/10.1080/14623520601056240 
Ybarra, M. L., Boyd, D., Korchmaros, J. D., \& Oppenheim, J. K. (2012). Defining and measuring cyberbullying within the larger context of bullying victimization. Journal of Adolescent Health, 51(1), 53-58. https://doi.org/10.1016/j.jadohealth.2011.12.031

Yoneyama, S., \& Naito, A. (2003). Problems with the paradigm: The school as a factor in understanding bullying (with special reference to Japan). British Journal of Sociology of Education, 24(3), 315-330. https://doi.org/10.1080/01425690301894 
Appendix A: Carleton University Research Ethics Board-A Clearance Certificate Carleton

U N I V E R S I T Y

Office of Research Ethics and Compliance

5110 Human Computer Interaction Bldg | 1125 Colonel By Drive

| Ottawa, Ontario K1S 5B6

613- 520-2600 Ext: 2517

ethics@,carleton.ca

\section{CERTIFICATION OF INSTITUTIONAL ETHICS CLEARANCE}

The Carleton University Research Ethics Board-A (CUREB-A) has granted ethics clearance for the research project described below and research may now proceed. CUREB-A is constituted and operates in compliance with the Tri-Council Policy Statement: Ethical Conduct for Research Involving Humans (TCPS2).

Ethics Protocol Clearance ID: Project \# 108098

\section{Project Team Members: Ms. Robyn Pepin (Primary Investigator)}

Vincent Kazmierski (Research Supervisor)

Project Title: The Ontario Anti-Bullying Framework and Its Potential Influence on Indigenous Students [Robyn Pepin]

Funding Source (If applicable):

Effective: January 26, 2018

Expires: January 31, 2019.

\section{Restrictions:}

This certification is subject to the following conditions:

1. Clearance is granted only for the research and purposes described in the application.

2. Any modification to the approved research must be submitted to CUREB-A via a Change to Protocol Form. All changes must be cleared prior to the continuance of the research.

3. An Annual Status Report for the renewal of ethics clearance must be submitted and cleared by the renewal date listed above. Failure to submit the Annual Status Report will result in the closure of the file.If funding is associated, funds will be frozen.

4. A closure request must be sent to CUREB-A when the research is 
complete or terminated.

5. Should any participant suffer adversely from their participation in the project you are required to report the matter to CUREB-A.

Failure to conduct the research in accordance with the principles of the TriCouncil Policy Statement: Ethical Conduct for Research Involving Humans 2nd edition and the Carleton University Policies and Procedures for the Ethical Conduct of Research may result in the suspension or termination of the research project.

Upon reasonable request, it is the policy of CUREB, for cleared protocols, to release the name of the PI, the title of the project, and the date of clearance and any renewal(s).

Please contact the Research Compliance Coordinators, at ethics@,carleton.ca, if you have any questions or require a clearance certificate with a signature.

\section{CLEARED BY:}

Date: January 26, 2018

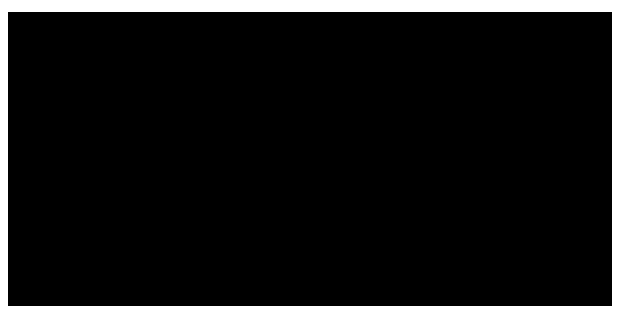

Andy Adler, PhD, Chair, CUREB-A

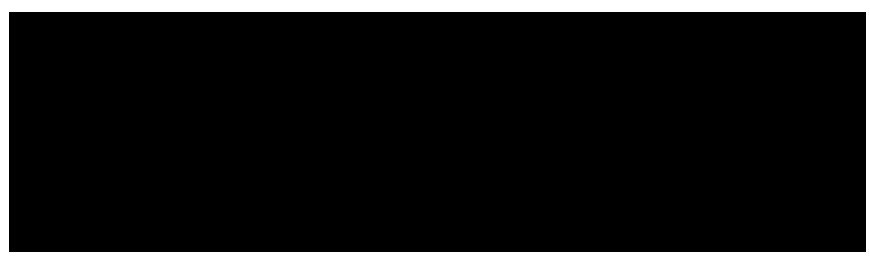

Bernadette Campbell, PhD, Vice-Chair, CUREB-A 
Appendix B: Letters to potential participants (two separate letters)

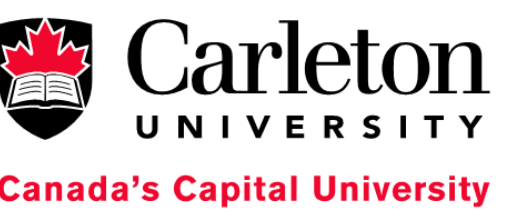

\section{Letter of Invitation to Potential Participants from Catholic/Public Schools}

Title: The Ontario Anti-Bullying Framework and Its Potential Influence on Indigenous Students

Carleton University Research Ethics Board Clearance Number: 108098

Date of ethics clearance: To be determined by the REB (as indicated on the clearance form)

Ethics Clearance for the Collection of Data Expires: To be determined by the REB (as indicated on the clearance form)

\section{(Insert date)}

\section{Dear Sir or Madam,}

My name is Robyn Pepin and I am a doctoral student in the Department of Law and Legal Studies at Carleton University. I am working on a research project under the supervision of Dr. Vincent Kazmierski.

I am writing to you today to invite you to participate in a study on Ontario's anti-bullying framework and its potential impact on Indigenous students. This study aims to obtain data from front-line educators about how they perceive the anti-bullying frameworks developed under provincial legislation and how these educators apply the frameworks to Indigenous students, when instances defined as bullying take place.

Participation in this study is entirely voluntary and will not affect your employment. This study involves one 60 minute interview that will take place in a mutually convenient, safe location. With your consent, interviews will be audio-recorded. The audio-recording will be destroyed after transcription. At that time, all identifiable data will be destroyed. There is also the option to provide written responses to the questions, if you so choose. Upon receipt of a completed questionnaire, all identifiable data will be destroyed.

While this project does involve some professional and emotional risks, care will be taken to protect your identity. This will be done by keeping all the identities of the interviewees protected in any published paper relating to this research. Furthermore, you have the option to request that certain responses not be included in the final project. 
You will have the right to end your participation in the study up to 14 days post-interview or post submission of the written questionnaire. If you choose to withdraw, a written notice must be provided to by e-mail. Also, all the information you have provided will be destroyed.

As a token of appreciation, I will be providing you with a $\$ 50.00$ gift card to Lot 66 , Restaurant and Wine Bar, once the consent forms have been signed. No other compensation will be provided.

All research data, including audio-recordings and any notes, will be encrypted. Any hard copies of data (including any handwritten notes or USB keys) will be kept in a locked cabinet at Carleton University. Research data will only be accessible by the researcher and the research supervisor.

This ethics protocol for this project was reviewed by the Carleton University Research Ethics Board, which provided clearance to carry out the research. Should you have questions or concerns related to your involvement in this research, please contact:

\section{CUREB-A:}

If you have any ethical concerns with the study, please contact Dr. Andy Adler, Chair, Carleton University Research Ethics Board-A (by phone at 613-520-2600 ext. 2517 or via email at ethics@carleton.ca).

If you would like to participate in this research project, or have any questions, please contact me at (807)620-2616 or robynpepin@cmail.carleton.ca.

Sincerely,

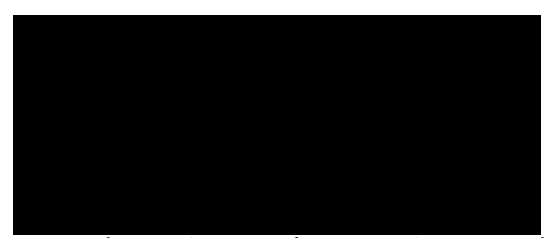

Robyn A. Pepin, HBA, M.Ed.

Ph.D. Candidate, Legal Studies

Carleton University, Ottawa, ON 


\section{Carleton}

universitr

Canada's Capital University

\section{Letter of Invitation to Potential Participant from the Indigenous Education Authority}

Title: The Ontario Anti-Bullying Framework and Its Potential Influence on Indigenous Students

Carleton University Research Ethics Board Clearance Number: 108098

Date of ethics clearance: To be determined by the REB (as indicated on the clearance form)

Ethics Clearance for the Collection of Data Expires: To be determined by the REB (as indicated on the clearance form)

\section{(Insert date)}

\section{Dear Sir or Madam,}

My name is Robyn Pepin and I am a doctoral student in the Department of Law and Legal Studies at Carleton University. I am working on a research project under the supervision of Dr. Vincent Kazmierski.

I am writing to you today to invite you to participate in a study on Ontario's anti-bullying framework and its potential impact on Indigenous students. This study aims to obtain data from front-line educators about how they perceive the anti-bullying frameworks developed under provincial legislation and how these educators apply the frameworks to Indigenous students, when instances defined as bullying take place.

Participation in this study is entirely voluntary and will not affect your employment. This study involves one 60 minute interview that will take place in a mutually convenient, safe location. With your consent, interviews will be audio-recorded. The audio-recording will be destroyed after transcription. At that time, all identifiable data will be destroyed. There is also the option to provide written responses to the questions, if you so choose. Upon receipt of a completed questionnaire, all identifiable data will be destroyed.

While this project does involve some professional and emotional risks, care will be taken to protect your identity. It must be noted that because

$$
\text { there are no assurances that }
$$

anonymity will be completely maintained once results have been analyzed and published. However, participant names will be anonymized and those participants will not be identified as employees . All the identities of the 
interviewees will be protected in any published paper relating to this research.

Furthermore, you have the option to request that certain responses not be included in the final project.

You will have the right to end your participation in the study up to 14 days post-interview or post submission of the written questionnaire. If you choose to withdraw, a written notice must be provided by e-mail. Also, all the information you have provided will be destroyed.

As a token of appreciation, I will be providing you with a $\$ 50.00$ gift card to Lot 66 , Restaurant and Wine Bar, once the consent forms have been signed. No other compensation will be provided.

All research data, including audio-recordings and any notes, will be encrypted. Any hard copies of data (including any handwritten notes or USB keys) will be kept in a locked cabinet at Carleton University. Research data will only be accessible by the researcher and the research supervisor.

This ethics protocol for this project was reviewed by the Carleton University Research Ethics Board, which provided clearance to carry out the research. Should you have questions or concerns related to your involvement in this research, please contact:

\section{CUREB-A:}

If you have any ethical concerns with the study, please contact Dr. Andy Adler, Chair, Carleton University Research Ethics Board-A (by phone at 613-520-2600 ext. 2517 or via email at ethics@carleton.ca).

If you would like to participate in this research project, or have any questions, please contact me at (807) 620-2616 or robynpepin@cmail.carleton.ca.

Sincerely,

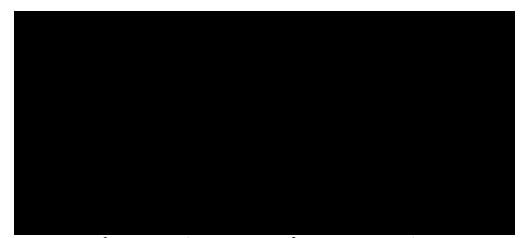

Robyn A. Pepin, HBA, M.Ed.

Ph.D. Candidate, Legal Studies

Carleton University, Ottawa, ON 


\section{Appendix C: Consent Forms (two separate forms)}

\section{Carleton \\ Canada's Capital University}

\section{Consent Form for Catholic/Public Schools}

Title: The Ontario Anti-Bullying Framework and Its Potential Influence on Indigenous Students

Carleton University Research Ethics Board Clearance Number: 108098

Date of ethics clearance: To be determined by the REB (as indicated on the clearance form)

Ethics Clearance for the Collection of Data Expires: To be determined by the REB (as indicated on the clearance form)

I [insert name of participant], choose to participate in a study on Ontario's anti-bullying framework and its potential impact on Indigenous students. I acknowledge that this study aims to obtain data from front-line educators about how they perceive the anti-bullying frameworks developed under provincial legislation and how these educators apply the frameworks to Indigenous students, when instances defined as bullying take place. I acknowledge that my participation in this study is entirely voluntary and will not affect my employment.

\section{The researcher for this study is Robyn A. Pepin in the Department of Law and} Legal Studies.

Ms. Pepin is working under the supervision of Dr. Vincent Kazmierski in the Department of Law and Legal Studies.

This study involves one 60 minute interview. With your consent, interviews will be audio-recorded. I am using audio recordings to ensure the accurate transcription of the answers provided by participants. If you do not wish to be audio-recorded, you have the option of providing your responses in writing. When written responses are received, all identifiable data will be destroyed. The audio-recording will be destroyed after transcription.

As this project will ask you about your employment, there are some potential professional risks to you if your statements are critical of your employer. While this risk is expected to be minimal, precautions will be taken to protect your identity. This will be done by 
keeping the identities of the interviewees protected in any published paper relating to this research. Furthermore, you have the option to request that certain responses not be included in the final project.

Should you experience any distress during the interview, you will be provided with contact information for counseling services available nearby.

You have the right to end your participation in the study up to 14 days post-interview or post submission of the written questionnaire. You can withdraw by providing written notice by email to Ms. Pepin or Dr. Kazmierski. If you withdraw from the study, all information you have provided will be immediately destroyed.

As a token of appreciation, you will receive a $\$ 50.00$ gift card to Lot 66 , Restaurant and Wine Bar. This is yours to keep, even if you withdraw from the study.

All research data, including audio-recordings and any notes, will be encrypted. Any hard copies of data (including any handwritten notes or USB keys) will be kept in a locked cabinet at Carleton University. Research data will only be accessible by the researcher and the research supervisor.

Once the project is completed, coded research data will be kept for five years and potentially used for other research projects on this same topic. At the end of five years, all coded research data will be securely destroyed. (Electronic data will be erased and hard copies will be shredded.)

If you would like a copy of the finished research project, you are invited to contact Ms. Pepin to request an electronic copy which will be provided to you.

The ethics protocol for this project was reviewed by the Carleton University Research Ethics Board, which provided clearance to carry out the research. If you have any ethical concerns with the study, please contact Dr. Andy Adler, Chair, Carleton University Research Ethics Board-A (by phone at 613-520-2600 ext. 2517 or via email at ethics@,carleton.ca).

Researcher contact information:

Name : Robyn A. Pepin

Department: Law and Legal Studies

Carleton University

E-mail: robynpepin@cmail.carleton.ca

Do you agree to be audio-recorded:

Will you be providing written responses:

\section{Supervisor contact information:}

Name: Dr. Vincent Kazmierski

Department: Law and Legal Studies

Carleton University

Tel: (613) 520-2600 ext. 8297

Email: vincent.kazmierski@carleton.ca

Yes No

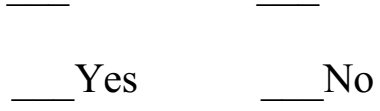


Signature of participant

Signature of researcher
Date

Date 


\section{Carleton \\ U N I V E R S I T Y \\ Canada's Capital University}

\section{Consent Form for Indigenous Education Authority Participants}

Title: The Ontario Anti-Bullying Framework and Its Potential Influence on Indigenous Students

\section{Carleton University Research Ethics Board Clearance Number: 108098}

Date of ethics clearance: To be determined by the REB (as indicated on the clearance form)

Ethics Clearance for the Collection of Data Expires: To be determined by the REB (as indicated on the clearance form)

I [insert name of participant], choose to participate in a study on Ontario's anti-bullying framework and its potential impact on Indigenous students. I acknowledge that this study aims to obtain data from front-line educators about how they perceive the anti-bullying frameworks developed under provincial legislation and how these educators apply the frameworks to Indigenous students, when instances defined as bullying take place. I acknowledge that my participation in this study is entirely voluntary and will not affect my employment.

\section{The researcher for this study is Robyn A. Pepin in the Department of Law and Legal Studies.}

Ms. Pepin is working under the supervision of Dr. Vincent Kazmierski in the Department of Law and Legal Studies.

This study involves one 60 minute interview. With your consent, interviews will be audio-recorded. I am using audio recordings to ensure the accurate transcription of the answers provided by participants. If you do not wish to be audio-recorded, you have the option of providing your responses in writing. When written responses are received, all identifiable data will be destroyed. The audio-recording will be destroyed after transcription.

While this project does involve some professional and emotional risks, care will be taken to protect your identity. It must be noted that because

there are no assurances that anonymity will be completely maintained once results have been analyzed and published. However, participant names will be anonymized and those participants will not be identified as employees 
interviewees will be protected in any published paper relating to this research.

Furthermore, you have the option to request that certain responses not be included in the final project.

Should you experience any distress during the interview, you will be provided with contact information for counseling services available nearby.

You have the right to end your participation in the study up to 14 days post-interview or post submission of the written questionnaire. You can withdraw by providing written notice by email to Ms. Pepin or Dr. Kazmierski. If you withdraw from the study, all information you have provided will be immediately destroyed.

As a token of appreciation, you will receive a $\$ 50.00$ gift card to Lot 66 , Restaurant and Wine Bar. This is yours to keep, even if you withdraw from the study.

All research data, including audio-recordings and any notes, will be encrypted. Any hard copies of data (including any handwritten notes or USB keys) will be kept in a locked cabinet at Carleton University. Research data will only be accessible by the researcher and the research supervisor.

Once the project is completed, coded research data will be kept for five years and potentially used for other research projects on this same topic. At the end of five years, all coded research data will be securely destroyed. (Electronic data will be erased and hard copies will be shredded.)

If you would like a copy of the finished research project, you are invited to contact Ms. Pepin to request an electronic copy which will be provided to you.

The ethics protocol for this project was reviewed by the Carleton University Research Ethics Board, which provided clearance to carry out the research. If you have any ethical concerns with the study, please contact Dr. Andy Adler, Chair, Carleton University Research Ethics Board-A (by phone at 613-520-2600 ext. 2517 or via email at ethics@,carleton.ca).

\section{Researcher contact information:}

Name : Robyn A. Pepin

Department: Law and Legal Studies

Carleton University

E-mail: robynpepin@cmail.carleton.ca

Do you agree to be audio-recorded:

Will you be providing written responses:

\section{Supervisor contact information:}

Name: Dr. Vincent Kazmierski

Department: Law and Legal Studies

Carleton University

Tel: (613) 520-2600 ext. 8297

Email: vincent.kazmierski@carleton.ca

Yes No

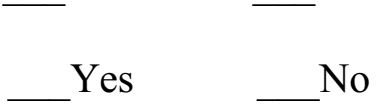


Signature of participant

Date

Signature of researcher

Date 


\section{Appendix D: Draft Interview Guide}

Title of Research Project: The Ontario Anti-Bullying Framework and Its Potential Influence on Indigenous Students

\section{Researcher: Robyn A. Pepin, PhD Student, Department of Law and Legal Studies \\ Supervisor: Dr. Vincent Kazmierski, Associate Professor, Department of Law and Legal Studies}

\section{Semi-Structured Interview Questions}

1a. What is your position at this school?

1b. How long have you been in this position?

2. How does this school define bullying?

3a. Approximately, how many students have reported instances classified as 'bullying'?

3b. Approximately, how many of those cases were the police involved in?

4a. Is Ontario's anti-bullying framework implemented in this school?

4b. If yes, what procedures are followed under the framework?

4c. If no, how are instances of bullying lessened?

5. Do you believe the Ontario anti-bullying framework protects Indigenous students from bullying in the same way it protects White/Other students? Why or why not?

6. Do you think police should be involved in instances of 'bullying'? Why or why not?

7. Are there any other external resources involved in instances of 'bullying'?

8a. If an instance of 'bullying' was an instance of racism, violence, classism or homophobia, would the event be named as it is or would it be identified as bullying?

8b. Can you please provide me with one or more examples.

9. When Indigenous students are involved in instances of bullying, are the events managed differently? If so, please provide me with one or more examples.

10a. When bullying happens, are parents involved?

10b. If so, what types of support do they provide?

10c. If not, how are they provided with knowledge of the events?

11. What about parents who do not reside in Thunder Bay? 
12. An Indigenous student is bullied merely because they are Indigenous

12a. Is racism recognized?

12b. Is colonization recognized? Are White/Other students educated about the impact of colonization?

12c. Are the police involved?

12d. What happens if the police blame the Indigenous student (i.e. turn the instance of victimization into vilification)?

12e. If an Indigenous student is bullied, but is subsequently blamed, how are parents informed?

13a. What, if any, connections do you see between the failures of Ontario's antibullying framework to support/ protect Indigenous students and the schoolto-prison pipeline?

13b. Did you ever think of these connections before? Why or why not?

14. What are the effects, if any, on Indigenous children's educational achievement if they moved off-reserve to Thunder Bay without family?

15. Do you believe Indigenous students should be protected from instances of bullying in the same way White/Other students are? Why or why not? 